A major purpose of the Technical Information Center is to provide the broadest dissemination possible of information contained in DOE's Research and Development Reports to business, industry, the academic community, and federal, state and local governments.

Although a small portion of this report is not reproducible, it is being made available to expedite the availability of information on the research discussed herein. 
ORNL-5TE6

Heallih and Safty Resench Divinion

\section{A Review and Analysis of Parameters for Assessing Transport of Environmentally Released Radionuclides through Agriculture}

C. F. Bues III

Environmental Sciences Division

R. D. Surp

Computer Sciences

A. L. Sjoreen

Computer Sciences

R. W. Ster

Health and Safety Research Division

Date Pubidad: Septentur 1984

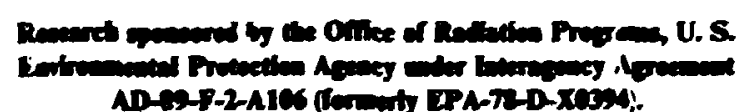

Purmed to the

Oak Rise National Laboratory

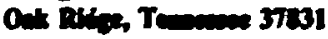

ermad th

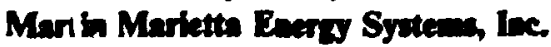

Ior to

U. S. DEPARTMENT OP ENERGY

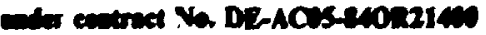

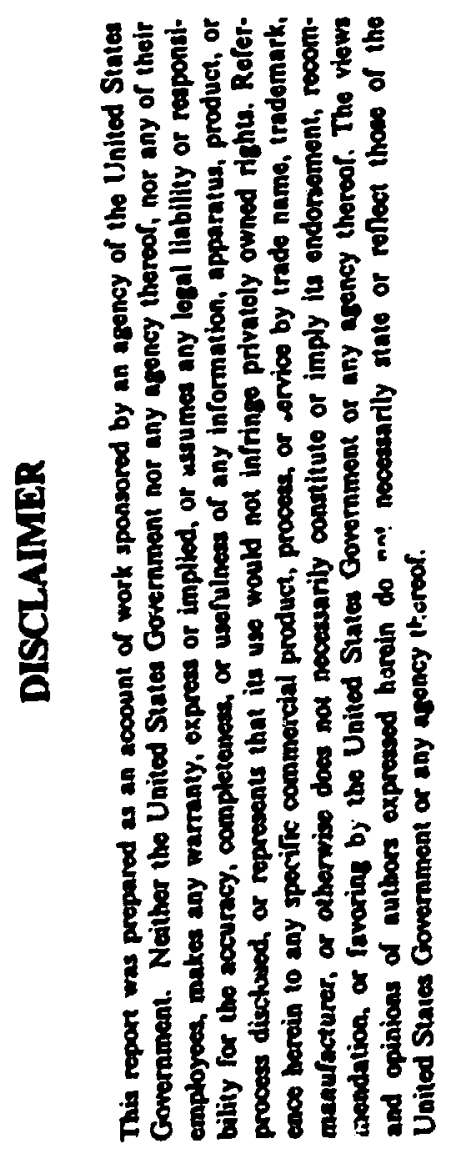




\section{DSCLAMIDR}

Although the research described in this report has been funded by the United States Environmental Protection Ageacy through Interagency Agreement Number AD-89-F-2-A106 (formerly EPA-78-D-X0394) with Oak Ridge National Laboratory, it has not been subjected to the Agency's required peer and policy revien and therefore does not necesearily reflect the views of the Agency and no official eadorsement should be inferred. 


\section{CONITNIS}

Pane

DSCLAIMISR

UST OF FGURS.

m

(n.

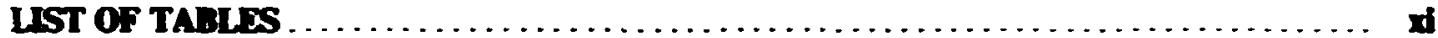

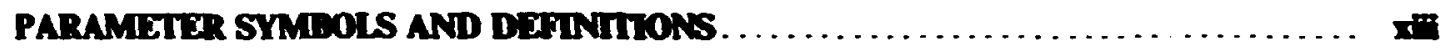

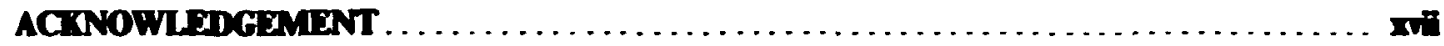

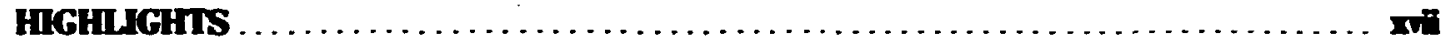

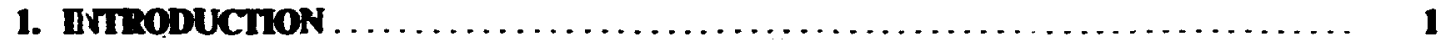

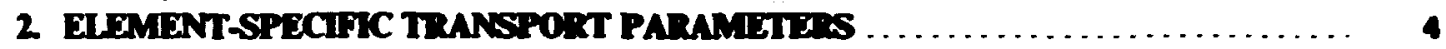

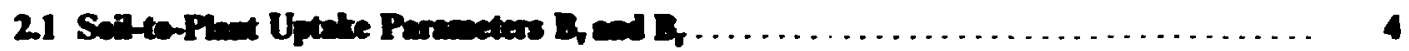

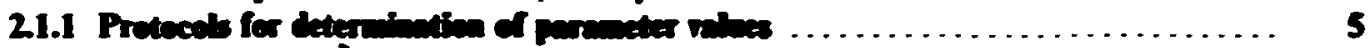

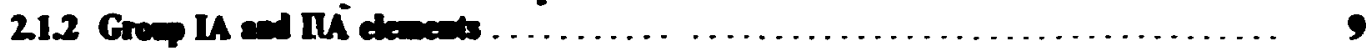

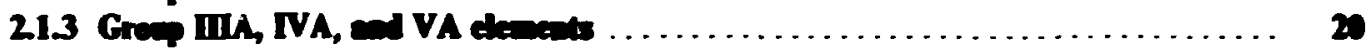

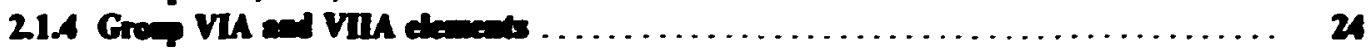

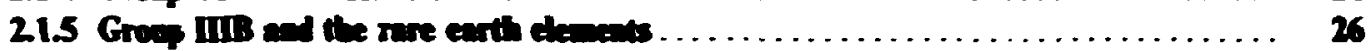

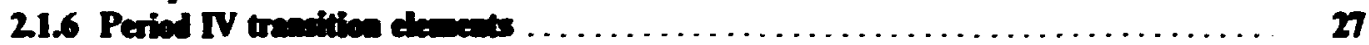

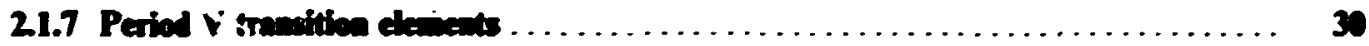

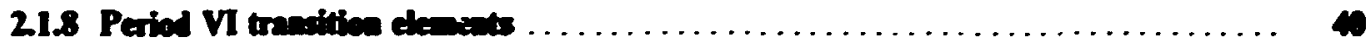

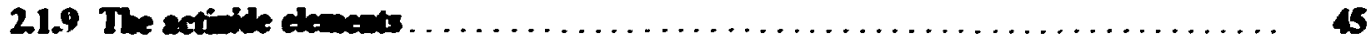

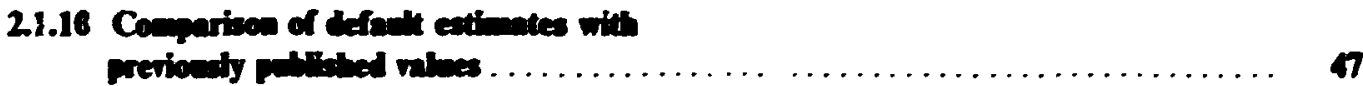

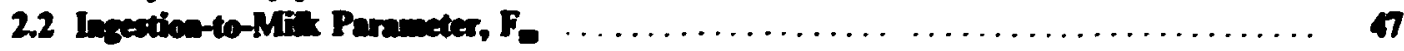

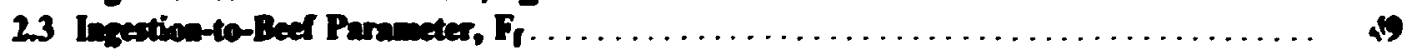

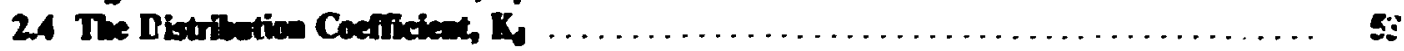

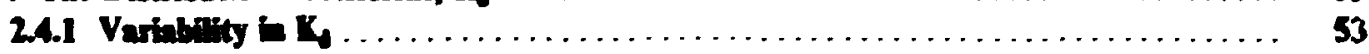

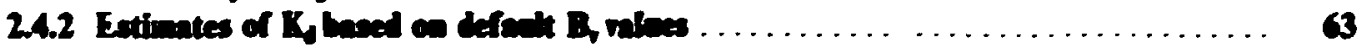

3. INTERCEPTION PRACTION FOR VBGETATION $\ldots \ldots \ldots \ldots \ldots \ldots \ldots \ldots \ldots$. 6

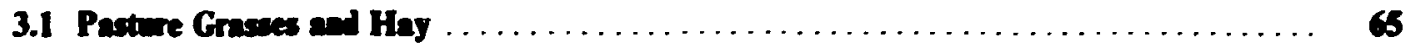

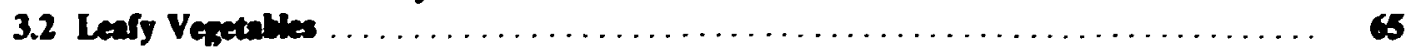

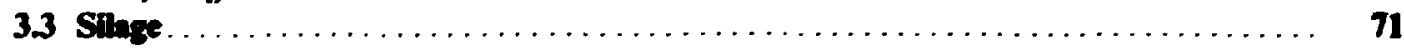

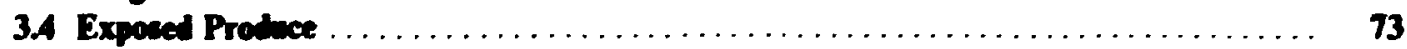

3.5 Correlation Betwees Imerception Fraction

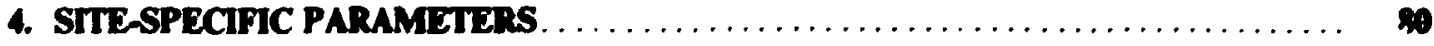

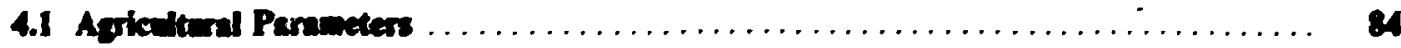

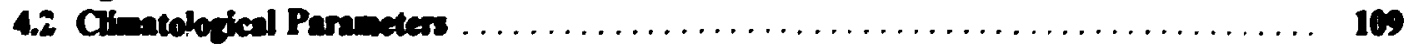

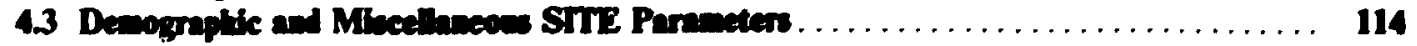

5. MISCELLANEOUS PARAMISTEDS $\ldots \ldots \ldots \ldots \ldots \ldots \ldots \ldots \ldots \ldots \ldots \ldots \ldots \ldots \ldots, 124$

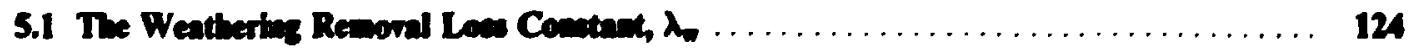

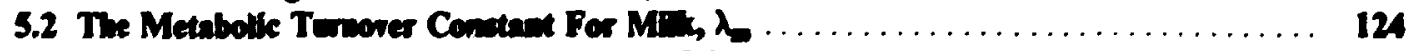

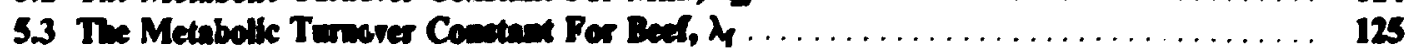

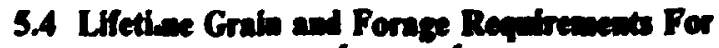

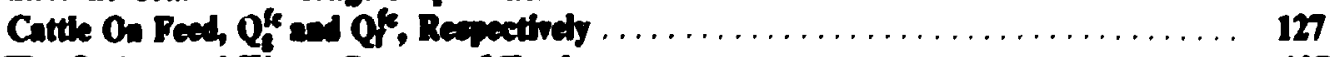

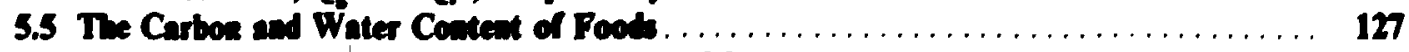

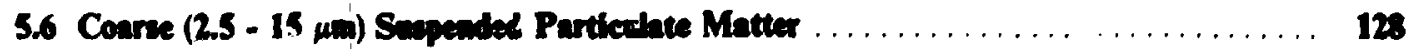

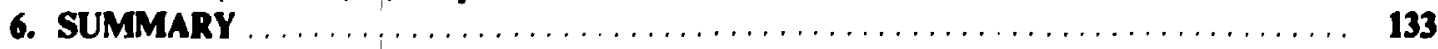

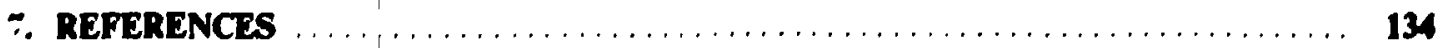


1.1. The calegurization of all requalite crops and ariad foeds in the TERRA code based on radioneclide traneport and eqrioulunal pathway charecteristics

21. Vaher of the soil-to-plant concentration fector B, adopted as defauh extimates in the completer code TERRA

22 Values of the soilto-plant coacentration factor $B_{r}$ adopted as defiant extimates in the competer cole TERRA

23. Lognormal probability plot of geometric means of $\boldsymbol{B}$, for cesium (calculated from referenves 26, 34, and 55-71), including one geometric standard deviation of the mean

24. Asoumed systematic trends in $B$, for Gropp IA and IIA elemeats. Solid dots and error bars represeat geometric means and standard deviations determined from available references

25. Corselation between soil potassium concentration and the soil-to-plant corcentration factor, $B_{n}$ for porasium based on references 16 and 65

26. Assumed systematic treads in $\left(B_{r} / B_{7}\right)$ ratio for

Group IA and IIA elements. Solid dots and error bars reprewent geometric means and standard deviations determined from available references

27. Lognormal probability plot of geonetric means of $B_{\text {, }}$ for strontium (calculated from references 11, 16, 17, 21, 31, 33, $59,60,62-70,72,74-76,78,81-83,85$, and 86), including one geometric standard deviation of the mean

28. Correlation between soil boron concentration and the soil-to-plant concentration factor, $B_{v}$, for boron based on references 16,65 , and 76

29. Correlation between soil phosphorus concentration and the soil-toplant concentration factor, $B_{w}$ for picosphorus based on reference 16

2.10. Assumed systematic trends in $B_{v}$ and $\left(B_{r} / B_{v}\right)$ ratio for aluminum, scandium, and yttrium. Solid dots and error bars represent geometric means and standard deviations of the mean determined from available references

2.11. Correlation between soil chromium concentration and the soil-toplant concentration factor, $B_{v}$, for chromium based on references 16 and 65 


\section{LST OF FIGURES (comtined)}

Nere

Pare

2.12. Correlation between soil manganese conceatration and the soit-to-

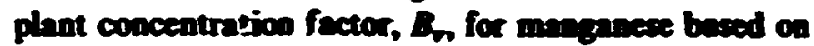
refereaces $16,36,37,104,112$, and 113

213. Correlation betwees soil irca concentration and the soitto-plant concentration factor, $B_{w}$ for iron based os refererses 16,65 , and 104

214. Correiation between soil coball concentration and the soit-toplant concentration factor, $B_{n}$ for cobalt based on referesces 16 and 65

215. Correlation between soil copper concentration and the soiltaplant concentration factor, $B_{v}$, for conpper besed on references 16, 104, and 115

216. Correlation between soil zinc concentration and the soil-to-plant concentration factor, $B_{n}$ for zinc based on refererces $16,35,37,67,97,104, ? 14,115$, and 119

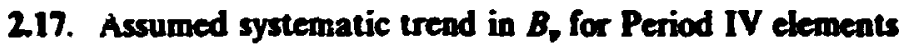
based on default $B_{r}$ eatimates. Solid dots and error bars represent geometric means and standard deviations determined from available references

2.18. Assumed systematic tread in $\left(B_{r} / B_{v}\right)$ ratio for Period IV elements. Solid dots and error bars represent geometric means and standard deviations of the meen determined from available references

219. Assumed systematic trends in the ratio of $B_{v}$ fx Period $V$ and IV elements $\left(\mathrm{Nb} / \mathrm{V}, \mathrm{Rh} / \mathrm{Co}_{0} \mathrm{Pd} / \mathrm{Ni}\right.$, and $\left.\mathrm{Ag}_{\mathrm{g}} / \mathrm{Cu}\right)$ based on the ratios of default $B_{v}$ extimates for other elements in the periods

220. Assumed systematic t, end in $B_{v}$ for Period $V$ transition elements based on default $B_{\boldsymbol{v}}$ entimates. Solid dots and error bars represent geometric means and standard deviations determined from available references

221. Assumed systematic trend in $B_{v}$ for Period VI elements bas.d on assumed systematic trends in Period IV and $V$ elements

2.22. Lognormal probability plot of geometric means of $B_{v}$ for plutonium (calculated from references 8-10, 30, 59, 101, $129,131,132$, and 134-138), including one geometric standard deviation of the mean 


\section{LIST OF FIGURES (conti med)}

Figre

2.23. Compar ison of soil-to-plant concentration factor default values reported in this report and derived from reference 15 . The -+" and "- " signs indicate whether our estimates are greater or less than, respectively, those derived from reference 15. The values indicated are the difference factor, and cirrled elements indicate a difference of at least an order of magnitude.

2.24. Values of the ingestion-to-milk transfer coefficient $\boldsymbol{F}_{\mathrm{m}}$ adopted as default estimates in the conputer code TERRA

2.25. Values of the ingestion-to-beef transfer coefficient $\boldsymbol{F}_{f}$ adopted as default estimates in the computer code TERRA

2.26. Systematic trends in the ratio of default estimates for $B_{v}$ and $F_{m}$ for successive elements and corresponding assumed ratios for $\boldsymbol{F}_{\boldsymbol{f}}$ for successive elements used to determine default $F_{f}$ estimates

2.27. Systematic variations in default $B$, estimates for Period II, III, IV, and V elements

228. Systematic variations in default $B_{v}$ estimates for

Perioul VI and VIl elements

2.29. Systematic veriations in default $F_{m}$ and $F_{f}$ estimates for Period II, III, IV, and V elements

2.30. Systematic variations in default $F_{m}$ and $F_{f}$ estimates for Period VI and VII elements

231. Values of the soil-water distribution coefficient $\boldsymbol{K}_{d}$ adopted as default estimates in the computer code TERRA

2.32. Percent =rror in $K_{d}$ esiimation from one to five percent overestimates of soll concentration or underestimates of water concent ation in a $10 \Omega-100 \mathrm{~mL}$ batch-type $K_{d}$ experiment .

2.33. Lognorm:.l probability plots of $K_{d}$ for cesium and strentium in soils of $\mathrm{pH} 4.5$ to 9 based on available references. .

2.34. Correlation between $B_{v}$ and $K_{d}$ based on geometric means of available reference geometric mears

3.1. Relationship between interception fraction alıd productivity for forage grasses (pasture and hay) 


\section{LIST OF FIGURES (comtioned)}

Fingere

Page

3.3. Hypothetical growth curve for plants. Leafy vegetables are harvested at the time of maximum growth, and silage is harvested

at grain maturity 70

3.4. Model of field geometry of silage plant spacings 72

3.5. Three plots of equal area containing hypothetical crops of varying size and planting density

3.6. Assumed relationships between interception fraction and fresh weight productivity for exposed produce and leafy vegetables and between interception fraction and dry weight productivity for silage

3.7. The ratio of interception fraction to productivity $\left(r^{\prime} / Y_{i}\right)$ ar a function of interception fraction dependent on (A) and independent of (B) productivity of silage, exposed produce, and leafy ver shles. The ranges of productivity found in the U. S., based on referesne 7 , are shown at the bottom of the figure

4.1. Map of the conterminous United States showing county delineations

4.2. Map of the conterminous United States with half degree longitudelatitude grid inficated

4.3. Geographic distribution of SITE parameter leafy vegetable production, $\boldsymbol{P}_{i v}$.

4.4. Geographic distribution of SITE parameter leafy vegetable productiviij, $Y_{i n}$

4.5. Geographic distribution of SITE parameter exposed produce production. $P_{e}$

4.6. Geographic distribution of SITE parameter exposed produce productivity, $Y$,

4.7. Geographic distriiution of SITE pararneter protected produce production, $\boldsymbol{P}_{P p}$

4.8. Geographic distribution of SITE parameter protected produce productivity, $Y_{p p}$

4.9. Gecgraphic distribution of SITE parameter grain food production, $\boldsymbol{P}_{\boldsymbol{g}}$ 


\section{LIST OF FIGURES (continued)}

Figure

4.10. Geographic distribution of SITE parameter grain food productivity, $Y_{\text {zh }}$

4.11. Geographic distribution of SITE parameter grain feed production, $P_{z f}$

4.12. Geographic distribution of SITE parameter grain feed productivity, $Y_{g}$

4.13. Geographic distribution of SITE parameter silage feed production, $P_{s}$

4.14. Geographic distribution of SITE parameter silage feed prnductivity, $Y_{s}$

4.15. Geographic distribution of SITE parameter hay feed production, $P_{k}$

4.16. Geographic distribution of SITE parameter hay feed areal yield, $Y_{k}^{a}$

4.17. Geograph:c distribution of SITE parameter number of frost-free days, $d_{f f}$

4.18. Geographic distribution of SITE parameter cattle and calves inventory, $n_{c c}$

4.19. Geographic distribution of SITE parameter milk cow inventor $\%, n_{m}$

4.20. Geographic distribution of SITE parameter annual number of cattle on ieed sold, $s_{g}$

4.21. Geographic distribution of SITE parameter sheep inventory, $n_{s}$

4.22. Geographic distribution of SITE parameter pasture area, $A_{p}$, shown as a fraction of total cell area

4.23. Geographic distribution of SITE parameter beef cows inventory, $n_{b}$

4.24. Geographic distribution of SITE parameter estimated annual z:erage evapotranspiration, $E$

4.25. Geographic distribution of SITE parameter estimated annual average irrigation, $I$ 


\section{LIST OF FIGURES (contived)}

Figure

4.26. Geographic distribution of SITE parameter estimated annual average precipitation, $P$

4.27. Geographic distribution of SITE parameter extimated annual average morning mixing height, $\boldsymbol{M}_{\mathbf{m}}$.

4.28. Geographic distribution of SITE parameter estimated annual average afternoon (evening) mixing height, $\boldsymbol{M}_{\boldsymbol{p}}$

4.29. Geographic distribution of SITE parameter estimated annual average absolute humidity, $\boldsymbol{H}$

4.30. Geographic distribution of SITE parameter (estimated 1980)

U. S. population, pop,

4.31. Geographic distribution of SITE parameter fraction of (1970) population classified as urban, pop. .

4.32. Geographic distribution of SITE parameter fraction of (1970) population classified as rural-farm, pop,f

4.33. Geographic distribution of SITE parameter fraction of (1970) population classified as rural-nonfarm, pop $_{n f}$

4.34. Geographic distribution of SITE parameter dominant land feature, $L_{d f}$

5.1. Metabolic half-times for the elements in milk (days), based on reference 145

5.2. Lognormal probability plot of coarse suspended particulate matter $(2.5-15 \mu \mathrm{m})$ 


\section{LIST OF TABLES}

2.1. Examples of non-uniform elemental distribution in plants

2.2. Relative importance of food crop categories in selected states and the conterminous U.S.

2.3. Dry-to-wet weight conversion factors for exposed produce, protected produce, and grains

2.4. Coinparison of observed and predicted concentrations of Group IA and IIA elements in produce and plants

25. Literature values of $B_{v}, B_{r}$, and the $\left(C_{r} / C_{v}\right)$ ratio for radium

2.6. Comparison of observed and predic: $\approx$ d concentrations of Group IIIA, IVA., and VA elements in produce and $-1:=$.ts

2.7. Comparison of ubserved and predicted concentrations of Group VIA ard VIIA eiements in produce and plants

2.8. Comparison of observed and predicted concentrations of Group IIIB and the rare earth elements in produce and plants

2.9. Comparison of observed and predicted concentrations of Period IV transition elements in produce and plants

2.10. Comparison of observed and predicted concentrations of Period $\mathbf{V}$ transition elements in produce and plants

2.11. Comparison of observed and predicted concentrations of Period VI transicion elements in produce and plants

2.12. Comparison of observed and predicted concentrations of actinide elements in produce and plants

2.13. Estimates of distribution of $\boldsymbol{K}_{d}$ for various elements in agricultural soils of $\mathrm{pH} \mathbf{4 . 5}$ to $\mathbf{9 . 0}$

3.1. Weighting factors for leafy vegetable interception fraction model sinulation

3.2. Relative importance of various exposed produce in the U.S.

3.3. Values of interception fraction for five important crops in the exposed produce catcgory

4.1. Example derivation of agricultural parametcrs for SITE cell

\#3284 from county-ave;aged parameters 


\section{LIST OF TABLES (CONTINUED)}

Table

4.2. Derivation of number of frost-free days for half degree cells from values for the three nearest weather stations to the rentroid of the cell

4.3. Agricultural and climatological parameters for seven selected

SITE r:lis and parameters derived from them in TERRA

5.1. Water content of produce, beef, and cow's milk

5.2. Carbon content of produse, beef, and cow's milk 
xiii

\section{PARAMETER SYMBOLS AND DEFINITIONS}

\begin{tabular}{|c|c|}
\hline Symbol & Definition \\
\hline $\boldsymbol{A}_{h i}$ & The area allocated to crop $i$ which is harvested or harvest area $\left(\mathrm{m}^{2}\right)$. \\
\hline$i_{i}$ & The inventory area allocated to crop $i\left(\mathrm{~m}^{2}\right)$. \\
\hline$A_{p}$ & The area of pasture $\left(\mathrm{m}^{2}\right)$. \\
\hline$B_{r}$ & $\begin{array}{l}\text { Soil-to-plant concentration factor which is the ratio of activity concentration in } \\
\text { plant parts usually associated with reproductive or storage functions (fruits, } \\
\text { seeds, 'ubers, etc.) in dry weight to the Jry weight activity concentration in root } \\
\text { zone soil at edible maturity or time of harvest (unitless). }\end{array}$ \\
\hline$B_{v}$ & $\begin{array}{l}\text { Soil-to-plant concentration factor which is the ratio of } \varepsilon \text { etivity concentration in } \\
\text { plant parts usually associated with vegetative functions (leaves, stems, straw, } \\
\text { etc.) in dry weight to the dry weight activity concentration in root zone soil at } \\
\text { edible maturity or time of harvest (unitless). }\end{array}$ \\
\hline$C_{a}^{\text {Eis }}$ & Carbon- 14 activity concentration in air $\left(\mathrm{Bq}\right.$ or $\left.\mathrm{Ci} / \mathrm{m}^{3}\right)$. \\
\hline$C_{a}^{H 3}$ & Tritium activity concentration in air $\left(\mathrm{Bq}\right.$ or $\left.\mathrm{Ci} / \mathrm{m}^{3}\right)$. \\
\hline$C_{a}$ & Resuspension air concentration ( $\mathrm{Bq}$ or $\mathrm{Ci} / \mathrm{m}^{3}$ ). \\
\hline$\tilde{C}_{c d}$ & Carbon- $\mathrm{I} 4$ activity concentration in atmospheric carbon dioxide ( $\mathrm{Bq}$ or $\mathrm{Ci} / \mathbf{k g}$ ). \\
\hline$c_{f o}^{4:}$ & . itiuin aci:iviy concentratisis in food ( $\mathrm{Bq}$ or $\left.\mathrm{Ci} / \mathrm{m}^{3}\right)$ \\
\hline$C_{z}$ & The annual consumption of pasture by livestock $(\mathrm{kg} / \mathrm{yr})$. \\
\hline$C_{r}$ & $\begin{array}{l}\text { Activity concentration in plant parls usually associated with reproductive } \\
\text { or storage functions (fruits, seeds, tubers, etc.) in dry weight ( } \mathrm{Bq} \text { or } \mathrm{Ci} / \mathrm{kg} \text { ). }\end{array}$ \\
\hline , & Activity concentration in dry weight in root zone soil (Bq or $\mathrm{Ci} / \mathrm{kg}$ ). \\
\hline & $\begin{array}{l}\text { Activity concentration in dry weight in aver } 1 \text { ge or typical root zone soil (Bq or } \\
\mathrm{Ci} / \mathbf{k g}) \text {. }\end{array}$ \\
\hline$C_{v}$ & $\begin{array}{l}\text { Activity concentration in plant parts usually associated with vegetative functions } \\
\text { (leaves, stems, straw, etc.) in dry weigh: (Bq or } \mathrm{Ci}_{i}^{\prime} \mathbf{k g} \text { ). }\end{array}$ \\
\hline$C_{w v}^{H 3}$ & Tritium activity conceritration in atmospheric water vapor $(\mathrm{Bq}$ or $\mathrm{Ci} / \mathbf{k g})$. \\
\hline$C^{p s}$ & The activity concentration on tie surfaces of plants ( $\mathrm{Bq} \mathrm{or} \mathrm{Ci} / \mathrm{kg}$ ). \\
\hline$D_{r}^{\prime}$ & The deposition. rate of resuspended material ( $\mathrm{Bq}$ or $\mathrm{C}: / \mathrm{m}^{2} / \mathrm{s}$ ). \\
\hline$d$ & Depth of the soil layer of interest, e.g., root zone $(\mathrm{cm})$. \\
\hline$d_{f f}$ & Average annual number of frost-free days (d). \\
\hline$d_{l}$ & $\begin{array}{l}\text { The linear distance bet ween a. weather station and the centroid of the SITE aell } \\
(\mathrm{km}) \text {. }\end{array}$ \\
\hline$d_{p}$ & The distance between plants in a. row in a field of row crops $(\mathrm{cm})$. \\
\hline$d$, & The distance between ruws o! plants in a field of row crops (cm). \\
\hline $\boldsymbol{E}$ & Average annual evapotranspiration $(\mathrm{cm})$ \\
\hline F, & $\begin{array}{l}\text { The fraction of daily ingested activity coricentration (from feeding) which is } \\
\text { transferred to and remains in a kilogram of nuscle at equilibrium }(\mathrm{d} / \mathrm{kg}) \text {. }\end{array}$ \\
\hline$f_{g}:$ & $\begin{array}{l}\text { The fraction of grain which is inported from outside of the assessinent area } \\
\text { (unitless). }\end{array}$ \\
\hline$F_{m}$ & $\begin{array}{l}\text { The fraction of daily ingested activity concentration (from feeding) which is } \\
\text { transferred to and remains in a kilog,ram of milk at equilibrium ( } / \mathrm{kg}) \text {. }\end{array}$ \\
\hline$f_{1 f}$ & The fractional transfer of ingested activity to beef (unitless). \\
\hline
\end{tabular}


xiv

\section{PARAMETER SYMBOLS AND DEFINITIONS (Contimed)}

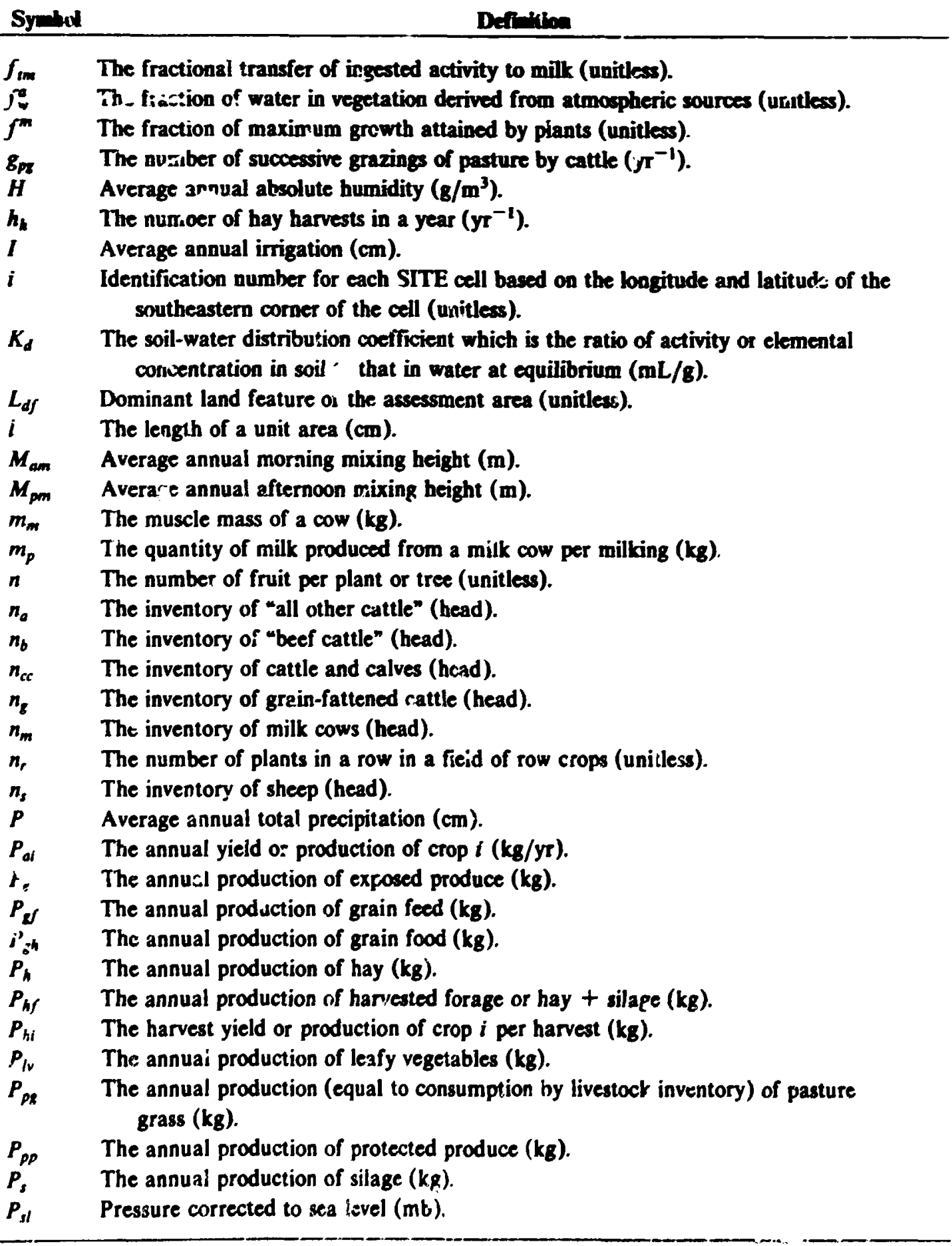




\section{PARAMETER YMBOLS AND DEFINITIONS (Contimed)}

$P_{\text {sus }} \quad$ Suspended particulate matter in the range of 2.0-15 $\mu \mathrm{m}$ from resuspension processes $\left(\mu g / \mathrm{m}^{3}\right)$.

pc The parameter value for a SITE cell (variable).

$p_{1} \quad$ The parameter value 'or the nearest weather station to the centroid of a SITE cell (variable).

$p_{2}$ The parameter value for the second nearest weather station to the centroid of a SITE cell (variable).

$p_{3}$ The sarameter value for the third nearest weather station to the centroid of a SITE cell (variable).

The fraction of the population classified as "rural-non-farm" (unitless).

The fraction of the population classified as "rural-farm" (unitless).

popt The total population of the assessment area (unitiess).

pop. The fraction of the population classified as "urban" (unitless).

$Q_{f}^{\prime} \quad$ The lifetime forage requirement of grain-fed cattle ( $\left.\mathrm{kg} / \mathrm{yr}\right)$.

$Q_{\text {feed }} \quad$ Feed ingestion rate by cattle used in meat and milk concentration calculations $(\mathrm{kg} / \mathrm{s})$.

$Q_{8}^{\text {fc }} \quad$ The lifetime grain requirement of grain-fed cattle $(\mathrm{kg} / \mathrm{yr})$.

$R_{f} \quad$ The collective forage requirement by livesteck $(\mathrm{kg} / \mathrm{yr})$.

$R_{g} \quad$ The collective grain requirement by livestock ( $\mathrm{kg} / \mathrm{yr}$ ).

$r_{f}$ The radius of an individual fruit or plant $(\mathrm{cm})$.

$r_{n} \quad$ The number of rows of plants in a field of row crops (unitless).

$r$ The average interception fraction for exposed produce (unitless).

ref The average interception fraction for exposed fruit (unitless).

$r^{h} \quad$ The interception fraction for hay (unitless).

$r^{i} \quad$ The interception fraction for plant $i$ (unitless).

$r^{\text {iv }}$ The interception fraction for leafy vegetables (unitless).

$\mathrm{mfl}^{\mathrm{mf}}$ The interception fraction for mature tree fruil (unitless).

$r$ The interception fraction for mature leafy vegetables (unitless).

$r^{m y} \quad$ The interception fraction for mature silage (unitless).

$r$ Ths interception fraction for mature snap beans (uuitless).

$r^{m+1} \quad$ The interception fraction for mature tomatoes (unitle's).

rpg The interception fraction for pasture grass (unitless).

$r^{s} \quad$ The interception fraction for silage (unitless).

$s_{g} \quad$ The annual sales of grain-fattened cattle (head $/ \mathrm{yr}$ ).

$r_{f} \quad$ The metabolic half-time for material in beef (s).

$T_{m} \quad$ The metabolic half-time for material in .nilk (s).

$T_{w} \quad$ The weathering removal half-time for material deposited on plant surfaces (s).

$t_{i} \quad$ The time of interest (d).

$i_{m} \quad$ The time at which milk is sampled (s). 


\section{PARAMETER SYMBOLS AND DEFINTTONS (Contiowed)}

\begin{tabular}{|c|c|}
\hline Symbot & Defritis \\
\hline$t_{\max }$ & The time at which maximum plant growth eccurs (d). \\
\hline$t_{3}$ & The time at which cattle are slaughtered (s). \\
\hline$V_{d}$ & The deposition veiocity of resuspended material $(\mathrm{cm} / \mathrm{s})$. \\
\hline$V_{i}$ & The velocity of a migrating material in a soil coiumn $(\mathrm{cm} / \mathrm{s})$. \\
\hline $\boldsymbol{y}_{w}$ & The velocity of water in a soil column $(\mathrm{cm} / \mathrm{s})$. \\
\hline$w$ & The width of a unit area $(\mathrm{cm})$. \\
\hline$w_{1}$ & $\begin{array}{l}\text { The weighting factor (inversely proportional to distance) used with the nearest } \\
\text { weather station to the centroid of a SITE cell (uritiess). }\end{array}$ \\
\hline$w_{2}$ & $\begin{array}{l}\text { The weight.rg factor (inversely proportional to distance) used with the second } \\
\text { nearest weather station to the centroid of a SITE cell (unitless). }\end{array}$ \\
\hline$w_{3}$ & $\begin{array}{l}\text { The weighting factor (inversely proportional to distance) used with the third } \\
\text { nearest weather station to the centroid of a SITE cell (unitless). }\end{array}$ \\
\hline $\boldsymbol{X}$ & Longitude $\left({ }^{\circ} \mathrm{W}\right)$ \\
\hline $\boldsymbol{Y}$ & Latitude $\left({ }^{\circ} \mathrm{N}\right)$ \\
\hline$Y_{e}$ & The productivity of exposed produce $\left(\mathrm{kg} / \mathrm{m}^{2}\right)$. \\
\hline$Y_{t}$ & The productivity of grain feed $\left(\mathrm{kg} / \mathrm{m}^{2}\right)$. \\
\hline$Y_{g h}$ & The productivity of grain food $\left(\mathrm{kg} / \mathrm{m}^{2}\right)$. \\
\hline$Y_{h}$ & The productivity of hay $\left(\mathrm{kg} / \mathrm{m}^{2}\right)$ \\
\hline$Y_{i}$ & $\begin{array}{l}\text { The productivity of plant } i \text { based on the ratin of production to area harvested } \\
\left(\mathrm{kg} / \mathrm{ma}^{2}\right) \text {. }\end{array}$ \\
\hline$Y_{i}^{p}$ & The =real yield oi crop $i\left(\mathrm{~kg} / \mathrm{yr} / \mathrm{m}^{2}\right)$ \\
\hline$Y_{l v}$ & The productivity of leafy vegetables $\left(\mathrm{kg} / \mathrm{m}^{2}\right)$. \\
\hline$Y_{p z}$ & The productivity of pasture grass $\left(\mathrm{kg} / \mathrm{m}^{2}\right)$. \\
\hline$Y_{p z}^{a g}$ & The areal yield of pasture grass $\left(\mathrm{kg} / \mathrm{yr} / \mathrm{m}^{2}\right)$. \\
\hline$Y_{p p}$ & The productivity of protected produce $\left(\mathrm{kg} / \mathrm{m}^{2}\right)$. \\
\hline$Y_{3}^{p p}$ & The productivity of silage $\left(\mathrm{kg} / \mathrm{m}^{2}\right)$. \\
\hline 2 & altitude $(\mathrm{m})$. \\
\hline$\lambda_{\ell}$ & The turnover rate of cattle in the "cattle on feed" category $\left(\mathrm{yr}^{-1}\right)$. \\
\hline$\lambda_{f}$ & The metabolic removal rate constant for beef $\left(s^{-1}\right)$. \\
\hline$\lambda_{m}$ & The metabolic removal rate constant for milk $\left(s^{-1}\right)$. \\
\hline$\lambda_{w}$ & The weathering removal constant for plant: surfaces $\left(s^{-1}\right)$. \\
\hline$\rho$ & Soil bulk density $\left(\mathrm{g} / \mathrm{cm}^{3}\right)$ \\
\hline$\theta$ & Volumetric water content of the soil [ $\mathrm{mL}$ (equal to $\mathrm{cm}^{3} \mathrm{~h}_{2} \mathrm{O}$ ) $\left./ \mathrm{cm}^{3}\right]$. \\
\hline
\end{tabular}




\section{INTRONUCTION}

Under Task I of contract EPA-AD-8n-F-2-A106 (formerly EPA-78-D-X0394), the Health and Safety Reseasch Division (HASR D) of tre Oak Ridge National iaboratury (ORNL) prepared the AIRDOS-EPA ${ }^{1}$ and DARTAB ${ }^{2}$ computer codes to provide the Environmental Protectir: Agency (EPA) with an integrated set of codes and data bases to simulate atmospheric and terrestrial transport of radionuclides routinely released to the atmosphere and to calculat: iesulting health impacts to man consequen: from these releases. Under Task II of the project an integrated set of computer codes and data bases is being designed to replace the AIRDOS-EPA and DAR TAB system. This report describes the Specific Information on the Terrestrial Euvironment (SITE) computerized data base, element-specific transport parameters. anci other parameters used in lieu of user input in th: terrestrial transport cede TERRA ${ }^{3}$ or accessed by the atmospheric transport code ANEMOS $^{4}$ and/or the dose and risk code ANDROS. ${ }^{5}$

The terrestrial transport and agricultural parameters reviewed and documented by Moore et al.' represented an attempt to update and reevaluate parameters previously recommended in USNRC Regulatory Guide 1.109.6 Experience with thr AI!.DOS-EPA computer code has highlighted several problems in the modeling approach and vertain limitations in the ascessment methodology which are addressed under Task II. One problem occurs in the piotocols used in reviewing literature values for soil-to-plant concentration factors. Other iirritations apparent it: the AIRDOS-EPA computer code are the absence of iransport pararreters fur many elements and the incorporation of a single set of default agricultural parameters to describe a highly diverse agricultural system in ti.e United States.

Much of the effort under Task II has been directed towards resolution of these problems or inconsistencies and construction of a location-specific data base of default agricultural, meteorological, and demographic parameters for use in generic assessments. Element-specific transport parameters have been reevaluated with regard to their use in the model TERRA, literature references given by Moore et al.' have been reevaluated, and new references have been added. For those elements for which experimental experience has been slight, systematic assumptions based on their location in the periodic table of the elements have been used to estimate default values. Theoretical models based on two- and three-dimensional geometries of fnod and feed crups have been used to suggest default valıes of the interception fraction, $r$.

It is beyond the scope of this report to detail the TERRA computer code, but a general uriderstanding of the simulation of transport in vegetable and feed crops is prerequisite to interpretation of our analyses. All vegetable and feed crops have been assigned to seven categories based on their phenotypic and agricultural transport characteristics. ${ }^{7}$ These categories are leafy vegetables, exposed produce, protected produce, grains, pasture, hay, and silage (Fig. 1.1). The first three are classed as human foods and the las! three as :.irstock feeds. Grains are classed as both. Leafy vegutables present a broad flat leaf surface for direct interception of atmospherically depositing material. Furthermore, the edible portion of tine plant is primarily concerneri with vegetative growth (leaves and stems). Exposed produce (snap beans, tomatoes, apples, etc.) intercept atmospherically depositing material on edible surfaces, but surface areas for exposure are relatively small compared io leafy vegetables. Additionally, edible portions are typically concerned with reproductive functions (fruits and seeds). Protected prodice (potatoes, peanuts, citrus fruits, etc.) are not directly exposed to atmospherically depositing material because their growth habit is underground, or if abaveground, the edible portions are protecied by pods, shells, or nonedible skins or peels. Typically, edible portions are reproductive or storage organs.

Grains are similar to protected produce. but their use as both livestixk feeds and food for man necessitates a separate category. The other three categories of livestock ieeds are pasture, hay, and (corn and sorghum) silage. All of these feeds are composed, primarily, if vegetative growth. Silage is categorized separately from hay and pasture based on its interception characteristics. Hay and pasture are separated because their residence times in the field are significantly different, and therefore, parent nuclide decay and ingrowth of daughters calculated in TERRA for these two 
OANL-DWG 82.122:'5A

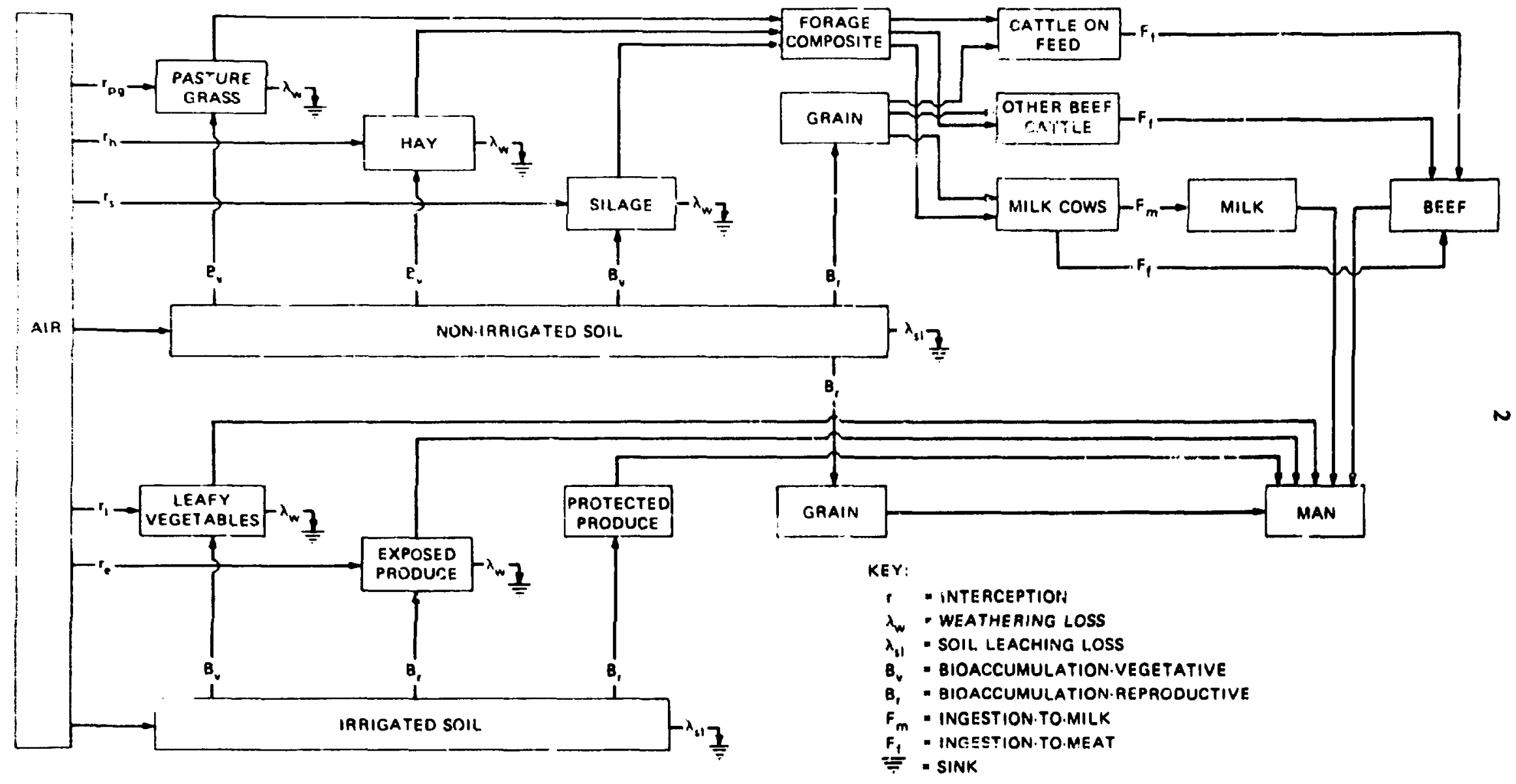

Figure 1.1. The cater,orization of all vegetable crops and animal feeds in the TERRA code based on radionuclice transport and agricultural pathway characteristics. 
citegories may be significantly different. Furthermore, hay is easily imported and exported from a kcation and pasture is not. This difference between the two is important in the caiculation of kcation-specific estimates of pasture productivity and feed fractions based on livestock inventories (Section 4.1).

The elaboration of vegetation into seven categories has been determined chiefly by the protocols necessary in analysing transport behavior, allowing for location-specific variability in agricultural practice, and simulating radiological decay in the TERRA code. Similarly, for all parameters the following analyses reflect our intent towards "reasonable estimates" based on unbiased approaches, parameter correlations, and theoretical or systematic models when available information is limited. We will attempt to estimate distributicns of these parameters whenever possible to allow the reader io select more or less conservative pary meter estimates than those used as default in TERRA. Finally, any changes in parameter definitions from those giver b; . ?wre et al.,' or listed in the USNRC Regulatory Guide 1.109,' have not been made capriciously, but reflect responses to limitations or incinsistencies of past approaches. 


\section{LLEMINTSPPCIFIC TRANSPORT PARAMETDES}

Quantification of nuclide transport through - icultural systems in TERRA involves the parameters describing soil-to-plant uptake for vegetative growth (leaves and stems), $B_{w i}$ and nunvegetative growth (fruits, seods, and ubbers), $B_{r i}$ ingestion-to-milk transfer, $F_{m ;}$ ingestion-tomeat transfer for beef cattle, $F_{f}$; and the soil-water distribution coefficient, $K_{d}$. Ideally, these transport narameters should be nuclide-specific. Fos example, isotopic differences in plant availability have been shown for plutoniun. ${ }^{2-10}$ However, available information for other elements and the lack of compelling theory for a nuclide-specific approach necessitates an element-specific determination for these parameters. Thus, it is assumed bere that variability among isotopes of the same element is insignificant compared to variability among different elements and the overall variability inherent in the parameters themselves. For soil-plant uptake of strontium, available information supports this assumption."

\section{Solito-Phat Uptake Parameters $B_{1}$ and $B_{r}$}

Root uptake of radionuclides incorporated into surface horizons of soil is parameterized by the transfer coefficients $B_{v}$ and $B_{r}$. representing the ratio of elemental concentrations in plant and soil at harvestable maturity. The parameters $B_{v}$ and $B_{r}$ are given by

$$
\begin{gathered}
B_{v}=\frac{C_{v}}{C_{s}} \text { and } \\
B_{r}=\frac{C_{r}}{C_{s}},
\end{gathered}
$$

where

$$
\begin{aligned}
& B_{v}=\quad \begin{array}{c}
\text { soil-to-plant elemental transfer coefficient for vegetative portions of food crops and } \\
\text { feed plants, }
\end{array} \\
& B_{r}=\quad \begin{array}{c}
\text { soil-to-plant elemental transfer coefficient for nonvegetative (reproductive) portions } \\
\text { of food crops and feed plants, }
\end{array} \\
& C_{v}=\quad \begin{array}{c}
\text { elemental coisentration in vegetative portions of food crops and feed plants (dry } \\
\text { weight) at edible maturity, }
\end{array} \\
& C_{r}=\quad \begin{array}{c}
\text { elemental concentration in sonvegetative (reproductive) portions of food crops and } \\
\text { feed plants (dry weight) at edible maturity, and }
\end{array} \\
& C_{s}=\quad \text { elemental concentration in root zone soil (dry weight). }
\end{aligned}
$$

This approach to concentration ratios is significantly differunt from the $B_{i v 1}$ and $B_{i v 2}$ approach used by Moore et al.' and is in response to some inconsistencies and insdequacies experienced with the Ar:DOS-EPA. approach. ${ }^{12}$ In Moore et al., $B_{i v 1}$ values were calculated from dry plant/dry soil concentration ratios for livestock feeds, and $B_{i v 2}$ values were calculated from fresh weight plant/dry soil concentration ratios for food crops. This approach was used beciuse information on feed and food crops is customarily reported in dry and fresh wcights, respect,vely. In analysis of available literature for these concentration ratios, all data in a reference were divided into "animal feeds" and "direct consumption by man" categories, corresponding to $B_{i v 1}$ and $B_{i v 2}$, respectively. $A$ literature reference could be used for $B_{i v 1}$ or $B_{i v 2}$ or both. Conversely, $B_{i v 1}$ and $B_{i v 2}$ for an element miglıt be derived from two sets of data and references which could be equal, share common elements, or be disjointed. For most :lements, $B_{i v 2} \leqslant B_{i v 1}$ was observed. This result is logical because the concentration of a finite quantity of material in a plant decreases as plant weight 
increases. However, if two disjointed sets of references were used, $B_{i=2} \geqslant B_{i=1}$ for an element could occur. The resultant values of $B_{i+1}$ and $B_{i v 2}$ were appropriate with respect to the references used to genciate them, but were not directly comparable with each other. In the approach used here, classification of references is based on physiologic plant characteristics, and not upon ultimate fate of the plant in the human food chain.

Also, in the Moore $t$ al.' approach, any statistical analysis of $B_{i z z}$ would have to be based on "converted" para.jeter values because they are usually reported in dry weight. Because very few references include dry-to-wet weight conversion factors, general ieferences such as Morrison $(1959)^{13}$ and Spxctor (1959) $)^{: 4}$ were used for generation of $B_{i-2 .}$. In some cases a value of $25 \%$ dry matter 1.6.15 was used to convert to wet weight. These transformations of reported data added unnecessary uncertainty to parameter estimates, and statistical analysis would be less precise than analysis of original data. Thus, the adoption of dry weight concentration ra. ios here reduces additional imprecision in parameter estimates and facilitates a more direct comparisin between the two concentration factors $\left(B_{v}\right.$ and $\left.B_{r}\right)$.

Adoption of $B_{v}$ and $B_{r}$ over $B_{i v 1}$ and $B_{i v 2}$ is based on an evaluation of literature reterences for root uptake and distritution of elements in plants. Nonuniform elemental distributions ir food and feed crops has been widely observed (Table 2.1). Typically, nonnutritional elemental concentrations in agricultural plants are generally orjered as 1 sots $>$ leaves $\geqslant$ stems $>$ tubers $\geqslant$ fruits $\geqslant$ seeds. $10.17,31-37$ Variations in the relative distribution of elements among plant parts occur with species, variety, growth conditions, and element, but in general for most elements, $C_{v}>C_{r}$.

Analysis of food and feed produrtion in the conterminous United States suggests that $B_{v}$ and $B_{r}$ are analogous to $B_{i v 1}$ and $B_{i v 2}$, respectively. Leafy vegetables are the orily group of food crops for whi $=$ h $B_{v}$ is the appropriate transfer parameter. Nationally, leafy vegetables comprise a relatively small portion of food crop production (Table 2.2). Thus, major portions of food crops in the United States are associated with the transport parameter $B_{r}$. For feed crops, grains are the unly caiegory associated with $B$. Although the relative importance of grain feeds varies considerably by state and county, in most areas nongrain feeds dominate. Therefore, the lise of default soil-to-plant iransport parameters (reviewed in the following sections) in the computer code AIRDOS-EPA merely requires substitution of $B_{v}$ for $B_{i v 1}$ and substitution of a $B_{r}$, converted from dry weight to wet weight, for $3_{i v 2}$. Appropriate generic factors for conversion of $B_{r}$ to $B_{i v 2}$, based on relative importance of various nonleafy vegetab'es in the Unites States, are $0.126,0.222$, and 0.888 fo: exposed produce, protected produce, and grains, respectively (Taile 2.3). Weighting these conversion factors by the relative importance (based on production in kilograms) of each catezory in the United States (Table 2.2) yields an overall average value of 0.428 . However, regional differences in the relative importance of the food categories and assessment requiremints may require the selection of more appropriate conversion factors from Tables 2.2 and 2.3 .

\subsubsection{Protocols for determiantion of parameter values}

All estimates of $B_{v}$ and $B$, are based on any combination of 1) analysis of literature references, 2) correlations with other parameters, 3) elemental systematics, or 4) comparisons of observed and predicted elemental concentrations in foods. In general, no a priori biases or protocols were used to produce conservative values.

Analysis of literattire references required subjective evaluation of the experimental techniques, reliability of reported data, and appropriateness of reported valies to the parameters. Practically, when many references were available for an element, subjective standards were relatively high; when only one or a few references were available, standards were less rigorous, and alternative approaches brcame increasingly important. Occasionally, reported data was not amenable for direct calculation of $b$ or $B$, based on Fqs. (1) and (2). If such corollary information such as soil bulk density, crop yield, background concentration, counting efficiency, and specific activities were not reported or easily available from other references, estimates of them were made for indirect calculation of $B_{v}$ or $B_{r}$. Acceptance or rejection of such references was subjective, depending on the number and quality of other available references and comparison of indirect estimates with 


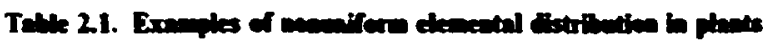

\begin{tabular}{|c|c|c|c|}
\hline Element & $\left(C_{r} / C_{v}\right) r$ & Plant & Reference \\
\hline $\mathbf{L i}$ & $1.6 \times 10^{-1}$ & pumptin & 16 \\
\hline $\mathrm{Be}$ & $1.4 \times 10^{-1}$ & pumptin & 16 \\
\hline B & $3.1 \times 10^{-1}$ & varions vegetables & 17 \\
\hline $\mathrm{Na}$ & $0^{2} \times 10^{-1}$ & pumptin & 16 \\
\hline$M_{8}$ & $6.6 \times 10^{-1}$ & grain and root crops & 18 \\
\hline $\mathrm{Ca}_{2}$ & $1.6 \times 10^{-1}$ & grain and root crops & 18 \\
\hline Ti & $5.3 \times 10^{-1}$ & sode and nut grasses & 19 \\
\hline $\mathrm{Cr}$ & $5.7 \times 10^{-1}$ & pumptin & 16 \\
\hline Mn & $20 \times 10^{-1}$ & various vegetables & 17 \\
\hline $\mathrm{Fe}$ & $1.1 \times 10^{-1}$ & pumptin & 16 \\
\hline Co & $27 \times 10^{-1}$ & sedge and nut grasses & 19 \\
\hline$Z_{n}$ & $3.5 \times 10^{-1}$ & corn & 20 \\
\hline Sr & $8.7 \times 10^{-2}$ & oats & 21 \\
\hline $\mathbf{Y}$ & $1.3 \times 10^{-1}$ & bean: & 22 \\
\hline Mo & $1.2 \times 10^{-1}$ & various vegetables & 17 \\
\hline Tc & $1.9 \times 10^{-2}$ & wheat & 23 \\
\hline Cd & $7.0 \times 10^{-2}$ & various vegetables & 24 \\
\hline 1 & $4.9 \times 1 n^{-1}$ & various vegetubles & 25 \\
\hline Cs & $26 \times 10^{-1}$ & wheal & 26 \\
\hline$B=$ & $9.6 \times 10^{-2}$ & pumptin & 16 \\
\hline $\mathrm{Ce}$ & $3.4 \times 10^{-1}$ & beans & 22 \\
\hline $\mathrm{Pb}$ & $4.2 \times 10^{-2}$ & various vegetubles & 27 \\
\hline Po & $1.5 \times 10^{-1}$ & various veztables & 28 \\
\hline $\mathbf{U}$ & $5.11 \times 10^{-1}$ & various grain and roos crops & 29 \\
\hline Np & $3.5 \times 10$ & wheat & 30 \\
\hline Pu & $1.2 \times 10^{-2}$ & various vegetables & 10 \\
\hline Am & $4.2 \times 10^{-3}$ & various vegetables & 10 \\
\hline $\mathrm{Cm}_{\mathrm{m}}$ & $6.7 \times 10^{-3}$ & various vegetables & 10 \\
\hline
\end{tabular}

$\left(C_{r} / C_{v}\right)$ ratios were determined when pairs of observations were reported for a plant type. Valites in the table are the geometric mean of these ratios for the given reference.

direct estimates from reliable sources. Often reported data were presented graphically. When such references were used, some error from visual interpretation of the graphs is inherent in resultant parameter estimates.

Although past estimates of plant uptake parameters have oun based on the assumption of equilibrium, ${ }^{39,40}$ studies in w!,ich the concentration of polonium, ${ }^{41}$ radium, ${ }^{42}$ cecium, ${ }^{42}$ a mixture of fission produsts, ${ }^{44}$ or strontium $\mathrm{m}^{43,45-51}$ in assorted plants has been repeatedly measured indicate that concentration factors for radionuclides change with time. If equilibrium or near-equilibrium conditions are achieved, they occur late in plant ontogeny. Because the transport parameters are used to generate plant concentrations at cdible maiurity for all vegetative categorie:, except pasture, an attempt was made to use references in whish plant and soil concentration: were measured at edib'e maturity of the plant. In a majority of references, soil concentrations are given for the beginning of the experiment and plant concentrations are usually measured several weeks or months later. Because for most elements concentration factors are small and remo: al mechanisms from soil are controlled, only slight error is introduced in using such references. Also, concentration factors determined before edible ma:lrity were used if subjective evaluation of the experiment suggested only slight error would be introduced from using these references. However, most references in which concentrition factors were measured within three weeks of seed germination were rejected. For experimental determination of c'sncentration factors for technetium, the alove considerations severely limited the available datd base. 


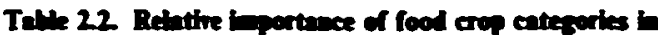

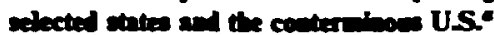

\begin{tabular}{|c|c|c|c|c|}
\hline & \multicolumn{4}{|c|}{ Percent of rocal } \\
\hline & $\begin{array}{c}\text { Leafy } \\
\text { rezetebles }\end{array}$ & $\begin{array}{l}\text { Expoed } \\
\text { produce }\end{array}$ & $\begin{array}{l}\text { Protected } \\
\text { produce }\end{array}$ & Grains \\
\hline \multicolumn{5}{|l|}{ Calưfornia } \\
\hline Area harvested & 8.1 & 32.7 & 42.6 & 16.5 \\
\hline Production & 14.4 & 52.3 & 29.7 & 3.5 \\
\hline \multicolumn{5}{|l|}{ Florida } \\
\hline Area harvested & 28 & 6.8 & 87.0 & 3.5 \\
\hline Production & 4.9 & 7.2 & 87.4 & 0.6 \\
\hline \multicolumn{5}{|l|}{ Maine } \\
\hline Area harvested & 0.1 & 14.9 & 83.1 & 2.0 \\
\hline Production & 0.1 & 3.1 & 96.6 & 0.2 \\
\hline \multicolumn{5}{|l|}{ Minnesota } \\
\hline Area harvested & $<0.1$ & 0.4 & 25.2 & 74.3 \\
\hline Production & 0.2 & 1.3 & 46.6 & $\$ 1.9$ \\
\hline \multicolumn{5}{|l|}{ Montana } \\
\hline Area harvested & $<0.1$ & $<0.1$ & 4.1 & 95.9 \\
\hline Production & $<0.1$ & 0.1 & 12.0 & 87.9 \\
\hline \multicolumn{5}{|l|}{ Texas } \\
\hline Area harvested & 1.4 & 1.8 & 33.1 & 63.7 \\
\hline Production & 10.3 & 5.2 & 55.1 & 29.4 \\
\hline \multicolumn{5}{|l|}{ Virginia } \\
\hline Area narvested & 1.5 & 14.6 & 32.1 & 51.8 \\
\hline Production & 4.7 & 31.7 & 34.9 & 28.6 \\
\hline \multicolumn{5}{|l|}{ Cunterminous U.S. } \\
\hline Area harvested & 1.2 & 6.1 & 23.3 & 69.4 \\
\hline Production & 5.8 & 20.0 & 42.2 & 32.0 \\
\hline
\end{tabular}

'Re'erence: Shor, Baes, and Sha:p', Appendix B.

If a reference was judged appropriate, analysis of the reported values was done in a manner similar to that of Moore et al.' with several modifications. First, all reported values were divided into those for vegetative growth (leaves, stems, straws) or nonvegetative growth (reproductive and storage parts such as fruits, seeds, and tubers). Plant cuncentrations for the former were used in calculation of $B_{v}$ and the latter for $B_{r}$. Also, if $C_{v}$ and $C_{r}$ were reported for a single plant type (e.g., wheat straw and grain or carrot top and roo.), the ratio $\left(C_{p} / C_{\nu}\right)$ was calculated. The geometric mean of ail reported values applied to $B_{v}, B_{r}$, or $\left(C_{r} / C_{v}\right)$ ratio was calculated for each reference. For some references the $\left(C_{r} / C_{v}\right)$ ratio could be calculated, but $B_{v}$ and $B$, could not because hydroponic solutions were used to grow plants or $C_{s}$ was not reported. Finally, the geometric means for each reference were used to construct a distribution for $B_{v}, B_{v}$, or $\left(C_{r} / C_{v}\right)$ ratio. The geometric means of these (inter-reference) distributions were taken to be the best unbiased estimates of the parameters, because reported values often spanned more than an order of magnitude, and because the distributions for elements strontium, cesium, and plutonium (for which there were nuinerous references) appeared to be lognormally distributed. 


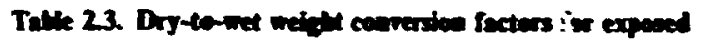
previces, protected produce, and groing

\begin{tabular}{|c|c|c|c|c|c|c|c|}
\hline Vegetable & $\begin{array}{c}\text { Conversion } \\
\text { factore }\end{array}$ & $\begin{array}{l}\text { Weighting } \\
\text { fectot }\end{array}$ & Reference & Vezetable & $\begin{array}{c}\text { Conversion } \\
\text { fector }\end{array}$ & $\begin{array}{l}\text { Weighting } \\
\text { factor }\end{array}$ & Reference \\
\hline Exposed produce & & & & Prolected produce & & & \\
\hline Apple & 0.159 & 15.4 & 14 & Orion & 0.125 & 3.6 & 14 \\
\hline Asparagus & 0.070 & 0.6 & 14 & Orange & 0.128 & 22.8 & 14 \\
\hline Bushberries & 0.151 & 1.6 & 14 & Peanut & 0.920 & 3.4 & 38 \\
\hline Cherry & 0.170 & 0.7 & 14 & Peas & 0.257 & 0.4 & 14 \\
\hline Cucumber & 0.039 & 4.0 & 14 & Potato & 0.222 & 33.7 & 14 \\
\hline Egsplant & 0.073 & 0.1 & 14 & Sugarbeet & 0.164 & 6.5 & 13 \\
\hline Grape & 0.181 & 20.2 & 14 & Sugarcane & 0.232 & 5.5 & 13 \\
\hline Peach & 0.131 & 6.9 & 14 & Sweet coro & 0.261 & 6.0 & 14 \\
\hline Pear & 0.173 & 3.5 & 14 & Sweet potato & $0.3: 5$ & 1.5 & 14 \\
\hline Plums and prunes & 0.540 & 3.1 & 14 & Tree aues & 0.967 & 0.4 & 14 \\
\hline Sweet pepper & 0.074 & 1.3 & 14 & Watermelon & 0.079 & 2.6 & 14 \\
\hline Snap bean & 0.111 & 0.7 & 14 & & & & \\
\hline Squash & 0.082 & 1.8 & 14 & Weighled average & 0.222 & & \\
\hline Strawberry & 0.101 & 1.3 & 14 & & & & \\
\hline \multirow[t]{2}{*}{ Tomato } & 0.059 & 38.8 & 14 & Grains & & & \\
\hline & & & & Barley & 0.889 & 10.1 & 14 \\
\hline \multirow[t]{2}{*}{ Weighted average } & 0.126 & & & Corn (for meal) & 0.895 & 37.7 & 38 \\
\hline & & & & Oats & 0.917 & 2.3 & 14 \\
\hline Protected produce & & & & Rye & 0.830 & 0.5 & 14 \\
\hline Bcan (dry) & 0.878 & 2.2 & 14 & Soybean & 0.925 & 5.3 & 14 \\
\hline Cantaloupe & 0.060 & $1 . !$ & 14 & Wheat & 0.875 & 44.0 & 14 \\
\hline Carrot & 0.118 & 2.4 & 14 & & & & \\
\hline Grapefruit & $0.1: 2$ & 5.5 & 14 & Weighted average & 0.888 & & \\
\hline Lemon & 0.107 & 2.4 & 14 & & & & \\
\hline
\end{tabular}

${ }^{\circ}$ Conversion factor $=$ grams dry/grams wet.

${ }^{b}$ Relative importance based on production in kilograms (percent of total) in the United States based on reference 7.

When only a few literature references were available, alternatives or supplements to the geometric means of distributions method were employed. For example, it was found that $B_{v}$ was correlated with $C_{s}$ for several elements, e.g., $\mathrm{B}, \mathrm{P}, \mathrm{Cu}$, and $\mathrm{Zn}$. That is, entry of the element into the plant appeared to be regulated rather than a constant fraction of the soil concentration. Therefore, studies employing highly enriched soil concentrations might yield inappropriate concentration factors for model calculations. Such correlations were combined with average or typical observed soil concentrations ${ }^{32}$ to generate appropriate concentration factors.

Another approach to determination of concentration factors was to compare plant concentrations surreyed in the literature ${ }^{53,54}$ with those generatec by the equations

$$
\begin{aligned}
& C_{v}=B_{v} C_{s} \text { and } \\
& C_{r}=B_{r} C_{s},
\end{aligned}
$$

where $C_{s}^{\prime}$ is an average or typical soil concentration reported in the literature. ${ }^{57}$ If predicted plant concentrations were clearly atypical of reported values, the concentration factors were revised accordingly. In general, this meihod served as a critique of, or supplement to, other methods hecause of the uncertainties in values for "average" soil and plant concentrations. Typically, these values ranged over two orders of magnitude. 
Finally, for rare elements and elements with little or no experimental information available, elemental systematics were used to derive best estimates when no other method or information was available. That is, relationships established between concentration factors for in element and those for other elements of the same or adjacent periods or groups were examined for trends. Such trends were extrapolated to the element in question, with the implication that chemically similar elements act similarly in the soil-plant environment. This elemental analog approach was extremely useful when support information for $B_{r}$ was unavailable or meager. Systematic trends in observed $\left(C_{r} / C_{v}\right)$ ratios were often used to predict $B_{r}$ from $B_{v}$ when the support data for the former was lacking, but relatively good for the latter.

Selection of values used as default in the TERRA code involved all of the above proceedures. The final value selected as default was estimated to two significant digits rounded off to the nearest 0.5 decimal place (Figs. 2.1 and 2.2). That is, if a value of 1.3 was determined from the various above-outlinea proceedures a value of 1.5 was adopted. A determined value of 1.2 was rounded off to 1.0. The values of $B_{v}$ and $B$, in Figures 2.1 and 2.2 are further discissed in the following sections (2.1.2 through 2.1.10).

\subsubsection{Grop IA and IIA elements}

The Group IA or alkali metals ( $\mathrm{Li}, \mathrm{Na}, \mathrm{K} . \mathrm{Rb}, \mathrm{Cs}$, and $\mathrm{Fr}$ ) and the Group IIA or alkaline earth metals ( $\mathrm{Be}, \mathrm{Mg}, \mathrm{Ca}, \mathrm{Sr}, \mathrm{Ba}$, and $\mathrm{Ra}$ ) are, generally, relatively easily taken up from soil by plants. Many of the lighter of these elements are essential plant nutrients and some, including isotopes of cesium, sirontium, and radium, are extremely important radinlogically. Literaiure references for calculation of $B_{v}$ and $B_{r}$ for cesium ${ }^{26,34,55-71}$ and strontium ${ }^{11.16-19.21 .31-33,59-86}$ are quite abundant. Available references for the rest of the elements in these two groups are less numerous. References were available for lithium, ${ }^{16}$ sodium, ${ }^{16,17,65}$ potassium, ${ }^{16-18,65,71,84}$ rubidium, ${ }^{65}$ berylium, ${ }^{16}$ magnesiun,, ${ }^{16.18,65.71}$ calcium, ${ }^{16,18,65,71.72,84,85}$ and radium. ${ }^{87-93}$ No references were found for francium.

Cesium is the best Jocumented of the Group IA elements. Analysis of the 18 references from which $B_{v}$ estimates were taken suggests that the distribution of geometric means is lognormal (Fig. 2.3). The geometric means established for each of the 18 references ranged from 0.018 to 0.52 with a geometric mean of the means $=0.078$. This value was rounded off to 0.08 for use in TERRA. Half of the $B_{v}$ references included information pertinent to $B_{r}$, yielding a geometric mean of 0.018 for $B_{r}$. Ten of the references yielded $\left(C_{r} / C_{v}\right)$ ratios, suggesting a value of 0.49 for this ratio. Using this ratio value with the the $B_{v}$ estimate previously mentioned yields a seciond estimate of $B$, of 0.038 by the equation

$$
B_{r}=B_{v}\left(\frac{C_{r}}{C_{v}}\right)
$$

Thus, an estimate of $B_{r}=0.03$, which is near the midpoint of the range $(0.018$ to 0.038$)$, was adopied. The ratio of default values of $B_{r}$ and $B_{v}\left(B_{r} / B_{v}\right)$ is within one standard deviation of the $\left(C_{r} / C_{v}\right)$ ratio distribution determined from the 10 references. Comi- rrison of observed concentrations of cesium in plant foods with those predicted using the default estimate for $B_{r}$ (Fig. 2.2) suggests that the default value is not unreasonable (Table 2.4). No infermation on naturally ocsuiring cesium in vegetation applicable to $B_{v}$ was available, but a radiological survey of the Marshall Islands ${ }^{94}$ indicates that predicted Cs-137 concentrations in plants using the default estimate of $B_{v}$ and measured soil concentrations are less than cbserved concentrations (which include resuspended material).

The $B_{v}$ and $B$, values chosen for lithium are derived from an unpublished study by Baes and Katz of natural variations in elemental concentiations in associated pumpkins and soils. ${ }^{16}$ 


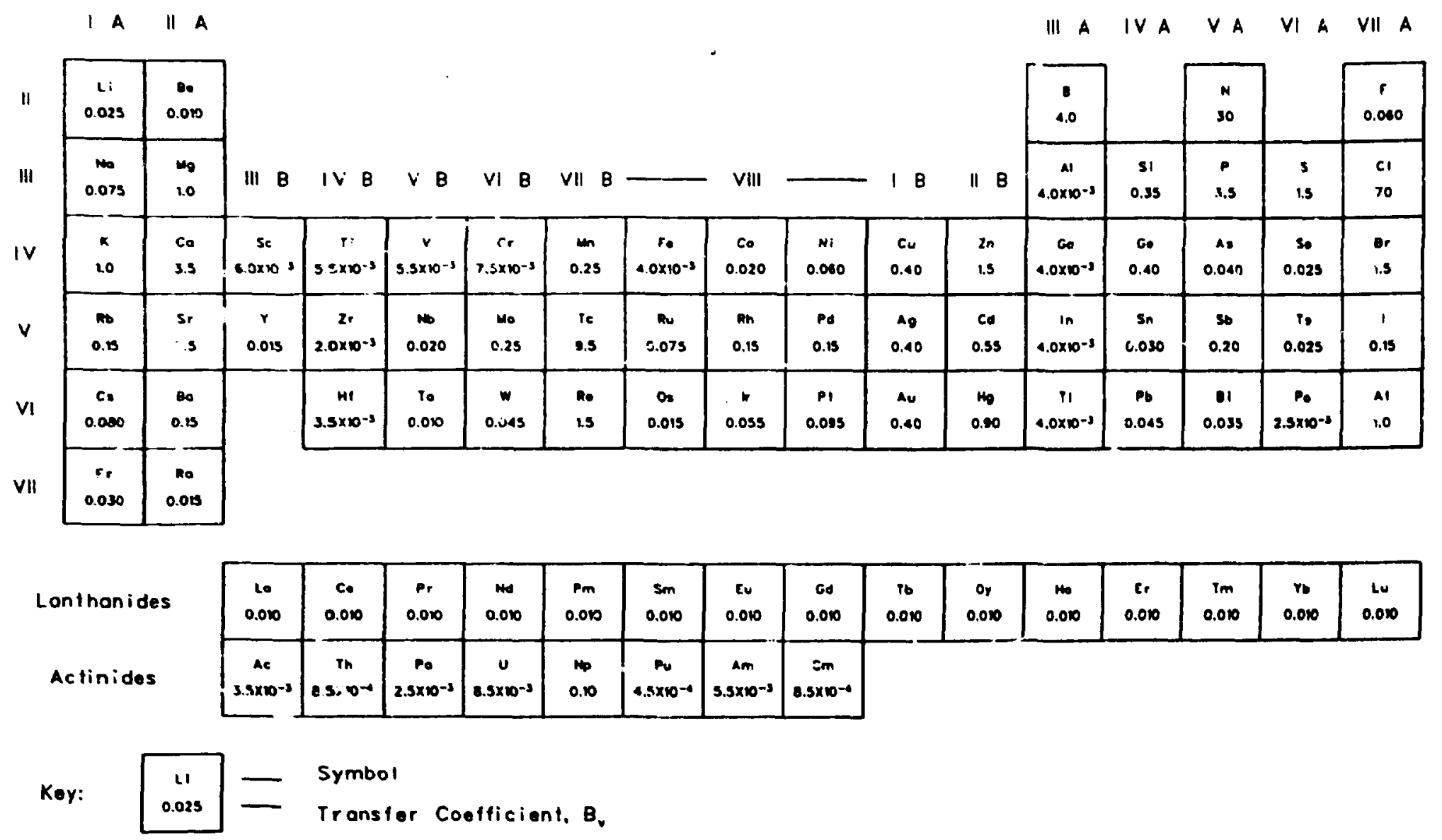

Figure 2.1. Values of the soil-to-plant concentration factor $B_{v}$ adopted as default estimates in the computer code TERRA. 


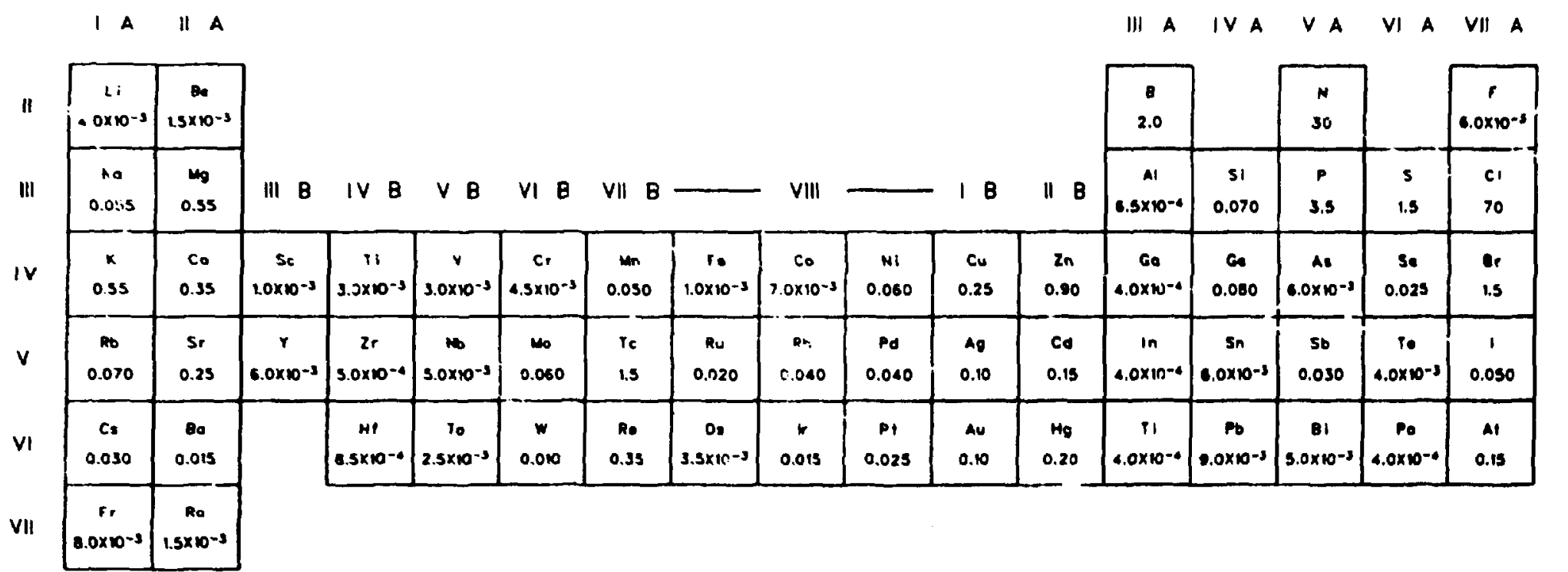

\begin{tabular}{|c|c|c|c|c|c|c|c|c|c|c|c|c|c|c|c|}
\hline Lanthanides & 40 & $\begin{array}{c}c 0 \\
4.0 \times 10^{-3}\end{array}$ & $\begin{array}{c}\mathrm{Pr} \\
4.0 \times 10^{-3}\end{array}$ & $\mid \begin{array}{c}\mathrm{No} \\
4.0 \times 10^{-3}\end{array}$ & ${ }_{0.0 \times 10^{-3}}^{9 m}$ & $\begin{array}{c}\mathrm{sm} \\
.0 \times 10^{-2}\end{array}$ & $\begin{array}{c}54 \\
0.0 \times 10^{-3}\end{array}$ & $\begin{array}{c}00 \\
0.0 \times 10^{-3}\end{array}$ & $\begin{array}{c}T 6 \\
0.0 \times 10^{-3}\end{array}$ & $\begin{array}{c}D y \\
0.0 \times 10^{-3}\end{array}$ & $\begin{array}{c}\text { Ho }^{2} \\
4.0 \times 10^{-3}\end{array}$ & $\begin{array}{c}E \\
0.0 \times 10-5\end{array}$ & $i_{0.0 \times 10^{-3}}^{\mathrm{Im}}$ & $\begin{array}{c}16 \\
0.0 \times 10^{-3}\end{array}$ & $\begin{array}{c}10 \\
0.0 \times 00-3\end{array}$ \\
\hline Actinides & $\begin{array}{c}\mathrm{Ac} \\
3.5 \times 10^{-4}\end{array}$ & $\begin{array}{c}\text { in } \\
0.5 \times 10^{-3}\end{array}$ & $\begin{array}{c}P_{0} \\
2.5 \times 10^{-0}\end{array}$ & $\begin{array}{c}U \\
4.0 \times 10^{-3}\end{array}$ & 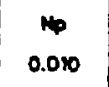 & $\begin{array}{c}P u \\
.5 \times 10^{-9}\end{array}$ & $2.5 \times 10.0$ & $\begin{array}{c}\mathrm{cm} \\
1.3 \times 10^{-3}\end{array}$ & & & & & & & \\
\hline
\end{tabular}

Key: $\begin{gathered}41 \\ 4.0 \times 10^{-3}\end{gathered}-\begin{aligned} & \text { Symbol } \\ & \text { Transfer Coofficient, } B_{r}\end{aligned}$

Figure 2.2. Values of the soil-to-plant concentration factor $B_{r}$ adopted as default estimates in the computer code TERRA. 


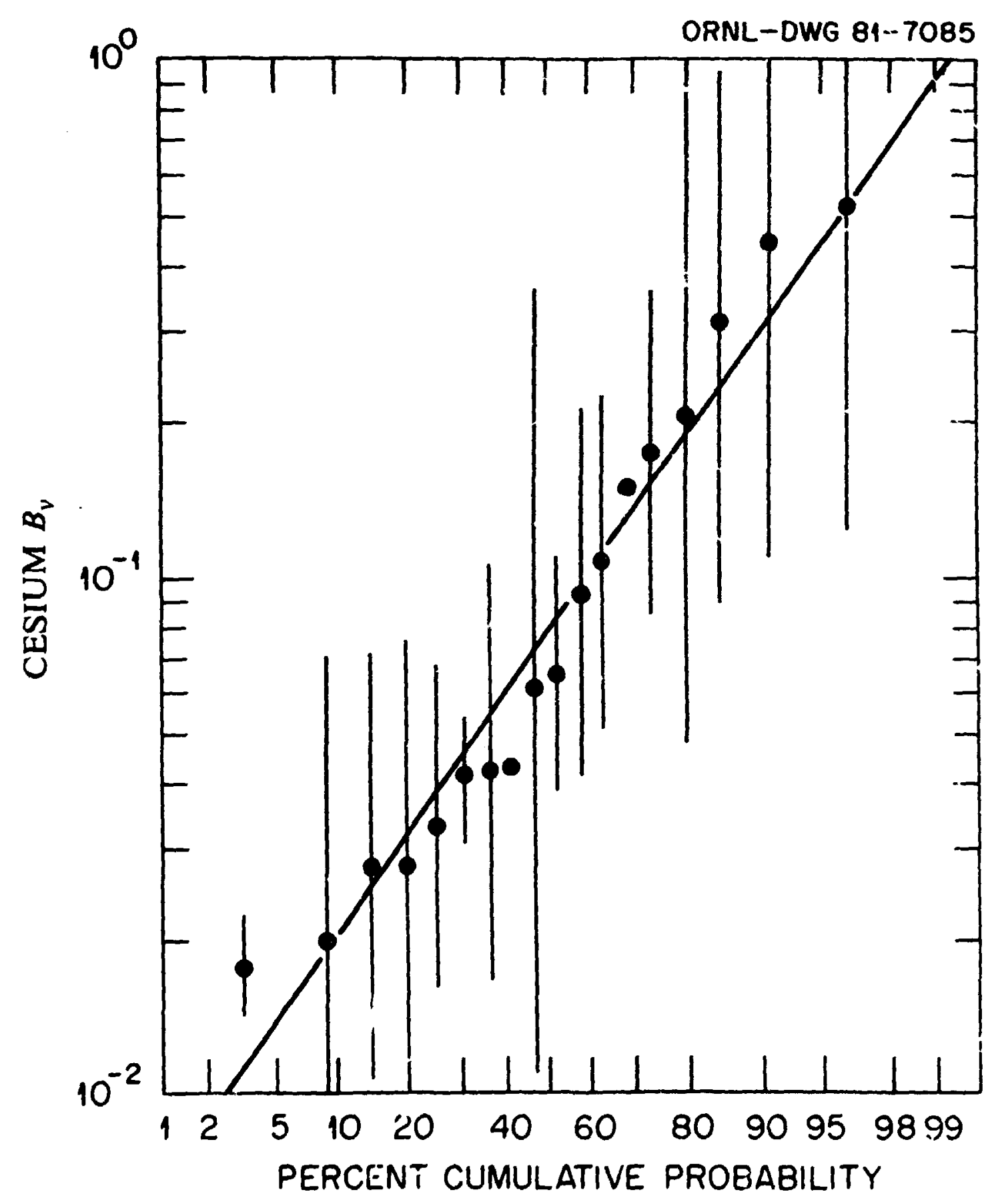

Figure 2.3. Lognormal probability plot of geometric means of $B_{v}$ for cesium (calculated from references 26,34 , and $55-71$ ), including one geometric standard deviation of the mean. 
Comparison of observed and predicted plant concentrations in Table 2.4 indicates that both defau it $B_{r}$ and $B_{r}$ predict plant concentrations which are within observed renges.

The $B_{y}$ for sodium (0.075) was also derived from reference 16. Reference 65 reported soil and plant concentrations from which a lower estimate of $B_{v}$ for sodium was derived, but systematic trends observed by plotting $B_{\text {v }}$ against ztomic number for Group IA and IIA elements (Fig. 2.4), suggest the rejection of this lower value. Comparison if observed and predicted plant sodium using the bigher value supports its selection, because the predicted value is slightly below the reported range.

An estimate of the $\left(C_{r} / C_{v}\right)$ ratio for sodiun of 0.74 was derived from references 16 and 17 . One and iwn standard deviations of the data reported in references 17 and 16, respectively, include the value I.C. Thus, $B_{v}=B_{r}$ for sodium is quite iikely for many plants. However, reported values of $C_{r}$ for sodium are generally less than $C_{r}$. Thus, the derived ratio of 0.74 was iudged acceptable, yielding a default value of 0.055 for sodium $B_{r}$ using $\mathrm{Eq}$. (5). This estimate of $B_{r}$ appears reasonabic (Table 2.4\%.

The default value of $B_{v}$ for potassium was determined to be 1.0. This value is based on the geometric mean of values determined for two references (16 and 65), the correlation between $B$. and $C_{s}$ for potassium observed from these references (Fig. 2.5), and the assumption that typical agricultural practice includes soil fertilization with potassium.

The $\left(C_{r} / C_{p}\right.$; ratio based on literature references is quite variable for potassium. Values at or near $1.0 \mathrm{w}$ re found for pumpkin ${ }^{16}$ and many common vegetables, ${ }^{17}$ including root crops. ${ }^{\text {"I }}$ Lower ratios near 0.4 have been observed for grains. ${ }^{18,71,84}$ From Table $2.4, C_{r}<C_{v}$ appears to apply to potassium, and thus the geometric mean of values determined for references 16-18, 71, and 84 was used to generate a vaiue of $B_{r}=0.55$. This estimate yields predicted $C_{r}$ for potassium which agrees well with the observed range (Table 2.4 ).

One reference was found for rubidium $B_{\nu}$, but both default $B_{v}$ and $B$, values were derived by assuming systematic trends in $B_{v}$ (Fig. 2.4) and $\left(B_{r} / B_{v}\right)$ ratio (Fig. 2.6) for Group IA and IIA elements and comparing observed and predicted $C_{v}$ and $C_{r}$. iso references were found for fraicium $B_{v}, B_{r}, C_{v}$, or $C_{r i}$ and therefore, assumed systematic trends in $B_{v}$ and $\left(B_{r} / B_{v}\right)$ ratio were used exclusively for default estimates of the concentration factors. The $B_{y}$ of 0.03 determined here for francium compares well with the value of 0.04 derived from $\mathrm{Ng}_{\mathrm{g}}$ et al. ${ }^{15}$ (assuming $25 \%$ dry matter).

Strontium is perhaps the best studied of all elements in the periodic table with respect to plant uptake. As for cesium, analysis of the references for $B_{v}$ indicates that this parameter is lognormally distributed (Fig. 2.7). The range of reference mean values, 0.077 to 17 , is larger than the range for cesium, but the nuıber of references is also greater. The geometric mean of the reference means $=2.7$, and it was rounded off to 2.5 for use in TERRA. Fifteen references applicable to $B$, yielded a value of 0.25 . Twenty-five references yielded estimates of $\left(C_{r} / C_{v}\right)$, which when multiplied by the default value of $B_{v}$ also gave a $B_{r}=0.25$.

$A B_{v}=0.01$ for beryllium was derived from reference 16 . That reference also yielded a $B_{r}=$ 0.0028 for pumpkin, but examination of Figs. 2.4 and 2.6 suggest that a value of 0.0015 is more reasonable. Adoption of this value yields a predicted $C_{f}$ value which is approximately an order of magnitude higner than reported values (Table 2.4). However, as noted by Shacklette et al., ${ }^{53}$ toxicity to plants is severe and mer surable amounts are rarely observed in plants.

The $B_{v}$ for magnesium (1.0) was determined from references 16 and 65 . The geometric muan of values of $\left(C_{r} / C_{v}\right)$ ratio for references 16,18 , and 71 was used to derive a $B_{r}=0.55$. Predicted and observed $C_{v}$ and $C_{r}$ for magnesium agree well (Table 2.4).

Calcium $B_{v}$ (3.5) was derived from references $16,65,71$, and 72 . Comparison of $\mathrm{pr}$ 'icted and observed $C_{v}$ values using this $B_{v}$ value (Table 2.4 ) and comparison among other Group IIA elements for $B_{v}$ in Fig. 2.4 support the reasonableness of this value. Calculated mean $\left(C_{r} / C_{v}\right)$ ratios for calcium, strontium, barium. and radium, $0.081,0.13,0.18$, and 0.095 , respectively, suggested the adoprion of a value of 0.1 for all Group IIA elements below magnesium. Thus, $B$. 0.35 for calcium is used in TERRA. Comparison of predicted and observed $C_{r}$ values using this. , (Table 2.4) is good. 


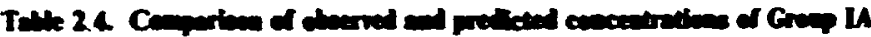

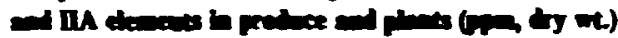

\begin{tabular}{|c|c|c|c|c|c|}
\hline \multirow{2}{*}{ Element } & \multirow{2}{*}{$\begin{array}{c}\text { Arerage } \\
\text { conceatration } \\
\text { in sil }\left(C_{2}\right) \text { r }\end{array}$} & \multicolumn{2}{|c|}{ Vereative grouth $\left(C_{v}\right)$} & \multicolumn{2}{|c|}{ Fraits and tubers $\left(C_{r}\right)$} \\
\hline & & Oberved rases & Prodictad & Oberved rasest & Predisted \\
\hline \multicolumn{6}{|l|}{ Groop IA } \\
\hline Li & 30 & 0.15 to 55 & 0.75 & 0.010 10 9.8 & 0.12 \\
\hline $\mathbf{N a}$ & 6,300 & 700 in 20,000 & $4 m$ & 15 to 3,500 & 350 \\
\hline $\mathbf{K}$ & 14,000 & 1,000 to $77,000^{.5}$ & 14,000 & 7,800 to 28,000 & 7,500 \\
\hline $\mathbf{R} \mathbf{b}$ & 100 & 1820400 & 15 & 1.01050 & 7.0 \\
\hline Cs & 5.0 & & 0.40 & $20 \times 10^{-3}$ to 0.35 & 0.15 \\
\hline $\mathbf{f r}$ & & & & & \\
\hline \multicolumn{6}{|c|}{ Group IIA } \\
\hline Be & 6.0 & 0.090 & 0.060 & $1.0 \times 10^{-3}$ & $9.0 \times 10^{-3}$ \\
\hline$M_{8}$ & 6,300 & 110 ic $14,000=$ & 6,300 & 200 to 11,0008 & 3,500 \\
\hline C & 14,000 & 1,000 to 78,000 & 48,000 & 71 to 6,400/s & 4,800 \\
\hline $\mathbf{S r}$ & 300 & 13101,900 & 750 & 0.060 in 40 & 75 \\
\hline $\mathrm{Ba}$ & 500 & 281080 & 75 & 0.30 20 86 & 7.5 \\
\hline $\mathbf{R a}$ & $8.0 \times 10^{-7}$ & $26 \times 10^{-3}$ & $1.2 \times 10^{-5}$ & $1.1 \times 10^{-9}$ & $1.2 \times 10^{-9}$ \\
\hline
\end{tabular}

- Reference 52

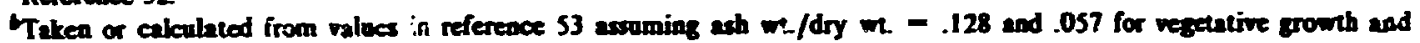
fruits and tobers, respectively.

The product, $B_{v} \cdot C_{s}$.

The product, $B, \cdot C_{s}$.

Reference 13.

IReference 14.

iReference 54.

The $B_{v}$ for barium (0.15) was determined from references 16,59 , and 65 . The default $B_{v}$ value was calculated in a manner similar to that for calcium using Eq. (5). Observed and predicted $C_{v}$ and $C_{r}$ agree well (Table 2.4).

Because of its importance radiologically, the concentration factors for radium used in AIRDOS-EPA have been both highly scrutinized and criticized.95 Reevaluations of the $B_{i v 1}$ and $B_{\text {lv2 }}$ values listed in Moore et al.' have been based on corrections of values reported in the literature $^{12}$ and subjective evaluation of the quality of the references. ${ }^{95}$ Unfortur.ately, available references for calculation of soil-to-plant concentration factors for radium must all be judged subjectively (Table 2.5). However, separation of plants into the two catergories in association with $B_{v}$ and $B_{r}$ eliminates inconsistersies in the $B_{i v 1}$ and $B_{i v 2}$ approach and suggests that only one available reference reports questionable results. The earliest reference found for radium soil-plant concentration factors, reported by Kirchmann and Boulerm; in $1968,{ }^{87}$ has not been used in support of $B_{v}$ or $B$, here because their analytical technique st questionables and yields extremely high values. Furthermore, the experimental technique for determination of radium used by Kirchinann and Boulenger has been que.stioned. ${ }^{95}$ However, reference 87 does yield a $\left(B_{f} / B_{v}\right)$ ratio consistent with those for calcium, strontium, and barium. Insufficient criteria have been found for rejection of any of the remaining references. 


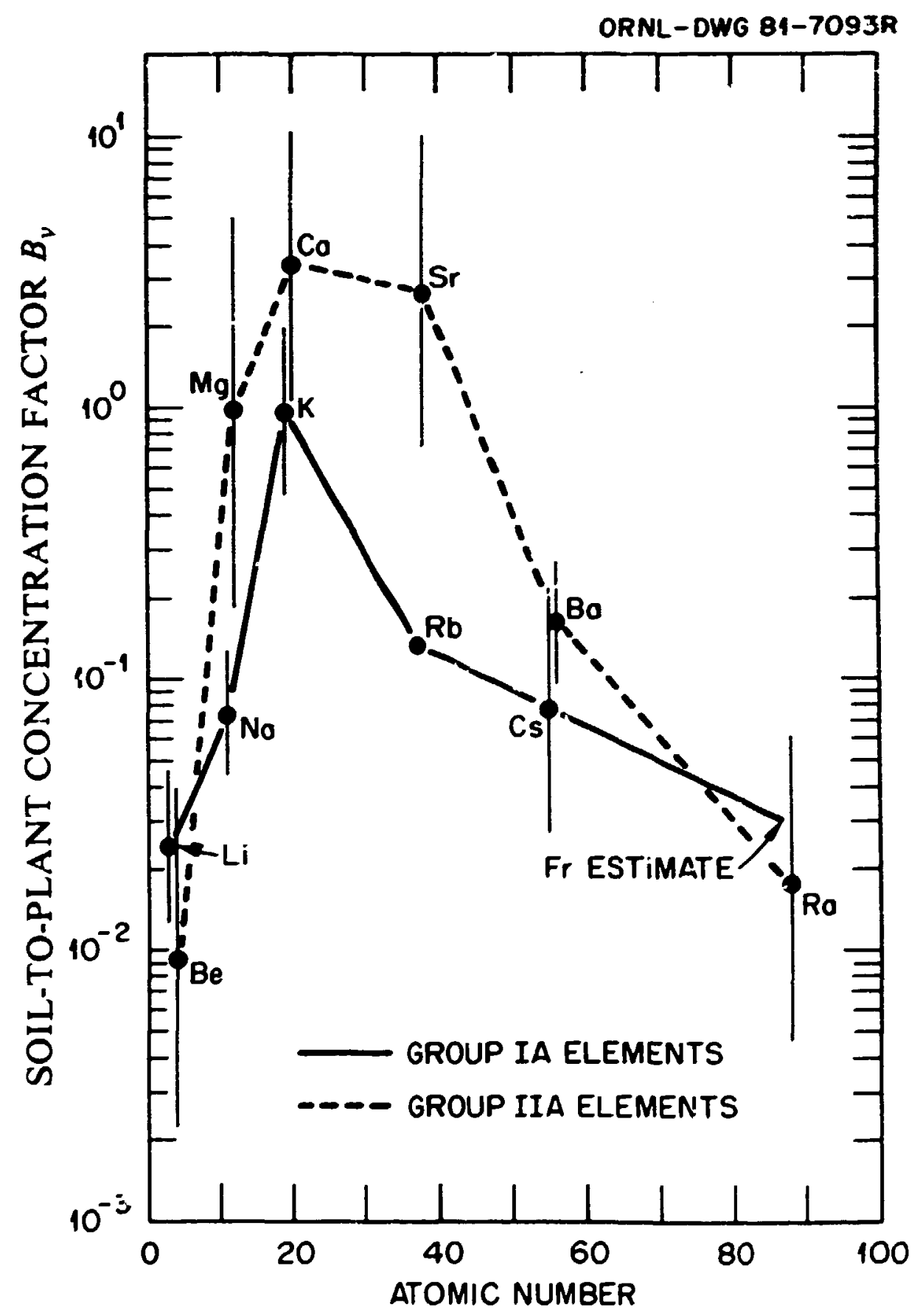

Figure 2.4. Assumed systematic trends in $B_{v}$ for Group IA and IIA elements. Solid dots and error bars represent geometric means and standard deviations determined from availabie references. 


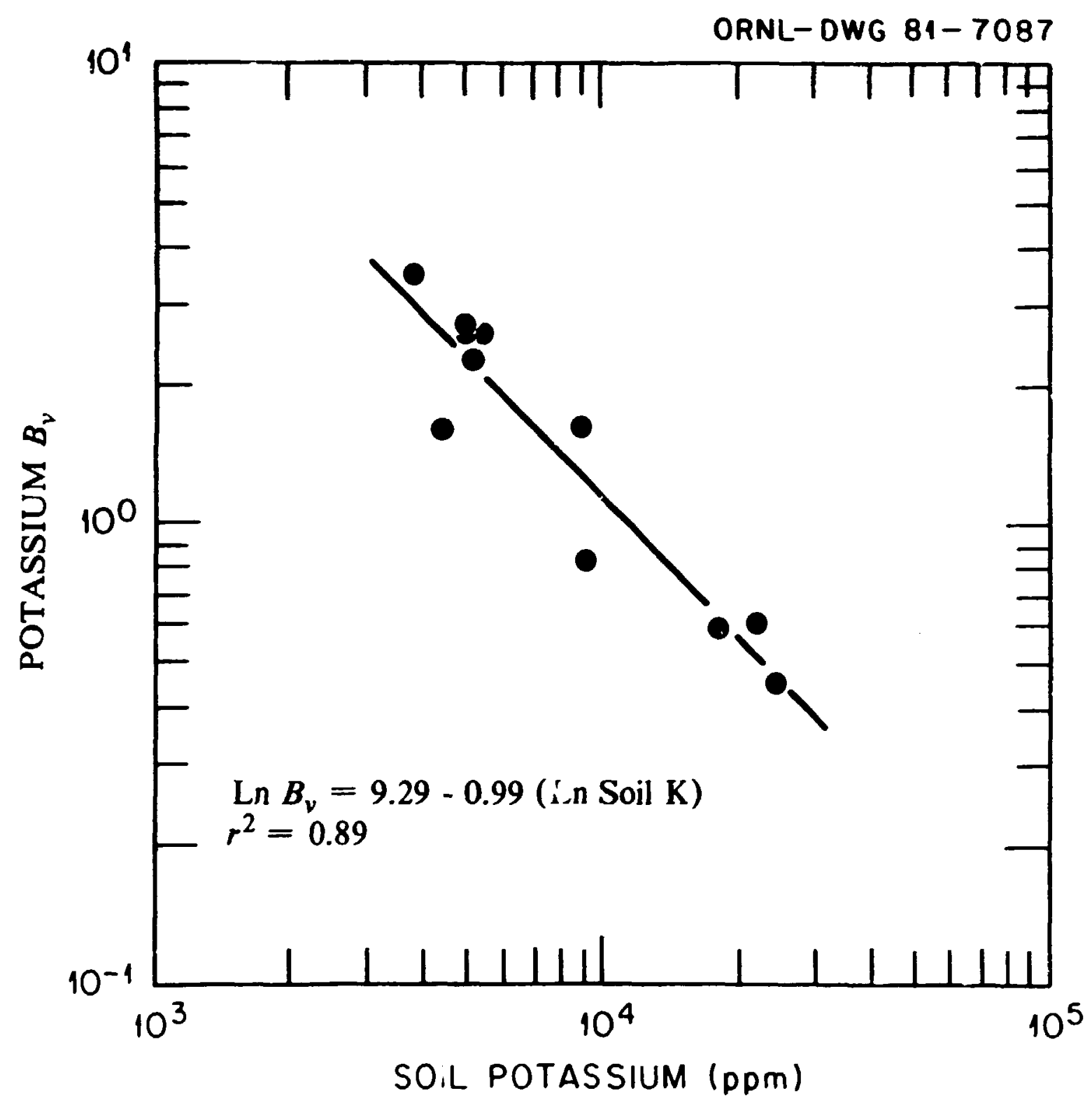

Figure 2.5. Correlation between soil potassium concentration and the soil-to-plant concentration factor, $B_{v}$, for potassium based on references 16 and 65 . 


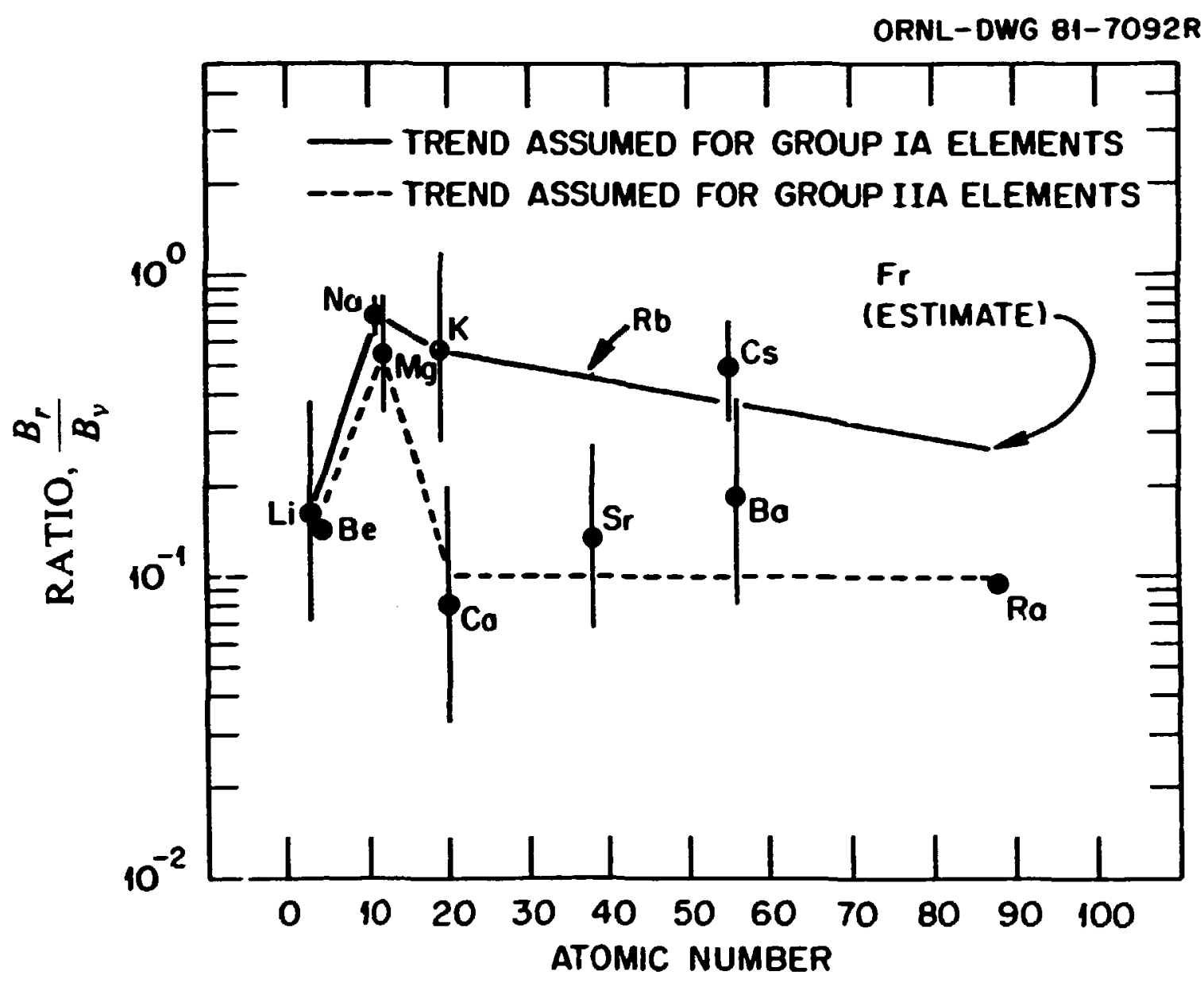

Figure 2.6. Assurr 1 systematic tren ss in $\left(B_{r} / B_{v}\right)$ ratio for Group IA and IIA elements. Solid dots and error bars represent geometric means and standard deviations determined from available r-ierences. 


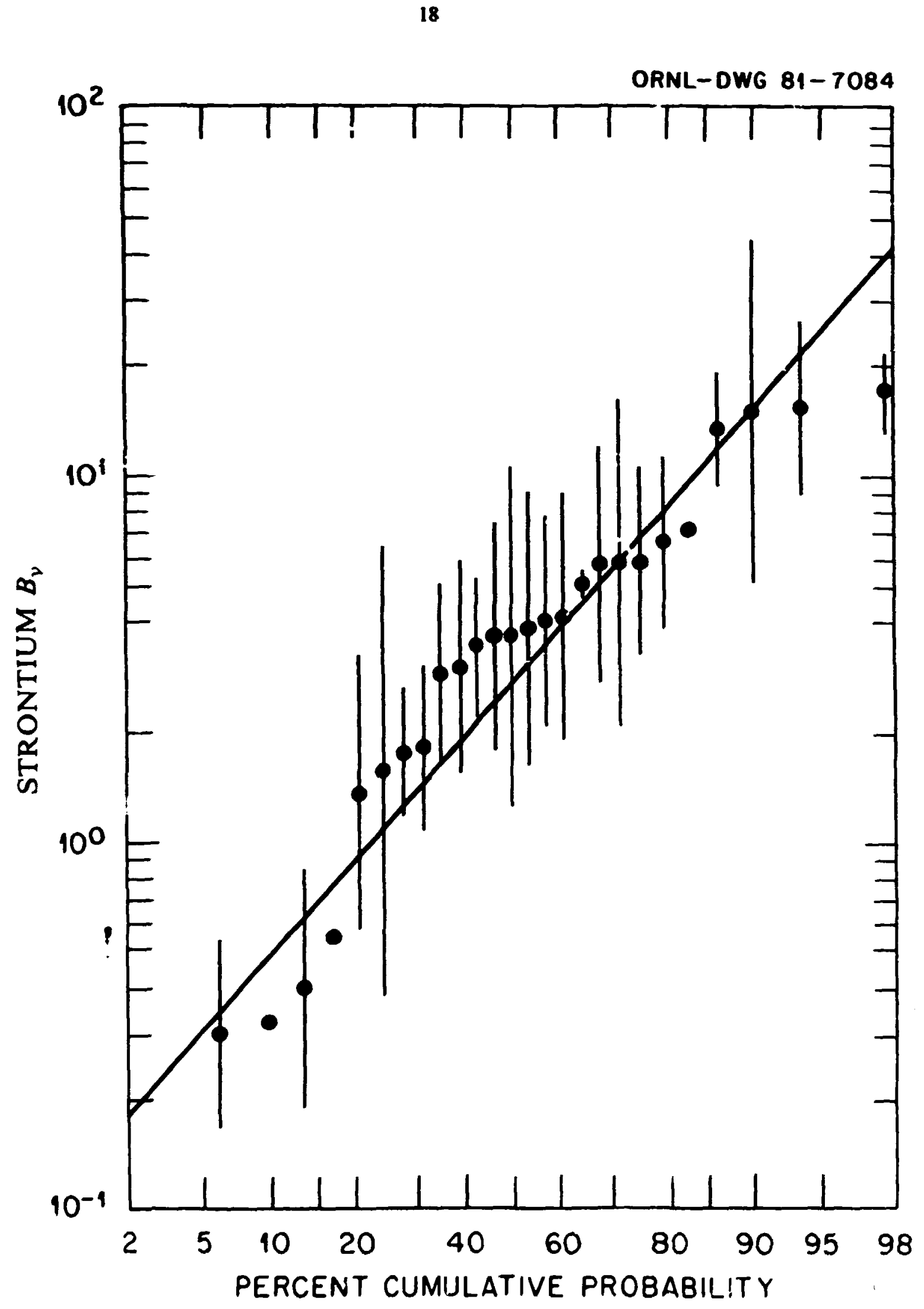

Figure 2.7. I ognormal probability plot of geometric means of $B_{v}$ fni strontium (calculated from references $11,16,17,21,31,33,59,60,62-70,72,74-76,78,81-83,85$, and 86 ), including one geometric standard deviation of the mean. 


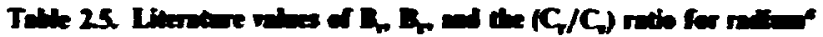

\begin{tabular}{|c|c|c|c|c|}
\hline$B$ & $B_{r}$ & $\left(C_{r} / C_{\nabla}\right)$ & Reference & Comments \\
\hline \multirow[t]{2}{*}{0.71} & 0.10 & 0.95 & 87 & 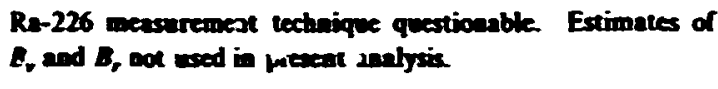 \\
\hline & $5.0 \times 10^{-4}$ & & 90 & $\begin{array}{l}\text { Reported wet weight plant concentrations converted to dry } \\
\text { weight esing reference } 13 \text {. }\end{array}$ \\
\hline 0.045 & $3.2 \times 10^{-3}$ & & 88 & 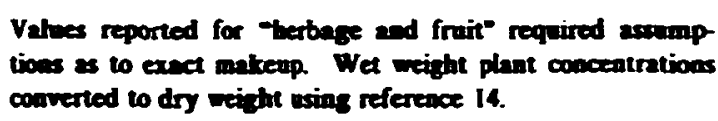 \\
\hline 0.060 & & 1.8 & 93 & $\begin{array}{l}\text { Vesetution sumpled inappropriate to humen pathways. } \\
\text { Resespession of sol onto pient sarfeces suspected. }\end{array}$ \\
\hline 0.012 & & & 89 & 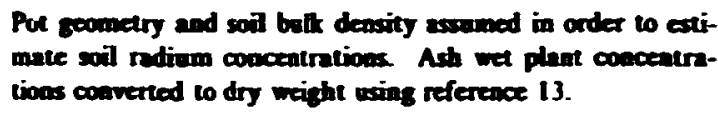 \\
\hline 0.020 & & & 91 & \\
\hline $24 \times 10^{-3}$ & $8.2 \times 10^{-4}$ & & 92 & $\begin{array}{l}\text { Salas" was assumed to be kettuce Ash weight plant con- } \\
\text { ceatrations converted to dry weight using referewce } 14 \text {. }\end{array}$ \\
\hline
\end{tabular}

- Geometric means of all values reported.

In a review of Ra-226 t:ansport by McDowell-Boyer, Watson, and Travis," a value of 0.09 was recommended for a iadium forage and hay concentration factor. The authors recommended a value of $\mathbf{0 . 0 2}$ for vegetables, fruit, and grain. The dry weight equivalent of this value would be a factor of 4 to 10 higher, depending on the assumed water content of vegetables, fruit, and grains. The value for $B_{y}$ derived from five references listed in Table 2.5 is 0.017 , which is roughly a factor of 5 lower than the value recommended in reference 96 . This value has been rounded off to 0.015 . The $B$, value derived from three references listed in Table 2.5 is 0.0011 , which is much lower than the value recommended in reference 96 . The $\left(B_{r} / B_{r}\right)$ ratio obtained from reference 87 and similar ratios found for calcium, strontium, and barium suggest that a $B_{r}=0.0015$ is reasonable. These default $B_{v}$ and $B_{r}$ values appear to be acceptable based on systematic trends (Figs. 2.4 and 2.6) for Group IIA elements and comparison of observed and predicted $C_{v}$ and $C$, values (Table 2.4).

Much work has been done on the effect of available soil calcium on the uptake of strontium by plants, 18.21.33.71.78.79.81.82 and this subject has been thoroughly reviewed by Francis; ${ }^{233}$ in general. plant uptake of strontium is inversely proportional to the amount of exchangeable calcium in the soil. The same effect of soil calcium on plant uptake of radium has also been suggested." Therefore, it is likely that plant uptake of all Group IIA elements will be negatively affected by increasing soil calcium. The exact relationships between calcium and other IIA elements will be affected by plant type, plant part, and soil characteristics; therefore, in the TERRA somputer code, soil calcium influence on $B_{v}$ and $B$, for Group IIA elements is not considered. However, a user of the code may wish to select higher $B_{v}$ or $B$, values than the defaults (Figs. 2.1 and 2.2 ) for Group IIA elements for pasture pathways and lower values for food crop pathways, assuming that in the latter case soils are more intensively prepared and ammended (including liming). 


\section{Grop IIA, IVA, and VA elements}

Groups IIIA, IVA, and VA contain elements which are essential plant nutrients, elements for which some isotopes are important radiologically, and elements for which experimental evidence for $B_{v}$ and $B_{r}$ is scanty. By far, the best documented element of these groups for $B_{r}$ and $B_{r}$ is

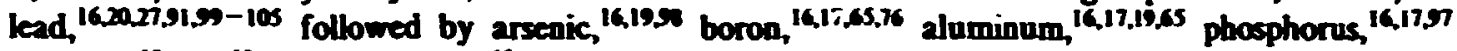
indium, ${ }^{65}$ tin, 6 and antimoay. ${ }^{65}$ No references were readily obtainable fer nitrogen, silicsa, gailium, germanium, thalium, and bismuth. Corollary information was used to estimate transfer parameters for these elements.

The $B$, value of 4.0 adopted for boron is based on the relationship between soil boron concentration and boron $B$, determined frum references 16,65, and 76 (Fig. 2.8), and an assumed average soil boron concentration of $10 \mathrm{ppm}$ (Tabie 26). ${ }^{52}$ The $\left(B_{r} / B_{v}\right)$ retio as tetermined from references 16 and 17 is approximately 0.5 , and a $B$, value of 2.0 was adopted. Comparison of observed and predicted boron food concentrations (Table 2.6) indicates that the default $B$, and $B_{r}$ values are reasonable.

The $B_{v}$ estimate of 0.004 for aluminum is based on references 16 and 65 . The $\left(B_{r} / B_{v}\right)$ ratio of 0.167 determined from reference 17 was used to generate a default value $i e x, \bar{B}$, of $6.5 \times 10^{-4}$. This value is a factor of 2.5 greater than tine single value of $26 \times 10^{-4}$ found by Baes and $\mathrm{Katz}^{16}$ but comparison of observed and predicted aluminum concentrations in produce (Table 2.6) indicates the default $B$, and $B$, estimates give reasonable predictions which are near the low end of reported ranges.

The $B_{v}$ for indium was taken from a single value determined from reference 65 . Because the default $B$, estimate for indium equals the default $B_{v}$ estimate for aluminum, a gallium $B$, of 0.004 was also assumed for this Period IV element. Since no data were available for thallium $B$ its value was set equal to that for aluminum, gallium, and indium. $A\left(B_{r} / B_{v}\right)$ ratio of 0.1 was assumed for gallium, indium, and thallium, yielding a $B$, of $4.0 \times 10^{-4}$ for these elements. Unfortunately, elemental concentrations of gallium, indium, and thallium in soils and a variety of produce are not well-documented. However, the values assumed here are consistent with the fragmentary information of observed plant concentrations of these elements.

Of th: Group IVA elements, lead is the best documented with respect to $B_{v}$ and $B_{r}$. The default $B$, value of 0.045 is the geometric mean of values determined for nine references. A $\left(B_{r} / B_{v}\right)$ ratio of 0.2 based on references $16,20,27,99$ and 102 yields a $B_{r}$ estimate of 0.009 . Table 2.6 shows that these $B_{v}$ and $B_{r}$ default values yield appropriate estimates of lead concentrations in produce.

No references for the direct measurement of $B_{v}$ or $B$, for silicon were found. $\mathrm{N}_{g}$ et al. ${ }^{15}$ provide data from which a dry weight transfer factor of $6.1 \times 10^{-4}$ can be derived. Menzel, ${ }^{106}$ however, reported that the transfer coefficient for soluble forms of silicon ranged between 0.1 and 1.0. Using the $330,000 \mathrm{ppm}(33 \%)$ value for silicon in soil reported by Vinogradow ${ }^{52}$ and the $C$, range reported by Schachlette et al., ${ }^{53}$ the $\mathrm{Ng}$ et al. value is approximately an order of magnitude 100 low and the range reported by Menzel is too high. Therefore, for a $B_{v}$ estimate, the $C_{v}$ value reported for grasses of $110,000 \mathrm{ppm}$ silicon (plant concentrations for other produce or vegetables were reportet in wet or ash weight) was combined with the reported average soil concentration according to $\mathrm{Eq}$. (3) to give a $B_{v}=0.35$ for silicon. The $\left(B_{r} / B_{v}\right)$ ratio for silicon was assumed to be the same as for lead, generating a $B$, estimate of 0.07 .

Reference 15 yields a dry weight transfer factor of 0.4 for germanium. This value appears to be slightly low when predicted and measured $C_{v}$ values are compared (Table 2.6). However, in the absence of experimental evidence and because the value agrees well with the default $B_{v}$ estimate for silicon, it is used for germanium $B_{v}$ also. The $\left(B_{r} / B_{v}\right)$ ratio is also assumed to be 0.2 as for lead and silicon, yielding a $B$, estimate of 0.08 .

The $B_{v}$ for tin of 0.03 is based on reference 65 , and the $B_{r}$ value of 0.006 is based on an assumed $\left(B_{r} / B_{v}\right)$ ratio of 0.2 . Comparison of observed and predictud $C_{v}$ and $C_{r}$ values in Table 2.6 indicates that the default $B_{v}$ and $B$, values are reasonable. 


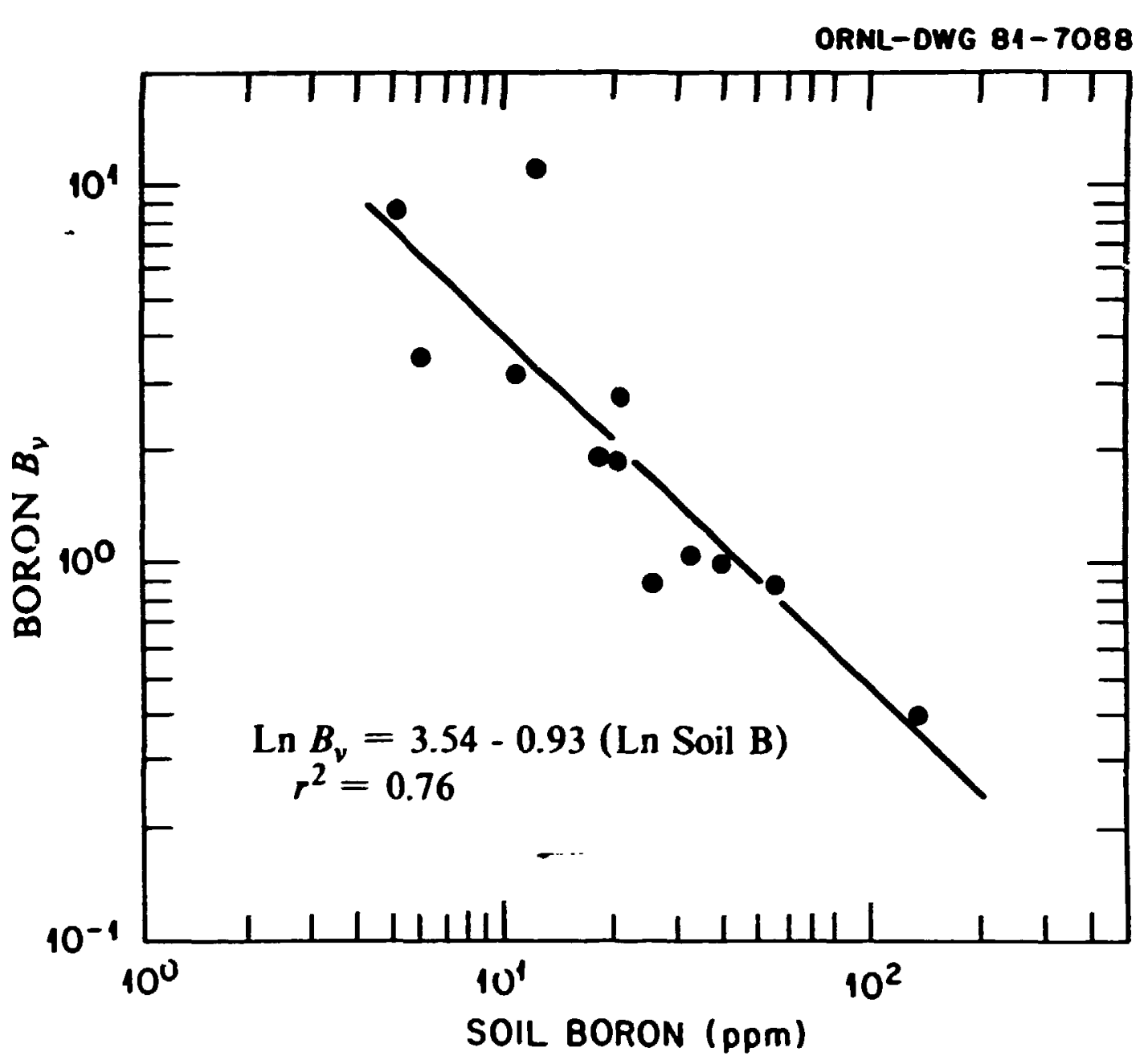

Figure 2.8. Correlation between soil boron concentration and the soil-to-plant concentration factor, $B_{*}$, for boron based on references 16,65 , and 76 . 


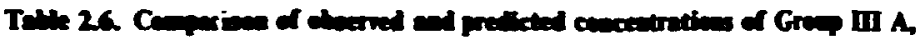

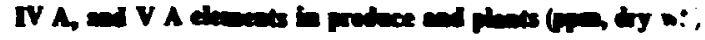

\begin{tabular}{|c|c|c|c|c|c|}
\hline \multirow{2}{*}{ Element } & \multirow{2}{*}{$\begin{array}{c}\text { Averase } \\
\text { concentration } \\
\text { in soil }\left(C_{s}\right)\end{array}$} & \multicolumn{2}{|c|}{ Vegetative growh $\left(C_{\nabla}\right)$} & \multicolumn{2}{|c|}{ Fruits and tubers $\left(C_{r}\right)$} \\
\hline & & Oberved ranget & Predictede & Oboerved ranget & Predictert \\
\hline \multicolumn{6}{|c|}{ Group III A } \\
\hline $\mathbf{B}$ & 10 & $4.0 t 02,100$ & 40 & 6610520 & 20 \\
\hline $\mathbf{A} \mathbf{l}$ & 71,000 & 900 & 280 & Il to 86 & 46 \\
\hline In & 30 & 0.13 & 0.12 & & 0.012 \\
\hline$\pi$ & . & 0.26200 .90 & & & \\
\hline \multicolumn{6}{|c|}{ Group IV A } \\
\hline $\mathbf{S i}$ & 330,000 & 24,000 to 110,000 & 120,000 & & 23,000 \\
\hline Ge & 1.0 & 0.64 to 13 & 0.40 & & 0.080 \\
\hline $\sin$ & 10 & 2.1 & 0.30 & 0.10 เ 1.8 & 0.060 \\
\hline $\mathbf{P t}$ & 10 & 0.13109 .0 & 0.45 & 0.015 to 1.0 & 0.090 \\
\hline \multicolumn{6}{|c|}{ Group V A } \\
\hline $\mathbf{N}$ & 1,000 & $16,0001043,000$ & 30,000 & 4,500 to $29,000^{\prime}$ & 30,000 \\
\hline $\mathbf{P}$ & 800 & 600 ๑ 9,800 & 2,800 & 630 to $52,000^{\prime}$ & 2,800 \\
\hline As & 5.0 & $<0.05$ w0 0.25 & 0.20 & $<0.05$ w0 3.9 & 0.030 \\
\hline So & 0.10 & $<0.056$ & 0.020 & $1.3 \times 10^{-4}$ to 0.039 & $3.0 \times 10^{-3}$ \\
\hline $\mathrm{Bi}$ & 1.0 & 0.15 & 0.035 & 0.068 & $5.0 \times 10^{-3}$ \\
\hline
\end{tabular}

- Refereace 52

Taken or calculated from values in reference 53 ascuming ash $\mathrm{wt} / \mathrm{dry} \mathrm{w}-0.128$ and 0.057 for vegetative growth and fruits and tubers, respectively.

The product. $B_{v} \cdot C_{g}$.

The product. $B_{r} \cdot C_{\mathrm{g}}$.

'Reference 14.

SRefereace 13.

EReferesce 54 .

No references for experimental determination of $B_{v}$ for the essential plan: nutrient nitrogen were readily availabie. The review reference 15 yields a default value of 30 , which gives a predicted $C_{v}$ in the midrange of reported values (Table 2.6). Thus, this value was adopted for use in TERRA. Comparison of observed $C_{v}$ and $C_{r}$ ranges indicates that nitrogen uptake in vegetative and reproductive plant parts is approximately the same. In the absence of evidence to the contrary, $B_{v}=B$, was assumed.

The $B_{v}$ for phosphorus is based on the relationship between soil phosphorus concentration and $B_{v}$ found from data in reference 16 (Fig. 2.9), assuming an average soil concentration of phosphorus of $800 \mathrm{ppm} .52$ Three references yield estimates of $\left(B_{r} / B_{v}\right)$ ratio. Two references (16 and 97) yield estimates greater than 1.0. Reference 17 yields a value oi 0.78 , but one standard deviation of the mean includes 1.0. Thus as for nitrogen, $B_{v}=B$, was adopted. Comparison of observed and predicted $C_{v}$ and $C_{r}$ indicates that default values of $B_{v}$ and $B$, for phosphorus are reasonable.

The $B_{v}$ for arsenic of 0.04 was determined from references 16 and 98 . References 16 and 19 both indicate that, unlike the lighter members of Group VA elements, the accumulation of arsenic in nonvegetative plant parts is less than for vegetative parts. $A\left(B_{r} / B_{v}\right)$ raiio for arsenic of 0.15 was used to calculate a default $B_{r}=0.006$. Comparison of observed and predicted $C_{v}$ and $C_{r}$ values (Table 2.6) shows that the default $B_{v}$ predicts $C_{v}$ vain is mis the high end of the observed range and the $B$, preoicts $C$, values nea: the low end of the obse red range. 


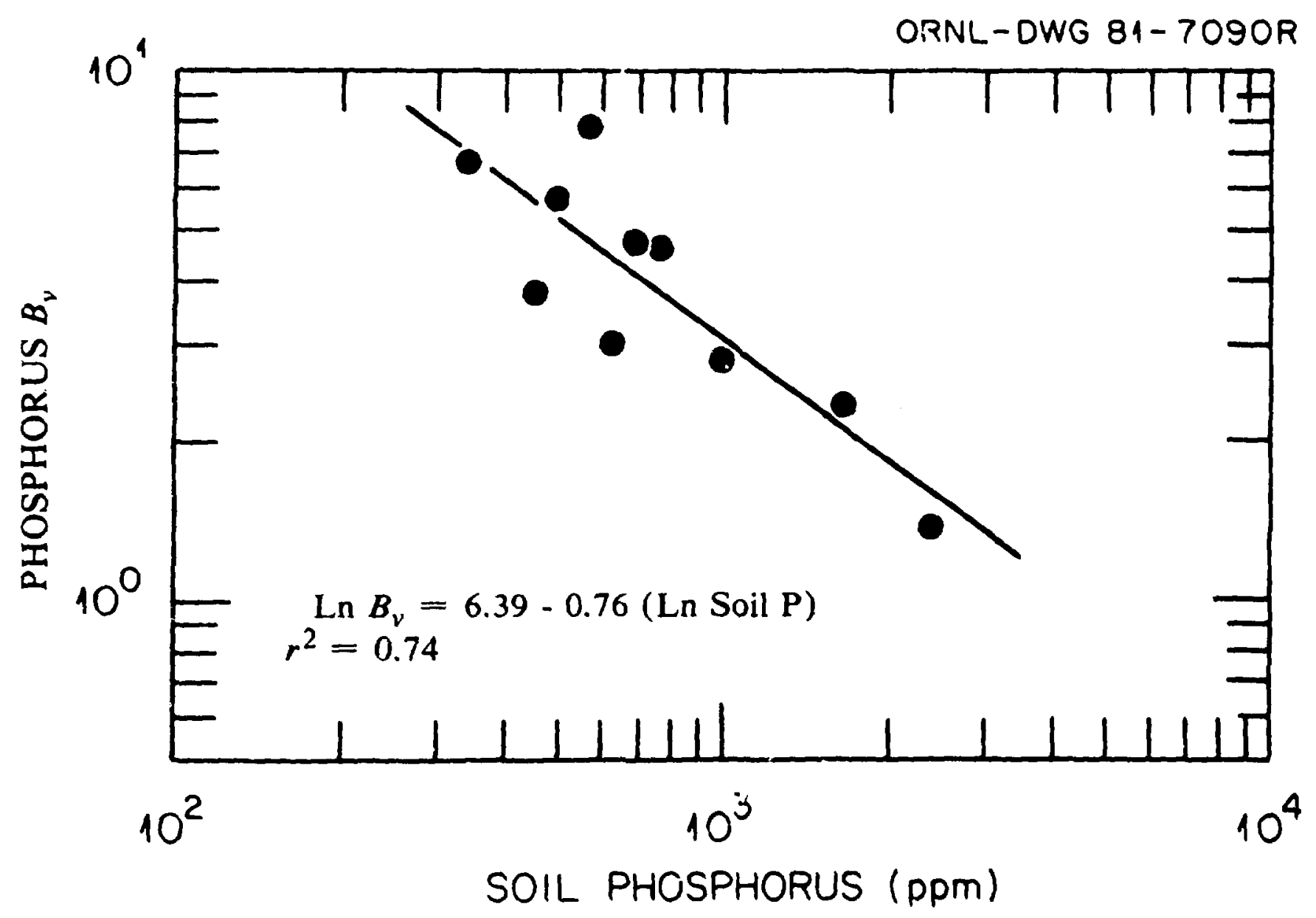

Figure 2.9. Correlation between soil phosphorus concintration and the soil-to-plant concentration factor, $B_{p}$, for phosphorus based on reference 16 . 
The $B_{v}$ f:r antimong was taken from reference 65 . The $\left(B_{r} / B_{v}\right)$ ratio for arsenic was also used for antimony. Comp irisons of observed and predicted $C_{v}$ and $C_{r}$ for arsenic (Table 2.6) are reasonatily good.

The $B_{v}$ for bismu.h was determined from the $B_{v}$ estimates for lead and polonium (discussed in Sec. 2.1.4). The $B_{r}$ estimate was generated from the default $B_{v}$ of 0.035 and the $\left(B_{r} / B_{v}\right)$ ratio used for arsenic and antimony. Comparison of observed and predicted $C_{v}$ and $C_{r}$, although not defiritive, are relatively good (Table 2.6 ).

\subsubsection{Grow VIA and VIIA elements}

The Group VIA and VIIA elements include the relatively mobile anions and the radiologically important elements polonium and iodine. Of these elements the best documented are iodine, ${ }^{25,59,65,107,234,235}$ selenium, ${ }^{15,65,76}$ and polonium. ${ }^{28,91}$ Single references were available for fecorine, ${ }^{18}$ chlorine, ${ }^{65}$ and bromine, ${ }^{65}$ and no references were readily available for sulfur, tellurium, and astatine.

No references on direct determination of soil-to-plant transfer coefficients for sulfur were readily available. However; assuming an average sulfur concentration of $1400 \mathrm{ppm}$ in vegetative portions of plants ${ }^{10}$ and $850 \mathrm{ppm}$ in soil, ${ }^{52}$ a $B_{v}$ of 1.5 results. Comparison of observed $C_{v}$ and $C_{r}$ for sulfur indicate that $B_{v}=B_{r}$ for this element (Table 2.7).

The default $B_{v}$ value for selenium of 0.025 was determined via several approaches. The value obiained from references 65 and $76(0.032)$ was compared with values given by $\mathrm{Ng}_{g}$ et al.$^{15}$ and Menzel. ${ }^{106}$ The latter two estimates were several orders of magnitude higher than the value obtained from references 65 and 76 . Although $B_{v}$ for plant-fly ash relationships ${ }^{10,65,76}$ is comparable to $B_{v}$ estimates given by $\mathrm{Ng}$ et al. ${ }^{15}$ and Menzel, ${ }^{106}$ their estimates, when combined with an arerage selenium soil conecntration of $1 \mathrm{ppm}$, tend to over-predict observed $C_{v}$ values (Table 2.7). Therefore, as a model for selenium the As/P and $\mathrm{Br} / \mathrm{Cl} \mathrm{B}_{v}$ ratios were used as ainalogs for i.te $\mathrm{Se} / \mathrm{S} B_{v}$ ritio. If such ratios are assumed to rhange systematically, then the $\mathrm{Se} / \mathrm{S}$ ratio may be assumed to be 0.016 . This value, multiplied by the $B_{v}$ for sulfur, yields a default sel-..ium $B_{v}$ estimate of 0.025 . Comparison of observed and predicted selenium $C_{v}$ using this de'ault value (Table 2.7$)$ suggests that the default value is reasonable. Although the $\left(B_{r} / B_{v}\right)$ ratio for selenium taken from refere .ce 19 is less than 1.0, comparison of observed $C_{v}$ and $C_{r}$ ranges subcest that $B_{v}=B_{r}$, for selenium also.

The $B_{v}$ for polonium bar zi on references 28 and 91 is $2.5 \times 10^{-3}$. The $\left(B_{r} / B_{v}\right)$ ratio taken from ref rence 28 is 0.15 . This ratio gensrates a default $B$, value of $4.0 \times 10^{-4}$. Unfortunately, no references for comparison of observed $C_{v}$ and $C$, were immediately available for comparison with predicted values.

No references were found for tellurium. The default $B_{v}$ values determined for selenium and polonium suggest that a reasonable assumption for tellurium $B_{v}$ is also a value of 0.025 . Correspondingl $\mathrm{j}_{j}$, the $\left(B_{r} / B_{v}\right)$ ratio of 0.15 for polonium was used to predict a $B_{r}$, for tellurium of 0.004 . As for polonium, no observed $C_{\nu}$ or $C_{r}$ values were available. Furthermore, no average tellurium soil concentrations were availasle either.

The $B_{v}$ for fluorine is based on reference 108 . The value of 0.06 generates a predicted $C_{v}$ value which falls within the range of observed values (Table 2.7). Comparison of observed $C_{v}$ and $C_{r}$ ranges suggest a discrimination 'factor of approximately an order of magnitude. Thus, a $\left(B_{r} / B_{v}\right)$ ratio of 0.1 was assumed and $B_{r}=0.006$.

The $B_{v}$ and $B$, for chloriue were determined through comparison of observed $C_{v}$ and $C_{r}$ and average $C_{r}$ for chlorine (Table 2.7). Both the resulting $B_{v}$ and $B_{r}=70$, the highest concentration factors foi: any eicment reviewed here. Reference 65 yielded a $B_{v}$ of 2.1 and a value of 20 was ontained from reference 15 , but the $C_{v}$ predicted with these factors are wel! below the reported range. This the more indirect method was deemed more appropriate for chlorine. 


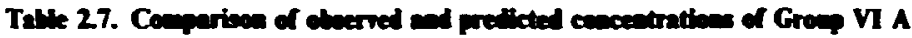

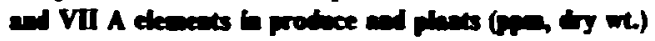

\begin{tabular}{|c|c|c|c|c|c|}
\hline \multirow{2}{*}{ Element } & \multirow{2}{*}{$\begin{array}{c}\text { Average } \\
\text { concentration } \\
\text { in soil }\left(C_{s}\right)\end{array}$} & \multicolumn{2}{|c|}{ Vegete ive growth $\left(C_{v}\right)$} & \multicolumn{2}{|c|}{ Fruits and tubers $\left(C_{p}\right)$} \\
\hline & & Observed range" & Predicteds & Obeerved ranget & Predicted \\
\hline \multicolumn{6}{|c|}{ Group VI A } \\
\hline $\mathbf{S}$ & 850 & 100 to 17,000 & 1,300 & 200 to $450^{\circ}$ & 1,300 \\
\hline Se & 1.0 & $<0.01$ to 0.35 & 0.025 & $<0.01$ to 0.50 & 0.025 \\
\hline Te & & & & & \\
\hline Po & $1.0 \times 10^{-11}$ & & $2.5 \times 10^{-14}$ & & $4.0 \times 10^{-15}$ \\
\hline \multicolumn{6}{|c|}{ Group VII A } \\
\hline $\mathbf{F}$ & 200 & 1.3 to 28 & 12 & 0.020 to 8.4 & 1.2 \\
\hline $\mathrm{Cl}$ & 100 & 2,000 to 23,000 & 7,000 & 300 to 8,500 & 7,000 \\
\hline $\mathrm{Br}$ & 5.0 & 0.31 to 4.9 & 7.5 & 0.20 to 260 & 7.5 \\
\hline I & 5.0 & 4.31010 & 0.75 & 28 to 10 & 0.25 \\
\hline At & & & & & \\
\hline
\end{tabular}

- Reference 52

bTaken or calculated from values reported in reference 53 assuming ash $w t / d r y w t=0128$ and 0.057 for vegetative growth and fruits and tubers, resnectively.

'The product, $B_{r} \cdot C_{s}$.

The product, $B_{r} \cdot C_{2}$.

- Reference 14.

Based on values given in references 65 and 76.

The $B_{v}$ for bromine is based on reference 65 . Although the corresponding predicted $C_{v}$ is slightly high with respect to the observed $C_{v}$ range, comparison of observed $C_{v}$ and $C_{r}$ ranges suggest that the reported $C_{v}$ range may be low (the upper end of the $C_{r}$ range is higher than that for the $C_{v}$ range and a discrimination factor of greater than 1.0 for $C_{r}$ appears inlikely). In lieu of contrary information, a $\left(B_{r} / B_{v}\right)$ ratio of 1.0 was assumed for brumine, and thus $B_{v}=B$, was assumed.

The $B_{v}$ for iodine $(0.15)$ is the geometric mean of values determined for references $2.5,59,65$, 107, 234, and 235. Referer.es 59 and 107 indicate that $B_{v}$ for iodine ranges between 1.0 to 2.0 . However, references 65,234 , and 235 indicate a much lower $B_{v}$ for iodine $(0.04$ to 0.10$)$. Menzel 106 reports that the concentration factor for bromine is greater than that for iodine, and examination of Table 2.7 shows that the adopted $B_{v}$ for iodine does not predict a $C_{v}$ value greater than observid. Thus, the default value adopted in the TERRA code seems reasonable.

The $B_{r}$ value of 0.050 , adopted as a default in TERRA, is based on a compromise between the value of 0.02 derived from reference 234 and the product of the $B, / B_{v}$ ratio $(0.5)$ derived from refeiences 25 and 234 and the default $B_{v}$ of 0.15 . Examination of Table 2.7 shows that the default $B$, value does not overpredict observed $C$, values reported in the literatu:e.

No references were found for astatine. A value of 1.0 for $B_{v}$ is derived from $\mathrm{Ng}$ et al.,"s and this value is adopted as a default value for TERRA. Using polonium as an analog, the assumed $\left(B_{r} / B_{v}\right)$ ratio is 0.15 , producing a $B_{r}=0.15$. 


\subsection{Grop IIIB and the rare enrth elenewds}

The Group IIIB and the rare earth or lanthanide series elements are generally not important for plant nutrition, nor do they accumulate to any large extent in plants. Radiologically, isotopes of cerium are important. In our analysis, we found yttriam ${ }^{162259,00,67}$ and cerium $22,59,60,65$ to be the best documented of these elements, followed by scandium, ${ }^{65}$ lanthanum, ${ }^{65}$ promethium, 22,59 samarium, ${ }^{65}$ and ytterbium. ${ }^{65}$ No references were obtained for praseodymium, neodymium, europium, gadolinium, terbium, dysprosium, holmium, erbium, and thulium. However, iecause of the similarity of chemical behavior of all the lanthanides, ${ }^{110,111}$ soil-to-plant concentration factors for these undocumented elements are based on our analysis of cerium. The $B$, for yttrium of 0.015 was derived from references $16,22,59,60$, and 67. $A\left(C_{r} / C_{r}\right)$ ratio of 0.29 was determined from references 16,22 and 60 and compared with a $\left(B_{r} / B_{z}\right)$ ratio of 0.46 which was based on a $B_{r}$ derived from these same references. $A\left(B, / B_{v}\right)$ ratio midway between these two estimates $(0.36)$ was used to derive a default $B_{r}=0.006$. Comparison of observed and predicted $C_{v}$ and $C_{r}$ ior yttrium (Table 2.8) indicate that the default $B_{\text {, }}$ and $B_{r}$ values are perhaps slightly low, but not unreasonable.

The $B_{v}$ for scandium of 0.006 is based on the observation by Baes and Mesmer ${ }^{110}$ that the chemistry of scandium is between that for aluminum (Sect. 2.1.3) and that for yttrium, but surprisingly more like that for aluminum. A value of 0.0078 was taken from reference 65 , and data from $\mathrm{Ng}$ et al. ${ }^{15}$ yiclds a value of 0.01443 . The mean of these two values corresponds well with the value of 0.016 determined through systematir. interpretation of Baes and Mesmers' observation (Fig. 2.10). The $\left(B_{r} / B_{v}\right)$ ratio was de'ermined in a similar manner to $B_{v}$ assuming a systematic variation in this parameter. The ratio value of 0.2 was used to calculate a default $B_{r}=0.001$. Comparison of observed and prediced scandium food concentrations (Table 2.8) are difficult because of the uncertainity in the observer, range values. However, if the observed $C_{r}$ range reported is icasonable, then both niedicteal $C_{r}$ and $C_{v}$ values are not unreasonable.

The $B$, for cerium of 0.01 as derivel from references $22,59,60$, and 65 . Because of the similarity in the lanthanide elerients, the $B_{v}$ values from references 22,59 , and 65 for other members of the series were proled with ard without those for cerium to estimate $B_{v}$ for all of the lanthanides. Both sets of pooled references yielded a $B_{v}=0.01$. Thus, this value was adopted for e'ements 57 through 71 . T'onling of references for $\left(B_{r} / B_{v}\right)$ ratio 22,60 yielded a value of 0.4 . This value was also used for elements. 57 through 71 .

Comparisons of observed and precicted lanthanide concentrations in produce and plants is difficult because of the paurity of gcod experimental information. However, examination of Table 2.8 shows that for elements in which comparisons can 'se made, our soil-to-plant transfer coefficients tend to slight:y underpredict reported foud concentrations. Although some underpredictions are by more than an order of magnitude, the uncertainty involved in a typica! soil concentraticn or the applicability of a few measurements t/s the true range of food concentrations doe, not warrant revision of the estimates. 


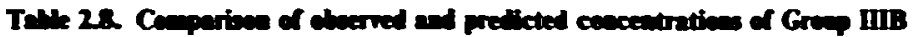

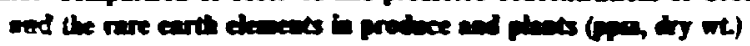

\begin{tabular}{|c|c|c|c|c|c|}
\hline \multirow{2}{*}{ Element } & \multirow{2}{*}{$\begin{array}{c}\text { Average } \\
\text { concentration } \\
\text { in soil }\left(C_{s}\right)^{2}\end{array}$} & \multicolumn{2}{|c|}{ Vezetative growth $\left(C_{r}\right)$} & \multicolumn{2}{|c|}{ Fruits and tubers $\left(C_{r}\right)$} \\
\hline & & Observed ranget & Predictedr & Observed ranget & Predicted \\
\hline Se & 7.0 & $1.0 \times 10^{-46}$ & 0.042 & $5.0 \times 10^{-5}$ to $0.10^{6 s}$ & $7.0 \times 10^{-3}$ \\
\hline $\mathbf{Y}$ & so & 27 to 9.1 & 0.75 & 0.40 to 4.5 & 0.30 \\
\hline La & 40 & $<0.074$ & 0.40 & 0.052 to $0.31^{\circ}$ & 0.16 \\
\hline Ce & so & 0.084 & 0.50 & 0.033 to $0.70^{38}$ & 0.20 \\
\hline $\mathbf{P r}$ & 4.5 & & 0.045 & & 0.18 \\
\hline Nd & 18 & & 0.18 & 0.080 & 0.072 \\
\hline Pm & & & & 0.080 & \\
\hline Sm & 4.9 & & 0.049 & 0.080 & 0.020 \\
\hline Ev & 0.39 & $<5.3 \times 10^{-3 x}$ & $3.9 \times 10^{-3}$ & 0.080 & $1.6 \times 10^{-3}$ \\
\hline Gd & 5.5 & & 0.055 & 0.080 & 0.022 \\
\hline $\mathbf{T b}$ & 0.85 & & $8.5 \times 10^{-3}$ & 0.080 & $3.4 \times 10^{-3}$ \\
\hline Dy & 6.0 & & 0.060 & 0.080 & 0.024 \\
\hline Ho & 0.95 & & $9.5 \times 10^{-3}$ & 0.080 & $3.8 \times 10^{-3}$ \\
\hline $\mathrm{Er}$ & 4.5 & & 0.045 & 0.080 & 0.018 \\
\hline $\operatorname{Tm}$ & 0.45 & & $4.5 \times 10^{-3}$ & 0.080 & $1.8 \times 10^{-3}$ \\
\hline $\mathbf{Y b}$ & 4.6 & 0.53 to 3.2 & 0.046 & 0.080 to 13 & 0.018 \\
\hline Lu & 1.2 & & 0.012 & 0.080 & $4.8 \times 10^{-3}$ \\
\hline
\end{tabular}

'Sc-Ce from reference 52; Pr-Lu estimated from ranges reported by Gibson et al."11

t Taken or calculated from values reported in reference 53 , assuming ash $w / d r y ~ w h=0.120$ and 0.057 for vegetative growth and fruits and tubers, respectively.

'The product, $B_{v} \cdot C_{z}$.

The product, $B_{r} \cdot C_{\text {r }}$.

'Reference 54.

\subsubsection{Period IV transition elements}

Elements of atomic numbe- 22 through 30 (titanium through zinc) are perhaps the best documented for plant uptake from soil. Several of these elements, including mang?nese, iron, and zinc are generally accepted as essential plant micronutrients. ${ }^{33}$ Others, including chromium and cobalt, are recognized as essential for animal nutrition and are suspected as plant nutrients, although their essentiality has not been established. Stable isotopes of these elements have been extensively studied because most are toxic to plan; and animals at sufficient concentrations, altheugh radiologically they are relatively unimportant. As the following discussion will show, the concept of a single equilibrium concentration factor for many of these elements can be questioned. For those elements which are essential to plant nutrition, and thus are likely to be regulated by the plant, correlations between soil concentrations and $B_{v}$ have been established in a manner similar to those for potassium, phosphorus, and nitrogen.

Available references for $B, B_{r}$, and $\left(B_{r} / B_{v}\right)$ ratio numbered 16 for

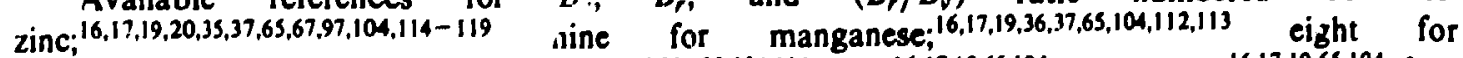
copper; ${ }^{16,17,19,20,65,104,114,115}$ five for nickel, ${ }^{16,20,102,104,114}$ iron, ${ }^{16,17,19,65,104}$ and cobalt, ${ }^{16,17,19,65,104}$ four for chromium; $;^{16,14,65,102}$ three for titanium; ${ }^{16,19,65}$ and two for vanadium. ${ }^{16,65}$ Correlations between soil concentrations and $B_{v}$ were found for all but vanadium, titanium, and nickel. These correlations were often used in lieu of the geometric means approach to define default $B_{v}$ values. 


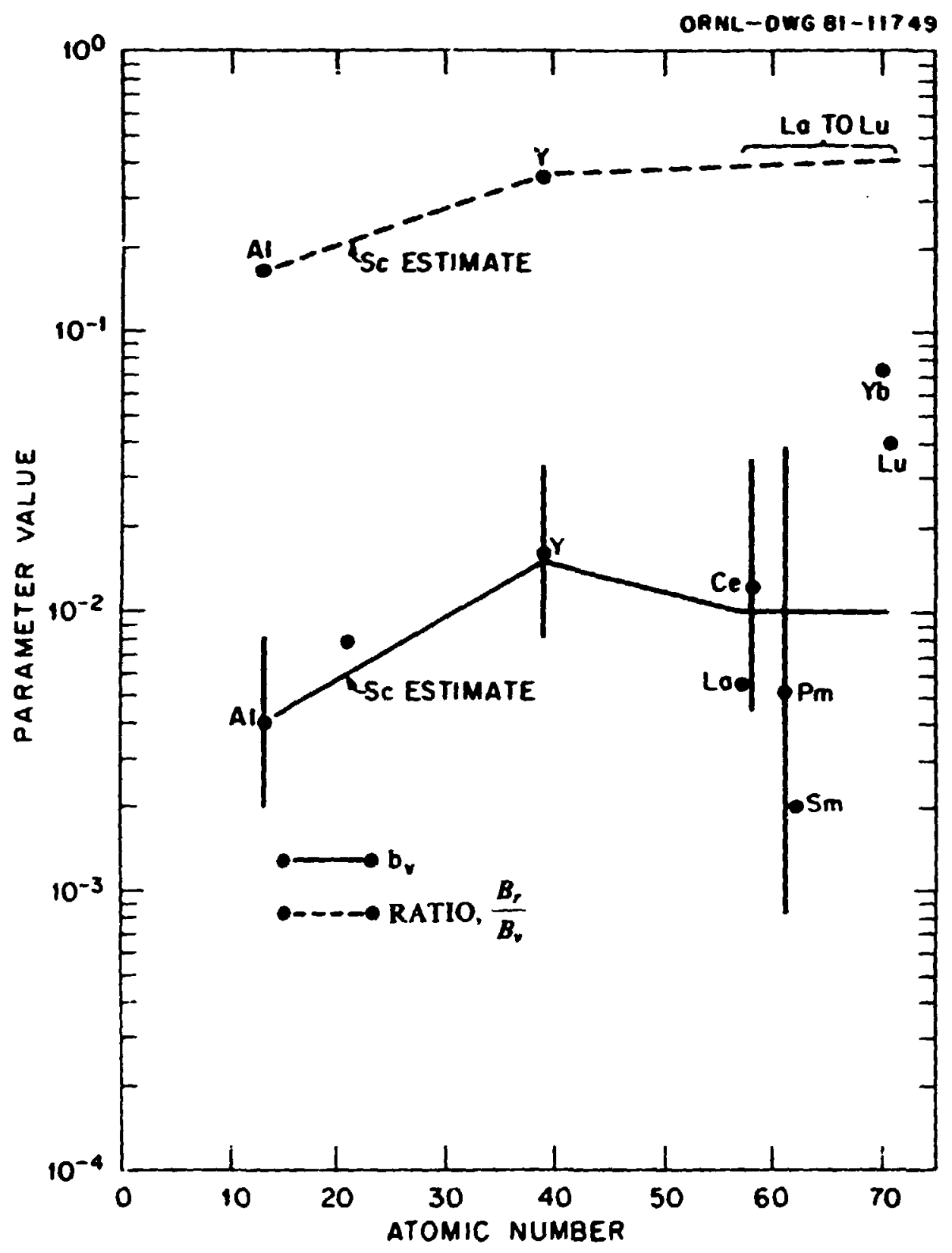

Figure 2.10. Assumed systematic trends in $B_{v}$ and $\left(B_{r} / B_{v}\right)$ ratio for aluminum, scandium, and yttrium. Solid dots and error bars represent geometric means and standard devirtions of the mean determined from available references. 
As before, predicted plant concentrations were compared with obseived values in order to assure reasonable $B_{v}$ and $B_{r}$ estimates. These approactes were used in lieu of elemental systematics because subsequent analyses (see Sec. 2.1.7 and 2.1.8) depended heavily on the values obtained for these Period IV elements.

The $B_{v}$ for titanium of 0.0055 is the geometric mean derived from references 16 and 65 . The $B_{r}$ value was generated from $3\left(B_{r} / B_{v}\right)$ ratio derived from reference 19 . Both soil-to-plant concentration factors predict plant concentrations from typical soil titanium concentrations which agree well with observed plant concentrations (Table 2.9).

The $B_{v}$ for vanadium was also derived from references 16 and 65 , and it is numerically equal to the $B_{v}$ for titanium. No information was available on the $\left(B_{r} / B_{r}\right)$ ratio for vanadium, and therefore, it was assumed equal to that for titanium, yielding a $B_{r}=0.003$. Comparison of observed and predicted $C_{v}$ and $C_{r}$ for vanadium (Table 2.9') is also good.

References 16 and 65 yield a $B$, by the geometric means method of 0.03 for chromium. However, a correlation between soil chromium concentration and chromium $B$, was observed from ihe data in these two references (Fig. 2.11). Although this correlation is weak, the $B_{r}$ determined by geometric means predicts $C_{v}$ for chromium greater than the observed range. Therefore, the relationship in Fig. 2.11 was used to predict a chromium $B_{v}$ of 0.0075 at a soil chromium concentratir 7 of $200 \mathrm{ppm} .{ }^{52}$ This value of $B_{v}$ does predict a reasonable $C_{v}$ (Table 2.9 ).

$A\left(B_{r} / B_{v}\right)$ ratio of 0.6 for chromium was determined from references 16, 19, and 102. This value generates a $B_{v}=0.0045$, which predicts a $C_{r}$ within the reported range of observed $C_{r}$ values (Table 2.9).

The $B_{v}$ for manganese generated by the geometric means method is $\mathbf{0 . 4 1}$. However, from data in references 16,36,37, 104,112, and 113 a strong correlation between $B_{v}$ and soil manganese concentration was observed (Fig. 2.12). At a typical soil manganese concentration of $850 \mathrm{ppm},{ }^{52}$ the corresponding $B_{v}=0.25$. This latter value was adopted for TERRA. Although :his latter $B_{v}$ value for manganese overpredicts $C_{v}$ with respect to the reported observed range, the former value overpredicts $C$, by an even larger factor.

The $\left(B_{r} / B_{v}\right)$ ratio for manganese of 0.2 was determined from references 16,17 , and 19 . This ratio generates a $B_{r}=0 . C 5$. Comparison of observed and predicted $C_{r}$ using this $B_{r}$ value (Table 2.9) indicates that the default $B_{r}$ is reasonable.

Iron is an essential plant nutrient, and therefore, root uptake is probably regulated by the plant. It is not surprising that the relationship between soil iron cencentration and $B_{v}$ shown in Fig. 2.13 was found. At a typical soil iron concentration of $3.8 \%, 52$ the corresponding $B_{v}=C \quad 04$. The $\left(B_{r} / B_{v}\right)$ ratio based on references 16,17 , and $19=0.25$, yielding a $B_{r}$ of 0.001 . Cor rarison of observed and predicted $C_{v}$ and $C_{r}$ (Table 2.9) for iron ind cates the reasonableness of $::$ default $B_{v}$ and $B_{r}$.

The $B_{v}$ for cobalt of 0.02 is based on the weak correlation between soil cobalt concentration and $B_{v}$ (Fig. 2.14) and a typical soil cobalt concentration of $8 \mathrm{ppm}^{52} A\left(B_{r} / B_{v}\right)$ ratio of 0.35 was derived from references 16,17 , and 19. This ratio generates a $B_{r}=0.007$. Predicted $C_{v}$ and $C_{r}$ using these default concentration factors for obalt agree well with observed $C_{v}$ and $C_{r}$ ranges (Table 2.9).

The $B_{v}$ for nickel is based on references 16 and 104 . Unlike chromium, manganess, iron, and cobalt, no clear relationship between soil nickel concentration and $B_{v}$ was indicated from the available data. Also, unlike the other Period IV transition elements no discrimination factor between vegetative and nonvegetative plant parts was found. In fact, the geometric mean of references $16,20,102$, and 114 for $\left(B_{r} / B_{v}\right)$ ratio was 1.2 . Therefore, a $\left(B_{r} / B_{v}\right)$ ratio of 1.0 was assumed and $B_{v}=B_{r}$ for nickel. Examination of Table 2.9 indicates that the observed $C_{r}$ range includes the $C_{v}$ range, supporting this assumption. Predicted $C_{v}$ and $C_{r}$ values agree well with renorted observed ranges.

The $B_{v}$ for copper is based on the strong correlation between soil copper concentration and $B_{v}$ shown in Fig. 2.15 and an average soil copper concentration of $20 \mathrm{ppm} .{ }^{52}$ The $\left(B_{r} / B_{v}\right)$ ratio, as 


\begin{tabular}{|c|c|c|c|c|c|}
\hline \multirow{2}{*}{ Element } & \multirow{2}{*}{$\begin{array}{l}\text { Average } \\
\text { concentration } \\
\text { in } \operatorname{col}\left(C_{g}\right)\end{array}$} & \multicolumn{2}{|c|}{ Vegetative gromh $\left(C_{n}\right)$} & \multicolumn{2}{|c|}{ Fruits and tubers $\left(C_{T}\right)$} \\
\hline & & Oberwad ranget & Predicted: & Obeerved ransel & Predicted \\
\hline $\mathbf{T i}$ & 4,600 & 1.6 to 160 & 25 & 0.037 to 80 & 14 \\
\hline $\mathbf{v}$ & 100 & $<0.091$ to 21 & 0.55 & $4.6 \times 10^{-4}$ to 47 & 0.30 \\
\hline $\mathbf{C r}$ & 200 & 0.18 to 29 & 1.5 & 0.030 10 8.0 & 0.90 \\
\hline Mn & 850 & 1.9 to 16 & 210 & 8.0 to 80 & 43 \\
\hline Fe & 38,000 & 6.5 to $410^{\circ}$ & 150 & 10 to 160 & 38 \\
\hline$C_{0}$ & 8.0 & 0.010 to 0.54 & 0.16 & $6.0 \times 10^{-3} 100.36$ & 0.056 \\
\hline $\mathbf{N i}$ & 40 & 0.23 to $5.2^{4}$ & 24 & 0.028 w0 10 & 24 \\
\hline $\mathrm{Cu}$ & 20 & 1.7 to 11 & 8.0 & 0.801027 & j.o \\
\hline $\mathbf{Z n}$ & so & 2.5 to 630 & 75 & 0.5010110 & 45 \\
\hline
\end{tabular}

- Reference 52

'Taken or calculated from values reported in reference 53, assuming ach wt/dry $\mathrm{w}=0.128$ and 0.057 for vegetative growth and fruits and tubers, respectively (wben neceasary).

The product, $B_{\boldsymbol{v}} \cdot C_{\boldsymbol{r}}$.

The product, $B, \cdot C_{e}$.

'Reference 14.

'Reference 54.

determined from references $16,17,19,20$, and 114 , equals 0.63 . This ratio yields a $B_{r}=0.25$. Both soil-to-plant concentration factors yield reasonable predicted plant copper concentrations (Table 2.9).

The $B_{v}$ for zinc was determined from the strorig correlation between soil zinc concentration and $B_{y}$ determined from references 16,35,37, 67, 97, 104, 114, 115, 117, and 119 (Fig. 2.16) and an average zinc soil concentration of $50 \mathrm{ppm} .{ }^{52}$ The $\left(B_{r} / B_{v}\right)$ ratio of 0.6 was determined from references $16,17,19,20,67,97,114$, and 116 . Combining this ratio with the default $B_{v}$ value generates a $B_{r}=0.9$. Examination of Table 2.9 shows that predicted plant concentrations using these default concentration factors fall well within observed ranges.

Figures 2.17 and 2.18 show the default $B_{v}$ and $3, / B_{v}$ ) ratios, respectively, for Period IV transition elements used in the TERRA computer code. The solid lines in the figures show the systematic trends in these parameters defined by the default estimates. The dots represent the parameter values as determined from the geometric means method. The error bars represent one geometric standard deviation. With the exception of chromium, all $B_{v}$ default values fall within one standard deviation of the mean. For all elements except nickel, the $\left(B_{r} / B_{v}\right)$ ratio is the seometric mean of the reference values.

\subsubsection{Period V traseition elements}

The Period $V$ transition elements contain the controversial and radiologically important element technetium and the toxic metal cadmium. Additionally, this piriod includes the element rutheniurn which is also important radiologically. For concentration factors, cadmium, ${ }^{16,17,19,20,24,65,97,102.104,105,114,116,124-126}$ molybdenum, ${ }^{16,17,19.65 .76,120.121}$ and technetium ${ }^{23,107,122,123,127}$ are the best documented, followed by ruthenium ${ }^{22,59,00,63}$ and zirconium. ${ }^{16}$ No references were found for niobium, rhodium, palladium, and silver. 


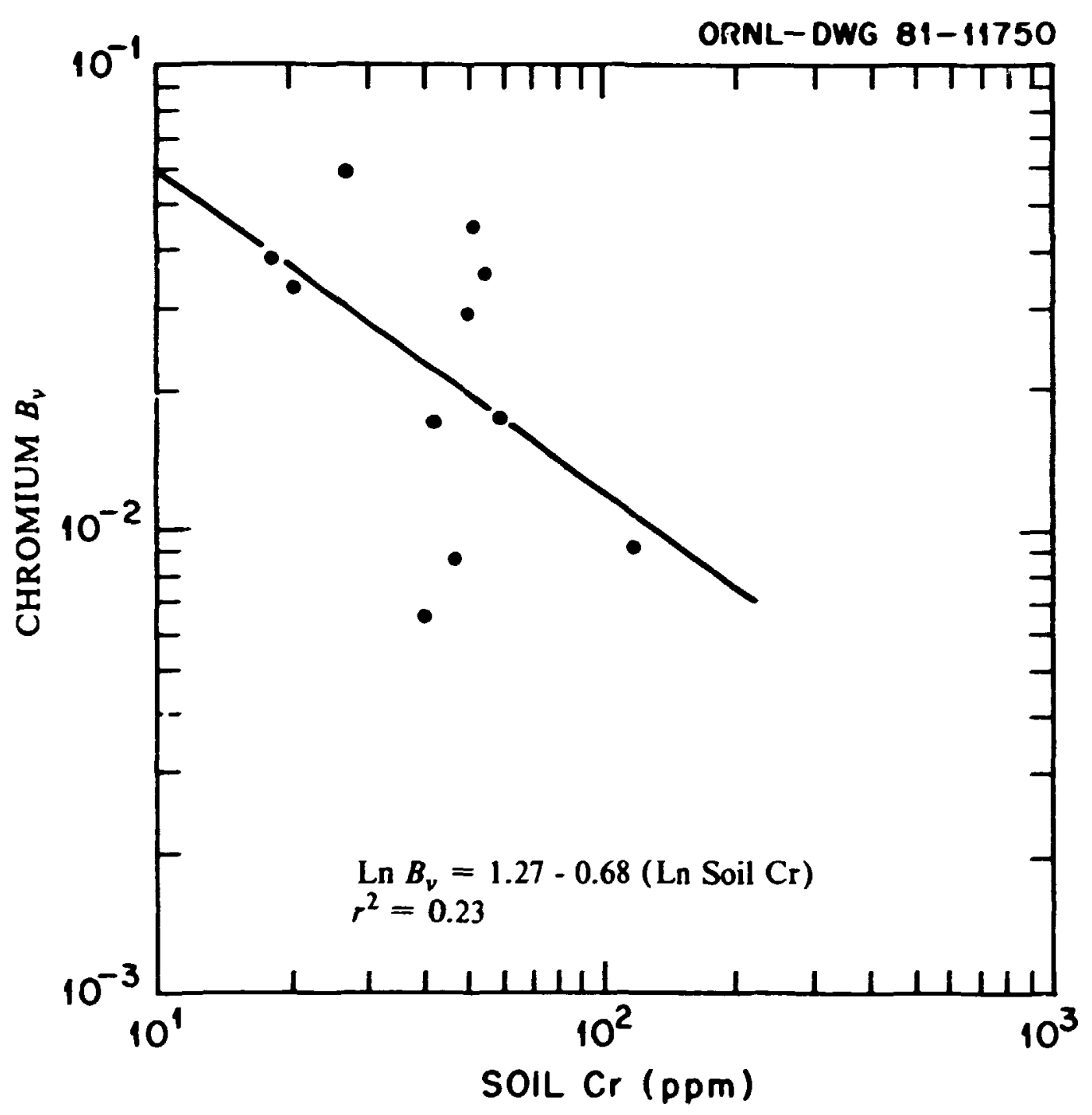

Figure 2.11. Correlation be:ween soil chromium concentration and the soil-to-plant concentration factor, $B_{v}$, for chromium based on references 16 and 65 . 


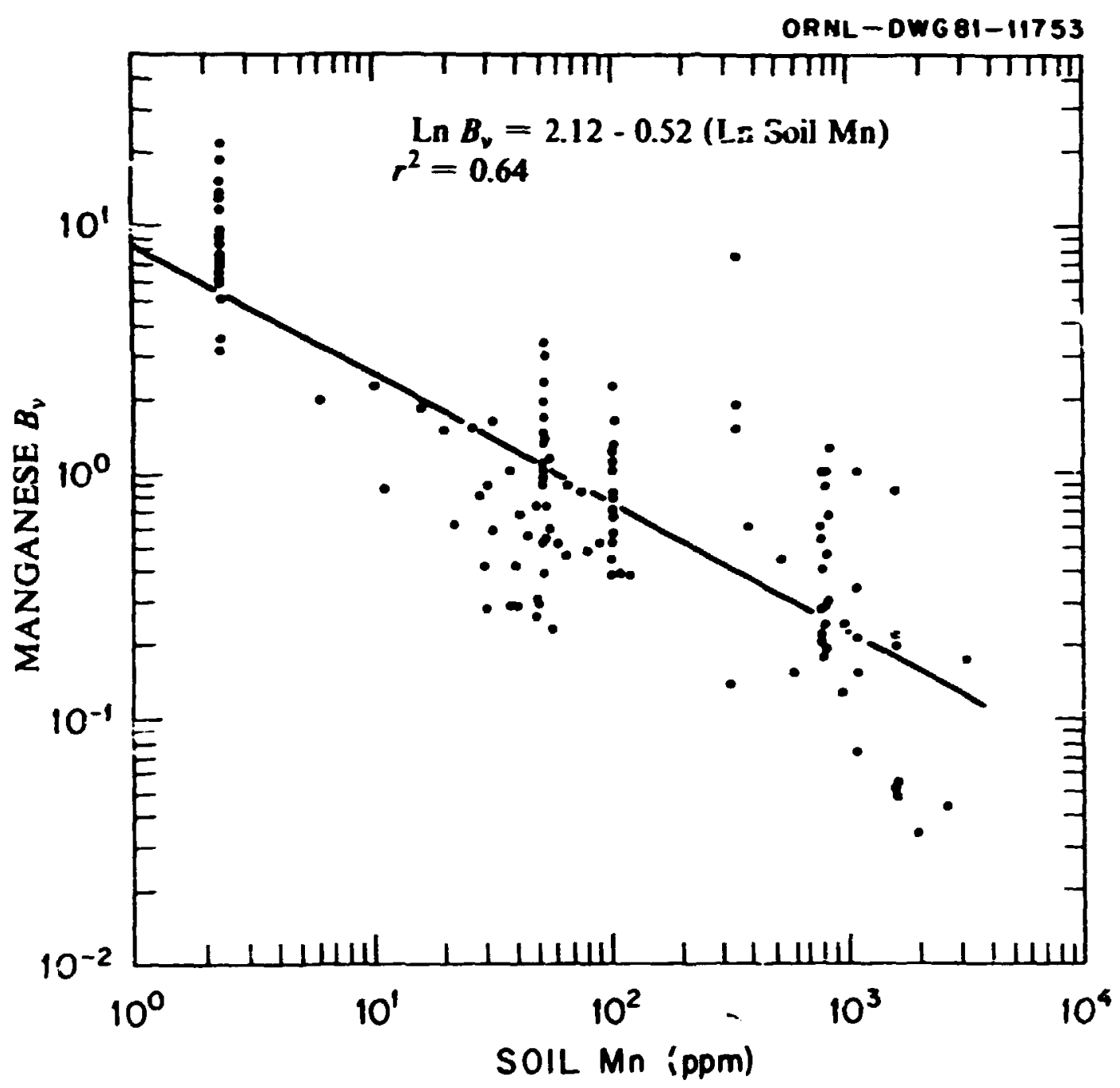

Figure 2.12. Correlation between soil manganese concentration and the soil-to-plant concentration factor, $B_{v}$, for manganese based on references $16,36,37,104,112$, and 113 . 


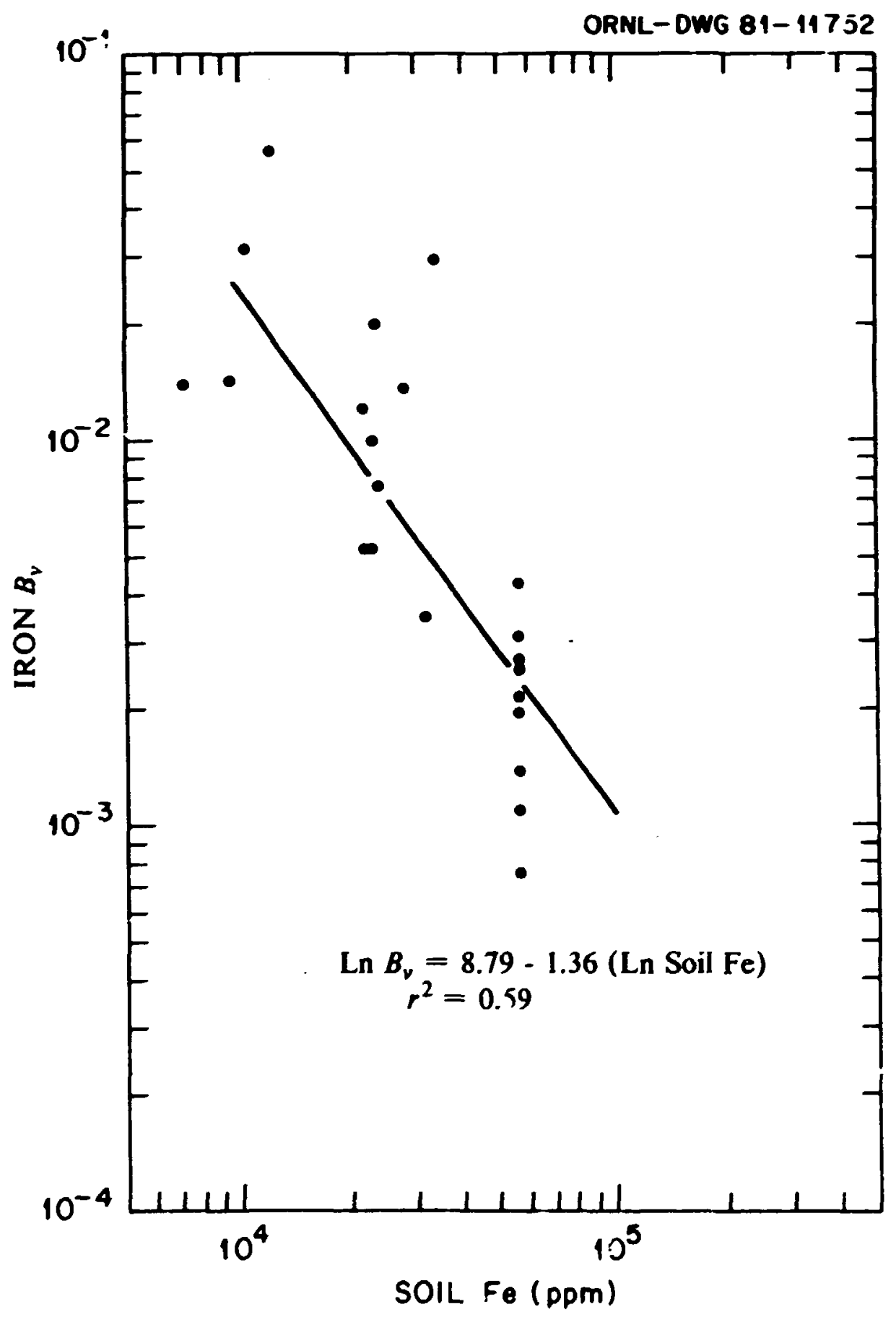

Figure 2.13. Correlation between soil iron concentration and the soil-to-plant concentration factor. $B_{v}$, for iron based on references 16,65 , and 104 . 


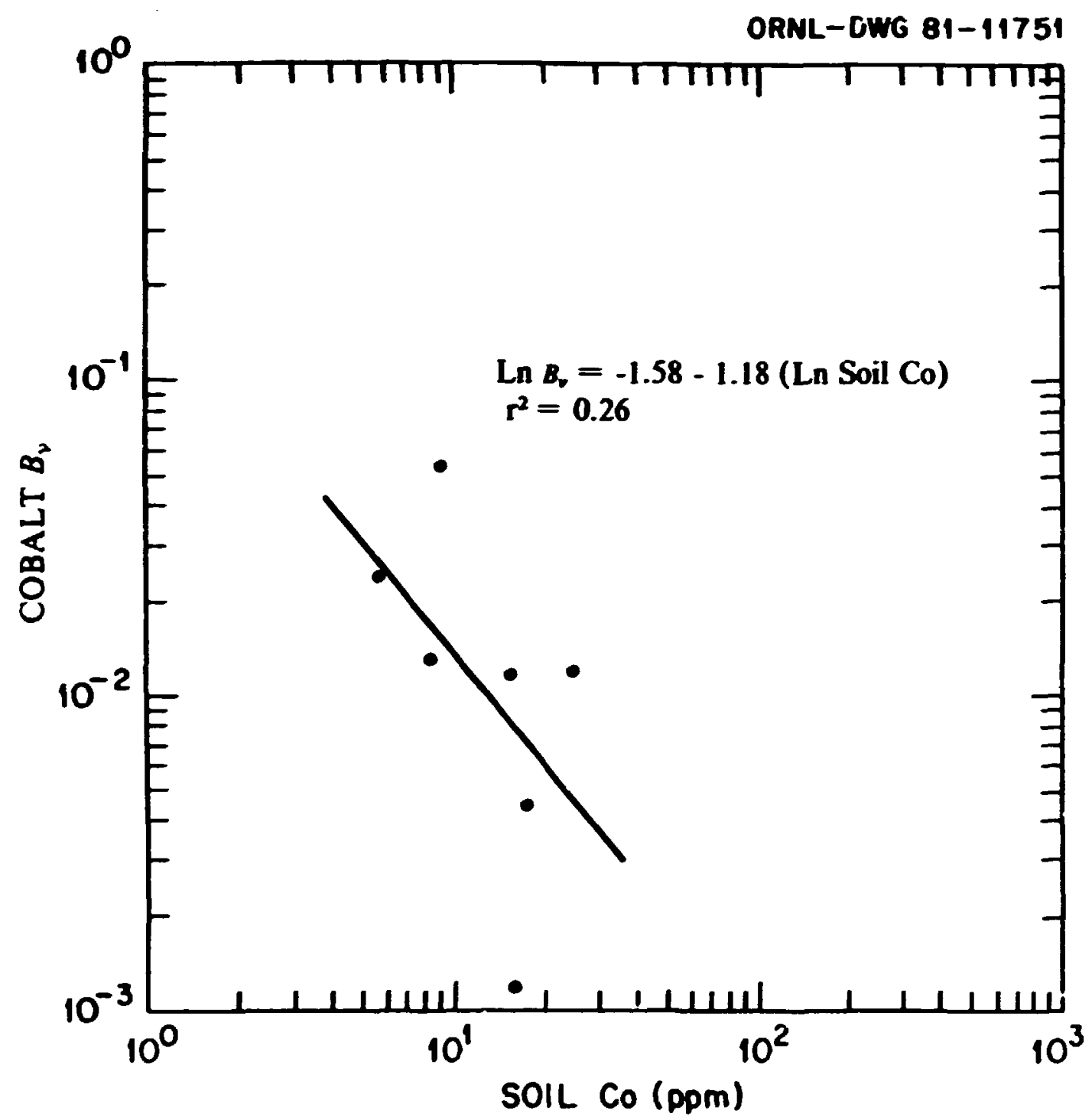

Figure 2.14. Correlation between soil cobalt concentration and the soil-to-plant concrntration factor, $B_{v}$, for cobalt based on references 16 and 65 . 


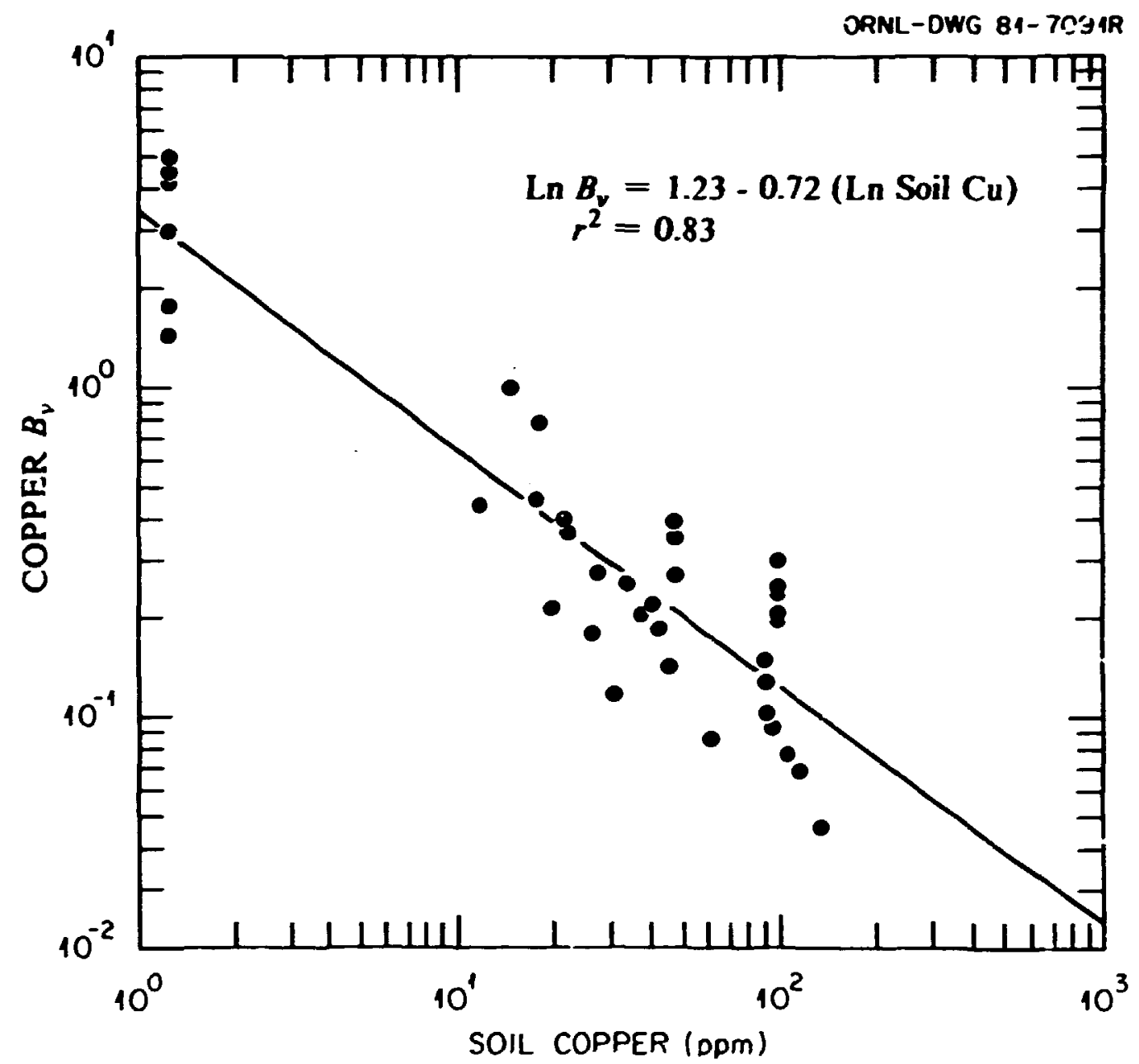

Figure 2.15. Correlation between soil copper concentration and the soil-to-plant concentration factor, $B_{v}$, for copper based on references 16, 104, and 115 . 


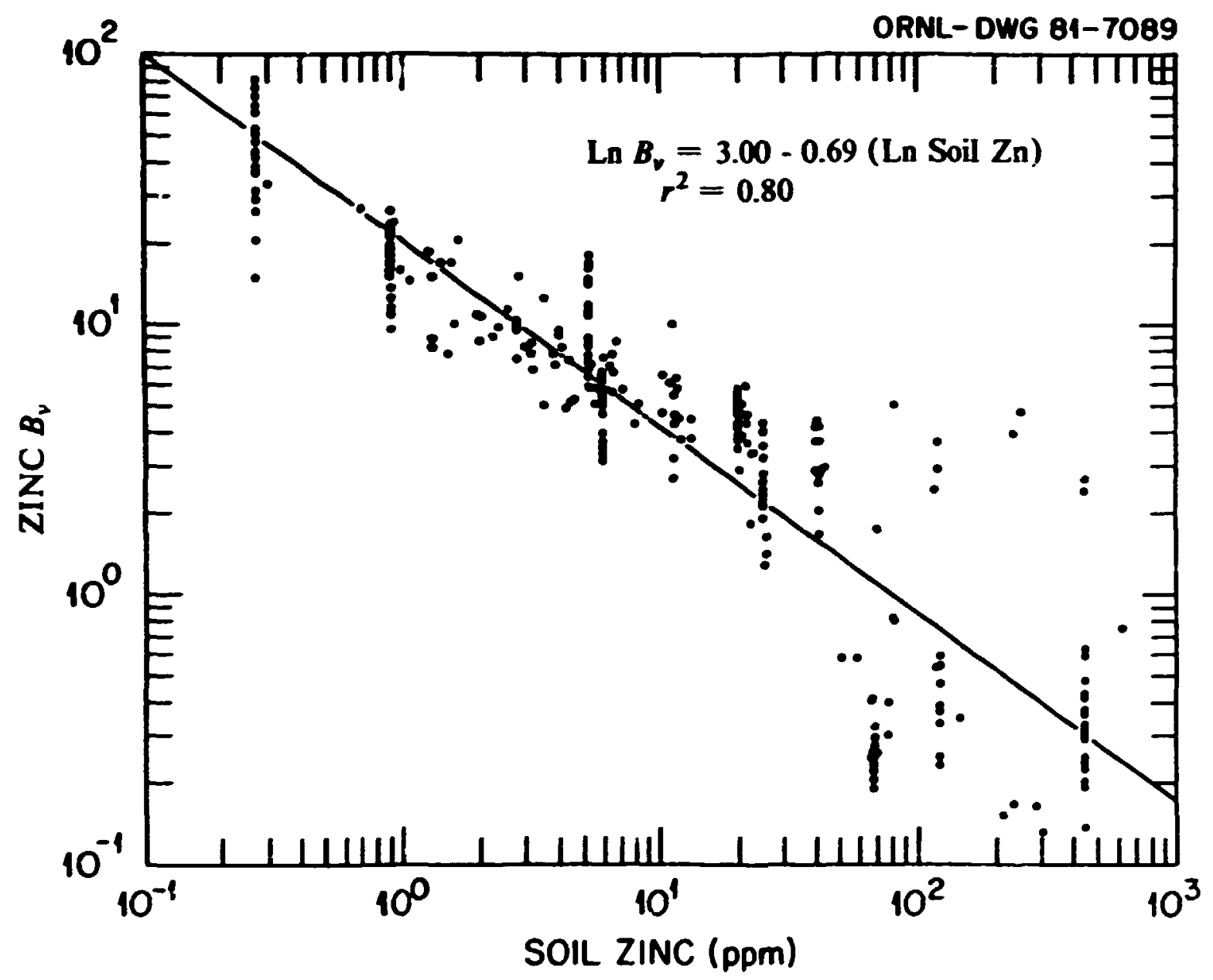

Figure 2.16. Correlation between soil zinc concentration and the soil-to-plant concentration factor, $B_{v}$, for zinc based on references $16,35,37,67,97,104,114,115$, and 119 . 


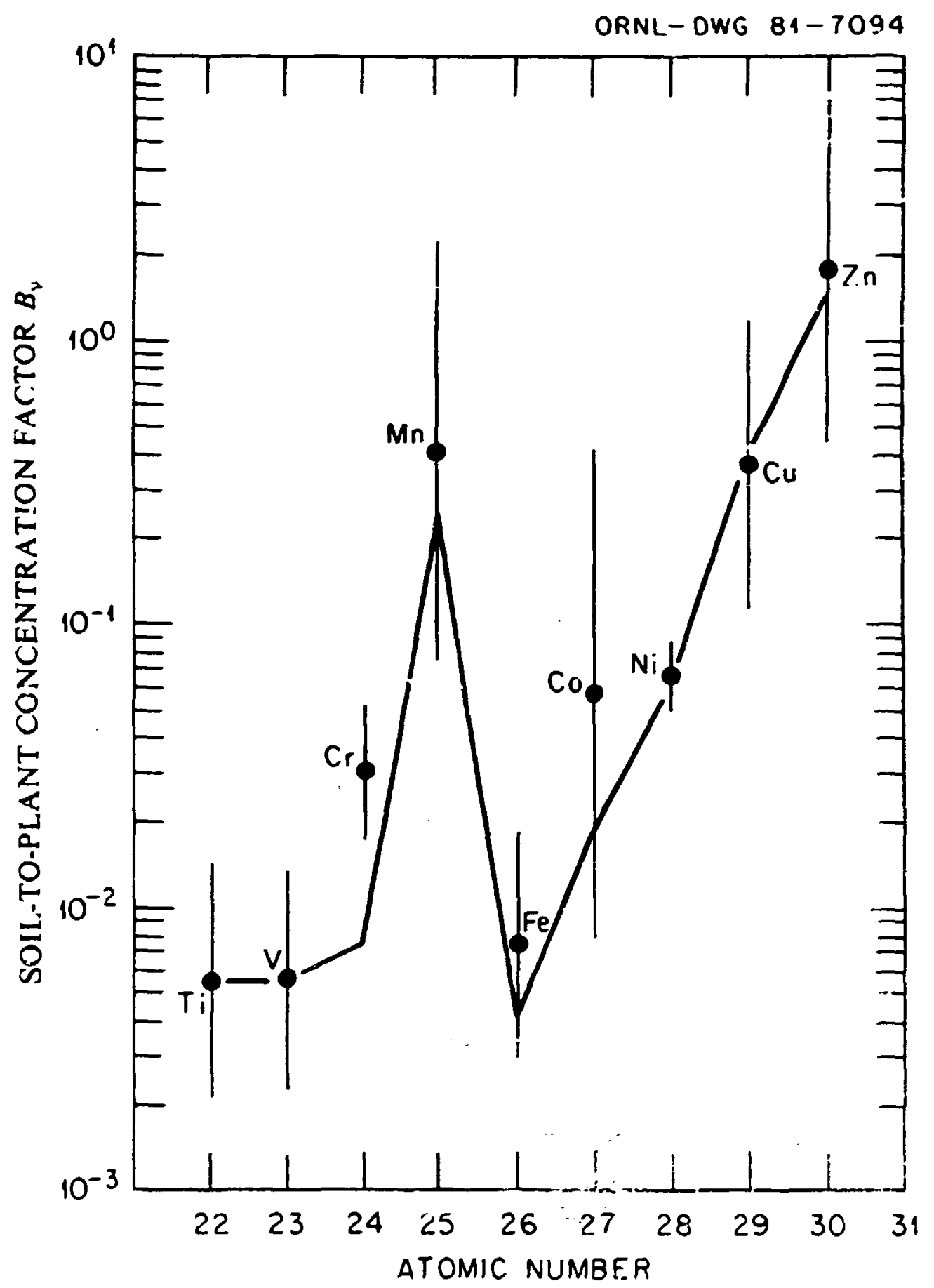

Figure 2.17. Assumed systematic trend in $B_{v}$ for Period IV eleinents based on default $B_{v}$ estimates. Solid dots and error bars represent geometric means and standard deviations determined from available references. 


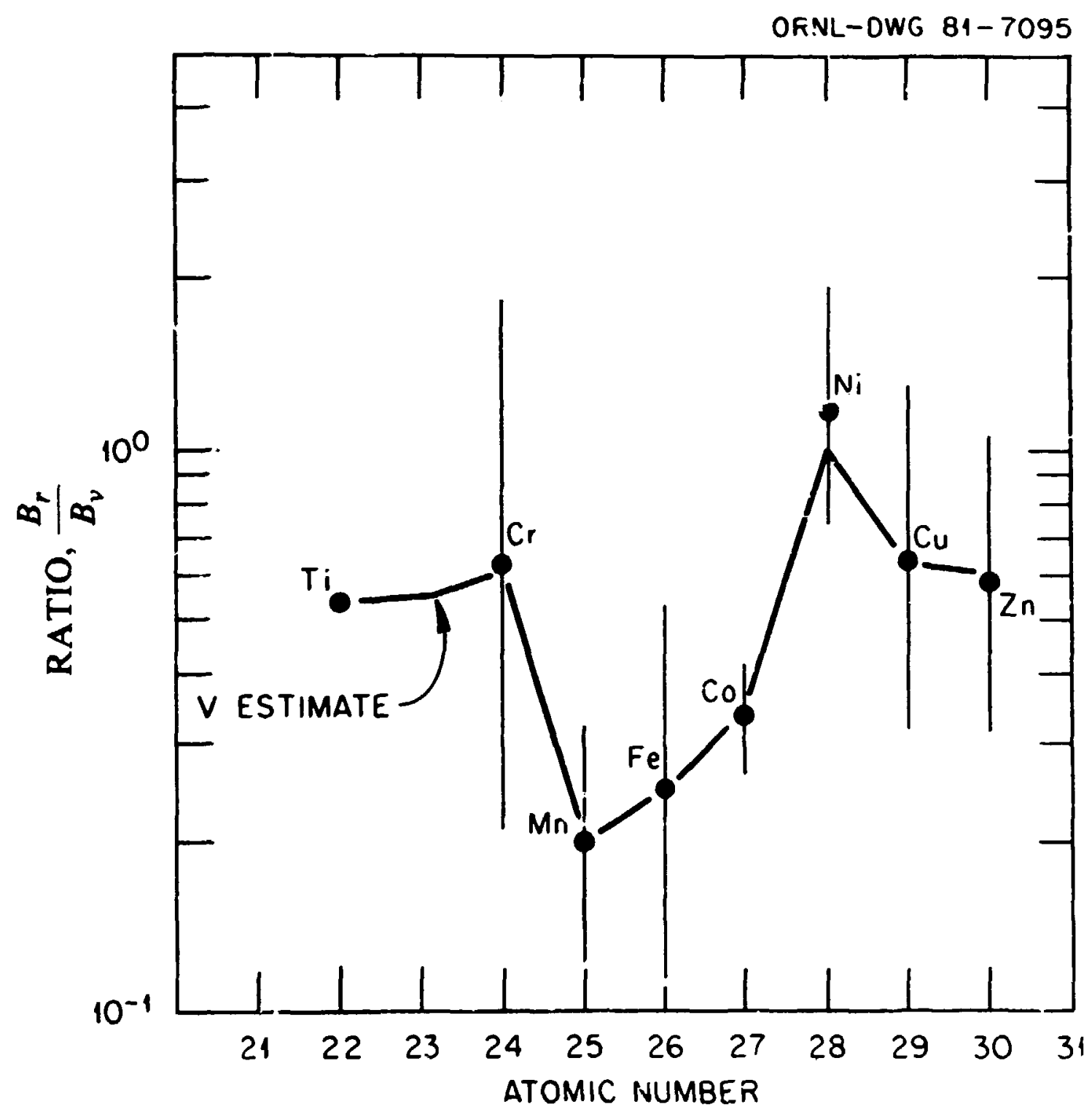

Figure 2.18. Assumed systematic trend in $\left(A, / B_{v}\right)$ ratio for Period IV elements. Solid dots and error bars represent geometric means and standard deviations of the mean determined from available references. 
Because of its importance radiologically and because of the high concentration factors previously reported for technetium, $23,107,122$ it will be given special attention. Hoffman et al. ${ }^{123}$ critiqued past studies of technetium uptake using the pertechnetate anion $\left(\mathrm{TcO}_{4}^{-}\right)$and concluded that the concentration factors of 100-1000 derived from these si:udies were inappropriate because of the high levels of technetium added to the soils and the measurenisent of concentration factors before plant maturity. Evidence further suggests that technetium in soil becomes increasingly sorbed and thus is less available for plant uptake with time. ${ }^{23.128}$ Aging of soils over 100 days decreased observed concentration ratios by factors of 1.5 to 5.1 in one study by Cataldo. ${ }^{107}$ Thus, the application of short-term pot studies to long-term assessments is clearly inappropriate for technetium. Therefore, the concentration factors representing field measurements of long-term technetium uptake in plants reported by Hoffman et al. ${ }^{123}$ were adopted for the TERRA code, and references 23,107 , and 122 were used only for calculation of $B_{r}$ or were excluded from our analyses.

The geometric mean of the $B_{v}$ values reported by Hoffman et al. ${ }^{123}$ is 9.5 . The geometric mean for $B_{r}$ derived from references 23 and 122 is 1.3 . This value was rounded to 1.5 for use as a default value in TERRA. The $\left(B_{r} / B_{v}\right)$ ratio generated by the two default values is 0.16 which compares favorably with the observed $\left(B_{r} / B_{v}\right)$ ratios for molybdenim and ruthenium. It is interesting that a $B_{i v 2}$ generated from $B_{r}$ (see Sect. 2.1) is roughly an order of magnitude less than the value suggested in Moore et al. ${ }^{1}$ which takes into account successive harvesting of food crops. No information is available on average technetium concentrations in typical soils and vegetation. Until such information becomes available the $B_{v}$ and $B_{r}$ for technetium remain suspect.

The $B_{v}$ for molybdenum of 0.25 is based on references 16, 65, 76, and 120. Although Singh and Ki:mar ${ }^{121}$ reported soybean grain and leaf molybdenum concentrations from which a $\left(B_{r} / B_{v}\right)$ ratio of 2.2 was derived, the $\left(B_{r} / B_{v}\right)$ ratio for determination of $B_{r}$ was derived from references 16 , 17, and 19. This $\left(B_{r} / B_{v}\right)$ ratio is 0.25 and yields a $B_{r}$ estimate of 0.06 . These $B_{v}$ and $B_{r}$ estimates predict vegetable and produce concentrations which agree well with observed concentrations (Table 2.10).

The $B_{v}$ estimate of 0.002 for zirconium is based on the datd on pumpkin leaves and vines by Baes \& Katz. ${ }^{16}$ A value of 0.25 was chosen for the default $\left(B_{r} / B_{v}\right)$ ratio for zirconium based on the above analysis for molybdenum. The resultant $B_{r}$ estimate of $5.0 \times 10^{-4}$ yields predicted plant concentrations which are consistent with observed concentrations (Table 2.10). Observed zirconium concentrations in vegetative growth in Table 2.10 are based on a range of values reported for cabbage. Shacklette et al. ${ }^{53}$ report that zirconium is "infrequently detected in food plants." Thus, the "observed" plant concentrations in Table 2.10 for zirconium may not be entirely representative of actual produce concentration. Therefore, agreement of observed and predicted concentrations in Table 2.10 was not considered essential to acceptance or rejection of $B_{v}$ and $B_{r}$ values. Thus, although the predicted $C_{v}$ is below the reported $C_{v}$ for zirconium the default $B_{v}$ for zirconium based on reference 16 is used as default in TERRA.

The $B_{v}$ for ruthenium of 0.075 is based on references $22,59,60$, and 63. The $\left(B_{r} / B_{v}\right)$ ratio fium references 2,60 , and 63 is 0.26 , yielding a $B$, estimate of 0.02 . Unfortunately, no estimate of ruthenium in typical soils was available for comparison of observed and predicted plant concentrations.

The occurrence of cadmium in soils and plants has been well studied. The $B_{v}$ for cadmium was determined from eleven references $(16,17,24,65,97,104,105,114$, and 124-126). The geometric mean of the eleven geometric means is 0.55 . $A\left(B_{r} / B_{v}\right)$ ratio of 0.26 was derived from references $16,19,20,24,97,102,105,114,116,125$, a.d 126, yielding an estimate of $B_{r}=0.15$. Agreement between observed and predicted cadmium concentrations in plants is excellent (Table 2.10).

Default values of $B_{v}$ and $B$, for niobium, rhodium, palladium, and silver were determined primarily through elemental systematic approaches, because no references on direct determination of $B_{v}$ or $B$, for these elements were avaiiable. The assumption that Period $V$ transition elements 


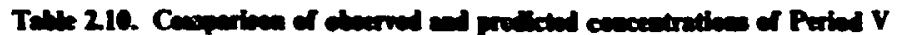

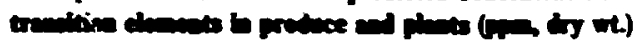

\begin{tabular}{|c|c|c|c|c|c|}
\hline \multirow{2}{*}{ Element } & \multirow{2}{*}{$\begin{array}{l}\text { Average } \\
\text { concentration } \\
\text { in soil }\left(C_{s}\right)\end{array}$} & \multicolumn{2}{|c|}{ Vegentive grouth $\left(C_{v}\right)$} & \multicolumn{2}{|c|}{ Frrits and tubers $\left(C_{r}\right)$} \\
\hline & & Obeerved ranget & Predicted & Obeerved ranget & Predicted \\
\hline $\begin{array}{l}\mathbf{Z r} \\
\mathbf{N b}\end{array}$ & 300 & $\begin{array}{l}531074 \\
0.038\end{array}$ & 0.60 & $\begin{array}{c}5.0 \times 10^{-3} \text { to } 11 \\
0.017\end{array}$ & 0.15 \\
\hline $\begin{array}{l}\text { Mo } \\
\text { Tc } \\
\text { Ru } \\
\text { Rh } \\
\text { Pd }\end{array}$ & 2.0 & 0.35 to 29 & 0.50 & $\begin{array}{c}0.0601013 \\
1.0 \times 10^{-4} 104.0 \times 10^{-}\end{array}$ & 0.12 \\
\hline $\begin{array}{l}\mathrm{Ag} \\
\mathrm{Cd}\end{array}$ & $\begin{array}{l}0.10 \\
0.50\end{array}$ & $\begin{array}{c}0.13 \\
0.131024\end{array}$ & $\begin{array}{l}0.040 \\
0.28\end{array}$ & $\begin{array}{c}0.057 \\
0.013 \text { to } 0.82\end{array}$ & $\begin{array}{l}0.010 \\
0.075\end{array}$ \\
\hline
\end{tabular}

- Reference 52.

-Taken or calculated from values rsported in reference 53, assuming sh widry wt -0.128 and 0.057 for vesetative growth and fruits and tubers, respectively (whea neceseary).

'The product, $B_{\nabla}-C_{s}$.

The product, $B_{r} \cdot C_{s}$.

are natural analogs of Period IV transition elements suggested that the ratio of $n_{\nu}$ estimates for these pericu's might vary systematicaliy from Group INB to Group IIB. Examination of these ratios fo: which $B_{y}$ estimates had been made via other appioaches (Fig. 2.19 i yielded estimates of $B_{v}$ ratio for $\mathrm{Nt} / \mathrm{V}$ by linear extrapolation between the $\mathrm{Zr} / \mathrm{Ti}$ atio zod the $\mathrm{Mo} / \mathrm{Cr}$ ratio. Likewise the $\mathrm{Rh} / \mathrm{Co}, \mathrm{Pu}_{i} \mathrm{Ni}$, and $\mathrm{Ag} / \mathrm{Cu}$ ratios were exirapolated from the $\mathrm{Ru} / \mathrm{Fe}$ and $\mathrm{Cd} / \mathrm{Zi}$ ritixs. These estimated ratios, wien multiplied by default $B_{v}$ estimates for Perixd IV elements (Sect. 2.1.6), yielded $B_{v}$ estimates for the Period $V$ elements nisbium, rhodium, cobalt, palladium, asid silver. Plotting of the resu' ant Period $V$ transition element $B_{v}$ estimates by atomic number (Fig. 2.20) yields results somewhat sirvilar to the same plot for ieriod IV transition elements (Fis. 2.17). Unfortunately, comparison of observed and predicted $C_{v}$ and $C_{r}$ for niobium, rhodium, and palladium is not possible unti; more information is available. Some conparison for silver is possible (Table 2.10), although typical silvar concentrations in plants are only aporoximates. The systematics approach seems to underpredict $B_{v}$ for silver, but by less than an order of magnitude. The default $B$, estimates for niobium, thodium, palladium, and sil/er used in Fig. 2.2 werc derived from an assumed $\left(B_{r} / B_{y}\right)$ value of 0.2 .5 , which is consistent with observations for molybdenum and cadmium.

\subsubsection{Period VI transition elements}

Very few references for plant uptake of the Period VI transition elements were available. Aiso, comparisons between cbserved and predicted produce and plant concentrations were difficult to make because of the uncertainty in typical scil and plat concentrations (Table 2.11). Therefore, $B_{v}$ and $B$, default estimates for Period VI transition elements are mostly based on their Period IV and $Y$ analogs.

Sirgle measurements of assuciated soil and plant concentrations applicable to $B_{y}$ were found in reference 65 for hafnium, tantalum, and tungsten. Three additional measurements were found in reference 101 for tungsten. The geometric means approach for tungsten indicates a $B_{y}$ which is 


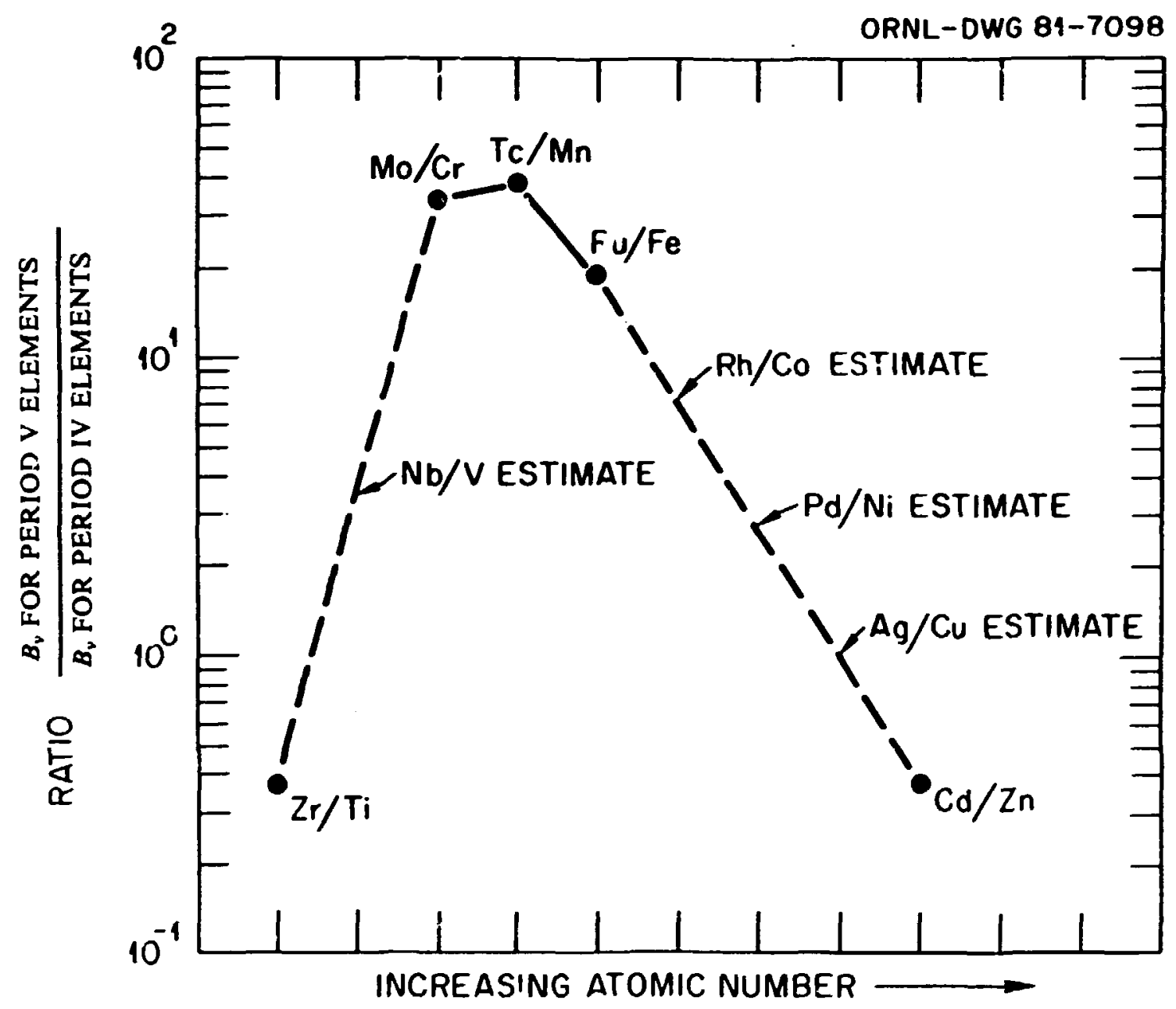

Figure 2.19. Assumed systematic trends in the ratio of $B_{v}$ for Period $V$ and $I V$ elements $(\mathrm{Nb} / \mathrm{V}$, $\mathrm{Rh} / \mathrm{Co}, \mathrm{Pd} / \mathrm{Ni}$, and $\mathrm{Ag} / \mathrm{Cu}$ ) based on the ratios of default $B_{v}$ estimates for other elements in the periods. 


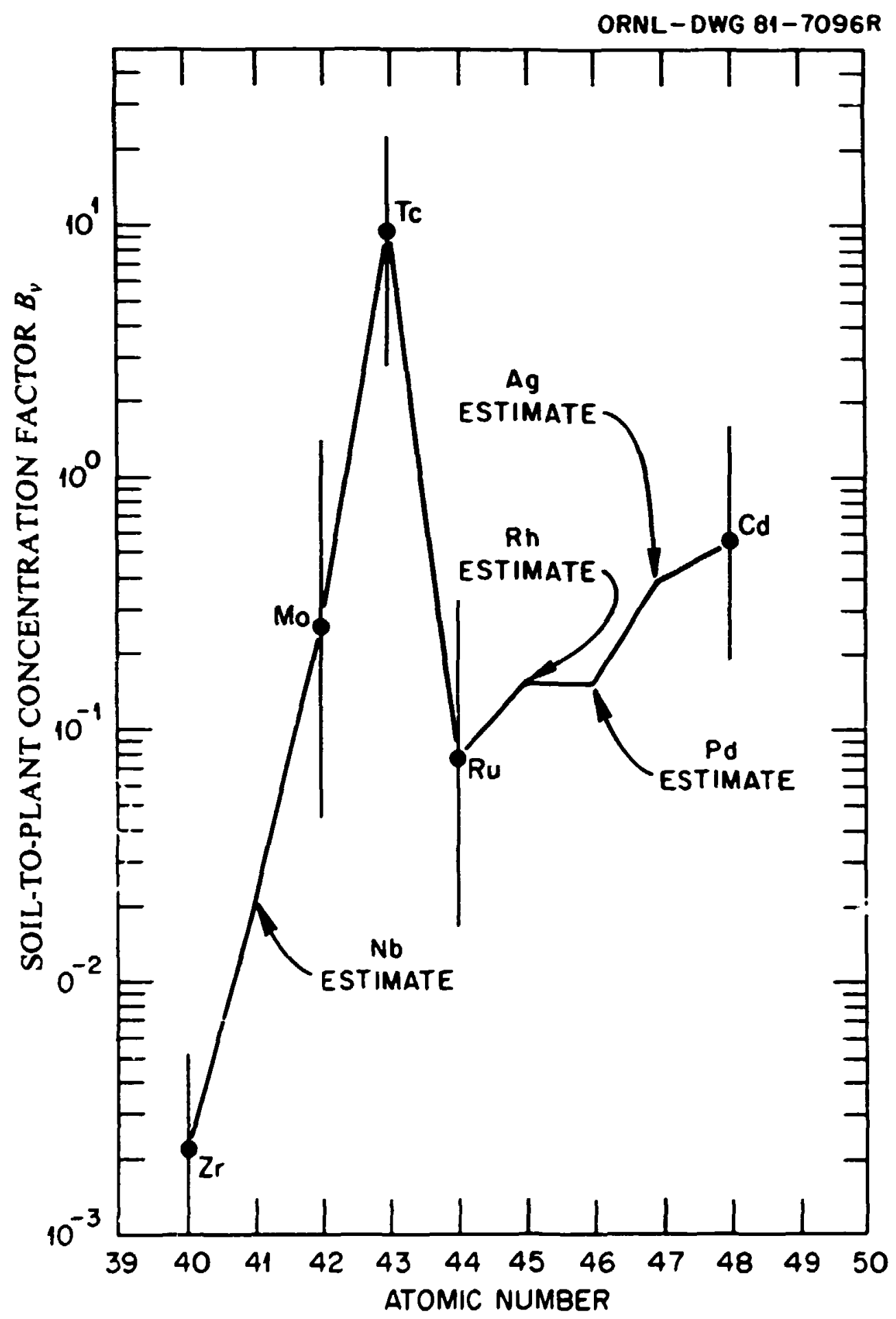

Figure 2.20. Assumed systematic trend in $B_{v}$ for Period $V$ transition elements based on default $B_{v}$ estimates. Solid dots and error bars represent geometric means and standard deviations determined from available references. 
Talle 211. Compriven of chesved and preticted concentrations of Period V

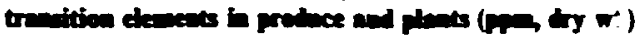

\begin{tabular}{|c|c|c|c|c|c|}
\hline \multirow{2}{*}{ Element } & \multirow{2}{*}{$\begin{array}{c}\text { Average } \\
\text { concentration } \\
\text { in soil }\left(C_{,}\right)^{C}\end{array}$} & \multicolumn{2}{|c|}{ Vegetative growth $\left(C_{C}\right)$} & \multicolumn{2}{|c|}{ Fruits and tubers $\left(C_{r}\right)$} \\
\hline & & Observed ranget & Predicted & Observal range & Predicted \\
\hline $\begin{array}{l}\mathbf{H f} \\
\mathrm{T}_{\mathbf{z}}\end{array}$ & 6.0 & $<6.3 \times 10^{-36}$ & 0.021 & $2.3 \times 10^{-3}$ to $2.6^{6}$ & $5.1 \times 10^{-3}$ \\
\hline $\mathbf{w}$ & & 0.064 & & 0.029 & \\
\hline $\mathbf{R e}$ & & $6.4 \times 10^{-4}$ & & $2.9 \times 10^{-4}$ & \\
\hline $\begin{array}{l}\text { Os } \\
\text { Ir }\end{array}$ & & & & & \\
\hline $\mathbf{P t}$ & & & & & \\
\hline $\mathbf{A u}$ & & $<1.1 \times 10^{-4}$ to $5.3 \times 10^{-3}$ & & $1.0 \times 10^{-5}$ to $1.1 \times 10^{-36}$ & \\
\hline $\mathbf{H}_{\mathbf{g}}$ & 0.010 & $<0.01$ to 0.020 & $9.0 \times 10^{-3}$ & $<0.010$ to 0.020 & $2.0 \times 10^{-3}$ \\
\hline
\end{tabular}

- Reference 52.

Taken or calculated from values reported in reference 53, assuming ash wt/dry wt $=0.128$ and 0.057 for vegetative growth and fruits and tubers, respectively (when necessary).

The product, $B_{r} \cdot C_{s}$.

The product, $B_{r} \cdot C_{3}$.

'Reference 54.

much greater than that for chromium and more nearly equal to that for molybdenum, although in reference 65 the derived molybdenum $B_{v}$ exceeds the derived tungsten $B_{v}$ by a factor of approximately three. Comparison of $B_{\mathfrak{b}}$ values derived from reference 65 for hafnium and tantalum with their respective Puriod IV and $V$ analogs indicates that if the single derived values are appropriate, the Period VI transition element concentration factors exceed those for their Period IV analogs, but are less than their Period $V$ analogs.

While the above observations lend insight into the concentration factors for some Period VI transition elements, concentration factors for the rest must rely on supposition until further experimental evidence is available. Figure 2.21 represents the methodology used in determination of default $B_{v}$ estimates for Period VI transition elements. To derive these, $B_{v}$ default estimates for Period IV transition elements (Sect. 2.1.6) and Period $V$ transition elements (Sect. 2.1.7) were plotted by increasing atomic numbur. The default $B_{v}$ estimate for the Period VI elements were simply the log-averages of the two other elements within each group rounded to the nearest 0.5 decimal place. This method insures that trends observed in Periods IV and $V$ are ge.nerally repeated in Period VI (increasing $B_{v}$ for the first four members of the period, decrease in the fifth, etc.). While such repetition of trends may be acceptable if general chemical properties are assumed to be an important basis for $B_{v}$ behavior, our method has serious limitations. Our procedure implies that, except for Groups IVB and IIB, Period VI element $B_{v}$ values exceed those for Period IV and are exceeded by those for Period V. Such an implication is unfounded and may be a serious limitation to our approach. However, determination of the most appropriate default estimates of $B_{v}$ for Period VI transition elements will require direct experimental measurement of then.

There were no available references for the $\left(B_{r} / B_{v}\right)$ ratio or for $B_{r}$ for the Period VI elements. Therefore, a value of 0.25 for the $\left(B_{r} / B_{v}\right)$ ratio was assumed, based on analysis of Period $V$ transition elements. This value was used with the default $B_{v}$ estimates to generate default $B$, estimates. 
SOIL-TO-PLANT CONCENTRATION FACTOR $B_{v}$

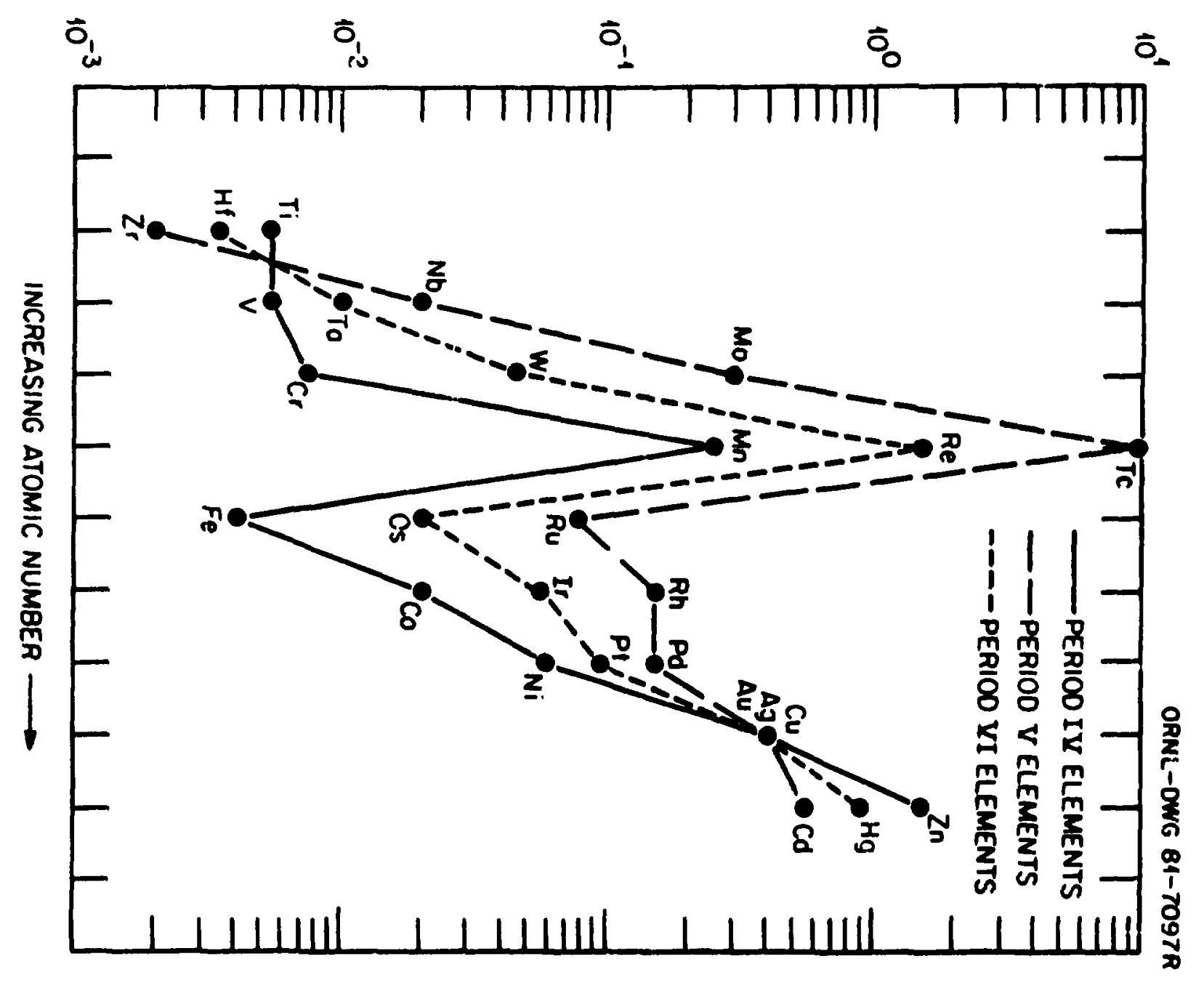


Comparisons of observed and predicted plant concentrations were possible only for hafnium and mercury. For these elements predicted values were always within an order of magnitude of the observed ranges. However. observed ranges were usually bounded on the low sides by detection limits of the analysis procedures. ${ }^{\text {st }}$

\subsubsection{The activide elenewents}

The actinide elements have been extensively studied with respect to plant uptake from soil. The greatest number of references were found for piutonium $8-10,30.59 .101 .129-138$ and americium, ${ }^{10.30 .129 .131 .133 .136,137.139-142}$ with fewer references for uranium, ${ }^{29.6590 .91 .143}$ thorium, ${ }^{65.90 .91}$ neptunium, at:d curium. ${ }^{10.30 .13 i}$ No literature references were found for actinium, protactinium, or any elements of atomic number greater than 96.

The $B_{v}$ for plutonium appears to be lognormally distributed and reported values range from $10^{-6}$ to $10^{-2}$ (Fig. 2.22). The fourteen references used to determine $B_{v}$ for plutonium yielded a geometric mean of $4.5 \times 10^{-4}$. The $\left(B_{r} / B_{v}\right)$ ratio of 0.1 was calculated from references $8,10,30$, $129,130,134$, and 136 . This value produces a $B_{r}=4.5 \times 10^{-5}$ which agrees well with the geometric mean of $B_{r}$ derived from references $8,10,30,129,133,134,136$, and 138 . No measurements of typical or average concentrations of plutonium in soils or vegetabie produce were available for comparison between predicted and observed concentrations. Comparisons of predicted and observed actinide concentrations were only possible for thorium and uranium (Table 2.12).

The $B_{\mathrm{r}}$ for americium of 0.0055 was derived from references $10,30,129,131,136,137$, and 139-142. A $B_{r}$ of $2.5 \times 10^{-4}$ was derived from references $10,30,129$, and 136 by selecting a value midway between the range defined by the geometric mean of $B_{r}$ and the product of the default $B_{v}$ estimate and the gewmetric mear: for $\left(B_{r} / B_{v}\right)$ ratio.

The $B_{v}$ for uranium of 0.0085 was determined from references 29,65 , and 91 . The $\left(B_{r i} B_{v}\right)$ ratios derived from data reported by Prister ${ }^{29}$ and Fidorov and Romanov ${ }^{143}$ both equaled a value of 0.5 , and this value was used to determine a default $B_{r}$ estimate of 0.004 . Comparison of predicted and observed vegetable concentrations supports the default concentration factors, although typical uranium concentrations in vegetative portions of produce are unavailable.

The $B_{v}$ for thorium of $8.5 \times 10^{-4}$ was determined from references 65 and 91 . No references were available for a thorium $\left(B_{r} / B_{v}\right)$ ratio, and thus the value of 0.1 used for radium was assumed, yielding a default $B$, estimate of $8.5 \times 10^{-5}$. Coraparisons of observed and predicted regetation concentrations are hampered by the incertainty in thorium concentrations in vegetation. In the food surveys carried out by Oakes et al. ${ }^{54}$ and Monford et al. ${ }^{144}$ most thorium concentrations in food items were at or below detection limits. However, it may be concluded that the default $B_{v}$ and $B_{r}$ estimates assumed here do not overpredict observed foni concentrations.

The default $B_{v}$ estimates for actinium and protactinium were determined from those of radium and thorium and thorium and uranium, respectively, by assuming systematic variation in $B_{v}$ with atomic number in a manner similar to that used for radium and francium (see Sect. 2.1.2). Such a procedure implies that thorium has the lowest $B_{v}$ of the actinides of at mic number 89 through 92. This implication has yet to be tested, but examination of our default estimates of the ingestion-tocow's milk $\left(F_{m}\right)$ transfer coefficient shows that it is less than or equal to those for actinium, protactinium, and uranium (see Sect. 2.2 for the milk iransfer coefficient). The $B_{r}$ for actinium and protactinium was determined by assumption of $a\left(B_{r} / B_{v}\right)$ ratio of 0.1 as for radium and thorium.

The $B_{v}$ for nep:unium of 0.1 is based on references 10, 30, and 131. The $B_{r}$ default estimate of 0.01 is hased on the geometric means of $B$, values from references 10 and 30 . This value suggests that a $\left(B_{r} / B_{v}\right)$ ratio of 0.1 is appropriate for neptinium also.

The $B_{v}$ for curium of $8.5 \times 10^{-4}$ is based on references 10,30 , and 141. The $B$, estimate of $1.5 \times 10^{-3}$ is based on the geometric means of $B$, from references 10 and 30 , suggesting an appropriate $\left(B_{r} / B_{v}\right)$ ratio of less than 0.1 . In the TERRA code $B_{v}$ and $B_{r}$ estimates for elements of atomic number greate. than 96 are set equal to those for curium (element 96 ). 


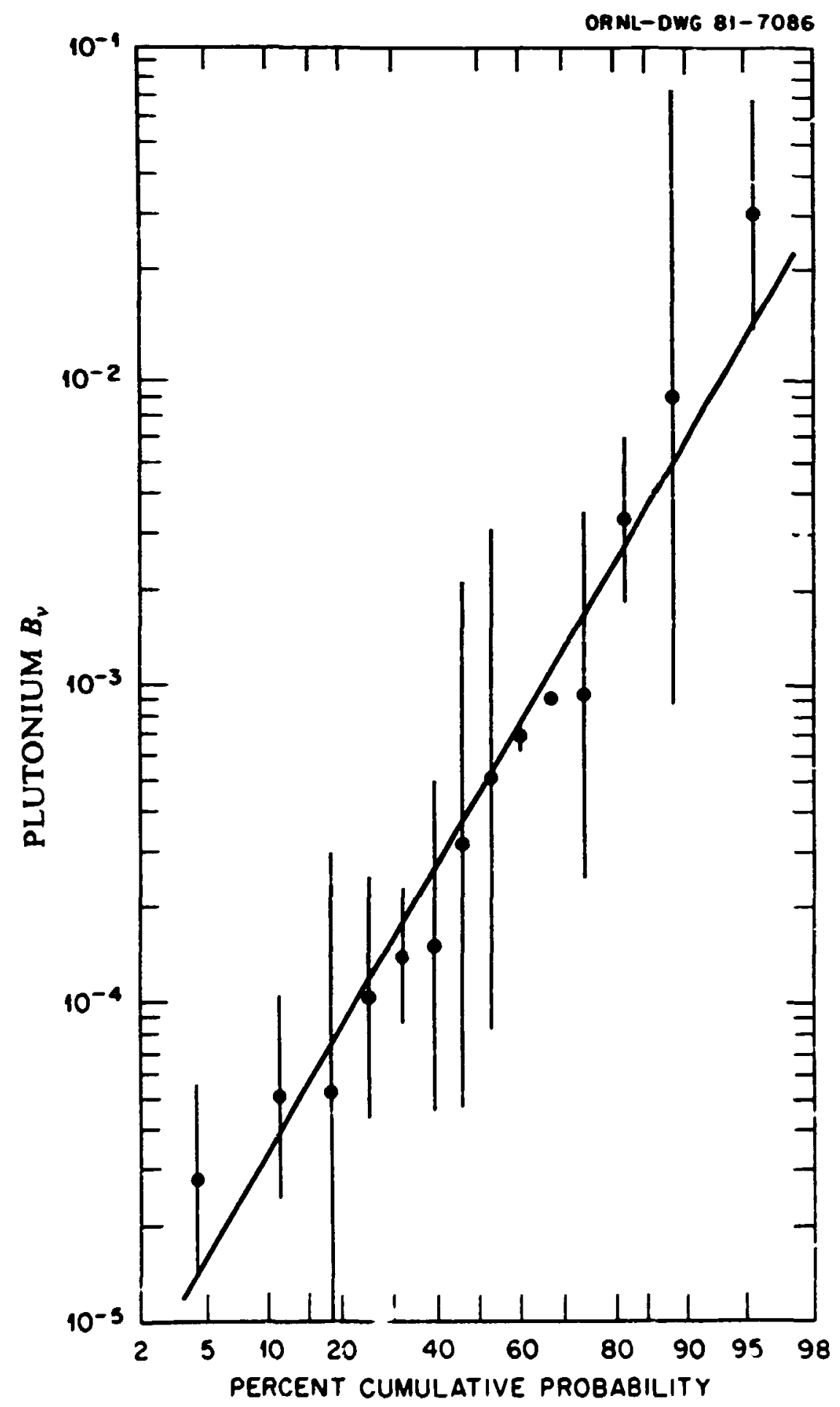

Figure 2.22. Lognormal probability plot of geometric means of $B_{v}$ for plutonium (calculated from references $8-10,30,59,101,129,131,132$, and 134-138), including one geometric standard deviation of the mean. 


\begin{tabular}{|c|c|c|c|c|c|}
\hline \multirow{2}{*}{ Element } & \multirow{2}{*}{$\begin{array}{l}\text { Average } \\
\text { concentration } \\
\text { in soil }\left(C_{z}\right)\end{array}$} & \multicolumn{2}{|c|}{ Vegetative growth $\left(C_{v}\right)$} & \multicolumn{2}{|c|}{ Fruits and tubers $\left(C_{r}\right)$} \\
\hline & & Obeerved ranges & Prodicted & Observed ranget & Predicted \\
\hline \multicolumn{6}{|c|}{ Actinide elements } \\
\hline \multicolumn{6}{|l|}{ Ac } \\
\hline $\begin{array}{l}\text { Th } \\
\mathrm{Pa}_{\mathbf{a}}\end{array}$ & 6.0 & $<0.032$ & $5.1 \times 10^{-3}$ & $<2.5 \times 10^{-3}$ to 0.12 & $5.1 \times 10^{-6}$ \\
\hline$\underset{\mathbf{N p}}{U}$ & 1.0 & & $8.5 \times 10^{-3}$ & $3.8 \times 10^{-}+$to 0.020 & $4.0 \times 10^{-3}$ \\
\hline Pu & & & & & \\
\hline Am & & & & & \\
\hline $\mathrm{Cm}$ & & & & & \\
\hline
\end{tabular}

- Reference 52.

Taken or calculated from values reported in reference 144.

The product, $B_{v} \cdot C_{s}$.

The product, $B_{r} \cdot C_{s}$.

\subsubsection{Comparison of default estimates with previomsly pablished values}

Comparisons of our default estimates of $B_{v}$ and $B_{r}$ with previously used or reported values is difficult because the parameter definitions used here differ somewhat from past soil-plant uptake parameter definitions. However, general comparisons may be made. The most useful crmparison is with the soil-to-plant uptake parameter $B_{i v}$ in Table E-I of the NRC Reg. Guide 1.109.6 Most of these values of $B_{i v}$ were, in turn, taken from reference is by dividing the "concentration in terrestrial plants" (Table 10A) by the "elemental composition of typical agricultural soil" (Table 4). In reference 15 the plant concentrations were converted to a wet or fresh weight basis by assuming $25 \%$ dry matter in plants. Thus, the $B_{i v}$ values generated from Tables $10 \mathrm{~A}$ and 4 may be converted to a dry weight basis by multiplying by a factor of four. The resultant dry weight $B_{i v}$ values may be directly compared with our $B_{v}$ estimates (Fig. 2.23).

In comparing plant uptake parameters it should be remembered that the criteria for $B_{y}$ and $B_{i v}$ definition are comparable, but not equivalent. Also, as evidenced by figures $2.3,2.7$, and 2.22, each default estimate is representative of a distribution of values. Thus, a factor of 2 or 3 difference between $B_{v}$ and $B_{i v}$ should not be considered significant. Therefore, in Fig. 2.23 we have highlighted those elements for which an order of magnitude difference or greater occurs between our numbers and those in reference 15 . These elements include fluorine, silicon, calcium, titanium, selenium, strontium, thodium, palladium, indium, tellurium, osmium, iridium. platinum, gold, thallium, bismuth, polonium, radium, thorium, neptunium, and curium. Our approaches to determination of $B_{v}$ estimates have led to lower estimates than those derived from reference 15 for more than half of these elements. For elements calcium, strontium, and neptunium, numerous experimental resuits indicate higher default values than those derived from reference 15 .

\subsection{Ingestion-to-Mill Parameter, F.}

The ingestion-to-milk transfer coefficients for milk cows used in TERRA are representative of the fraction of the daily elemental intake in feed which in transferred to a kilogram of milk. The 


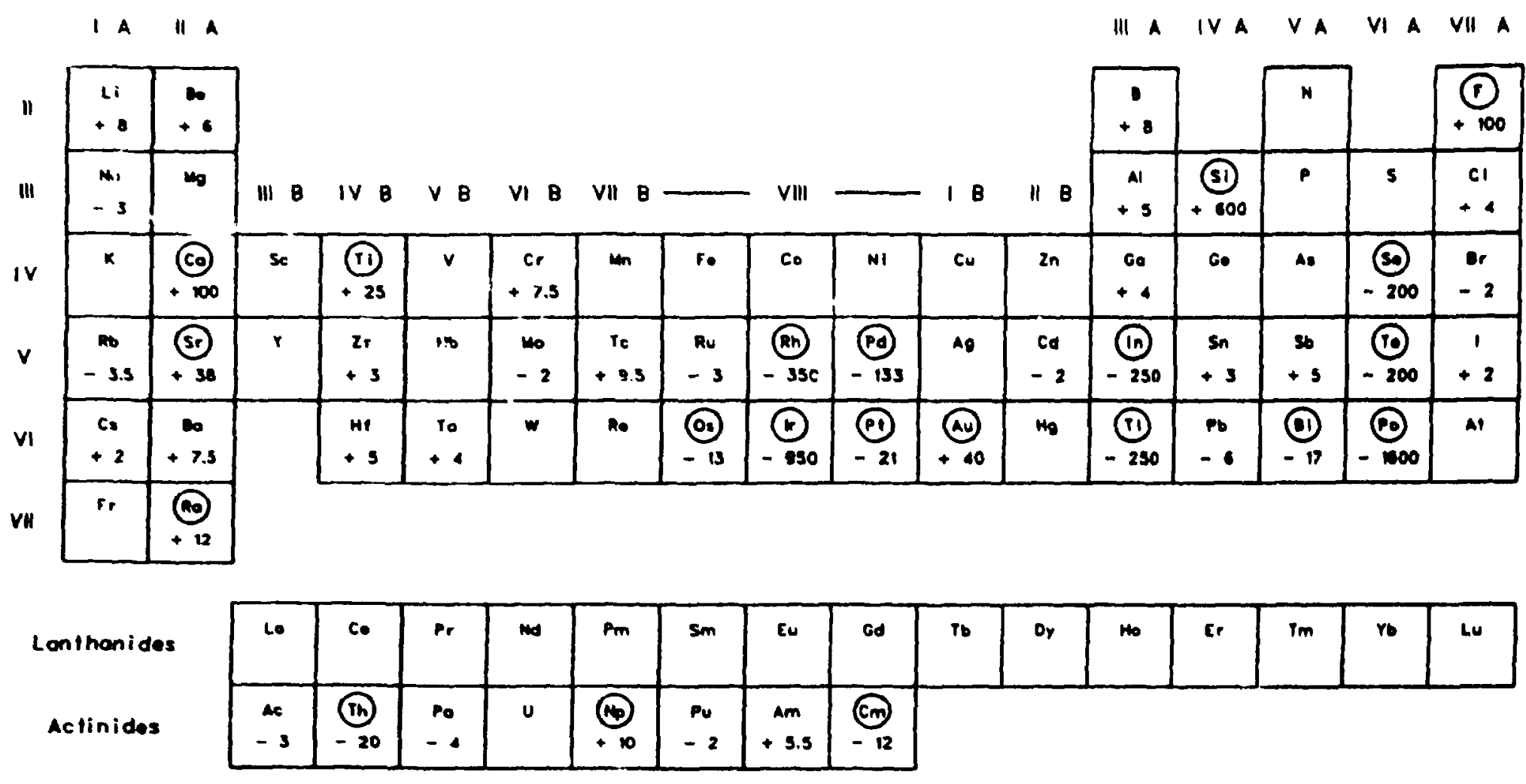

Figure 2.23. Comparison of soil-to-plant concentration factor default values reported in this report and derived from reference 15 . The "+" and "-" signs indicate whether our estimates are greater or less than, respectively, those derived from reference 15. The values indicated are the difference factor, and circled elements indicate a difference factor of at least an order of magnitude. 
elemental values for this parameter (Fig. 2.24) were taken from the extensive review in 1977 by $\mathrm{Ng}$ et al., ${ }^{145}$ except for the elements chromium, manganese, iron, nickel, zirconium, antimony, mercury, polonium, and americium which were taken from a later (1979) reference. ${ }^{.0}$ The protocol for rounding adopted for $B_{v}$ and $B_{r}$ was used also for $F_{m}$. The error introduced in defining the parameter in days/kilogram (here) rather than days/liter (as by $\mathrm{Ng}_{\mathrm{g}}$ and his associates) is much less than that introduced by the rounding protocol, because the density of milk ranges from 1.028 to $1.035 \mathrm{~kg} / \mathrm{L} .{ }^{146}$

\subsection{Inestion-to-Beef Parameter, Ff}

The ingestion-to-beef parameters in TERRA are representative of the fraction of the daily elemental intake in foed which is transferred to and remains in a kilogram of beef until slaughter. The elemental values for this parameter (Fig. 2.25) were either taken from several reviews published by $\mathrm{Ng}$ and his coworkers 15.39 .40 or d termined from elemental systematic assumptions. Estimates of $F_{f}$ for 32 elements were available from the more recent reviews (references 39 and 40). Values for sodium, phosphorus, potasium, ialcium, manganese, iron, zinc, strontium, niobium, antimony, and cerium were taken from reference 40 , and values for chromium, cobalt. nickel, copper, rubiöium, yttrium, zirconium, molybdenum, technetium, ruthenium, rhadium, silver, tellurium, iodine, cesium, barium, lanthanum, praseodymium, neodymium, tungsten, and americium were taken from reference 39. The $F_{f}$ estimates for the rernaining elements were derived from reference 15, except for those which exceeded a theoretical maximum value of $1.0 \mathrm{day} / \mathrm{kg}$.

A theoretical maximum $F_{f}$ value may be calculated by assuming a 1 unit/kg (wet) concentration of an element in feed. If an extremely conservative $100 \%$ efficiency in transfer from feed to muscle is assumed, and beef cattle consume $50 \mathrm{~kg}$ (wet) feed per day, ${ }^{15}$ and the average muscle mass per head of bee? cattle is $200 \mathrm{~kg}^{13}$ then the average daily increase in elemental concentration in beef muscle is given by

$$
\frac{(1 \text { unit } / \mathrm{k}}{2 l} \cdot \frac{(50 \mathrm{~kg} / \mathrm{head} / \mathrm{day})}{\mathrm{kg} \text { beef } / \mathrm{head}}=0.25 \text { unit } / \mathrm{kg} \text { beef } / \text { day } .
$$

Further, if a second extremely conse:vative assumption that there is no biological turnover of the eiement from the muscle is made, then assuming that the average beef cow is fed for 200 days before slaughter ${ }^{13}$ gives a value of 50 units $/ \mathrm{kg}$ beef at slaughter. Relating this value to the daily consumption of feed yields a conservative maximum $F_{f}$ of $(50$ units $/ \mathrm{kg}) /(50$ units/day $)$ or 1.0 days $/ \mathrm{kg}$. Clearly, default estimates near or exceeding this value are highly suspect.

Review of the $F_{f}$ values derived from reference 15 indicates that estimates for gallium, germanium, tantalum, polonium, astatine, francium, actinium, thorium, protactinium, neptunium, plutonium, and curium all exceed the above-calculated theoretical maximum. Because of the radiological importance of elements of atomic number greater than 82, a systematic approach based on elemental variation of $B_{v}$ and $F_{m}$ was used to determine default $F_{f}$ estimates (Fig. 2.26). A similar approach using systematic trends observed in $F_{m}$ for Period IV elements was used to determine $F_{f}$ estimates for gallium and germanium.

The approach used for elements of atomic number greater than 82 was to observe ratios of default $B_{v}$ (Fig. 2.1) and $F_{m}$ (Fig. 2.24) values for successive elements (Fig. 2.26). The ratios determined for hoth parameters were log-transformed and averaged. The exponentials of these

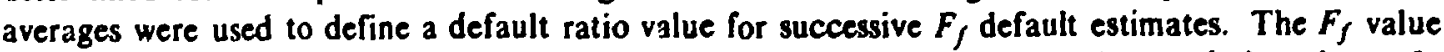
for americium was then used to determine the default $F_{f}$ estimates for curium and plutonium. In turn, each default $F_{f}$ estimate was calculated by multiplication with the proper ratio, i.e., $\mathrm{Pu} F_{f}=$ $(\mathrm{Pu} / \mathrm{Am})$ ratio $\times\left(\mathrm{Am} F_{f}\right), \mathrm{Np} F_{f}=(\mathrm{Np} / \mathrm{Pu})$ ratio $\times\left(\mathrm{Pu} F_{f}\right)$, and so on. Implicit in such an argument is the assumption that the availability of an element for plant uptake and transportability to milk is indicative of its availability or transportability to beef. Some support for this agrument is 


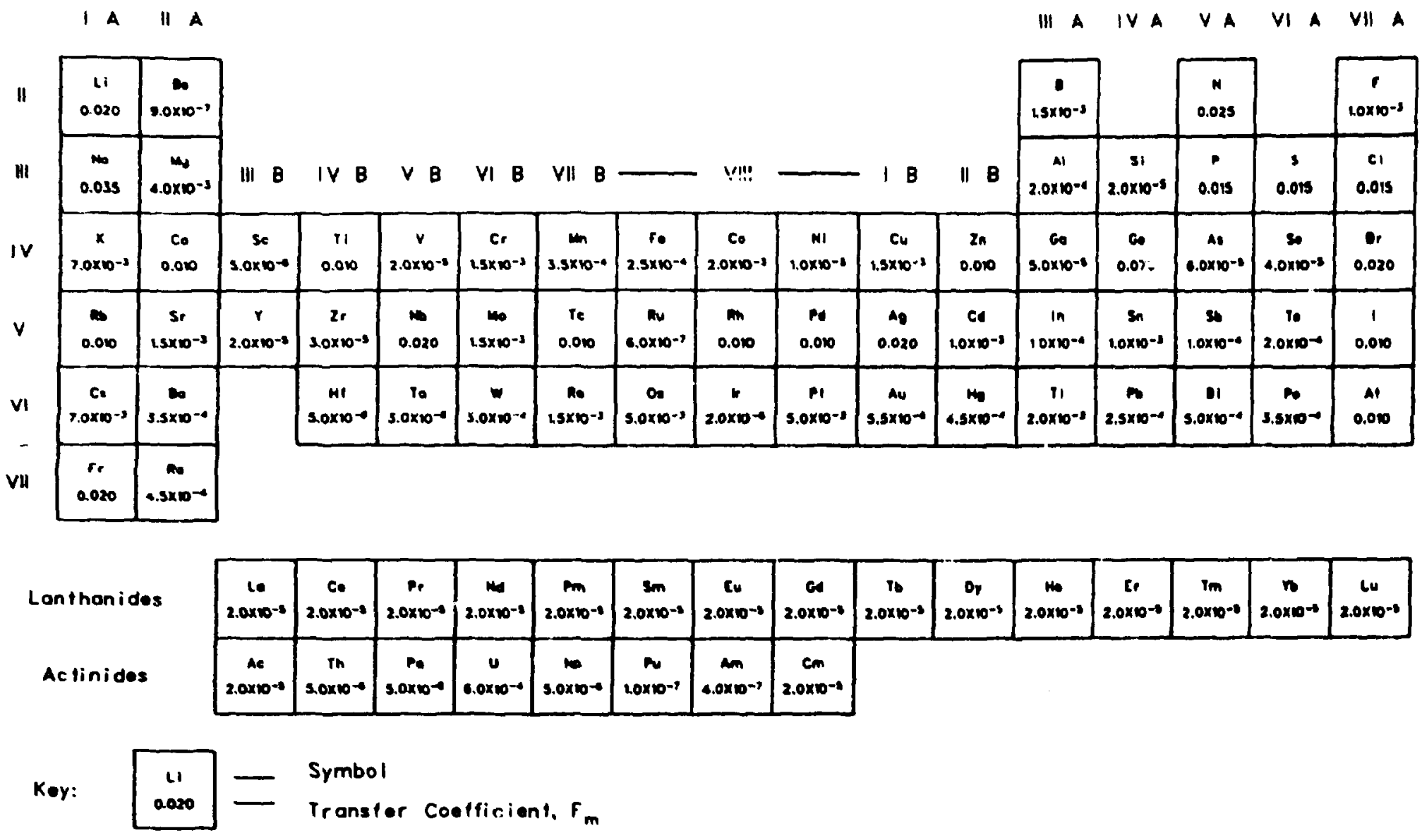

Figure 2.24. Values of the ingestion-to-milk transfer coefficient $F_{m}$ adopted as default estimates in the computer code TERRA. 

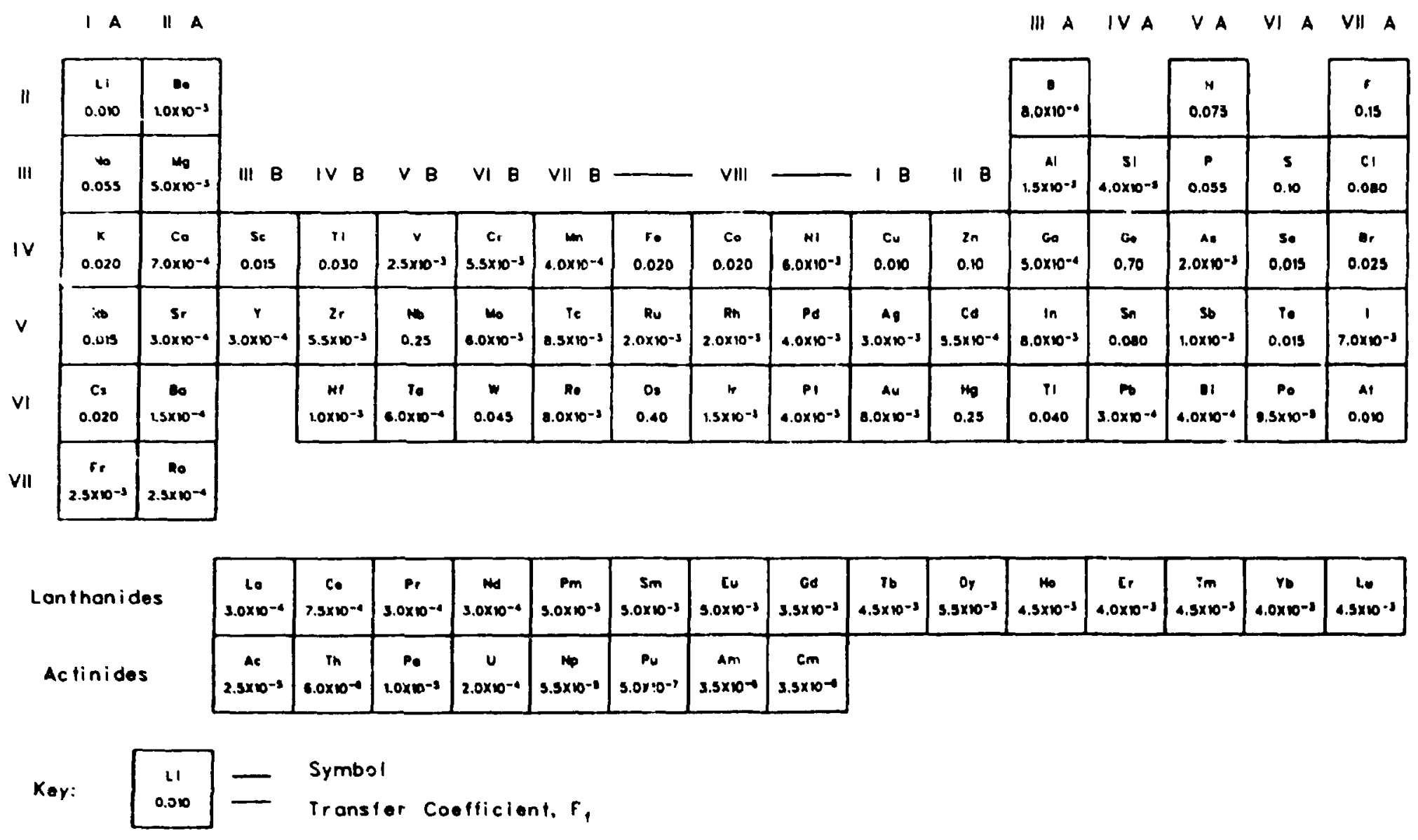

Figure 2.25. Vaiues of the ingestion-* beef transfer coefficient $F_{f}$ adopted as default estimates in the comnuter code TERRA. 


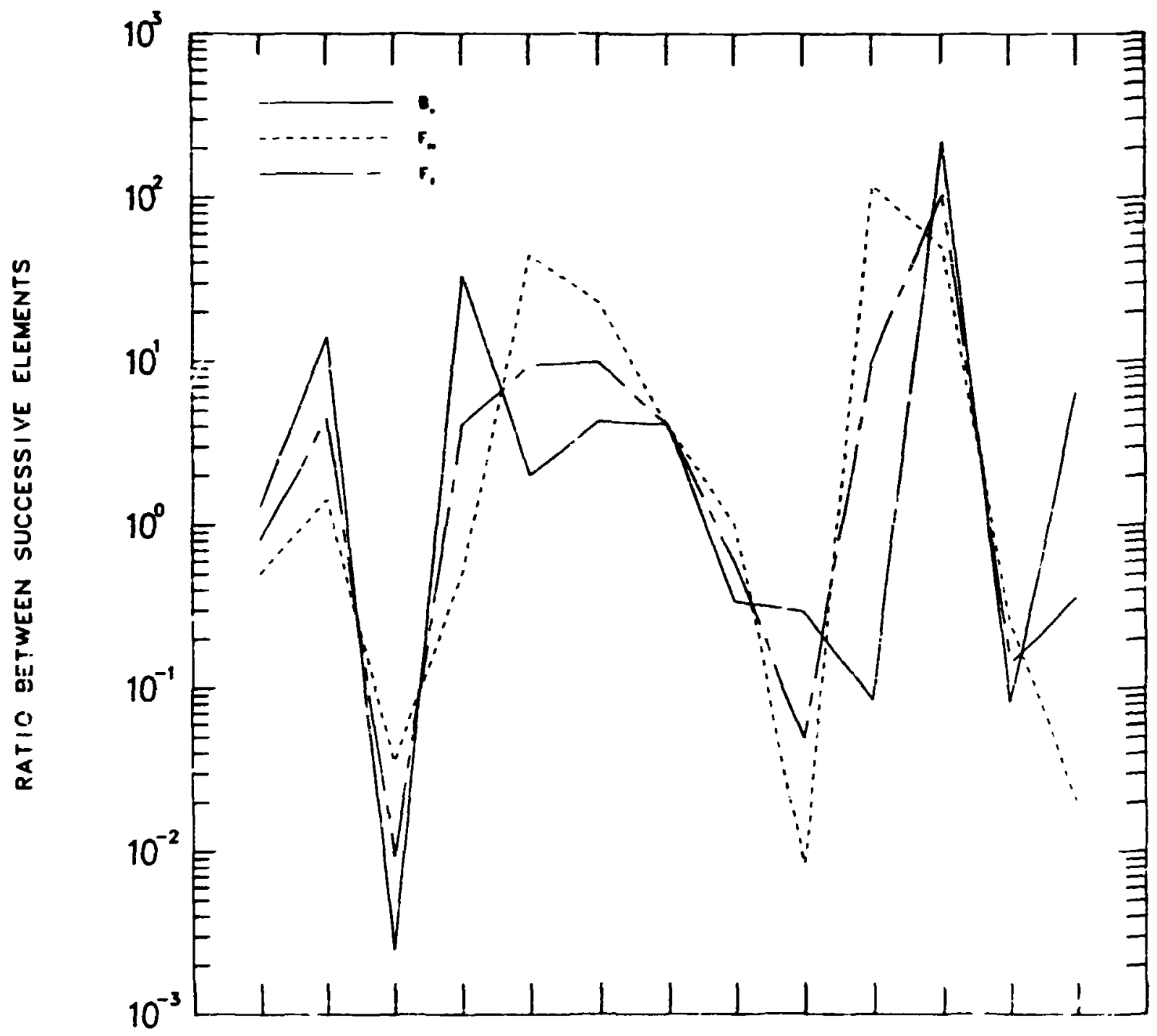

Po/O1 II/Po Po/Al aljigr Rr/Ro Ro/Ac Ac/Th Th/Po Po/U U/Mo Mo/Pu Pu/Am Am/Cm

Figure 2.26. Systematir, rends in the ratio of default eetimates for $B_{v}$ and $F_{m}$ for successive elemen is and wrre'sponding assumed ratios for $F_{f}$ for b'lccessive elements used to determine defaul: $F_{f}$ estimaies. 
seen in the systematic variability of our $B_{v}$ estimates (Figs. 2.27 and 2.28 ) and $F_{m}$ estimates (Figs 2.29 and 2.30). However, experimental determination of $F_{f}$ for elements of atomic number greater than 82 would be preferable to our present approach, if available.

\section{The Distribution Coefficieat, $\mathbf{K}_{\mathbf{d}}$}

The distribution cuefficient, $K_{d}$ is the ratio of elemental concentration in soil to that in water in a soil-water system at equilibrium. In general, $K_{d}$ is measured in terms of gram weights of soil and milliliter volumes of water. In TERRA the distribution coefficient is used in the following equation to determine a location-specific leaching constant for elemental removal from a given soil depth,

$$
\lambda_{l}=\frac{P+I-E}{\theta d\left[1+\left(\frac{P}{\theta} K_{d}\right)\right]},
$$

where

$$
\begin{aligned}
P & =\quad \text { annual average total precipitation }(\mathrm{cm}), \\
E & =\quad \text { annual average evapotranspiration }(\mathrm{cm}), \\
I & =\text { annual average irrigation }(\mathrm{cm}), \\
d & =\text { depth of soil layer from which leaching occurs }(\mathrm{cm}), \\
\rho & =\text { soil bulk density }\left(\mathrm{g} / \mathrm{cm}^{3}\right), \\
\theta & =\text { volumetric water content of the soil }\left[\mathrm{mL}\left(=\mathrm{cm}^{3}\right) / \mathrm{cm}^{3}\right), \text { and } \\
K_{d} & =\text { the distribution coefficient }(\mathrm{mL}-/ \mathrm{g}) .
\end{aligned}
$$

Default estimates of $K_{d}$ used in the TERRA code "are presented in Fig. 2.31. The mantissa of these values has been rounded off to the nearest 0.5 decimal place as for the other element specific transport parameters. The values for magnesium, potassium, calcium, manganese, iron, cobalt, copper, zinc, strontium, ftrium, molybdenum, technetium, ruthenium, cesium, lead, polonium, cerium, thorium, urarium, neptunium, plutonium, americium, and curium were determined through a review of thc $K_{d}$ literature. The estimates for the remaining elements were determined by a correlation of $K_{d}$ with $B_{v}$. Because of the inherent uncertainities in estimates of $K_{d}$ for various materials, a brief discussion of the parameter and its determination is appropriate.

\subsubsection{Variabillty in $K_{4}$}

The first source of variability in the parameter is associated with the laboratory methods used to determine $K_{d}$. Generally, the two most common techniques for determination of $K_{d}$ are the column and batch methods although other methods have been employed to measure distributions of chemical forms ${ }^{147}$ or distribution anong soil fractions. ${ }^{148}$ In the column method a solution of material in water is applied to a column containing uniformly packed soil. The $K_{c}$ of the material is determined from comparison of the $50 \%$ breakthrough curves for the water and material according to the equation

$$
\frac{V_{1}}{V_{w}}=\frac{1}{1+\frac{\rho}{\theta} K_{d}} \text {. }
$$

where

$V_{i}=$ he velocity of the migrating material (determined from the $50 \%$ breakthrough curve) and

$V_{w}=$ the velocity of the water. 


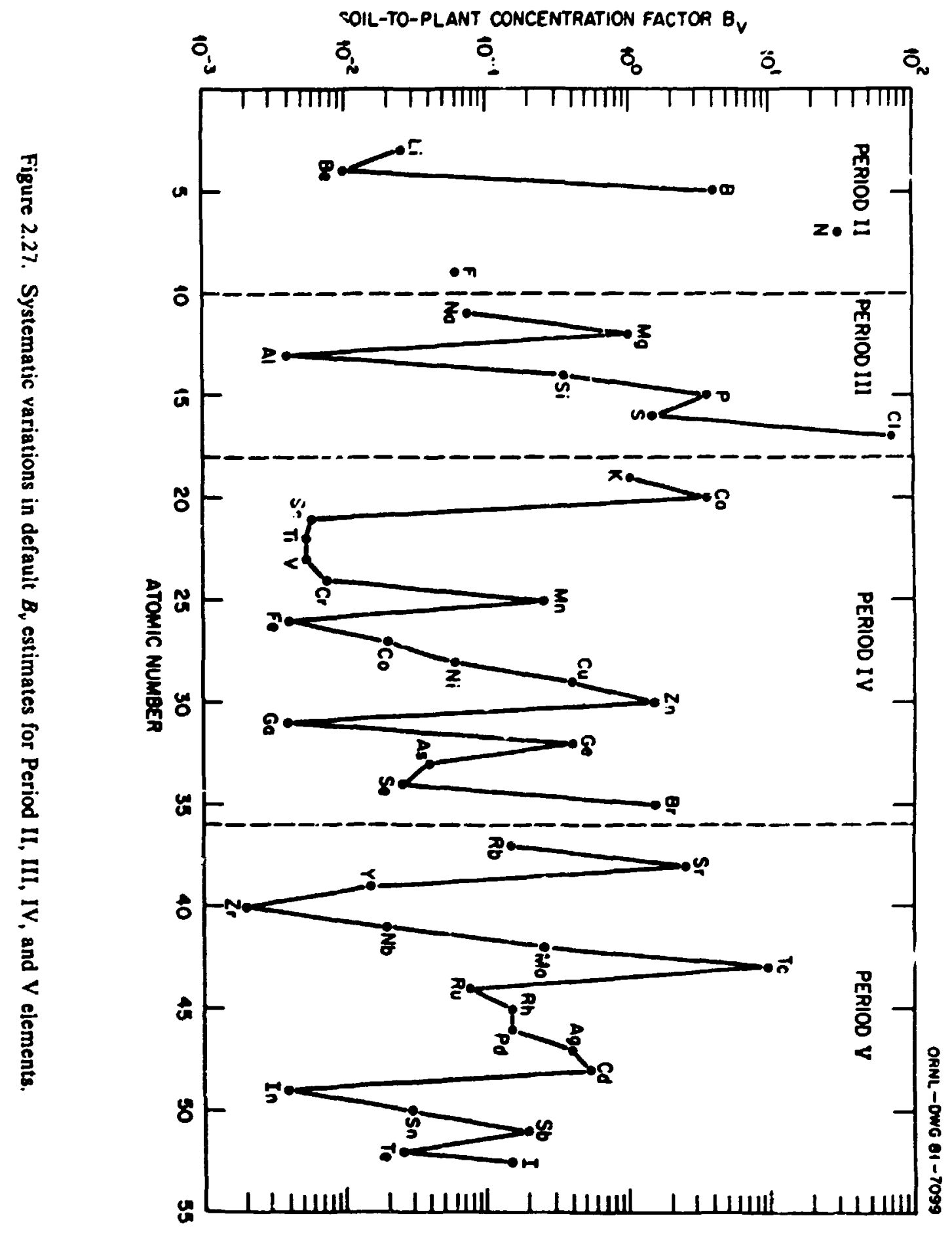




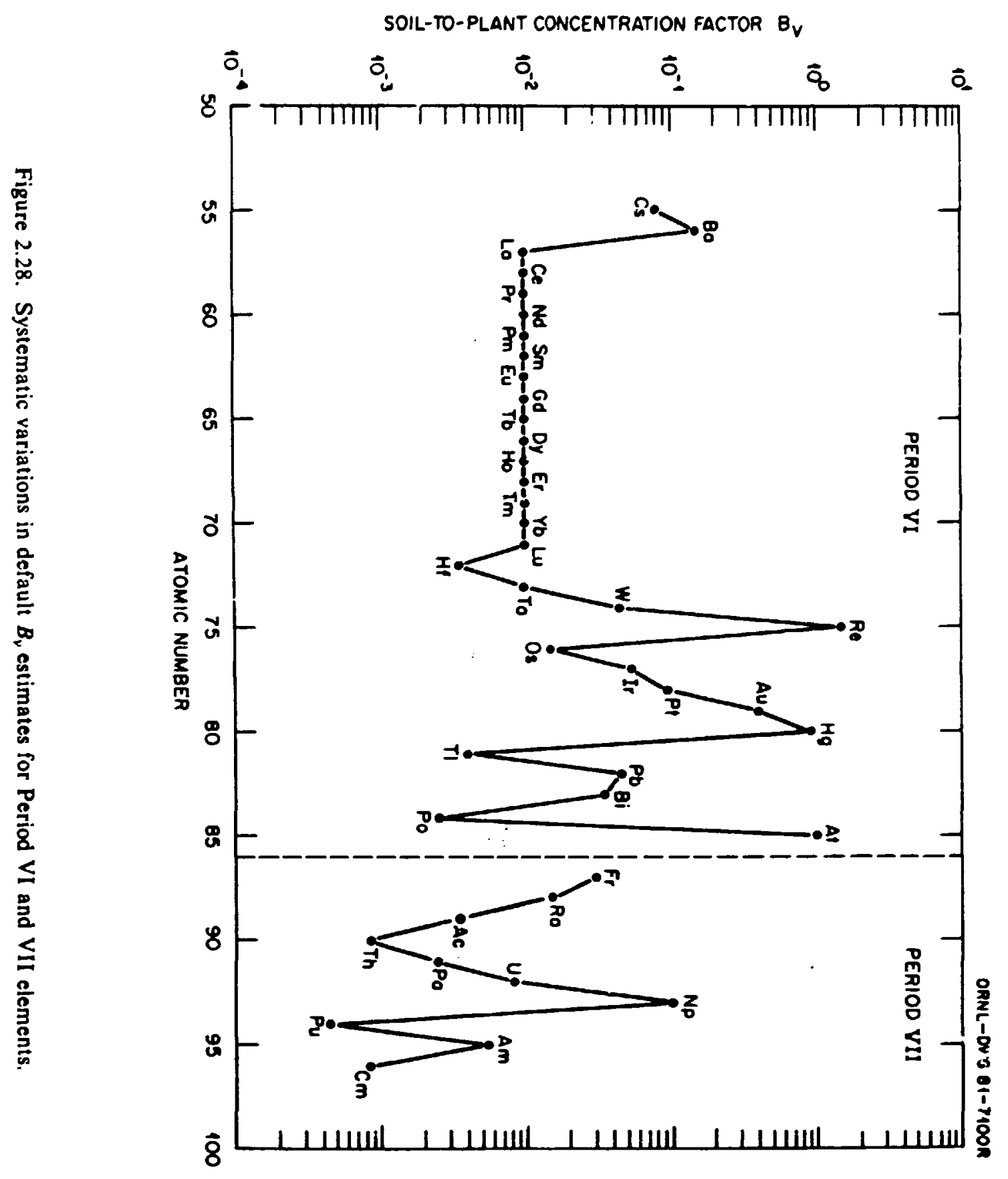




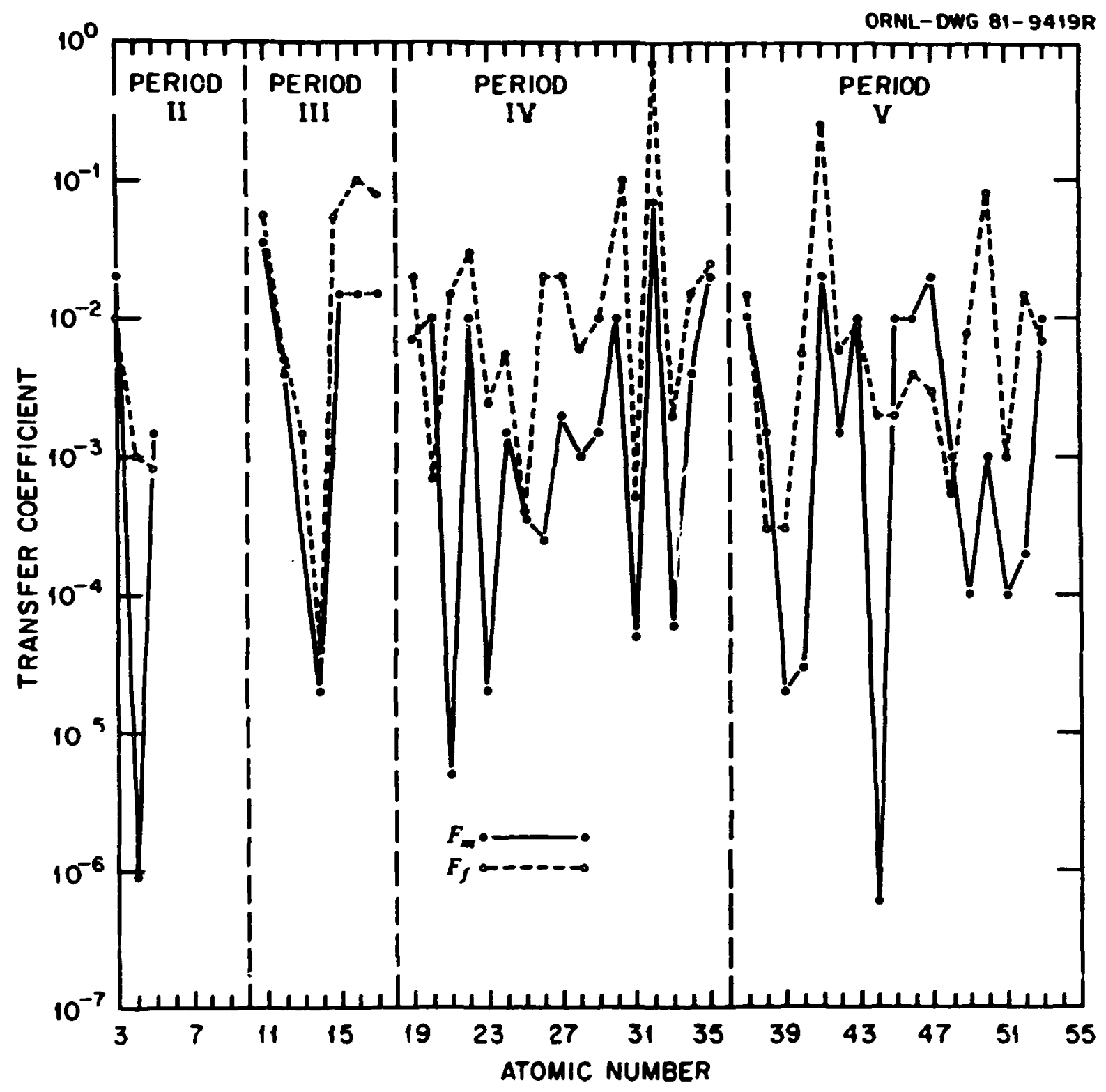

Figure 2.29. Systematic variations in default $\boldsymbol{F}_{m}$ and $\boldsymbol{F}_{f}$ estimates for Period II, III, IV, and V elements. 


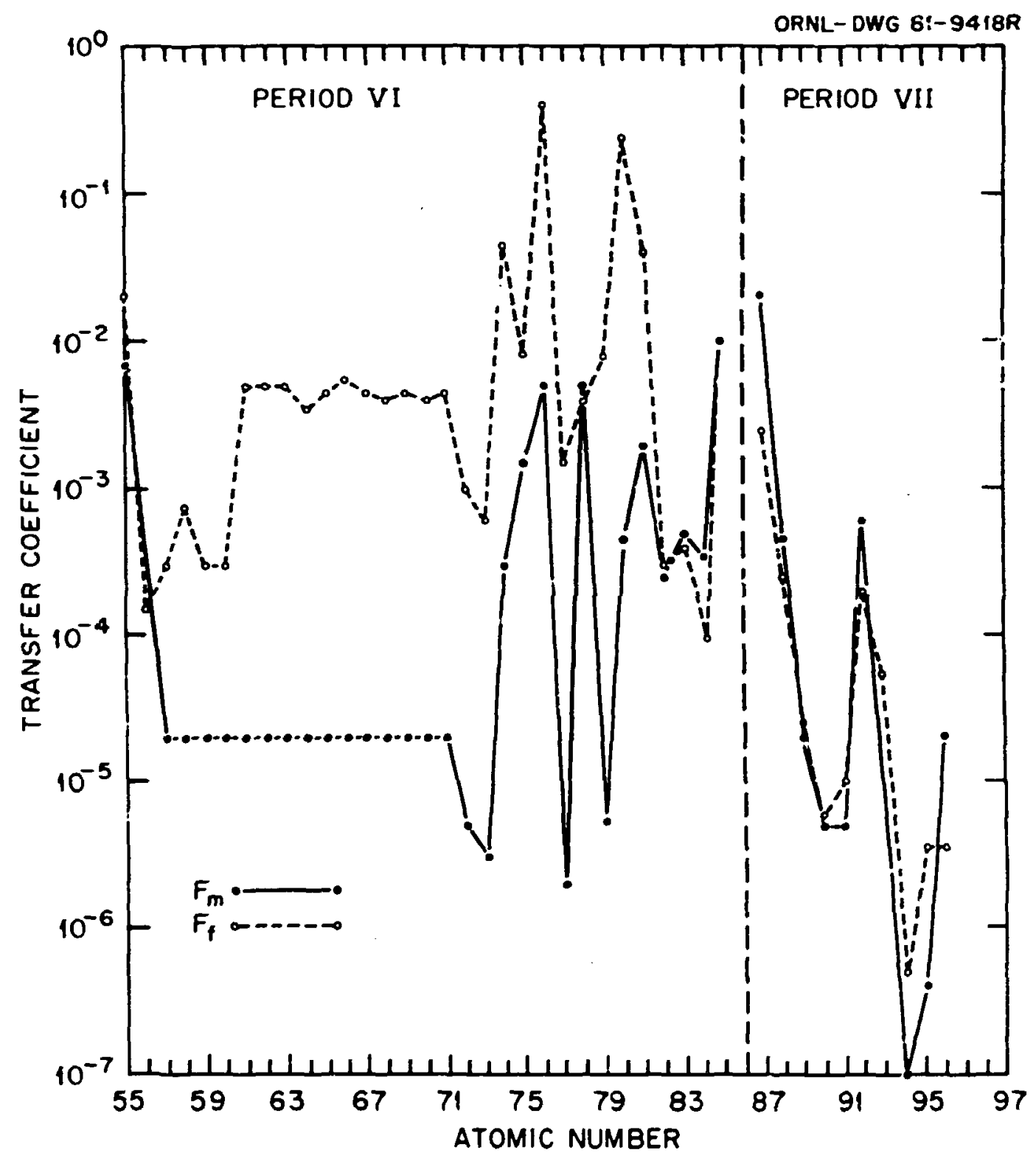

Figure 2.30. Systematic variations in default $F_{m}$ and $F_{f}$ estimates for Period VI and VII elements. 


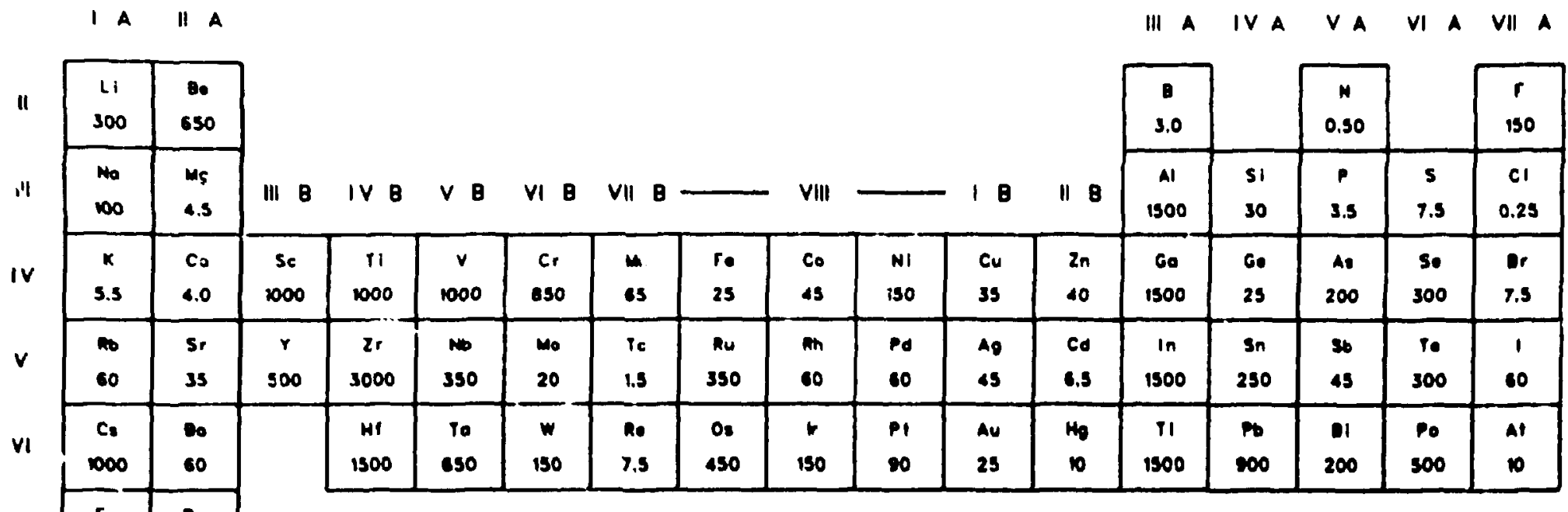

VII

\begin{tabular}{c|c|}
\hline ir & Ro \\
250 & 450 \\
\hline
\end{tabular}

\begin{tabular}{|c|c|c|c|c|c|c|c|c|c|c|c|c|c|c|c|}
\hline Lanthanides & $\begin{array}{l}\text { Le } \\
\text { eso }\end{array}$ & $\begin{array}{l}\text { ce } \\
\text { aso }\end{array}$ & $\begin{array}{l}\text { Pr } \\
\text { eso }\end{array}$ & $\begin{array}{l}\text { nd } \\
\text { sso }\end{array}$ & $\begin{array}{l}\text { Pm } \\
\text { iso }\end{array}$ & $\begin{array}{l}\text { sm } \\
\text { eso }\end{array}$ & $\begin{array}{l}\text { Eu } \\
\text { eso }\end{array}$ & $\begin{array}{l}04 \\
130\end{array}$ & $\begin{array}{c}\text { Tb } \\
\text { eso }\end{array}$ & $\begin{array}{l}\text { Dy } \\
\text { eso }\end{array}$ & $\begin{array}{l}\text { Ho } \\
\text { iso }\end{array}$ & Eso & im & $\begin{array}{l}\text { ro } \\
\text { eso }\end{array}$ & Ls \\
\hline Actinides & $\begin{array}{c}\text { AC } \\
1500\end{array}$ & $\begin{array}{c}\text { Th } \\
25 \times 10^{5}\end{array}$ & $\begin{array}{c}\text { Po } \\
2500\end{array}$ & $\begin{array}{c}u \\
150\end{array}$ & 30 & $\begin{array}{c}\text { Pu } \\
4500\end{array}$ & ${ }_{700}$ & $\begin{array}{c}\mathrm{cm} \\
2000\end{array}$ & & & & & & & \\
\hline
\end{tabular}

Ker: $\left[\begin{array}{l}11 \\ 300\end{array}\right]-\begin{aligned} & \text { Symbol } \\ & \text { Transter Coefflcient, } K_{d}\end{aligned}$

Figure 2.31. Vaiues of the soil-water distribution coefficient $\boldsymbol{K}_{d}$ adopied as default estimates in the computer code TERRA. 
In the batch method, soil and water are shaken with the material for a period of time until equilibirum distribution between soil and water is achievod or assumed. Because of nonequilibrium or the influences of convection and diffusion in the column method, these two techniques may give different results for nonionic elemental forms. ${ }^{149}$ Thus, in searching the literature for $\boldsymbol{K}_{\boldsymbol{d}}$ values, various biases and confounding factors inherent in the laboratory methods used to determine $K_{d}$ are reflected in the values reported.

A second factor responsible for variation or imprecision in $K_{d}$ measurement is a result of the parameter being a ratio of two concentrations. A small amount of error in measurement of either the soil or water concentration of material may produce a large amount of error in the resultant ratio. For example, in a batch-type experimt ntal system of $10 \mathrm{~g}$ soil, $100 \mathrm{~mL} \mathrm{H}_{2} \mathrm{O}$, and $100 \mu \mathrm{g}$ of material for which the true $K_{d}$ is $190 \mathrm{~mL} / \mathrm{g}$, a 19 , overestimate of the soil concentration $(95.95 \mu \mathrm{g}$ in soil) yields a $K_{d}$ of $237 \mathrm{~mL} / \mathrm{g}$, or approximately a $25 \%$ overestimate of $K_{d}$. The relative error in $K_{d}$ estimate from a given percent error in measurement of soil concentration increases rapidly with increasing $K_{d}$ (Fig. 2.32). The same is true with a given percent underestimate of the water concen:ration as the true $\boldsymbol{K}_{d}$ of the material decreases. Thus, if an investigator measures only one fraction of the soil-water system and determines the concentration of the other fraction by default, significant errors may be introduced into the $K_{d}$ estimate from very small experimental errors of measurement. This magnification of experimental error undoubtly contributes a significant amount of variability to $K_{d}$ estimates for $m_{s} a t e r i a l s$ which are highly soluble or insoluble.

A third source of variability in $K_{d}$ is its variation with soil type. Soils with differert pH, clay content, organic matter content, free iron and manganous oxide contents, or particle size distributions will likely yield different $\boldsymbol{K}_{d}$ values. For example, in a stuoy by Griffin and Shimp ${ }^{150}$ of lead absorption by clay minerals, $\mathrm{pH}$ was shown to be an extremely important determinant of $K_{d}$. From their data, an exponential relationship between $K_{d}$ and $\mathrm{pH}$ of the clays was found. At $\mathrm{pH}>7.0$, lead $K_{d}$ is on the order of $10^{3}$, and below this $\mathrm{pH}, K_{d}$ ranges from $10^{1}$ to $10^{2}$. Soil $\mathrm{pH}$ has also been shown to influence $K_{d}$ for plutonium and curium; ${ }^{151-153}$ ruthenium, yttrium, zirconium, niobium, and cerium; ${ }^{154}$ arsenic and selenium; ${ }^{155,156}$ and manganese, iron, zinc, cobalt, copper, cadmium, and calcium. ${ }^{157-159}$

Another source of variation in $\boldsymbol{K}_{\boldsymbol{d}}$ is the time factor involved with its determination. Batchtype $K_{d}$ determinations are usually made over a period of a few to several hours until equilibrium is achieved or assumed. If equilibrium does not occur within this short time period, some error is introduced. Errors from nonequilibrium $K_{d}$ determinations made after 24 hours, however, ar $s$ relatively insignificant. 151.152 .160 A more significant error may be introduced by using short term $\boldsymbol{K}_{d}$ determinations to simulate leaching over time periods of months or years. Gast et al. ${ }^{23}$ found that sorption of Tc-99 by low organic soils tended to significantly increase over a 5-6 week period. Treatments of the soil with dextrose, $\mathrm{H}_{2} \mathrm{O}_{2}$, and steam sterilization, and sorption variation with temperature-all indicated that microbiotz played either is direct or indirect role in sorption. Heterotrophic bacteria capable of solubilizing $\mathrm{PbS}$. $\mathrm{ZnS}$, and $\mathrm{CdS}$ have been reported by Cole, ${ }^{161}$ and microbial influences on the solubility of transuranics has also been suggested by Wildung and Garland. ${ }^{162}$ If microbial action is, indeed, important over the long term, then the applicability of $K_{d}$ experiments carried out with oven dried and sieved soil to models of leaching in agricultural soils over long time periods must be questioned.

An analysis of the literature was performed to ascertain appropriate distributions of $K_{d}$ for varinus elements (Table 2.13). Because of the variation of $K_{d}$ with soil $\mathrm{pH}$, an analysis of 222 agricultural soils ${ }^{163.164}$ was used to determine a typical rarige of $\mathrm{pH}$ for agricultural soils. In these soils, $\mathrm{pH}$ was found to be normally distributed with a mean ,iH of 6.7 and $95 \%$ of the values between a pH of 4.7 to 8.7. Thus, the criterion was adopted of discarding $K_{d}$ values which were measured in soils outside of the pH range of 4.5 to 9 . The $K_{d}$ determinations used to generate Table 2.13 represent a diversity of soils, pure clays (pure minerals were excluded), extracting solutions (com:tionly $\mathrm{H}_{2} \mathrm{O}, \mathrm{CaCl}_{2}$, or $\mathrm{NaCl}$ ), laboratory techniques, and magnification of experimen'al c-ror. Also, unavoidably, single measurements have been combined with replicates, means, and means of means to derive $K_{d}$ distributions. When many references have been used to 


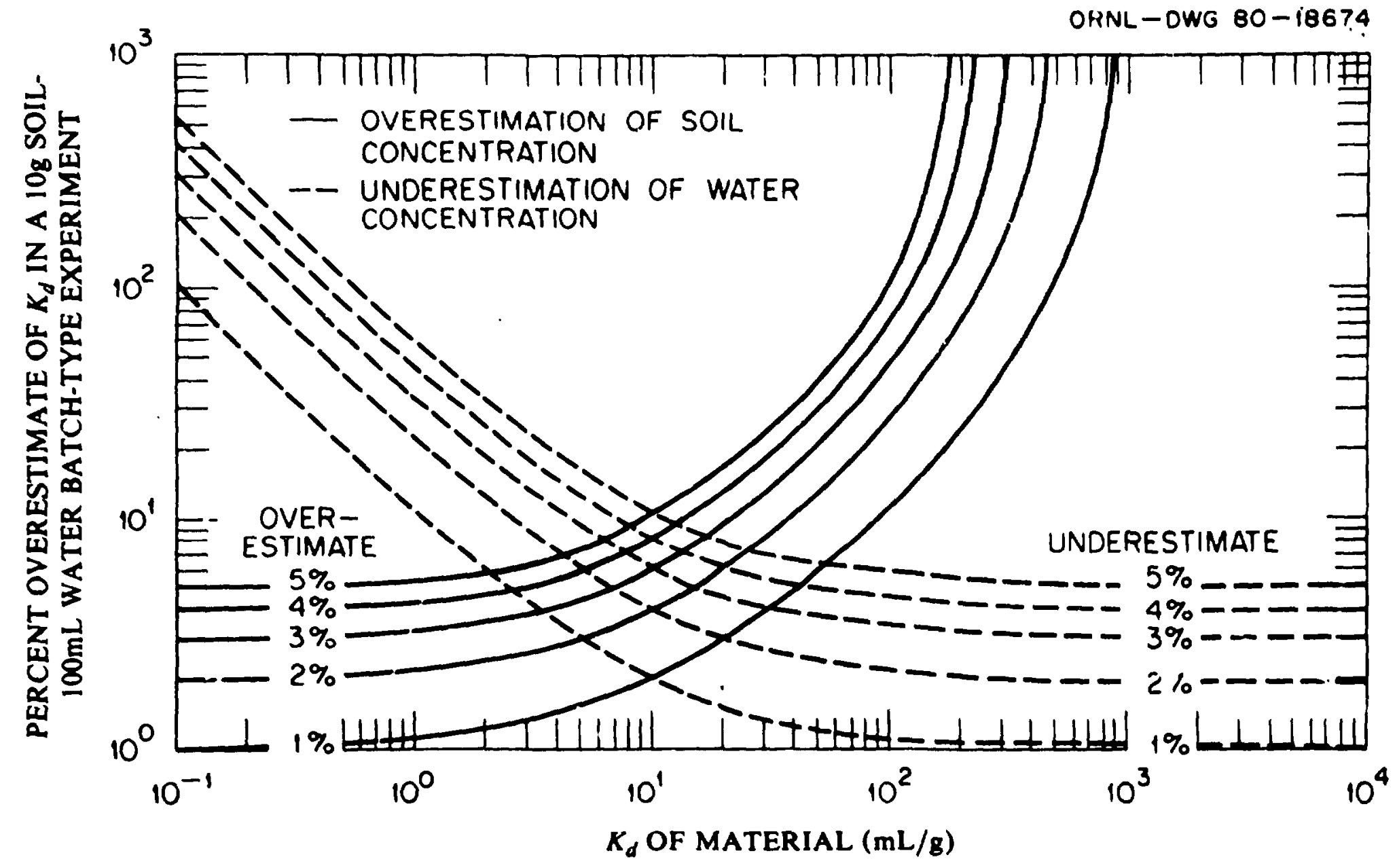

Figure 2.32. Percent error in $\boldsymbol{K}_{d}$ estimation from one to five percent overestimates of soil concentration or underestimates of water concentration in a $10 \mathrm{~g}-100 \mathrm{~mL}$ batch-type $K_{d}$ experiment. 


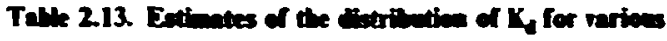
denews in agriculdurl solls of pH 45 it 9.0

\begin{tabular}{|c|c|c|c|c|c|c|}
\hline Element & Ots. & $\mu$ & b & $\exp (\mu)^{x}$ & Observed range & References \\
\hline & \multicolumn{6}{|c|}{$-\mathrm{mL} / \mathrm{B}$} \\
\hline $\mathbf{M g}$ & 58 & 1.5 & 0.40 & 4.6 & 1.6 to 13.5 & 165,166 \\
\hline $\mathbf{K}$ & 10 & I.7 & 0.49 & 5.6 & 2.0 to 9.0 & 165 \\
\hline $\mathrm{Ca}$ & 10 & 1.4 & 0.78 & $4 . i$ & 1.2 to 9.8 & 165 \\
\hline Mn & 45 & 4.2 & 2.5 & 65 & 0.2 to 10,000 & $149,158,167,168$ \\
\hline $\mathrm{Fe}$ & 30 & 3.2 & 2.0 & 25 & 1.4 to 1,000 & $149,158,167,169$ \\
\hline Co & 57 & 3.9 & I.I & 47 & 0.2 to 3,800 & $149,158,160,167,169-171$ \\
\hline $\mathrm{Cu}$ & .5 & 3.6 & 0.97 & 35 & 1.4 to 333 & 157,158 \\
\hline $\mathbf{Z n}$ & 146 & 3.6 & 1.8 & 38 & 0.1 to 8.000 & $149,157-159,167$ \\
\hline Sr & 218 & 3.6 & 1.6 & 37 & 0.15 to 3,300 & $\begin{array}{l}149,152,154,160,161 . \\
169,171-180\end{array}$ \\
\hline $\mathbf{Y}$ & 2 & 6.2 & 1.7 & 510 & 160101,640 & 154 \\
\hline Mo & 17 & 29 & 2.2 & 18 & 0.37 to 400 & 149 \\
\hline Tc & 24 & -3.4 & 1.1 & 0.033 & 0.0029 to 0.28 & 23 \\
\hline $\mathbf{R u}$ & 17 & 5.9 & 0.75 & 350 & . 9 to 1,000 & 154,160 \\
\hline $\mathbf{A}_{\mathbf{B}}$ & 16 & 3.8 & 1.5 & 46 & ic to 1,000 & 149,167 \\
\hline Cd & 28 & 1.9 & 0.86 & 6.4 & 1.26 to 26.8 & 157 \\
\hline Cs & 135 & 6.9 & 1.8 & 1000 & 10 to 52,000 & $\begin{array}{l}i 49,160,167,169,171 \\
173,175,177,178,180-183\end{array}$ \\
\hline $\mathrm{Ce}$ & 16 & 6.7 & 0.54 & 840 & 58 to 6,000 & 154,160 \\
\hline $\mathbf{P b}$ & 125 & 6.0 & 2.1 & 400 & 4.5 to 7640 & 150,184 \\
\hline Po & 6 & 6.3 & 0.65 & 520 & 196 to 1,063 & 184 \\
\hline Th & 17 & 12 & 0.57 & 150,000 & 2,000 to $\$ 10,000$ & $185-187$ \\
\hline U & 24 & 6.1 & 2.5 & 450 & 10.5 to 4.400 & $185-187$ \\
\hline$N_{p}$ & 44 & 3.4 & 2.5 & 29 & 0.16 to 929 & $148,186,188,189$ \\
\hline Pu & 40 & 8.4 & 2.4 & 4500 & 11 to 300,000 & $\begin{array}{l}151,152-154,177,182 . \\
186,187,189\end{array}$ \\
\hline Am & 46 & 6.5 & 2.4 & 680 & $1.01047,230$ & $148.188-190$ \\
\hline $\mathrm{Cm}$ & 31 & 7.6 & 1.6 & 1.900 & 99.3 to 51,900 & 148, 153, 189 \\
\hline
\end{tabular}

-The mean of the logarithms of the observed values.

'The standard deviation of the !Egarithms of the observed values.

'Geometric mean ( $50 \%$ cumulative probability).

generate the distribution, greater assurance can be given that the distribution is a representative distribution because it is not heavily biased by one or two experimental designs or techniques. Where a single or a few referencer were used, less assurance can be given.

On the basis of distributions computed for cesiun. and strontium (Fir. 2.33), a lognormal distribution for $K_{d}$ has heen assumed for all elements. Thu. , the median value of the assumed lognormal distribution is used as a best estimate default $\ell_{d}$ for TERRA (except for lead, and technetium where judgement was exercised). However, if the distribution of $\boldsymbol{K}_{d}$ computed for cesium and strontium are typical, then $\boldsymbol{K}_{d}$ may vary by as much as three orders of magnitude in soils of $\mathrm{pH} 4.5$ to 9.0. Such variation in $K_{d}$ is greater than or equal to the variation in $B_{v}$ observed for cesium, strontium, and plutonium (Figs. 2.3, 2.7, ind 2.22) and suggests the advisability of using site-specific values when available. 

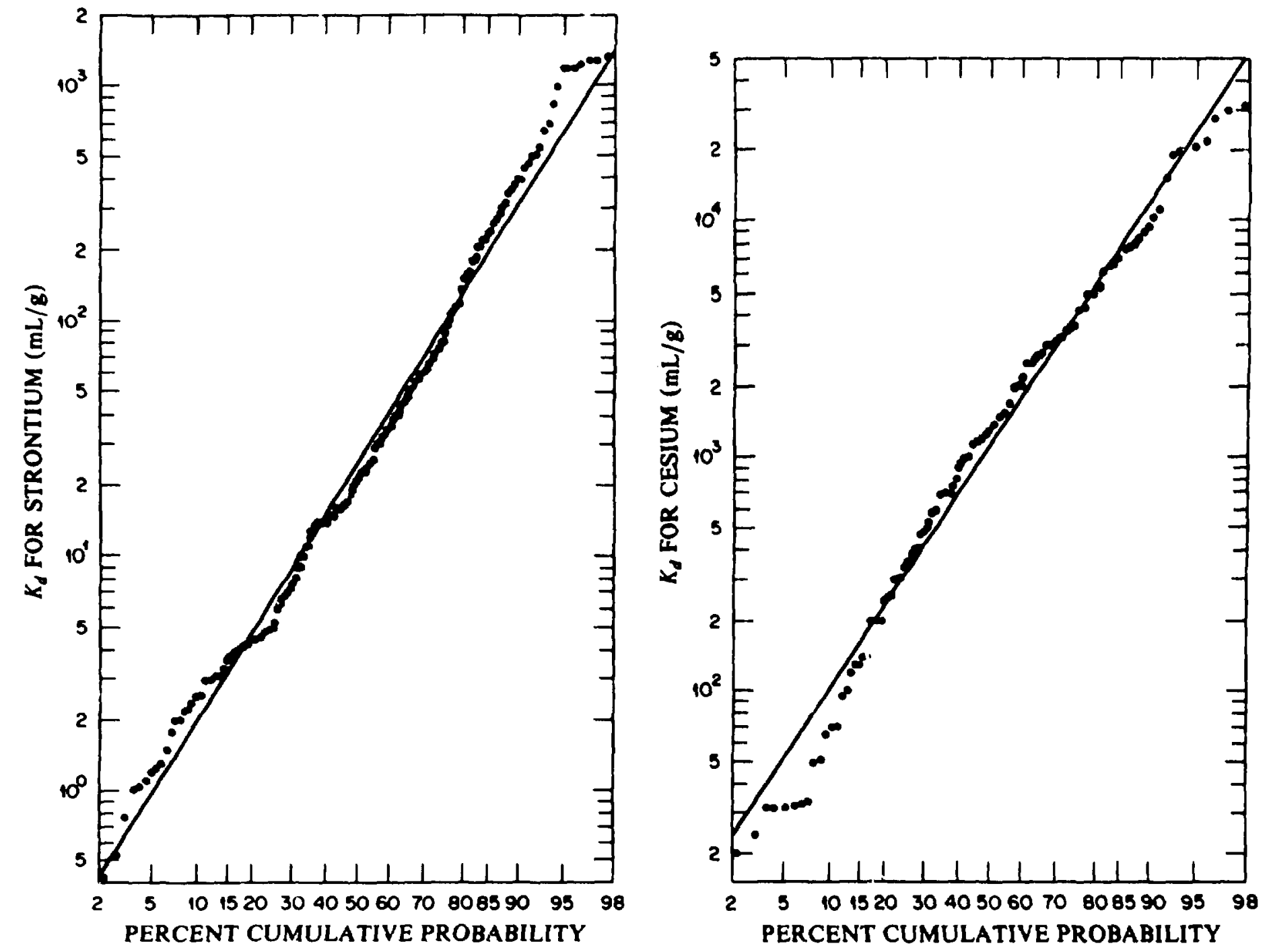

Figure 2.33. Lognormal probability plots of $K_{d}$ for resium and strontium in soils of pH 4.5 to $)$ based on available references. 


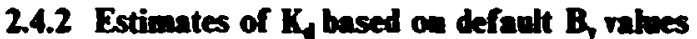

Although $K_{d}$ estimates for the 23 above-mentioned elerrents are subject to great uncertainty, they are based on values reported in the literature. No references are immediately available for the remaining elements of the periodic table. In order to provide a default estimate for these elements, an alternative method is used. In 1979, Van Dorp, Eleveld, and Frissel ${ }^{191}$ proposed a model for estimation of the soil-plant concentration factor. Their approach was to calculate the solubility of a nuciide in soil water, its ability to transfer across root membranes, and its upward movement with the transpiration stream. They reasoned that measured values of $K_{d}$, root selectivity coefficient $(S)$, and transpiration coefficient $\left(T_{c}\right)$ would allow them to predict the soil-plant concentration factor from soil-radionuclide concentration. Their model has not become generally used or accepted for dose calculations, but their implied dependency of $\boldsymbol{B}_{v}$ on $\boldsymbol{K}_{d}$ is the basis of our approach for estimat: $g$ default $K_{d}$ estimates in lieu of experimental determinations.

Our approach is to presume that the default $K_{d}$ estimates for elements in Sect. 2.4.i and their corresponding $B_{v}$ estimates represent a wide variety of soils and plants. Therefore, a single default estimate for $B_{v}$ and $K_{d}$ will reflect soils, plants, and injerimental conditions which are "averaged" or "generalized." Thus, any relationship observed between $\kappa_{d}$ and $B_{v}$ may be used to predict "average" or "generalized" $K_{d}$ estimates from our default $B_{v}$ estimates.

Figure 2.34 shows the correlation found between $B_{v}$ and $K_{d}$. It should be noted that the $B_{v}$ estimates in Fig. 2.34 are the geometric means determined directly through analysis of reviewed literature, and not necessarily the default values from Fig. 2.1. Technetium is an example. The technetium $B_{v}$ of 89 is the geometric mean of the giometric means of references $23,107,122$, and 123. It was felt that although the short-term plant uptake studies represented in references 23 , 107, and 122 were inappropriate for long-term $B_{v}$ estima $2 e s$, they were appropriately associated with the short-term $K_{d}$ determinations for technetium (because $B_{v}$ decreases and $K_{d}$ increases with time). Thus, these two short-term parameters were used in the definition of the $B_{v}-K_{d}$ relationship. However, in Fig. 2.31 we used our best estimate of technetium $B_{v}$ and the regression equation

$$
K_{d}=\exp \left(2.38-0.89\left(\ln B_{v}\right)\right)
$$

to determine our best estimate of technetium $\boldsymbol{K}_{d}$ of 1.5. In addition to technetium the $\boldsymbol{K}_{d}$ default estimates for elements not mentioned in Sect. 2.4.1 were determined via Eq. (9) and the best estimate $B_{v}$ default values in Fig. 2.1. 


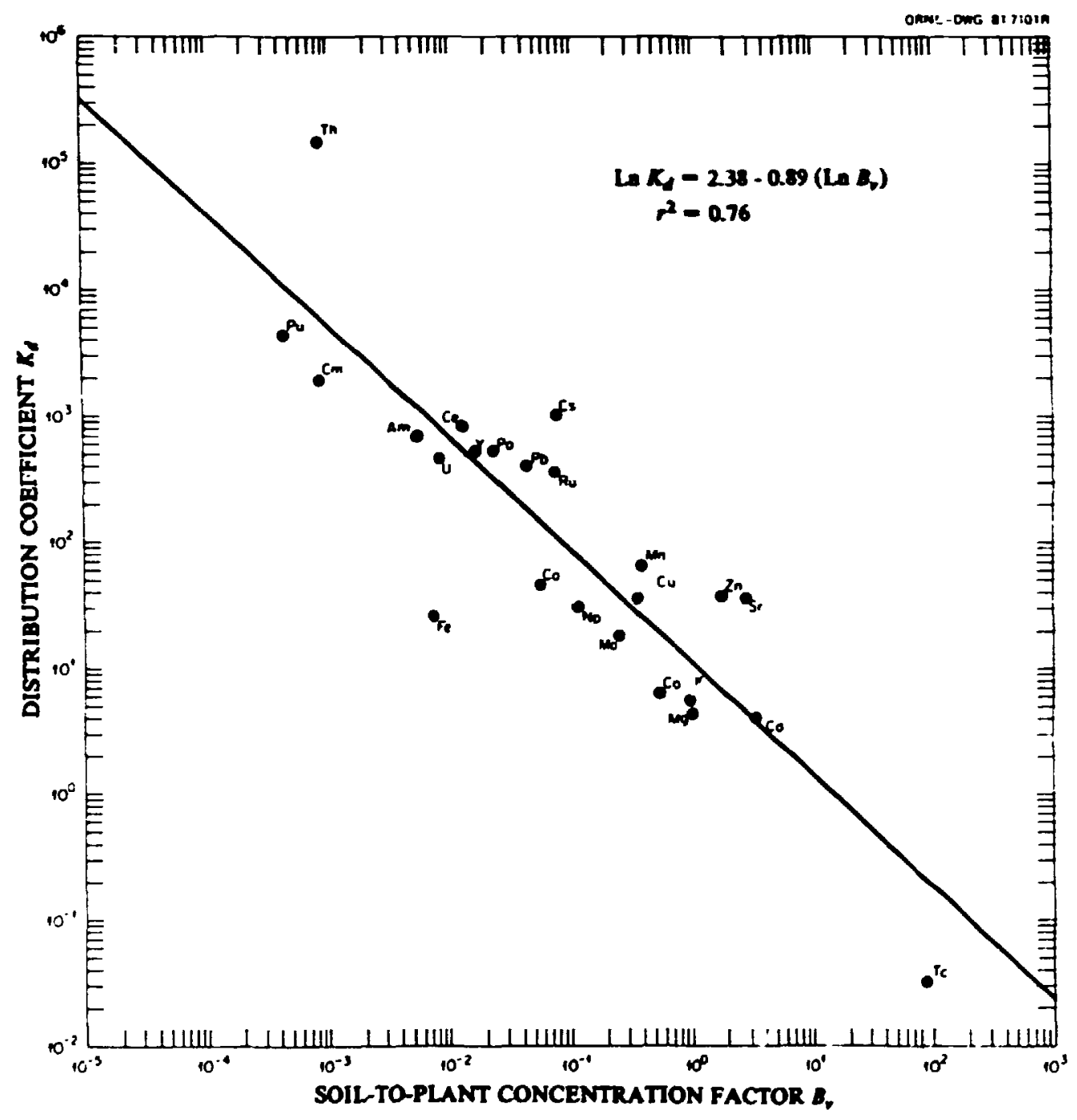

Figure 2.34. Correlation between $B_{v}$ and $K_{d}$ based on geometric means of availabl: reference geometric means. 


\section{INTERCEPTION FRACTION FOR VEGETATION}

The interception fraction for a given vegetation type, $r^{i}$, is a factor which accounts for the fact that not all of the airborne material depositing within a unit area will initially deposit on edible vegetation surfaces. The fraction of the total deposit which is initially intercepted by vegetation is the interception fraction, $r^{i}$, such that $0 \leqslant r^{i} \leqslant 1$. In the TERRA code, as in other food chain transport models, ${ }^{6}$ the processes of initial deposition and weathering removal with time are treated separately. In the NRC Regulatory Guide 1.109 model, separate interception fractions are suggested for iodines and other particulate types. ${ }^{6}$ The analysis of agricultural food and feed crops in the United States by Shor, Baes, and Sharp ${ }^{7}$ suggests that the diversity of growth forms necessitates vegetation-specific estimates of interception fraction as well. The folloxing sections outline a theoretical approach to vegetation-specific interception fractions. The results of such approaches have been used as default estimates in lieu of user-input values in the TERRA computer code. Variation of interception fraction with element, chemical form, and deposition process (e.g., wet, dry) will require further research.

In Section 3 pasture, hay, and silage productivities are considered to be on an air-dry weight basis as reported in reference 7 . Vegetable and produce productivities are in fresh weight as reported in reference 7 .

\subsection{Pasture Grasses ind Hay}

The interception fraction for pasture grasses and hay are modeled in a different manner than for other vegetation types because experimental determinations of interception fractions for grasses have been performed. ${ }^{192-198}$ In these studies a correlation between initial interception fraction and productivity (standing crop biomass) has been found. This relationship and an empirical fit of the available data (summarized in Table 3.5 of reference 199) is shown in Figure 3.1. The empirical relationship is given by

$$
r^{p t}=1-\exp \left(-2.88 Y_{p z}\right)
$$

where

$$
\begin{aligned}
& r^{P g}=\quad \text { the interception fraction for pasture grass and } \\
& Y_{P g}=\quad \text { the productivity of pasture grass }\left(\mathrm{kg} / \mathrm{m}^{2}, \mathrm{dry}\right)
\end{aligned}
$$

This relationship has been assumed to apply to hay as well as pasture grasses in the computer code TERRA.

\subsection{Leafy Vegeatables}

There are no readily avaiiable literaiure references for the interception fraction for leafy vegetables. Therefore, the interception fraction for leafy vegctables is based on a theoretical model (Fig. 3.2). With this model a range of mossible interception fractions may be generated if the following assumptions are made:

1. On a two-dimensional basis the fractional area represented by leafy vegetables is equal to the interception fraction;

2. leafy vegetables may be represented by circles on a two-dimensional basis (Fig. 3.2);

3. leafy vegetables are planted in rows; 


\section{6}

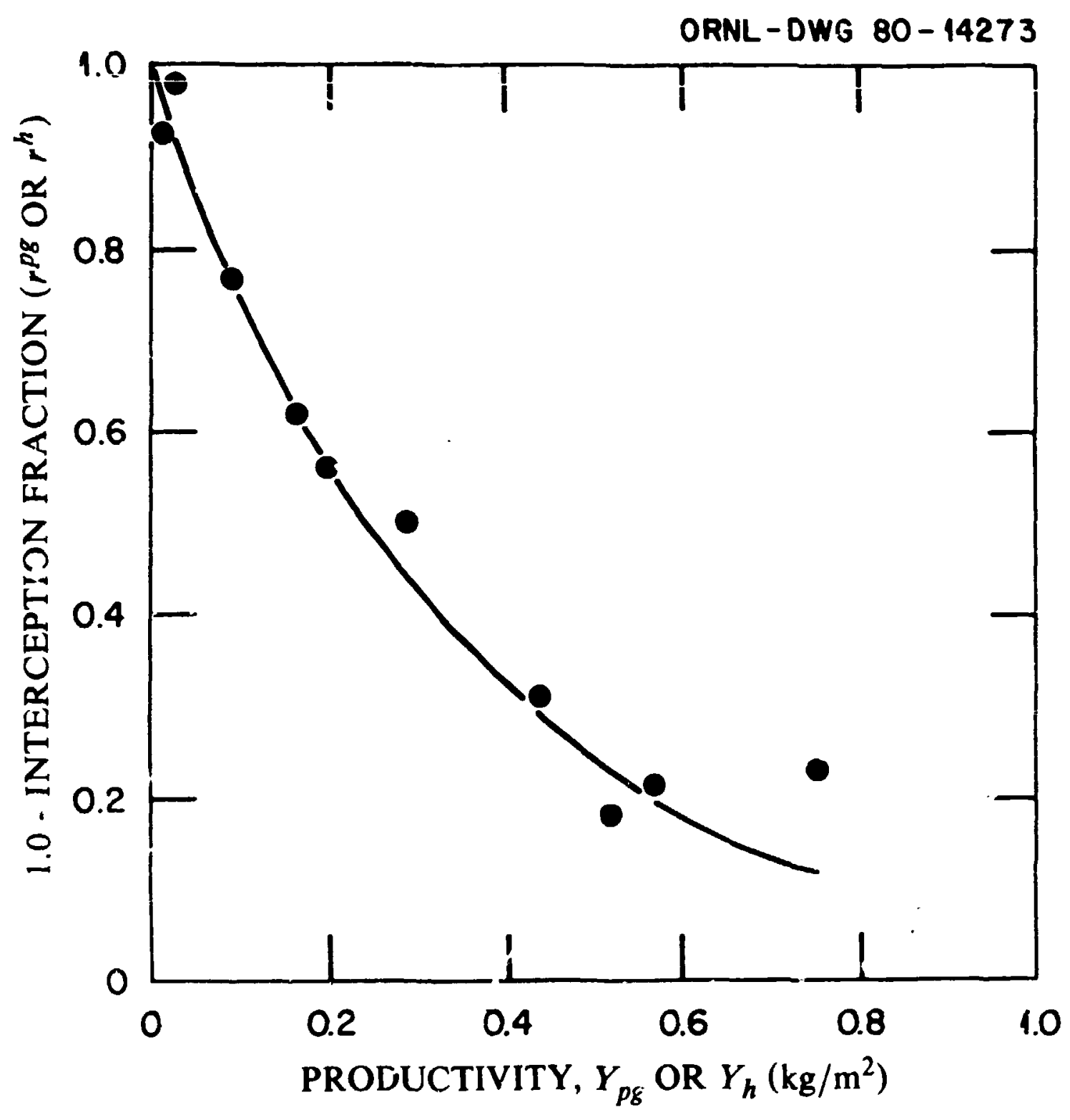

Figure 3.1. R:lationship between interception fraction and productivity (in dry weight) for forage grasses (pasture and hay). 


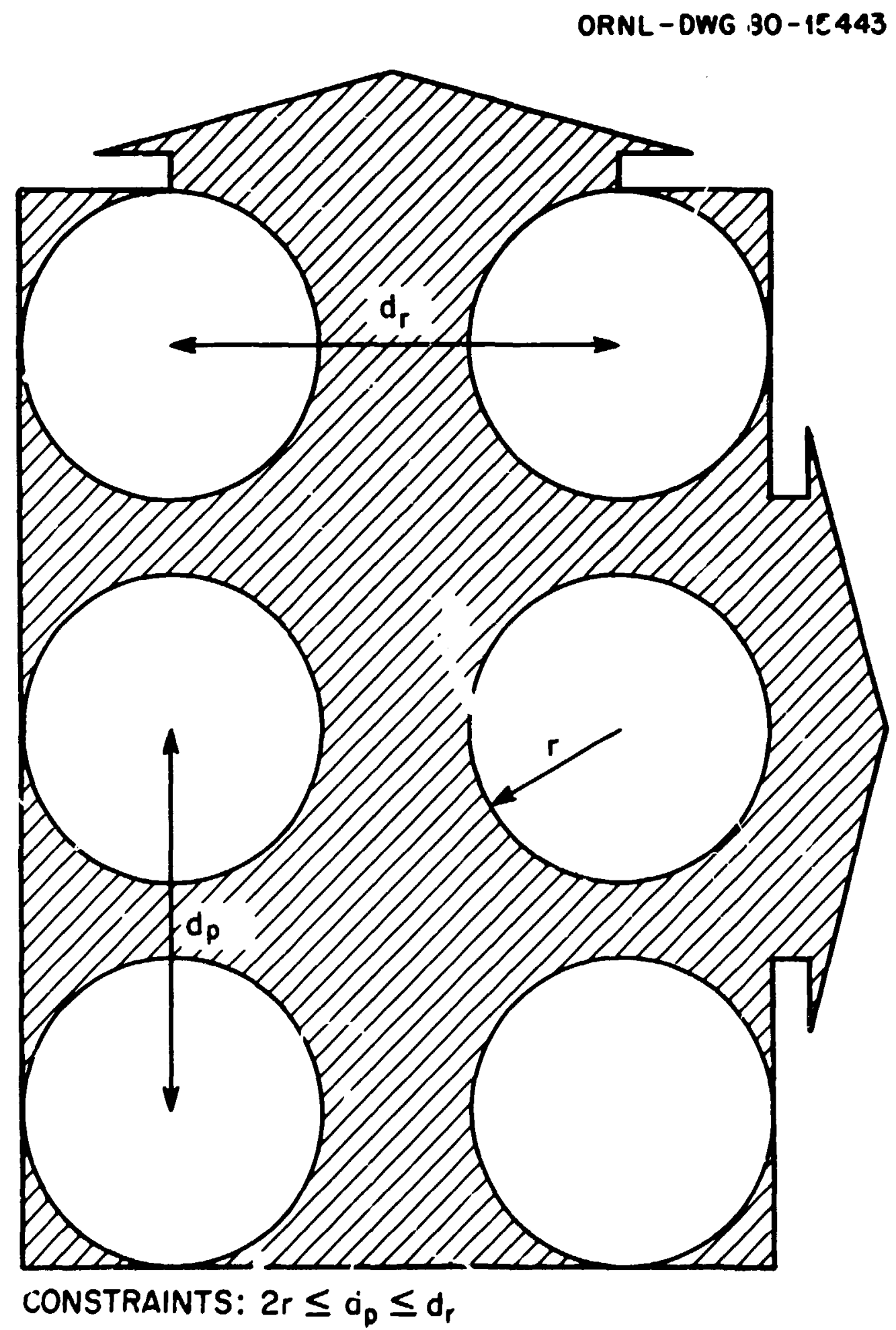

Figure 3.2. Model of field ge thetro of leafy vegetable spacings. 
4. the ranges of between-plant and between-row spacings in the United States are approximately equal to the minima and maxima recommended by Knott; 200

5. a farmer will not plant individual leafy vegetables so close together that leaves from adjacent plants overlap (thereby decreasing yield);

6. rows will generally be spaced farther apart thas individual plants in a row, and

7. harvest of leafy vegetables occurs at the time of maximum yield, and maximum yield corresponds to maximum plant diameter.

With the above assumptions, the model given by Fig. 3.2 predicts that the fraction of planted area occupied by leafy vegetables, equivalent to the interception fraction at harvestable maturity, is given by

$$
r^{m l v}=\frac{n_{r} r_{n} \pi r_{f}^{2}}{\left[\left(n_{r}-1\right) d_{p}+2 r_{f}\right]\left[\left(r_{p}-1\right) d_{r}+2 r_{f}\right]} .
$$

where
$r^{m l v}=\quad$ the interception fraction for mature leafy vegetables,
$n_{r}=$ the number of plants per row,
$r_{n}=\quad$ the number of rows of plants,
$r_{f}=$ the radius of an individual fruit or p.ant,
$d_{p}=$ the distance between plants in a row, and
$d_{r}=\quad$ the distance between rows of plants.

The constraints on the model are

$$
2 r_{f} \leqslant d_{p} \leqslant d_{r}
$$

As the land a:ea planted becomes infinitely large, Eq. (11) becomes

$$
r^{m / v}=\frac{\pi r_{f}^{2}}{d_{p} d_{r}}
$$

If a farmer maximizes the number of plants per row such that $d_{p}=2 r_{f}$, then Eq. (13) becomes

$$
r^{m / v}=\frac{\pi r_{f}}{2 d_{r}}
$$

When $2 r_{f}=d_{p}=d_{r}$ (maximum utilization of planted !and), then the interception fraction for mature leafy vegetables is 0.785 .

In order to predict an average interception fraction for the mature leafy vegetable, recommended field spacings ${ }^{200}$ for leafy vegetables were assumed to represent typical spacings actually encountered in American agriculture. A distribution of field spacings was determined by obtaining a range of recommended spacings for each leafy vegetable and weighting each vegetable according to its importance (by area planted) in the United States (Table 3.1). By determining distributions of typica! $d$, spacings and values of $r_{f}$, a "Monte Carlo technique was used to produce a distribution of solutions to Eq. (14). The muan value of this distribution is $r^{m / v}=v{ }^{2}{ }^{20}$. In this simulation the average $d_{r}$ was $73.5 \mathrm{~cm}(28.7$ inches $)$. 


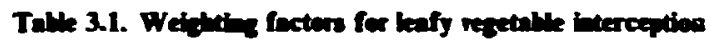
fraction medel anmination

\begin{tabular}{|c|c|c|c|}
\hline Leafy regetable & $\begin{array}{c}\text { Quantity planted } \\
\left(\mathbf{k m}^{2}\right)\end{array}$ & Percent & Weight factor \\
\hline Lettuce & 948 & 42 & \\
\hline$\infty$ & & & 14 \\
\hline bead & & & 14 \\
\hline lear & & & 14 \\
\hline Cabbage & 367 & 16 & \\
\hline early & & & 6 \\
\hline late & & & 5 \\
\hline chinese & & & 5 \\
\hline Greens & 246 & 11 & \\
\hline collards & & & 3 \\
\hline kale & & & 3 \\
\hline spinach & & & 3 \\
\hline New Zealand spinach & & & 2 \\
\hline $\begin{array}{l}\text { Broccooli } \\
\text { sprouting } \\
\text { rasb }\end{array}$ & 176 & 8 & 4 \\
\hline Mint & 160 & 7 & 7 \\
\hline Celery & 140 & 6 & 6 \\
\hline Caulifower & 113 & 5 & 5 \\
\hline Green onions & 59.3 & 3 & 3 \\
\hline Eucarole & 33.6 & 2 & \\
\hline chicory & & & 1 \\
\hline endive & & & 1 \\
\hline Bruseels sprouts & 24.8 & 1 & 1 \\
\hline Total & 2267.7 & 100 & 100 \\
\hline
\end{tabular}

From the theoretical interception fraction for mature leafy vegetables of 0.30 it is possible to generate an average interception fraction over the time in the field by taking into account the logistic growth characteristics of plaris (Fig. 3.3). It is commonly known that plants (and many living organisms) have growth patterns which follow a logistic growth pattern. $201-205$ Logistic growth curves have been defined by various equations wiil ih yield the appropriate shape. For our analysis the following equation was used:

$$
f^{m}=\frac{1-\cos \left[180\left(\frac{t_{i}}{t_{m}}\right)\right]}{2}
$$

where

$$
\begin{aligned}
f^{m} & =\text { the fraction of maximum growth, } \\
t_{i} & =\text { the time of interest, and } \\
t_{m} & =\text { the time at which maximum growth normally occurs. }
\end{aligned}
$$




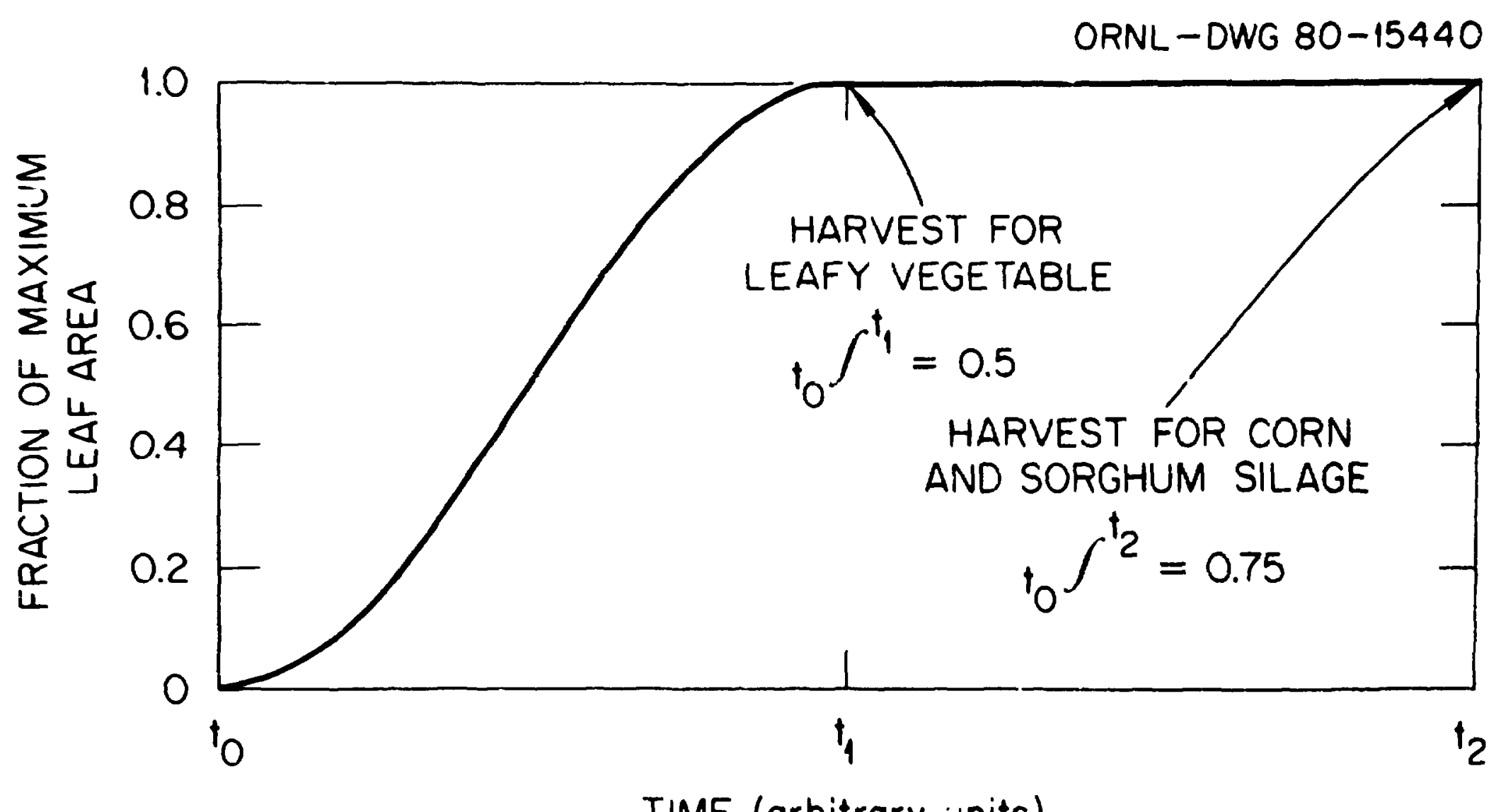

Figure 3.3. Hypothetical growth curve for plants. Leafy vegetables are harvested at the time of maximum growth, and silage is harvested at grain maturity. 
Equation (15) was chosen because at time $=t_{m} / 2, f^{m}=0.5$ and integration of Eq. (15) from $t_{0}$ to $t_{m}$ yields 0.5 . Thus, an average interception fraction for leafy vegetables over the time in the field is equal to $0.5 \times 0.30$ or 0.15 . It must be emphasized that the value of 0.15 represents a theoretical average over the United States for leafy vegetables. A corresponding theoretical maximum would be $0.5 \times 0.785$ or 0.39 .

\subsection{Shage}

The analysis of silage interception fraci $\rightarrow$ is based on an approach similar to that for leafy vegetables. A modification of the two-dimensic.. I andel was made to allow for overlap of leaves from adjacent plants (as seen in aerial views of $c, r n$ and sorghum fields). However, no overlap was allowed between leaves from adjacent rows (Fig. 3.4). It was assumed in our analyses that the silage is not harvested until the grain has matured. This period of maturity corresponds to the period $t_{1}$ to $t_{2}$ in Fig. 3.3. According to descriptions of growth stages in corn by Hanaway ${ }^{206}$ and Norman, ${ }^{207}$ grain maturity orcurs at a time approximately equal to twice the time to maximum plant growth (and thus maximum surface area). Accordingly, the integral of plant surface area from $t_{0}$ to $t_{2}$ in Fig. 3.3 is 0.75 .

From Fig. 3.4, the fraction of total area cocupied by the silage at maturity is given by

$$
r^{m s}=\frac{r_{f}^{2}\left[\frac{4 \pi}{3}+\left(n_{r}-1\right) \frac{\sqrt{3}}{2}+\left(n_{r}-2\right) \frac{\pi}{3}\right] r_{n}}{\left[d_{r}\left(r_{n}-1\right)+2 r_{f}\right]\left[d_{p}\left(n_{r}+1\right)\right]} .
$$

The model constraints are

$$
\eta_{f}=d_{p} \leqslant \frac{d_{r}}{2}
$$

As the planted area becomes infinitely large, Eq. (16) approaches

$$
r^{m s}=\frac{r_{f}^{2}\left(\frac{\pi}{3}+\frac{\sqrt{3}}{2}\right)}{d_{r} \cdot d_{p}} .
$$

Since $d_{p}=r_{f}$. Eq. (18) becomes

$$
r^{m s}=\frac{d_{p}\left(\frac{\pi}{3}+\frac{\sqrt{3}}{2}\right)}{d r}
$$

At maximum silage density $\left(d,=2 d_{p}\right)$ Eq. (19) becomes a value of 0.96 . Correspondingly, the maximum average interception iraction is equal to $C .72$.

The average interception fraction was derived from average values of $d_{r}$ ano $d_{p}$ for corn and sorghum plantings. An average $d_{p}$ of $30.5 \mathrm{~cm}$ (12 inches) and $d_{r}$ of $99 \mathrm{~cm}$ (39 incires) was taken from Knot ${ }^{20 C}$ and Rutledge. ${ }^{208}$ Using these values, an interception fraction at maturity of 0.59 was determined from Eq. (19). This value yields an average interception fraction of 0.44 . 


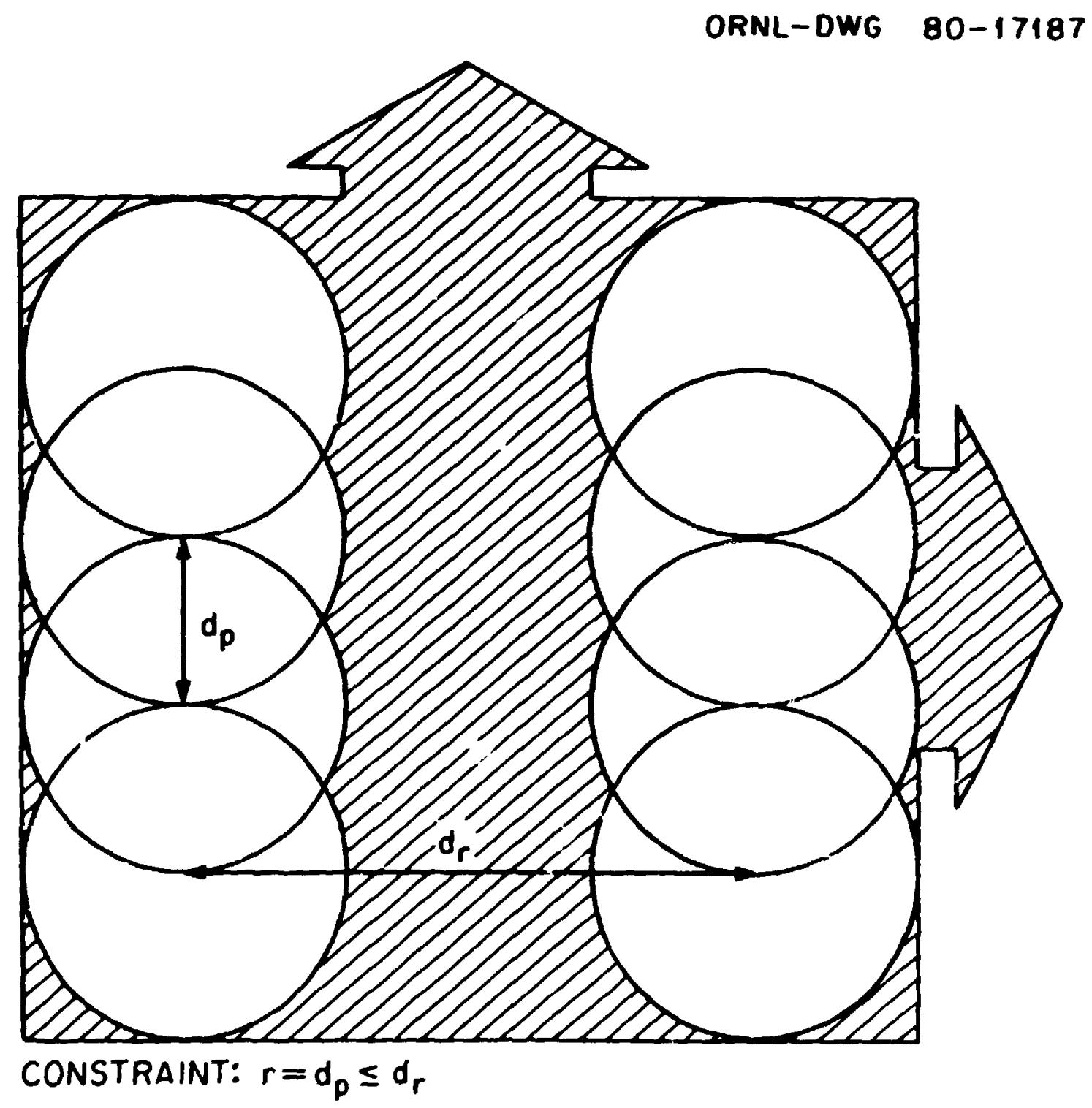

Figure 3.4. Model of field geometry of silage plant spacings. 


\subsection{Exposed Produce}

The exposed produce category includes 31 commercially important fruits and vegetables in the United States.' These produce may be broadly classified as noncitrus fruits, berries, and important field crops. Because of the diversity of growth forms in the exposed produce category, our analysis is based on five of the most important noncitrus fruits and field crops in the category-apples, snap beans, tomatoes, peaches, and cherries. For this analysis, importance is defined in terms of area - Jlanted (see Table 3.2).

For noncitrus fruits and tomatoes, as with leafy vegetables and silage, it is assumed that the fruits can be represented by circles on a two-dimensional basis. The interception fraction is calculated by determining the total fruit cross-sectional area per square meter which is given by

$$
r^{m f}=\frac{n \pi r_{f}^{2}}{l w},
$$

where

$$
\begin{aligned}
r_{f}^{m} & =\text { the interception fraction of the mature fruit, } \\
n & =\text { the number of fruit per square meter } \\
r_{f} & =\text { the radius of the fruit }(\mathrm{mm}) \\
l & =\text { the length of the unit area }(1000 \mathrm{~mm}), \text { and } \\
w & =\text { the width of the unit area }(1000 \mathrm{~mm}) .
\end{aligned}
$$

It is assumed that an average interception fraction over the lifetime of the fruit is provided for by the model of logistic growth and maturity used for silage. That is, half of the fruit's residence time in the tree or on the plant is assumed to be for growth and development, and one half of the time is assumed to be for maturing or ripening before harvest. Thus, Eq. (20) becomes

$$
r^{e f}=\frac{0.75 n \pi r_{f}^{2}}{l w} .
$$

where

$r^{e f}=$ average interception fraction for exposed fruit.

For snap beans the same approach as for round fruits is used, except that the effective surface aiea of a snap bean is modeled in two dimensions as a recentagle -a two dimensional view of a cylinder on its side. For mature snap beans

$$
r^{m s b}=\frac{n 2 r_{f} l_{f}}{l_{w}} .
$$

where

$$
l_{f}=\text { the length of the snap bean. }
$$

As with tree fruits and tomatoes, the average inteception fraction over the time in the field is 0.75 times the value of the mature interception fraction.

A search of the literature was performed to determine values of $n_{1} r_{f}, r_{1}$, and $l_{f}$ or collateral information from which to deduce them. Empirical measuren snts of $r_{f}$ and $r_{1}$ were combined with literature values to determine dofault values. Fruit weights were compared with estimated weights of spheres of water of the same radius to check default estimatis. Information from the 1974 


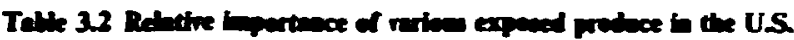

\begin{tabular}{|c|c|c|c|}
\hline Vequable & $\begin{array}{c}\text { Quantity planted } \\
\left(\mathbf{k m}^{2}\right)\end{array}$ & $\begin{array}{l}\text { Percent of } \\
\text { category }\end{array}$ & $\begin{array}{l}\text { Percent of sub- } \\
\text { category }\end{array}$ \\
\hline \multicolumn{4}{|c|}{ Non-citrus tree fruits } \\
\hline Apple & 1960 & 27.2 & 57.3 \\
\hline Apricot & 6.00 & 0.1 & 0.2 \\
\hline Cheary & 429 & 6.0 & 12.5 \\
\hline Date & 0.101 & $\leqslant 0.1$ & $\leqslant 0.1$ \\
\hline Fis & 0.0647 & $\$ 0.1$ & $\leqslant 0.1$ \\
\hline Mango & 4.86 & $\leqslant 0 . i$ & n.i \\
\hline Nectarine & 3.63 & $\leqslant 0.1$ & 0.1 \\
\hline Peach & 644 & 9.0 & 18.8 \\
\hline Pear & 229 & 3.2 & 6.7 \\
\hline Hor Pepper & 48.2 & 0.7 & 1.4 \\
\hline Plum & 36.6 & 0.5 & I.I \\
\hline Prone & 61.4 & 0.9 & 1.8 \\
\hline Total & 3423 & 47.6 & \\
\hline \multicolumn{4}{|l|}{ Betries a vine fruits } \\
\hline Blactberry & 94.5 & 1.3 & 10.6 \\
\hline B'ueberry & 154 & 2.1 & 17.3 \\
\hline Boysenberny & 4.75 & $\leqslant 0.1$ & 0.5 \\
\hline Cranterry & 91.2 & :.3 & 10.2 \\
\hline Currant & 1.12 & $\$ 0.1$ & 0.1 \\
\hline Gooseberry & 0.348 & $<0.1$ & $<0.1$ \\
\hline Grape & 411 & 5.7 & 46.1 \\
\hline Pimento & 1.64 & $\leqslant 0.1$ & 0.2 \\
\hline Rasberty & 29.9 & 0.4 & 3.4 \\
\hline Strawberry & 104 & 1.5 & 11.7 \\
\hline Total & 892 & 12.4 & \\
\hline \multicolumn{4}{|l|}{ Field crops } \\
\hline Asparagus & 269 & 3.7 & 9.3 \\
\hline Cucumber & 380 & 5.3 & 13.2 \\
\hline Egsplant & 16.0 & 0.2 & 7.6 \\
\hline Okra & 16.7 & 0.2 & 0.6 \\
\hline Rhubarb & 4.80 & 0.1 & 0.2 \\
\hline Sweet pepper & Iss & 2.2 & 5.4 \\
\hline Snap bean & $12 \leq 0$ & 17.4 & 43.4 \\
\hline Squash & 133 & 1.9 & 4.6 \\
\hline Tomato & 655 & 9.1 & 22.7 \\
\hline Total & 2880 & 4.0 & \\
\hline
\end{tabular}


Census of Agriculture ${ }^{2 n g}$ was used to calculate values of $\boldsymbol{n}$ for each fruit or vegetable. Estimated interception fractions for mature apples, snap beans, tomatoes, peaches, and cherries were calculated according to Eqs. (21) and (22) and weighted to derive a default interception fraction estimate of 0.052 for exposed produce (Table 3.3). Surprisingly, the values for the noncitrus fruits (apples, peaches, and cherries) are within approximately a factor of 1.3 of each other, and the values for the field crops are approximately equal to each other.

\subsection{Correlation Between Interception Fraction and Standias Crop Biomass}

As mentioned in Sect. 3.1, Chamberlain found a relationship between standing crop biomass or productivity and the interception fraction for pasture grasses. This relationship [Eq. (10)] is used in the TERRA code to calculate the interception fraction for pasture grasses and by: The analyses of intercaption fraction for leafy vegetables, silage, and exposed produce (Sect. 3.2, 3.3, and 3.4, respectively) are based on generalized or average crops. Use of the interception fraction values for these categories as default estimates independent of complementary values of productivity $\left(Y_{i}\right)$ could result in unreasonable overestimates of surface plant concentrations, $c^{p s}$, because

$$
c^{p s} \propto \frac{r^{i}}{Y_{i}}
$$

That is, low values of $Y_{i}$ coupled with values of $r^{i}$ for average crops (represented by average $Y_{i}$ values) could produce high values of $r^{j} / Y_{i}$. As $Y_{i}$ approaches zero, the $r^{i} / Y_{i}$ ratio approaches lfinity.

Figure 3.3 indicates that leaf (or edible produce) surface area increases with time as the plant $\mathrm{g}$ ows. Clearly, since intercertion fraction is proportional to surface area, the interception fraction for very young plants is less than that for mature plants, and $r^{i}$ is a function of $Y_{i}$ for the individual plant. However, it is not clear whether $r^{i}$ is a function of $Y_{i}$ for the mature plant in the field. Figure 3.5 illustrates the problem.

Figure 3.5 presents three plots of equal area with hypotietical crops represented by spheres. The relative ordering of productivity is A > B > C. In plots A and B planting geometry (packing) has been maximized (without staggering) by planting individual plants within $\triangle$ row and rows of plants adjacent to one another. The difference between the two crops is that the crop in plot $A$ is of greater size (radius, $r_{f}$ ) than the crop in plot $B$. In plots $B$ and $C$ the crop radii are equal, but planting geometry is less efficient in plot $C$. In all plots the interception characteristics of the individual crops are equal.

It can be shown mathematically that the total surface area of crops in plots $A$ and $B$ are equal. That is, the decrease in surface area per plant as plant radius is reduced is exactly counterbalanced by the increase in number of plants per unit area. Therefore, the interception fraction for crops $A$ and $B$ should be the same. The productivity, however, is dependent on the volume multiplied by the number of plants per unit area. Since volume is proportinnal to the cube of plant radius, the productivity of plot $A$ is greater than that of plot B. In this example, regardless of plant size the interception fraction is a constant value which is independent of productivity.

In plots $B$ and $C$ the interception fraction is a function of productivity. The surface area per plant is constant, and as planting geometry becomes less efficient, both productivity and interception fraction decrease porportionately.

The above examples illustrate that interception fraction for nongrasslike plants may or may not be a function of prociuctivity, depending on whether a difference in productivity reflects a difference in plant size or a difference in plant spacings. This dilemma has been addressed in TERR 4. As mentioned in the introduction to this report (and as will be discussed later), the TERRA code allows input of location-specific agricultural parameters, including location-specific productivity 
Talk 3.3. Valus of interception finction for the inportan creps in the exposed produce catepory

\begin{tabular}{|c|c|c|c|c|c|c|}
\hline Produce & $r_{1}$ & rs & $n$ & $I_{f}$ & $\begin{array}{l}\text { Interception } \\
\text { fraction }\end{array}$ & $\begin{array}{l}\text { Weighting } \\
\text { factor }\end{array}$ \\
\hline Apples & $4.2 \mathrm{~m}$ & $38 \mathrm{~mm}$ & $10 / \mathrm{m}^{2}$ & & $0.034^{\circ}$ & 0.29 \\
\hline Snap beans & & $4 \mathrm{~mm}$ & $220 / \mathrm{m}^{2}$ & $55 \mathrm{~mm}$ & $0.073^{4}$ & 0.21 \\
\hline Tomatoes & & $38 \mathrm{~mm}$ & $20 / \mathrm{m}^{2}$ & & $0.068^{\circ}$ & 0.29 \\
\hline Peaches & $1.8 \mathrm{~m}$ & $31.8 \mathrm{~mm}$ & $15 / \mathrm{m}^{2}$ & & $0.036^{b}$ & 0.14 \\
\hline Cherries & $5.3 \mathrm{~m}$ & $8.5 \mathrm{~mm}$ & $160 / \mathrm{m}^{2}$ & & $0.027^{b}$ & 0.07 \\
\hline Weighted average & & & & & 0.052 & \\
\hline
\end{tabular}

- Based on values in Table 3.2

Eq.(21).

$0.75 \times$ Eq. (22).

estimates. In TERRA the location-specific productivity estimate determines a corresponding interception fraction. In other words, it has been assumed that location-specific variations in productivity are more reflective of the differences in plots $B$ and $C$ than in $A$ and $B$.

Since observed relationships between interception fraction and productivity are unavailable for nongrasslike plants, the relationship shown in Fig. 3.1 has been assumed to apply to nongrasslike plants also. The coefficients of the exponential terms for exposed produce, leafy vegetables, and silage have been determined by fitting an exponential regression equation, forced through the point $\left[\left(1-r^{i}=0\right),\left(Y_{i}=0\right)\right]$ to the points representing the United States average productivity-average interception fraction and maximum observed productivity-theoretical maximum interception fraction. The average and maximum productivities are taken from Apper icies $B$ and $C$ of reference 7. The resulting relationships are (Fig. 3.6),

$$
\begin{gathered}
r^{e}=1-\exp \left(-0.0324 Y_{e}\right), \\
r^{l v}=1-\exp \left(-0.0846 Y_{l v}\right), \text { and } \\
r^{\prime}=1-\exp \left(-0.769 Y_{s}\right),
\end{gathered}
$$

where the superscripts and subscripts "e," $" / v, "$ and $" s^{n}$ are for exposed produce, leafy vegetables, and silage, respectively.

Although this approach is at best ad hoc, the consequences of setting the interception fraction at a constant value and allowing productivity to vary over its reported range are serious. Figure 3.7 compares the method of using Eqs. (24)-(26), case $A$, and using a singic interception fraction, case $B$, over the observed productivity range shown at the bottom of the figur : At the extremes of the ranges, especially at productivities les' than $0.1 \mathrm{~kg} / \mathrm{m}^{2}$, the ratio of $r^{\prime} / Y_{i}$ is particularly suspect. 
ORNL-DWG 81-17780

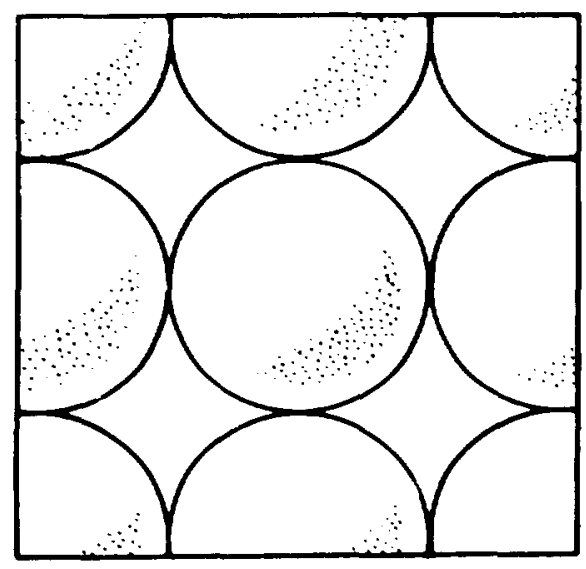

PLOT A

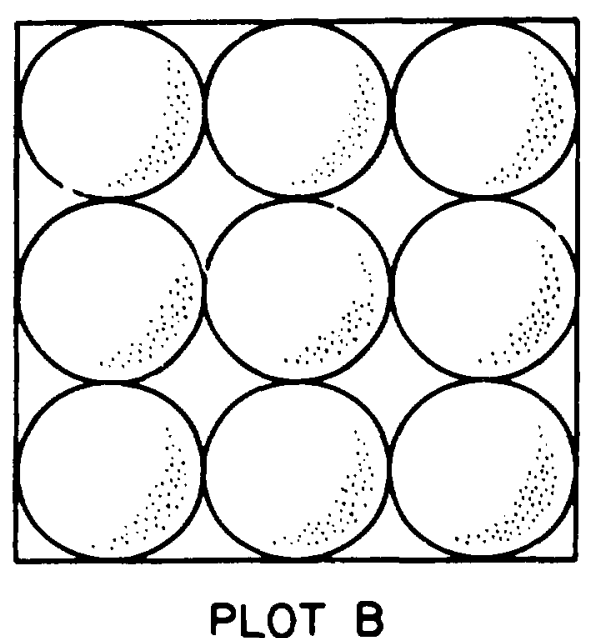

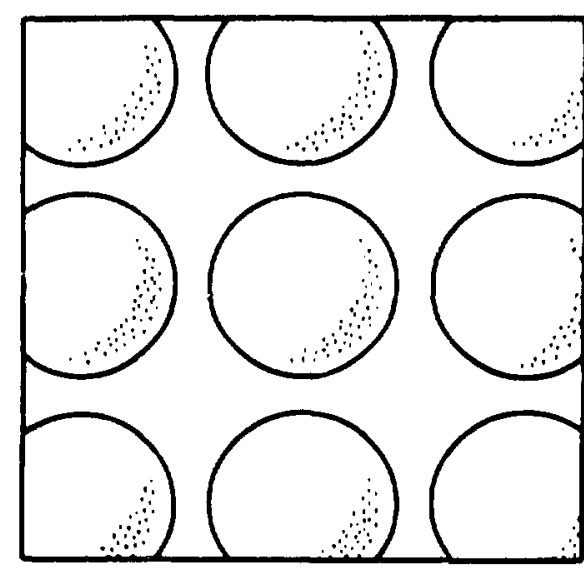

PLOT C

Figure 3.5. Three plots of equal area containing hypothetical crops of varying size and planting density. 


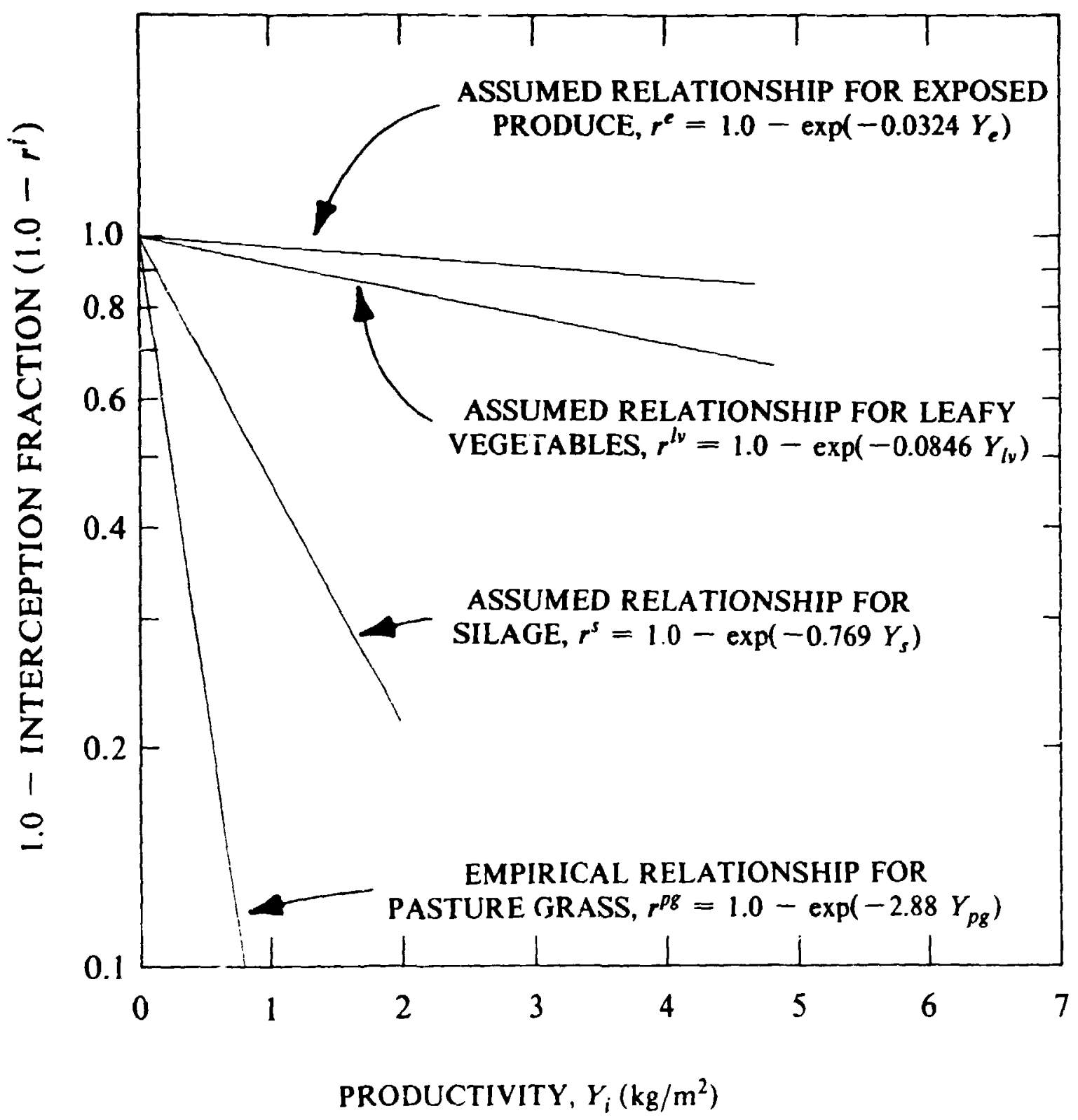

Figure 3.6. Assumed relationships between interception fraction and fresh weight productivity for exposed produce and leafy vegetables and between interception fraction and dry weight productivity for silage. 


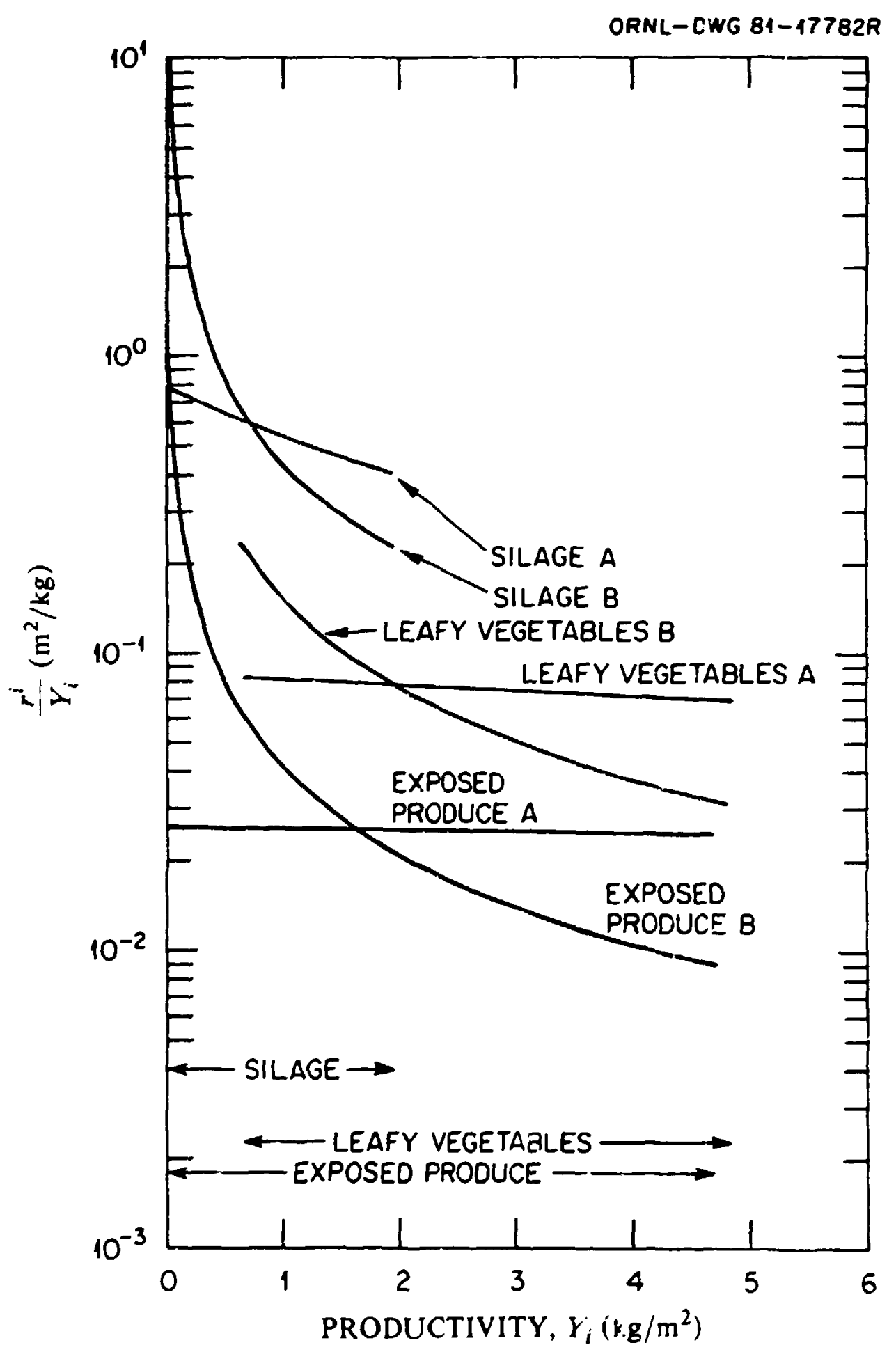

Figure 3.7. The ratio of interception fraction to productivity $\left(r^{i} / Y_{i}\right)$ as a function of interception frastion dependent on (A) and independent of (B) productivity of silage, expose. produce. and leafy vegetables. The ranges of produstivity found in the U. S., hased on reference ${ }^{-}$. are show, $n$ at the hottorn of the figure. 


\section{SITESPECTFIC PARAMETERS}

For a given location, as specified by a longitude-latitude coordinate $(X, Y)$, TERRA simulates terrestrial transport by incorporating 21 site-sperific agricultural and climatological parameters into its calculations. These parameters are available on a $1 / 2 \times 1 / 2$ degree longitude-latitude basis and are part of a data base, called SITE, which includes 36 agricultural, climatological, dernographic, and other parameters. The remaining 15 parameters not used by the TERRA code are either used by or are available for use by the other codes of the CRRIS system. The agricultural parameters were derived from the report by Shor, Baes, and Sharp, ${ }^{7}$ which analyzes the 1974 Census of Agriculture. $^{209}$ Climatolcgical parameters were interpolated from long-term averages recorded by United States weather stations as reported in several sources. ${ }^{210-212}$ Demographic parameters describing the fraction of the population in various urbanization categories were available on a half-degree cell basis from the analyses of the 1970 U.S. Census by Haaland and Heath. 213,214 Estimates of population were taken from the 1980 U.S. Census.

The half-degree cell grid was preferred over the United States county resolution because of the variation in county area (Fig. 4.1). Bristol county, Rhode Island, the smallest county, is $64.5 \mathrm{~km}^{2}$, and San Bernardino county, California, the largest, is $52,100 \mathrm{~km}^{2}$, a range of over 800 fold. Halfdegree cells provide a more uniform grid (Fig. 4.2). The areas of the cells vary from $2,030 \mathrm{~km}^{2}$ at $49^{\circ} \mathrm{N}$ latitude to $2,810 \mathrm{~km}^{2}$ at $25^{\circ} \mathrm{N}$ latitude-a variation of less than $30 \%$ over the conterminous United States. Half-degree cell areas are comparable to th - areas of counties in northeast Texas (Fig. 4.1).

Each SITE cell is defined by an identification number, such that

$$
i=2[(X-66.5)+116(Y-24.5)] \text {, }
$$

where

$$
\begin{aligned}
& X=\text { the longitude (in degrees } W \text { ) of the southeast corner of the cell and } \\
& Y=\text { the latitude (in degrees } N \text { ) of the southcast corner of the cell. }
\end{aligned}
$$

Equation (27) is based on the reference point $66.5^{\circ} \mathrm{W}, 24.5^{\circ} \mathrm{N}$ and the fact that the conterminous United States lies between $66.5^{\circ} \mathrm{W}$ and $125^{\circ} \mathrm{W}$. Cone hundred and sixteen half-degree cells define this span, horizontally.

Two methods were needed to convert county data to half-degree cell data because some data were stored per unit area and others were stored as a total count. The data stored as a total count was distributed according to the fraction of each cointy included in the individual cell (method A). The data stored per unit area was distributed accordj'ig to the fraction of each cell included in the appropriate counties (method B). Bc th of these transformation fractions were determined for each SITE sell and each United States col. 'y using the IUCALC program which calculates polygonpolygon intersections, unions, and relativ. differences. ${ }^{215}$ Table 4.1 shows the derivation of the number of cattle and calves, $n_{c c}$, and produciivity of protected produce, $Y_{p}$, for SITE cell \#32., which has coordinates at the southeast corner of $84.5^{\circ} \mathrm{W}, 38.5^{\circ} \mathrm{N}$. Three counties in Indiana and nine counties in Kentucky overlap this cell.

Method $\mathbf{A}$ is used for all parameters representing discrete entities, e.g., head of livestock, numbers of people, kilograms of produce. The assumption in effect is that number distribution is uniform throughout the county. The proportion of the county total within the cell is proportional to the area of the county within the cell. Method $B$ is used for all parameters representing densities and representative averages, e.g., productivities and climatic variables. The effective assumption here is that the contribution from the county to the cell is proportional to the fraction of the cell which coincides with the county. 


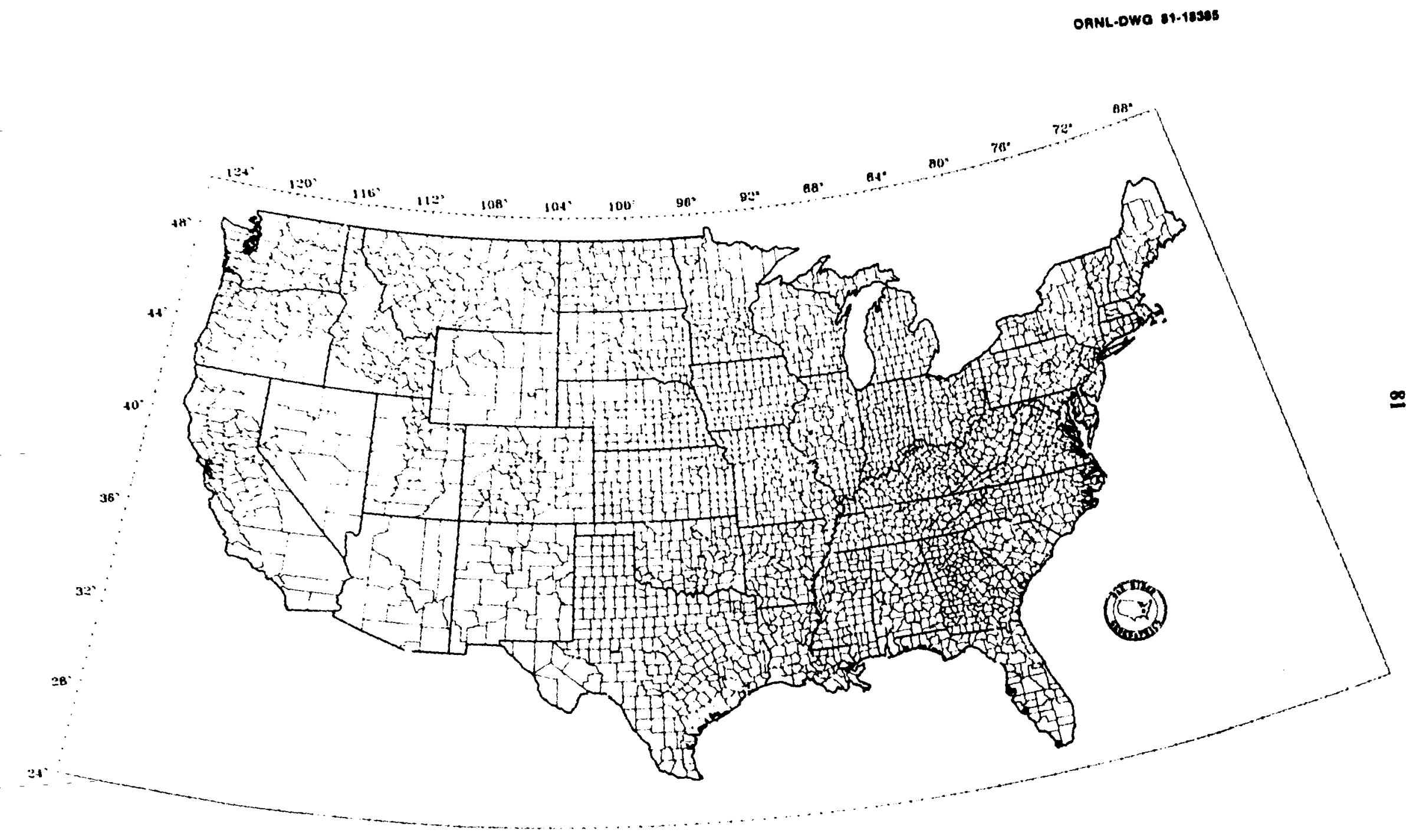

Figure 4.1. Map of the conterminous United States showing county delineations. 


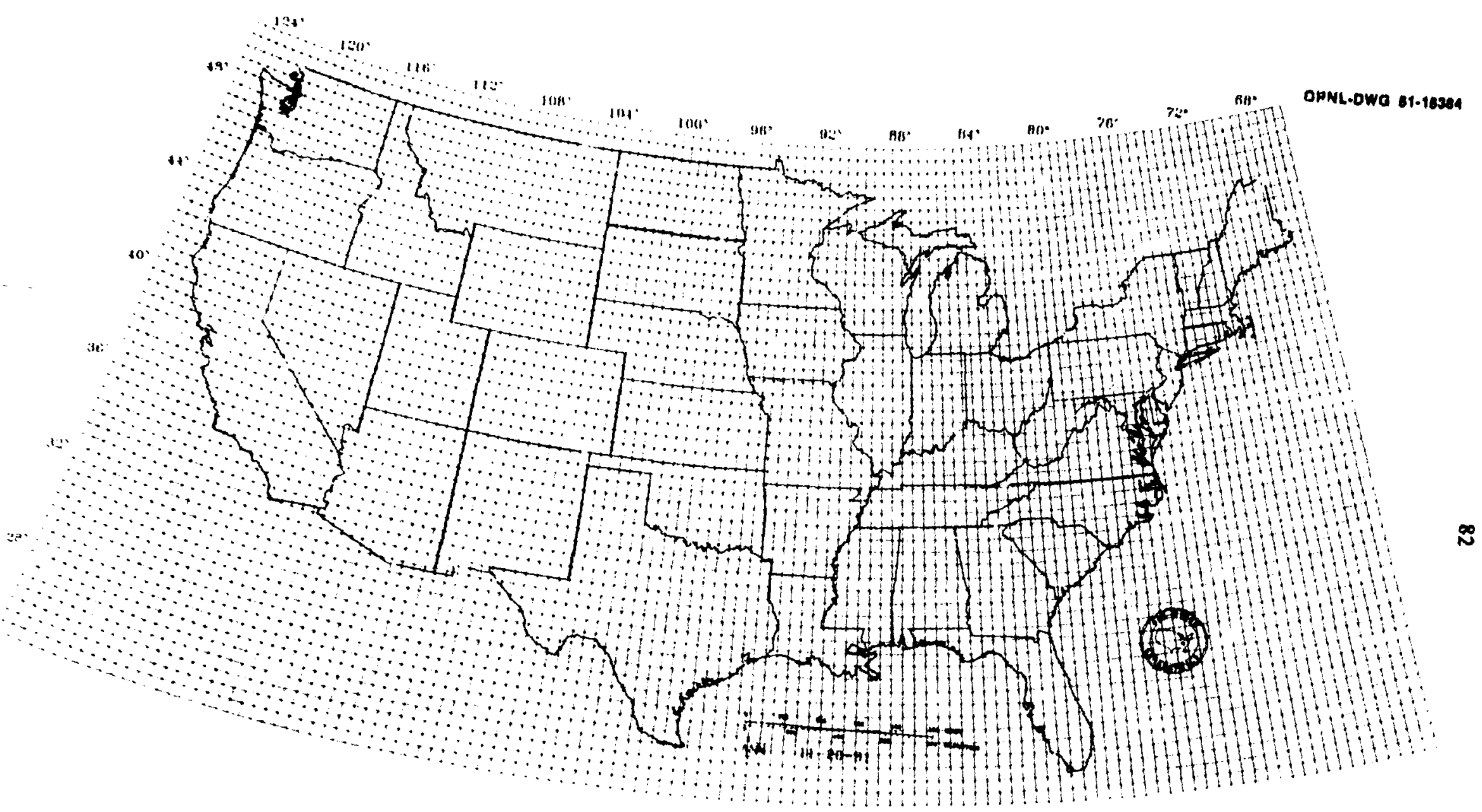

Figure 4.2. Map of the conterminous indicated. 


\begin{tabular}{|c|c|c|c|c|}
\hline \multirow{2}{*}{ County, state } & \multicolumn{2}{|c|}{ _- Transfer parameter } & \multirow{2}{*}{${ }_{\text {(bead) }}^{\varepsilon}$} & \multirow{2}{*}{$\left(\mathrm{k} / \mathrm{m}^{2}\right)$} \\
\hline & Method A & Method B & & \\
\hline Dearborn, In & $3.60 \times 10^{-3}$ & $1.25 \times 10^{-3}$ & 17228 & 1.52 \\
\hline Ohio, In & $5.59 \times 10^{-1}$ & $5.51 \times 10^{-2}$ & 7111 & 0.60 \\
\hline Switzerland, In & $3.74 \times 10^{-1}$ & $9.38 \times 10^{-2}$ & 12863 & 0.60 \\
\hline Boosne, $\mathrm{Ky}$ & $6.18 \times 10^{-1}$ & $1.75 \times 10^{-1}$ & 20926 & 1.42 \\
\hline Carroll, Ky & $8.45 \times 10^{-2}$ & $1.25 \times 10^{-2}$ & 11370 & 0.40 \\
\hline Gallation, $\mathbf{K} \mathbf{y}$ & $9.71 \times 10^{-1}$ & i $10: 10^{-1}$ & 7512 & 212 \\
\hline Grant, Ky & $9.31 \times 10^{-1}$ & $263 \times 10^{-1}$ & 22148 & 0.61 \\
\hline Harrison, $\mathrm{Ky}$ & $9.00 \times 10^{-4}$ & $3.14 \times 10^{-4}$ & 44345 & 1.22 \\
\hline Henry, Ky & $260 \times 10^{-3}$ & $8.52 \times 10^{-4}$ & 36319 & 0.78 \\
\hline Kenton, Ky & $4.74 \times 10^{-1}$ & $8.88 \times 10^{-2}$ & 10633 & 1.18 \\
\hline Owen, Ky & $4.91 \times 10^{-1}$ & $1.96 \times 10^{-1}$ & 26555 & 0.75 \\
\hline Pendileton. Ky & $1.32 \times 10^{-2}$ & $4.18 \times 10^{-3}$ & 24125 & 0.82 \\
\hline Total or average & & & 69190 & 0.99 \\
\hline
\end{tabular}

-All counties which share common area with SITE cell 13284 which has coordinates of southeast corner of $84.5^{\circ} \mathrm{W}$, 38.5 $5^{\circ} \mathrm{N}$.

"For method A parameter is fraction of each county within the cell. For methud B parameter is fraction of cell within each county.

'Number of caltic and calves.

¿Yield of procected produce.

Climatological parameters were determined on a half degree cell basis by selecting the three United States weather stations nearest the centroid of the cell. The three parameter values for the weather stations were weighted according to distance from the weather station to the cell centroid such that

$$
p_{c}=w_{1} p_{1}+w_{2} p_{2}+w_{3} p_{3}
$$

where

$$
\begin{aligned}
& p_{c}=\begin{array}{c}
\text { the parameter value for the half degree cell, } \\
w_{1}, w_{2}, w_{3}= \\
\text { the weighting factors for the first, second, and third nearest weather } \\
\text { stations, respectively, and }
\end{array} \\
& p_{1}, p_{2}, p_{3}=\quad \begin{array}{l}
\text { the parameter values for the first, second, and third nearest weather } \\
\text { stations, rsspectively. }
\end{array}
\end{aligned}
$$

The weighting factors were defined such that

$$
\begin{gathered}
w_{1}+w_{2}+w_{3}=1 \text { and } \\
w=\frac{1}{d_{1}},
\end{gathered}
$$


where

$d_{l}=$ the linear aistance between the weather station and the centroid of the cell.

The linear distance between weather stations and the centroid of the cell was determined by

$$
\begin{aligned}
& \frac{\text { kilometers }}{1.0^{\circ} \text { longitude }}=A \cos Y+B+C Y+D Y^{2} \text { and } \\
& \frac{\text { kilometers }}{1.0^{\circ} \text { latitude }}=\frac{F q \cdot(31)}{\cos Y}+E+F Y+G Y^{2}
\end{aligned}
$$

where

$$
\begin{array}{ll}
A= & 1.113 \times 10^{2}, \\
B= & -9.855 \times 10^{-2}, \\
C= & 7.789 \times 10^{-3} \\
D= & -5.894 \times 10^{-5} \\
E= & -8.570 \times 10^{-1}, \\
F= & 7.927 \times 10^{-3}, \text { and } \\
G= & 5.888 \times 10^{-5} .
\end{array}
$$

Table 4.2 shows example derivations of cell-averaged values of frost-free days from values from the three nearest United States weather stations.

\subsection{Agricultural Parameters}

The SITE data base contains 21 parameters describing location-specific agricultural practice. 14 of which are user by TERRA in simulating terrestrial transport of radionuclides. In addition, the climatic parameter, number of frost-free days, is used to estimate the number of harvests of hay and grazings of pasture by cattle. These parameters are described in detail in the report by Shor, Baes, and Sharp. ${ }^{7}$ It is beyond the scope of this report to detail their derivation, but a brief description of their use in TERRA follows.

As discussed in Sect. 3., atmospheric deposition on edible portions of food and feed crops is inversely proportional to standing crop biomass. The best estimate of standing crop biomass at harvest is given by the productivity, defined as

$$
Y_{i}=\frac{P_{h i}}{A_{h i}}
$$

where

$$
\begin{aligned}
& Y_{i}=\text { the productivity (yield) of crop } i\left(\mathrm{~kg} / \mathrm{m}^{2}\right) \\
& P_{h i}=\text { the harvest yield (production) of crop } i(\mathrm{~kg}) \text { pcr harvest, and } \\
& A_{h i}=\text { the area planted to crop } i \text { which is harvested or harvest area }\left(\mathrm{m}^{2}\right)
\end{aligned}
$$

For leafy vegetables, exposed and protected produce, grains, and silage, harvest yields and areas were obtained directly from the 1974 Census of Agriculture. However, for hay and pasture only, annua! yields (summed over all harvests) and areas allocated for hay and pasture (not nocessarily 


\begin{tabular}{|c|c|c|c|c|c|c|c|}
\hline \multirow{2}{*}{ Cens: } & \multirow{2}{*}{ 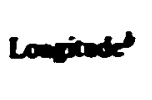 } & \multirow{2}{*}{ Letiat } & \multirow{2}{*}{ Stutions } & \multicolumn{3}{|c|}{ Weidwiog factors } & \multirow{2}{*}{$\begin{array}{c}\text { Froctifex } \\
\text { dess }\end{array}$} \\
\hline & & & & $\omega_{1}$ & $w_{2}$ & $w_{3}$ & \\
\hline 3615 & 760 & $\infty$ & $\mathbf{A} \mathbf{A} \mathbf{C}$ & 0.452 & 0.257 & 0.251 & 203 \\
\hline 3616 & 75.5 & $\infty 0$ & $\mathbf{A} \mathbf{F}, \mathbf{E}$ & asse & ans & 0067 & 201 \\
\hline 3617 & $\pi 0$ & $\infty 0$ & B, F.E & a.612 & 0.225 & a.163 & 201 \\
\hline 3618 & $\pi 5$ & 40.0 & A, F.E & 0.436 & 0.342 & 0.222 & 200 \\
\hline 3731 & 760 & $\infty$ & A RD & 0.372 & 0.334 & 0.294 & 185 \\
\hline 3732 & 765 & $\cos$ & RAD & 045 & 0.262 & 0.249 & 189 \\
\hline 3733 & 7.0 & 405 & B, F, D & 0.525 & 0.241 & 0.234 & 189 \\
\hline 3247 & 76.0 & 41.0 & D. A, B & 0.508 & 0279 & 0.213 & 181 \\
\hline
\end{tabular}

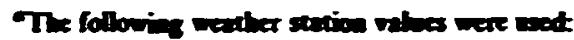

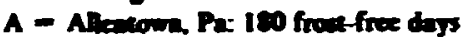

B - Harridure Pa 2Jl frear-free dys

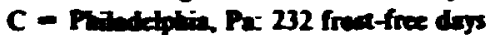

D - Sormener Pa: 174 froatice dess

E - Balcienore. Md: 234 froetfree days

F - Froderich, Md: 176 froct-free days

Soulvear coriver of cell

Firs, second, and thind nearax veather station, respecivehy.

Givia by Eqa (30) and (31).

areas actually harvested) were given or derived frem census information. Thus, for hay and pasture Shor, Bacs, and Sharp ${ }^{7}$ calculated "areal yields" defined by

$$
Y_{i}=\frac{P_{e}}{A_{i}}
$$

where

$r_{i}^{*}=$ the areal yield of crop $i\left(\mathrm{~kg} / \mathrm{yr} / \mathrm{m}^{2}\right)$,

$P_{a j}=$ the annual yield of crop $i\left(\mathrm{~kg}_{\mathrm{g}} / \mathrm{yr}\right)$, and

$A_{i}=$ the inventory area for crop $i\left(\mathrm{~m}^{2}\right)$.

The sum of all harvest yields (production) and productivity estimates for leafy vegetables (Figs. 4.3 and 4.4), exposed prizduce (Figs. 4.5 and 4.6), protected, roduce (Figs. 4.7 and 4.8), grain for food (Figs. 4.9 and 4.10), g.ain for foed (Figs. 4.11 and 4.12), and silage (Figs. 4.13 and 4.14) ate included in the SITE data base. Also included are the annual yield (production) of hay (Fig. 4.15) and areal yield estimate for hay (Fig. 4.16). The areal yield of pasture extimate is not in aluded in the SITE data base, but is calculated in TERRA from information contained in SITE (as discussed below). The productivity estimates for hay and pasture are calculated by dividing areal yields by the estimated numbers of hay harvests and successive pasture grazings by cattle. respectively.

Number of harvests per year for hay is initially estimated oy

$$
h_{k}=\frac{d_{/ f}}{60 \text { days }} .
$$




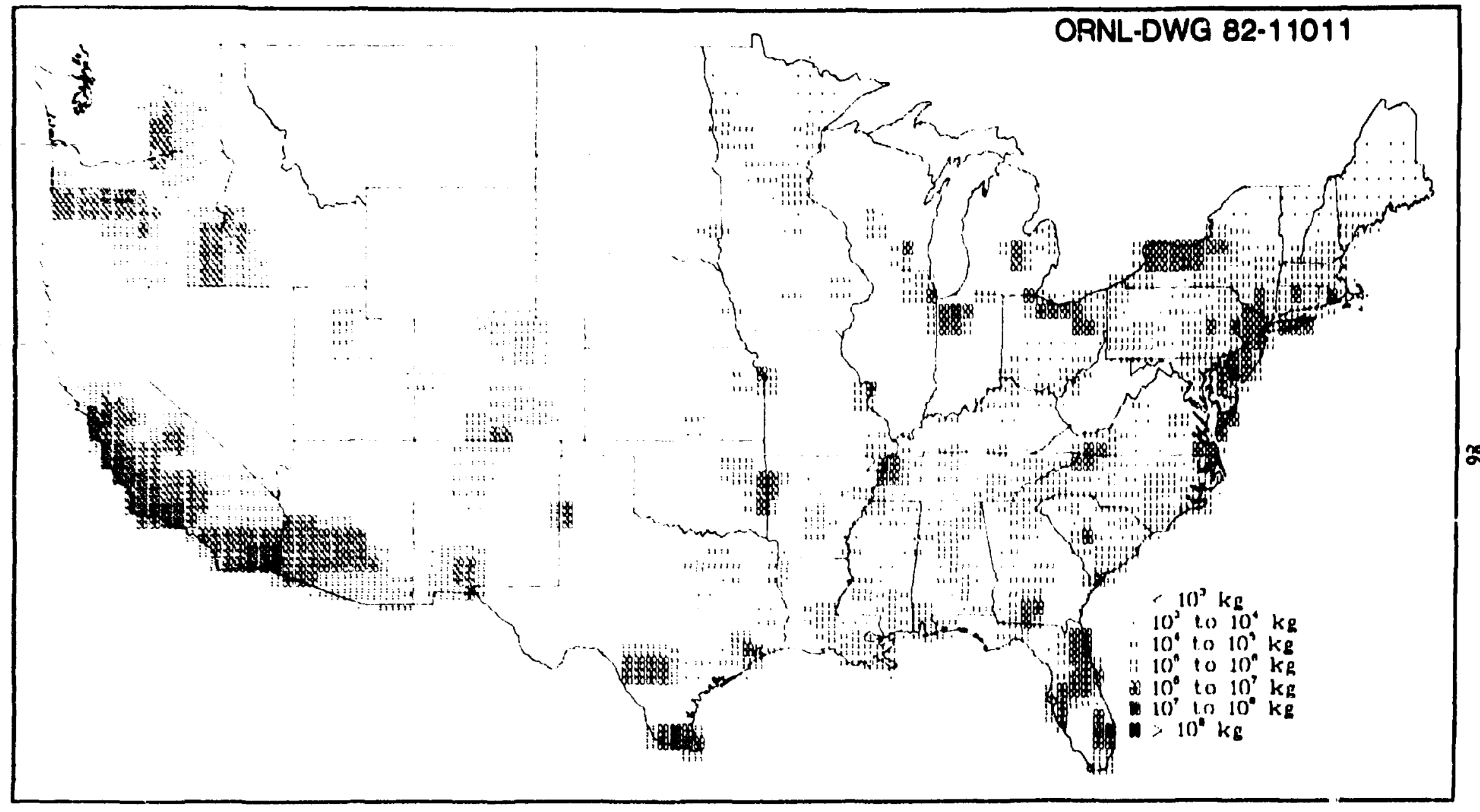

Figure 4.3. Geographic distribution of SITE parameter leafy vegetable production, $P_{1}$. 


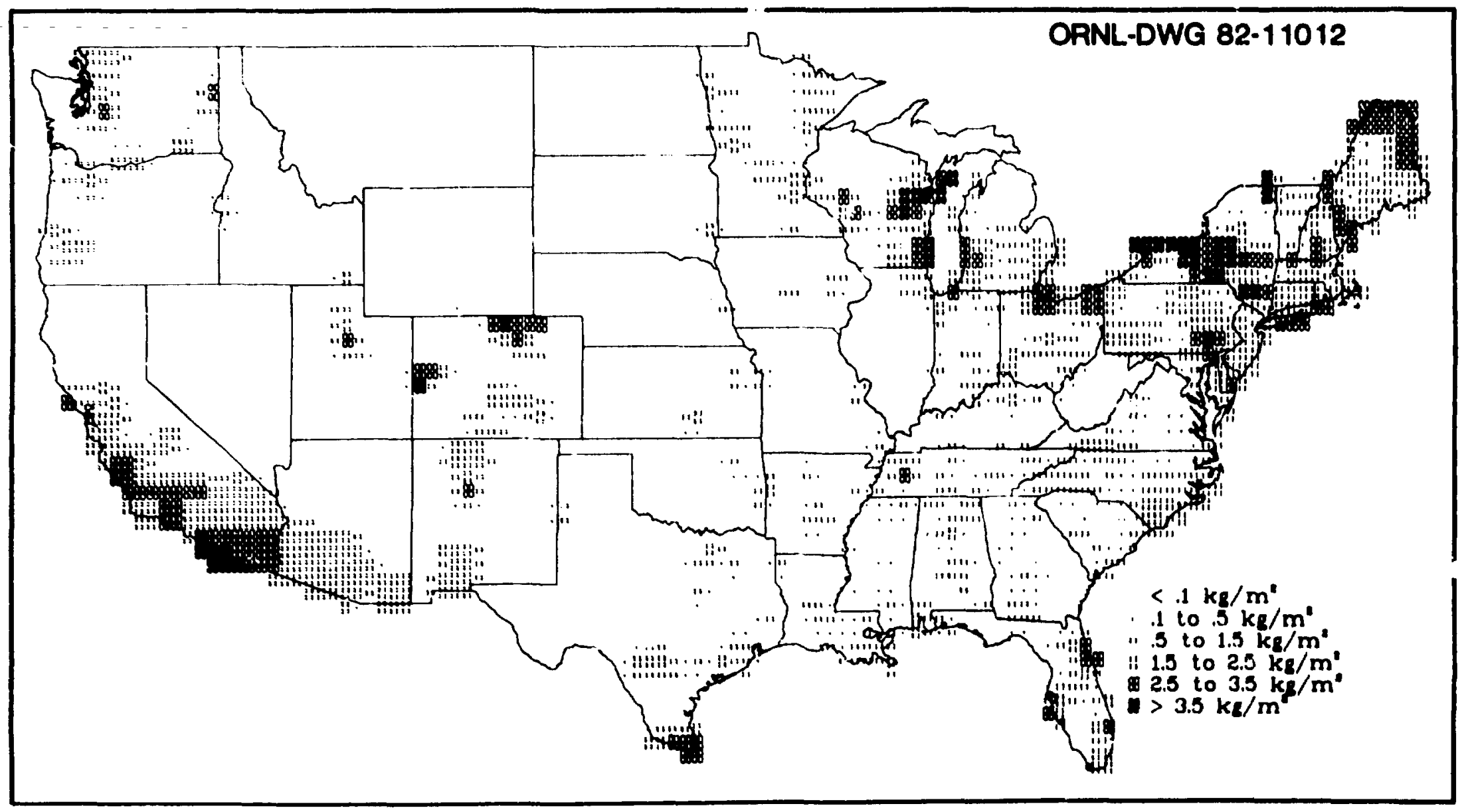

Figure 4.4. Geographic distribution of SITE pazameter leafy vegetable productivity, $Y_{l v}$. 


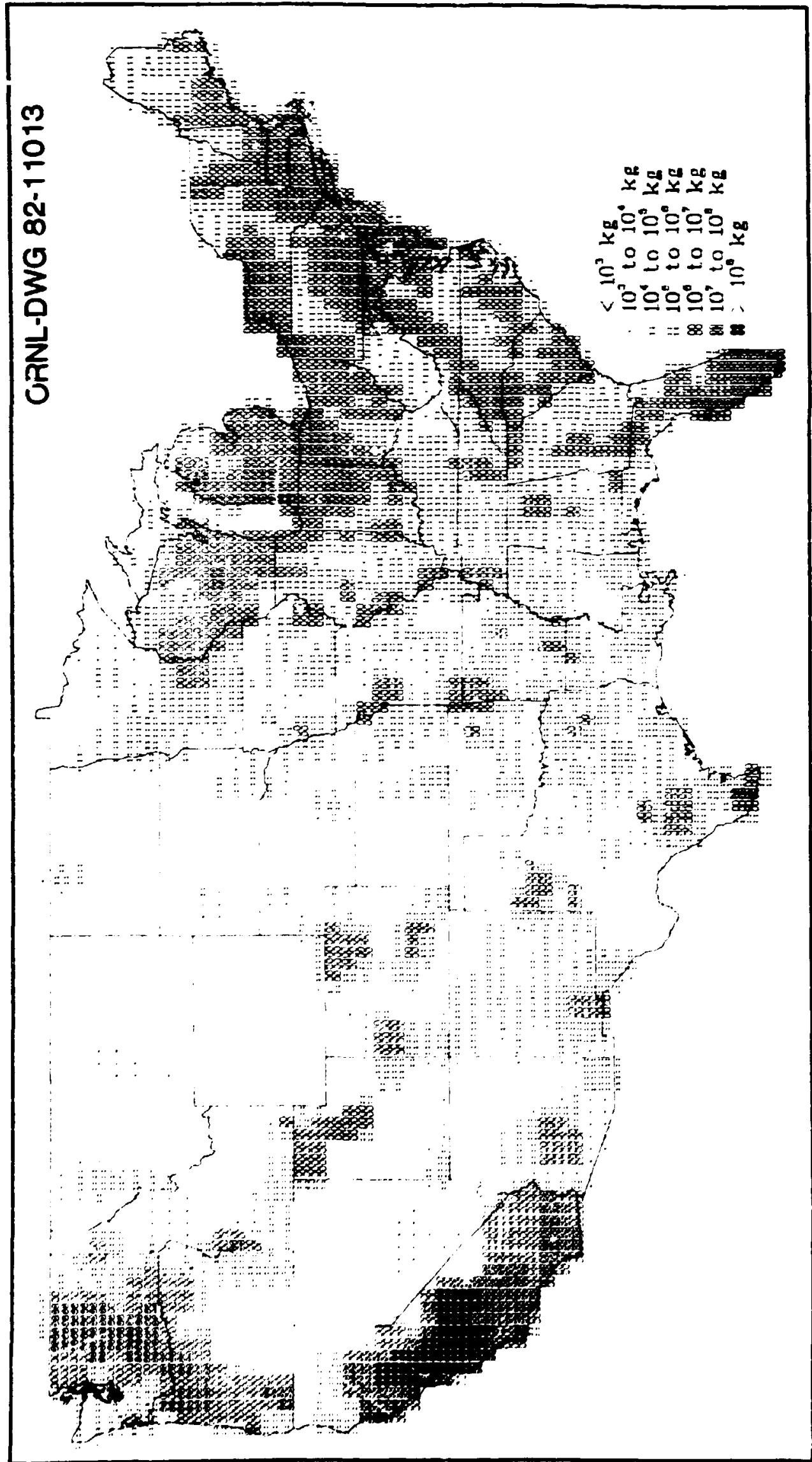

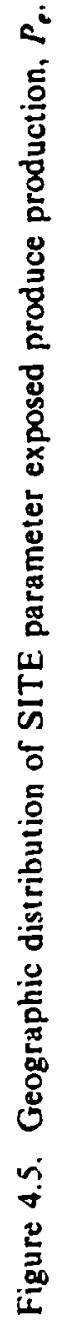




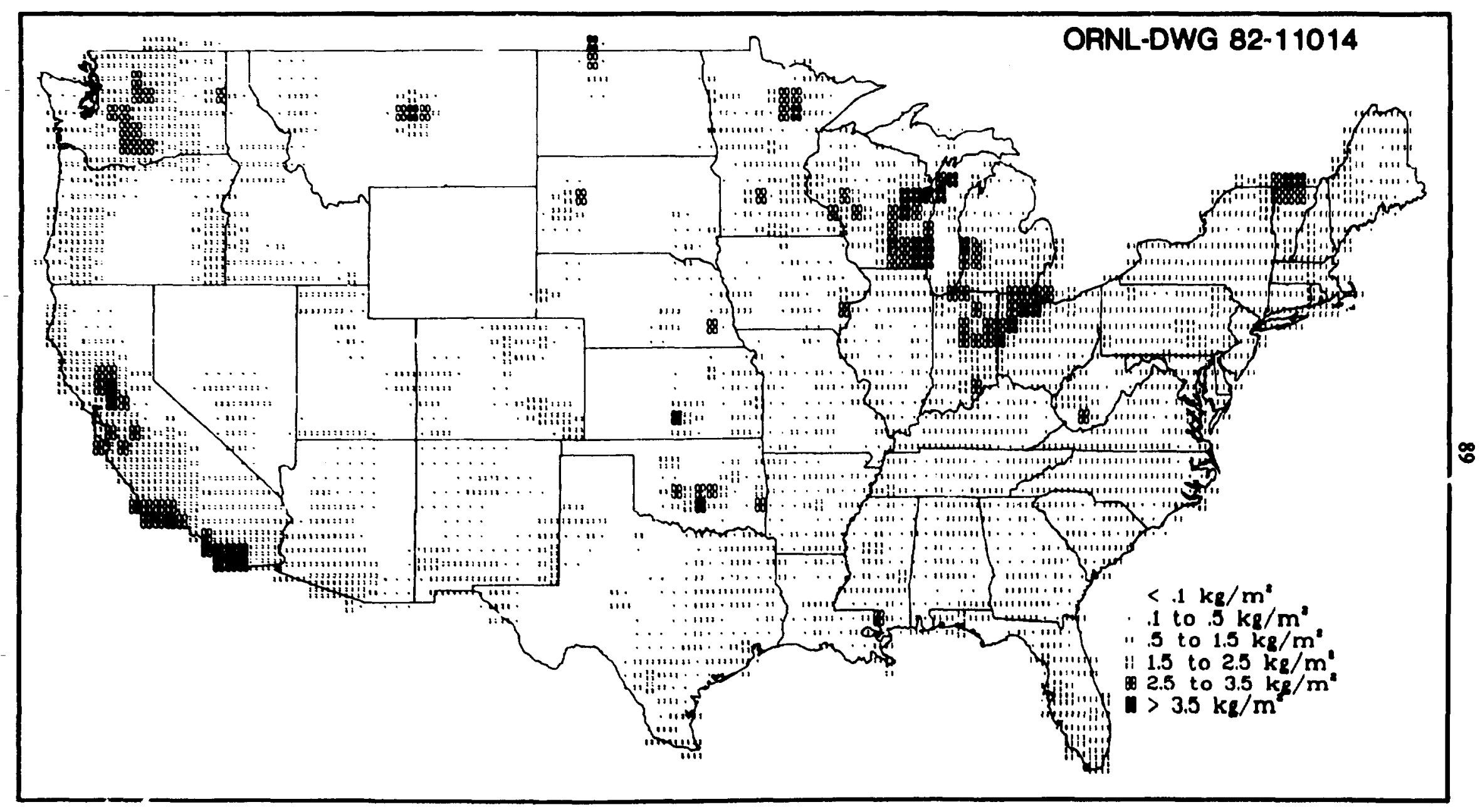

Figure 4.6. Geographic distribution of SITE parameter exposed produce productivity, $Y_{\text {e. }}$ 


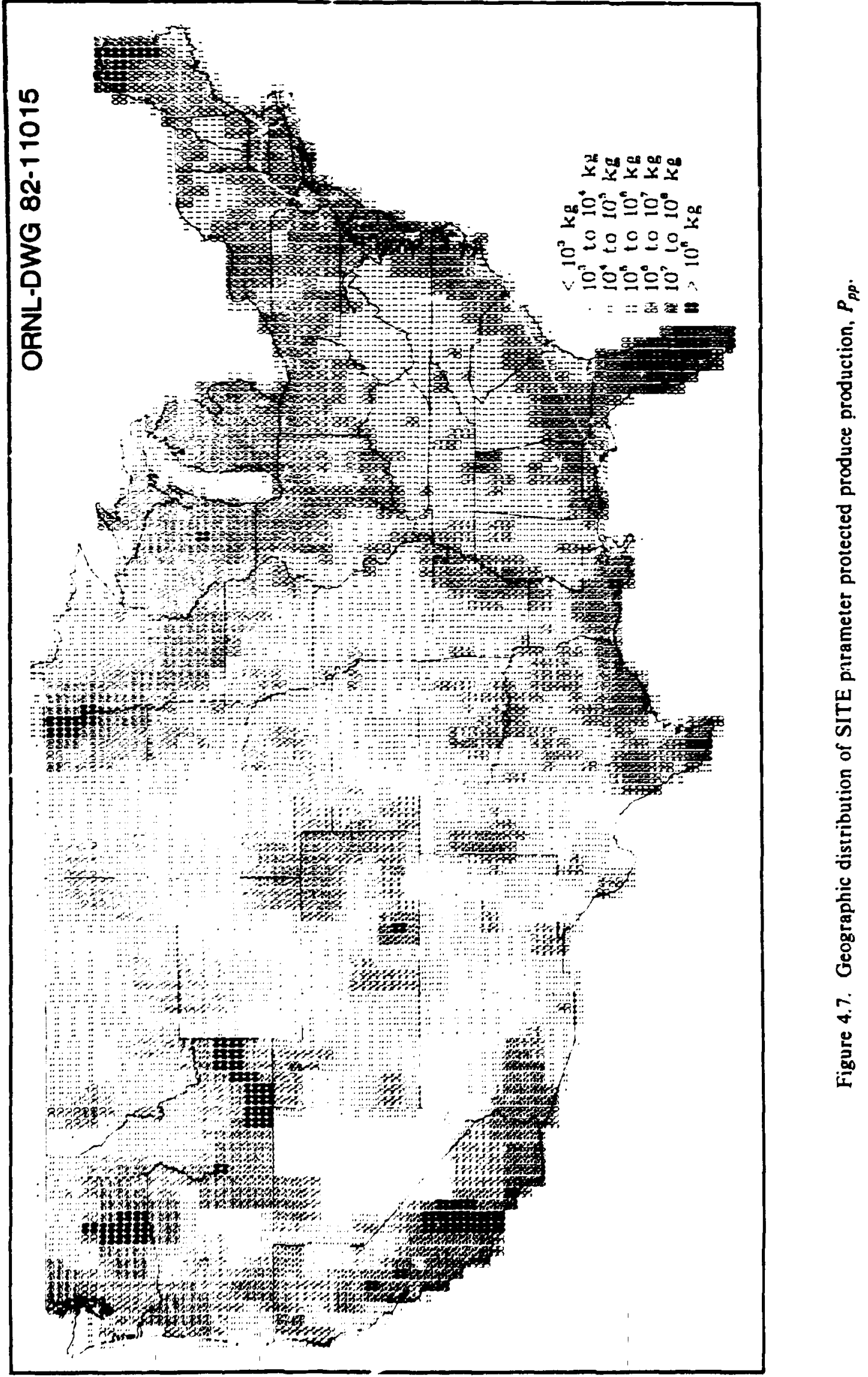




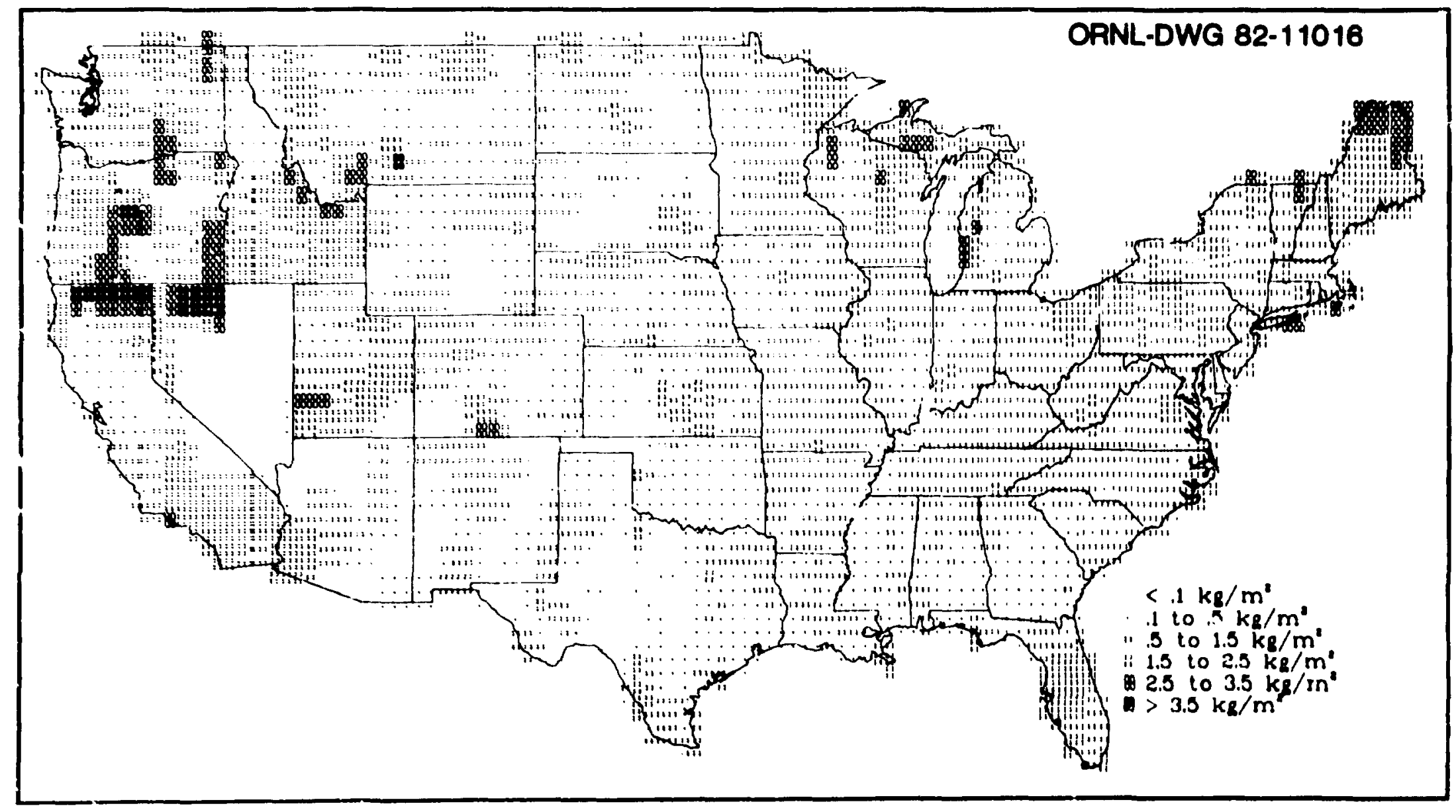

Figure 4.8. Geographic distribution of SITE parameter protected produce productivity, $Y_{p p}$. 


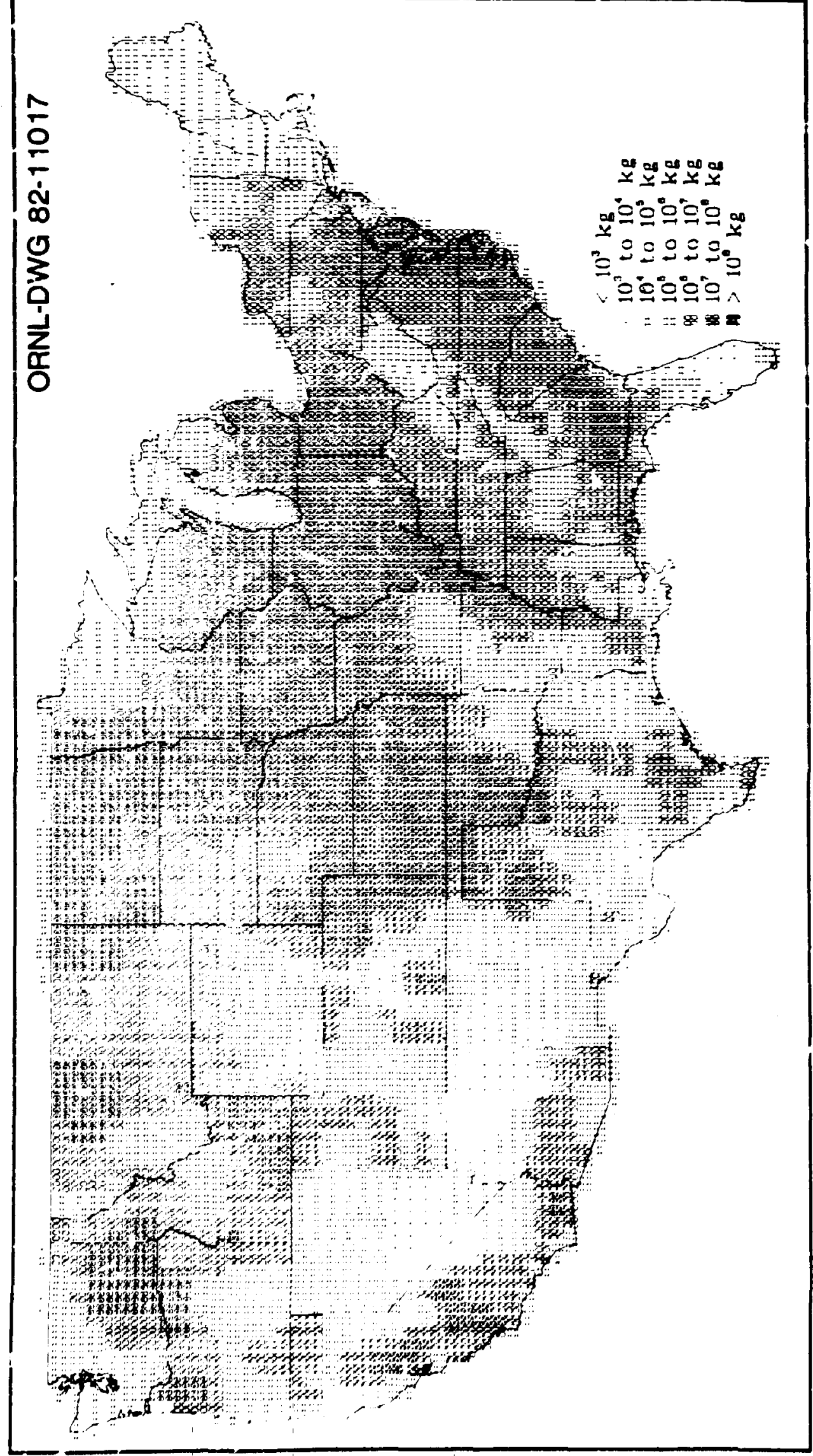

م. 


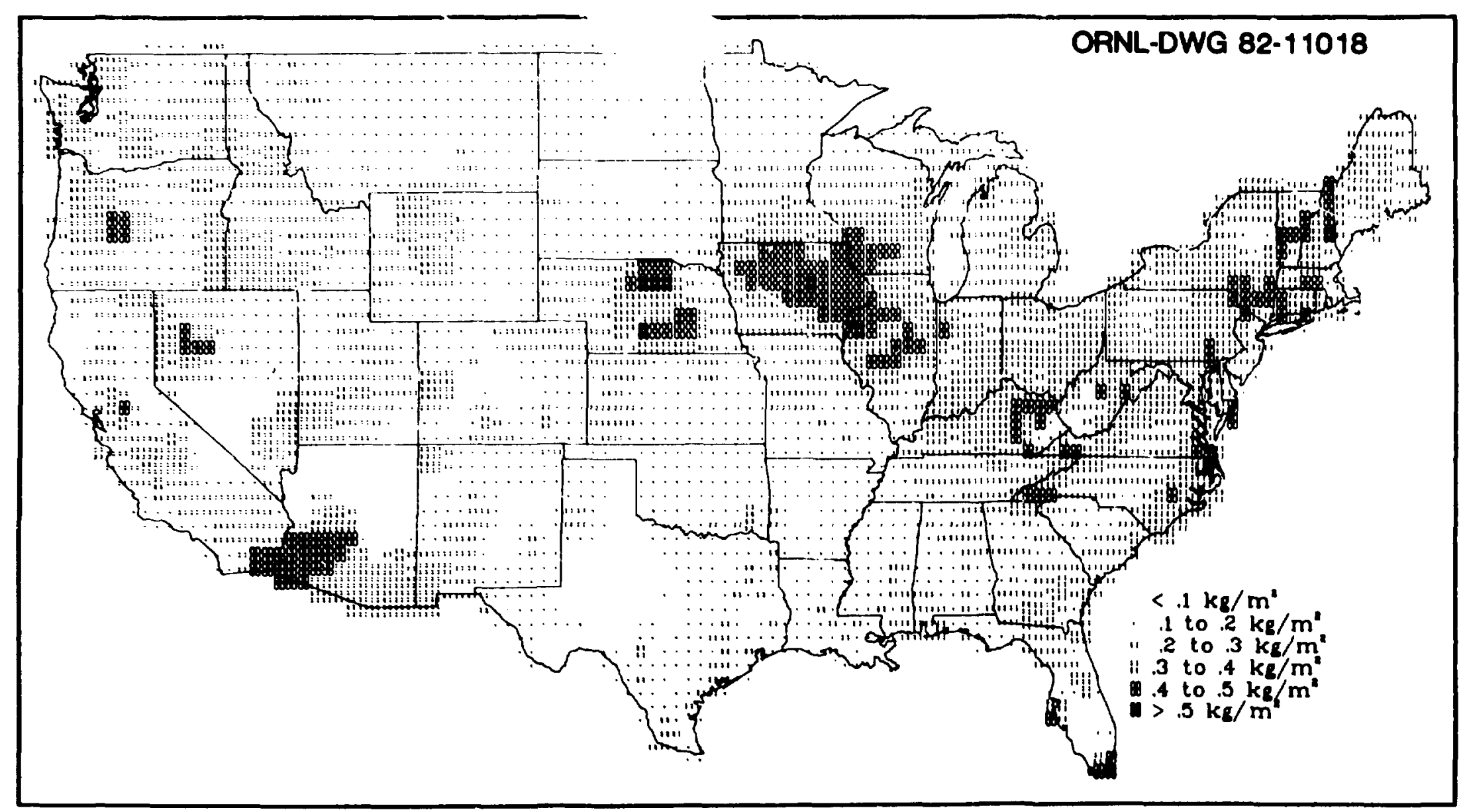

Figure 4.10. Geographic distribution of SITE parameter grain food productivity, $Y_{g h}$. 


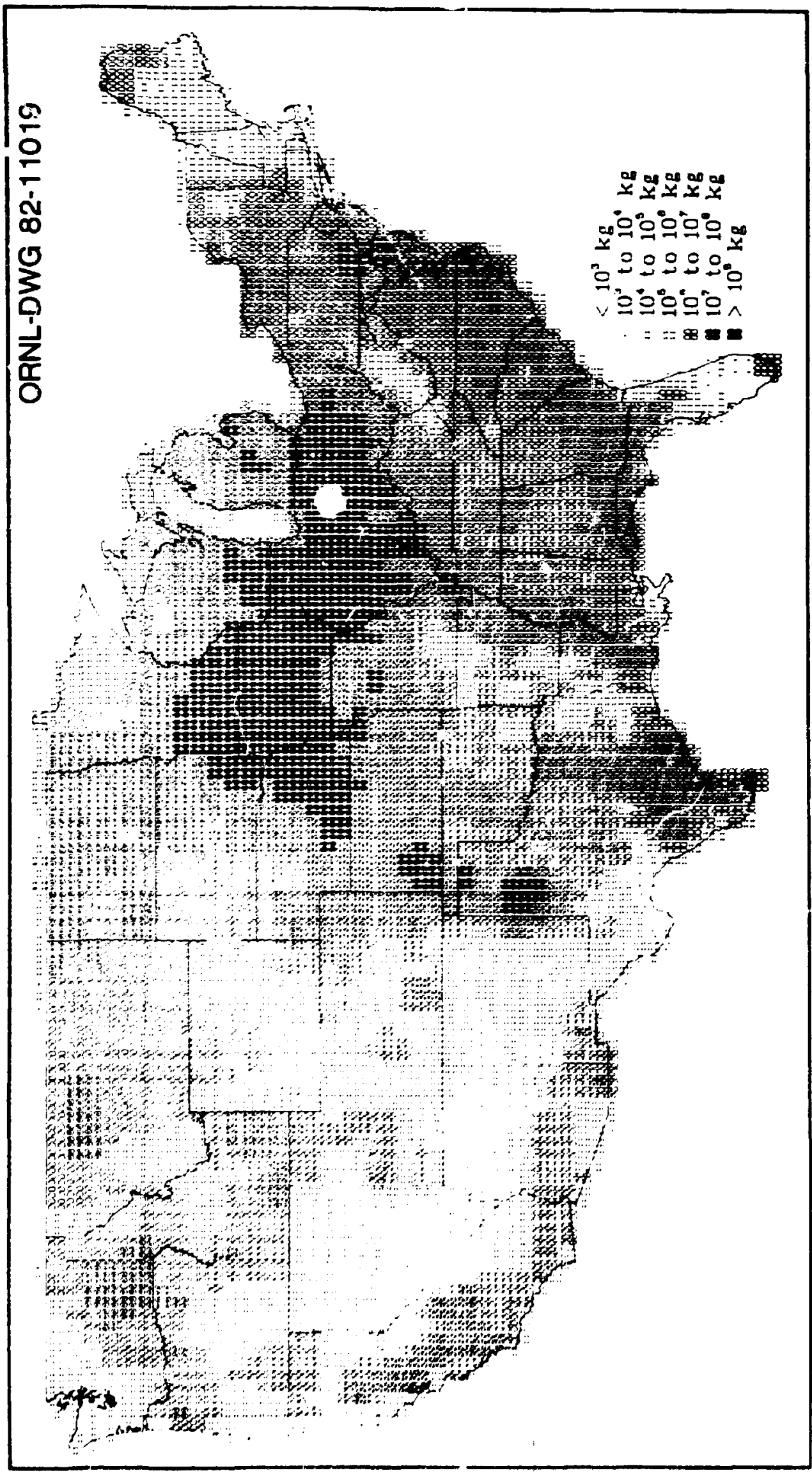

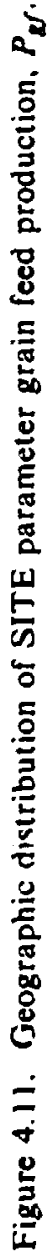




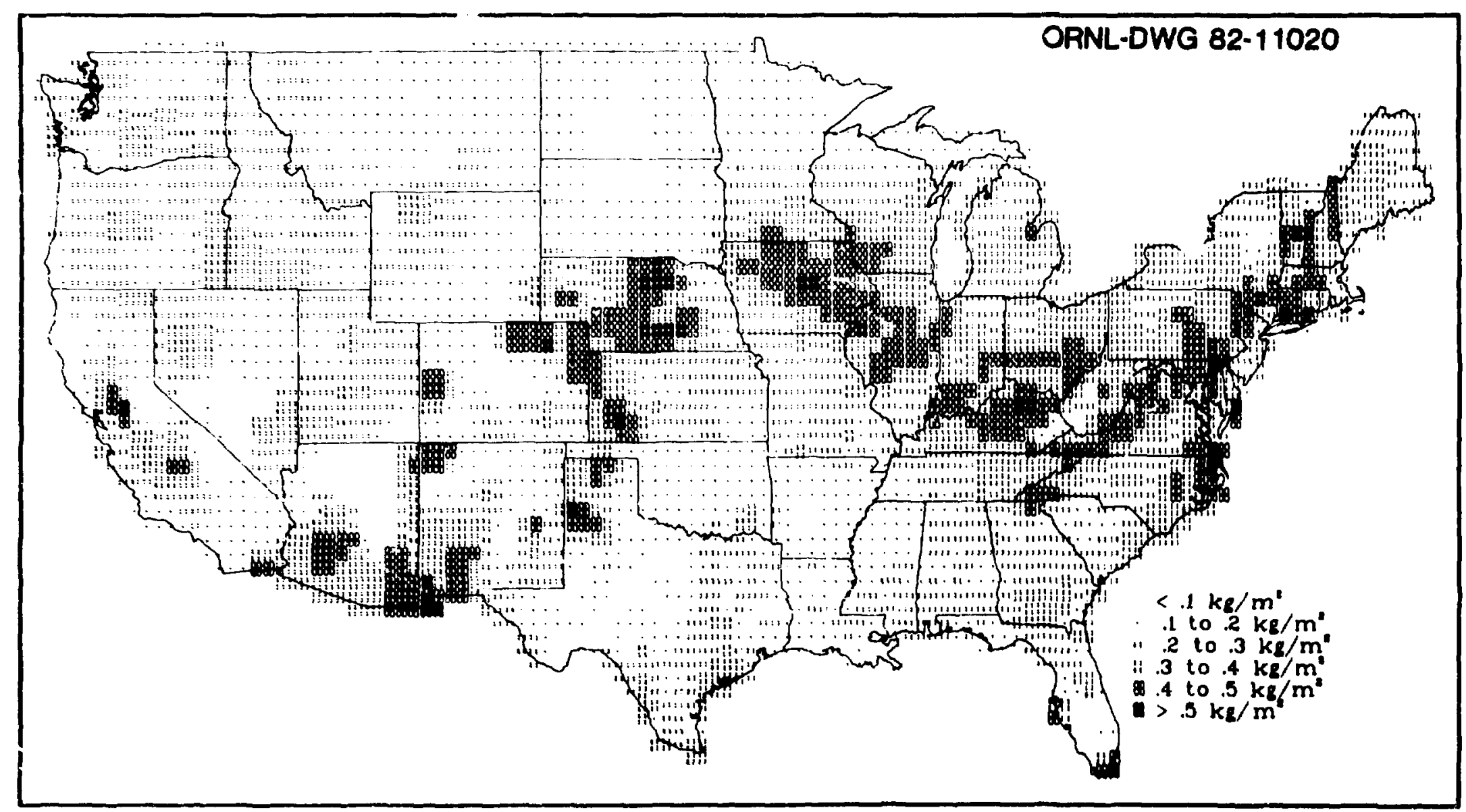

Figure 4.12. Cieographic uistribution of SITE parameter grain feed productivity, $Y_{q}$. 


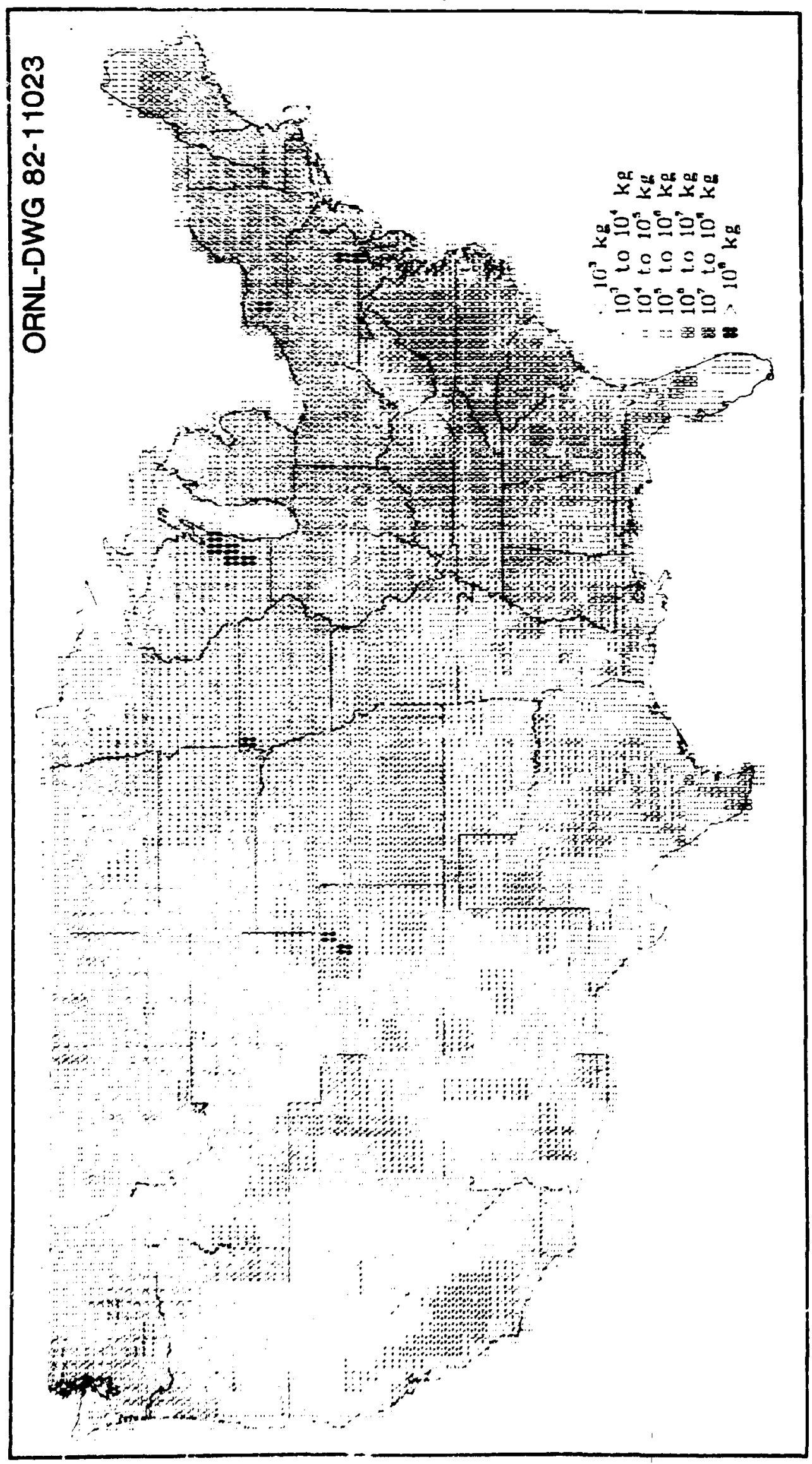

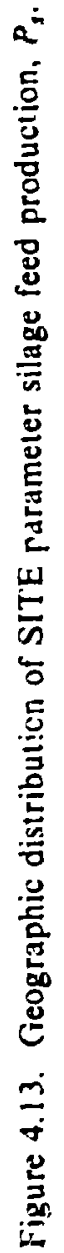




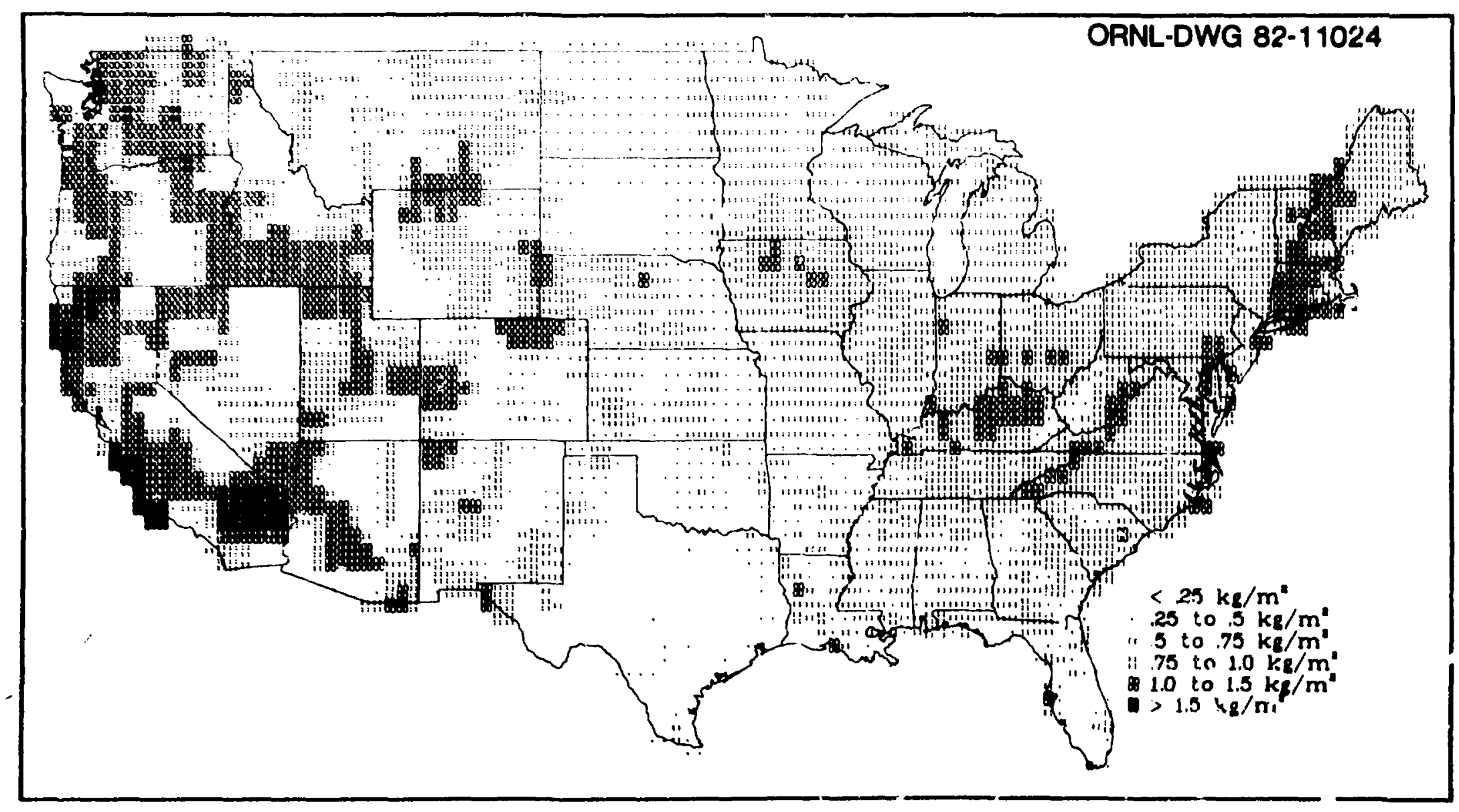

Figure 4.14. Geographic distribution of SITE parameter silage feed productivity, $Y_{s}$. 


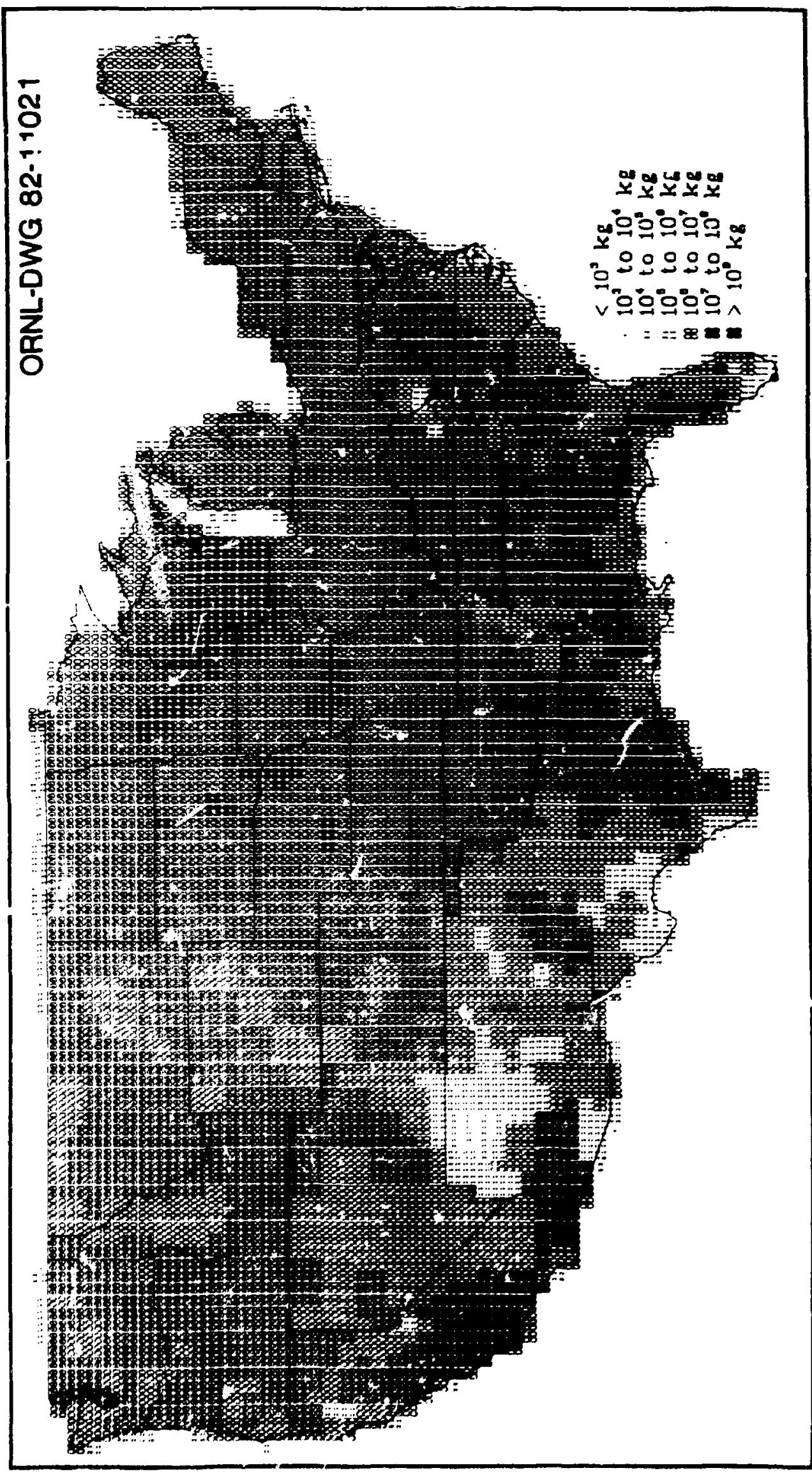

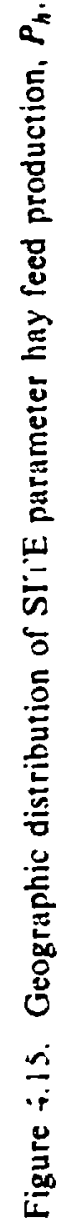




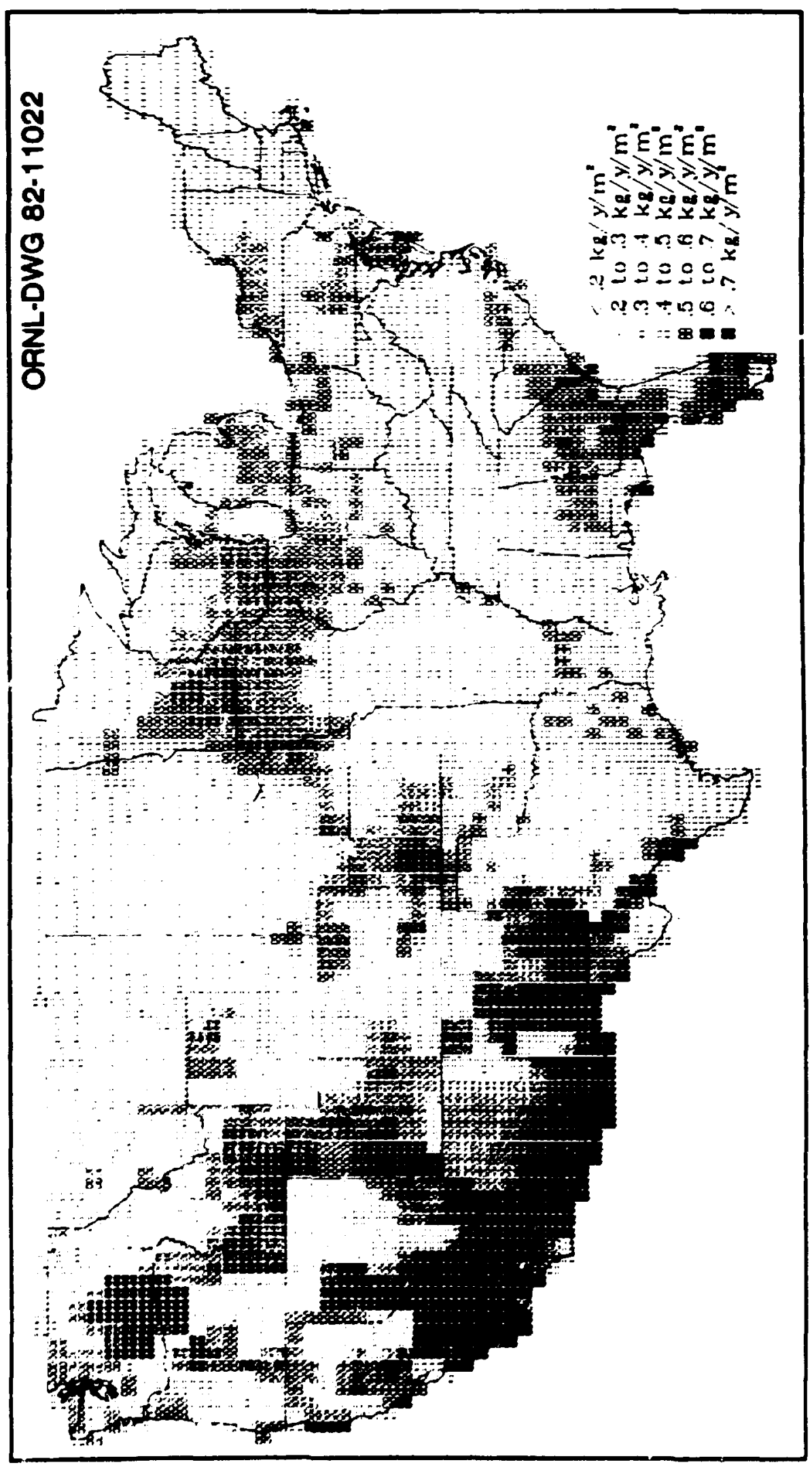

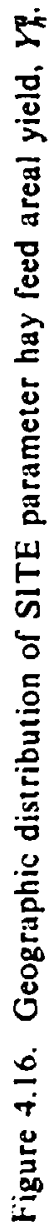


where
$h_{k}=$ the number of hay harves:- $\left.\mathbf{r}^{-1}\right)$,
$d_{f f}=$ the aumber of frosi-freo days (day/yr), and
60 days $=$ the average time between successive ilay harvests.'

The initial estimate of $h_{h}$ is sounded off to the nearest integer and hay productivity, $Y_{h}$, i calculated according to

$$
Y_{k}=\frac{P_{k}}{h_{k}}
$$

If $Y_{h}<0.10 \mathrm{~kg} / \mathrm{m}^{2}$, then the initial estimate of $h_{k}$ is reduced to the largest integer for which $Y_{h}>$ $0.10 \mathrm{~kg} / \mathrm{m}^{2}$. The value of $0.10 \mathrm{~kg} / \mathrm{m}^{2}$ is considered the minimum productivity at which hay harvesting is economically feasible." The same general procedure is followed for calculation of pasture grass productivity, $Y_{p z}$, except that the initial estimate of successive grazings (harvests) by cattle, $g_{p z}$, is given by

$$
g_{m t}=\frac{d_{f f}}{30 \text { days }} \text {. }
$$

where

30 days $=$ the average time between successive grazings by cattle. ${ }^{6}$

and the minimum productivity is $0.005 \mathrm{~kg} / \mathrm{m}^{2}{ }^{7}$ The SITE data base includes estimated number of frost-free days in a year (Fig. 4.17).

In TERRA the areal yield of pasture grass, from which pasture grass productivity is calculated, is estimated from the cattle and calf inventory, $n_{\alpha}$ (Fig. 4.18), the inventory of milk cows, $n_{m}$ (Fig. 4.19), the annual sales of cattle on grain, $s_{g}$ (Fig. 4.20), and the inventory of sheep. .7. (Fig. 4.21), in the manner described in Section 5.1 of the report by Shor, Baes, and Sharp. Brielly, annual consumption of pasture grass is defined by a mass balance of livestock forage requirement or need and harvested supply. The difference between need and supply is assumed to be pasture consumption. The harvested supply is defined as 75\% of hay and silage production, and need is defined according to the numbers and types of forage consuming livestock. The following equations are used to calculate pasture gress areal yield $r_{n}$ in TERRA:

$$
Y_{p z}^{e}=\frac{C_{p}}{A_{p}}
$$

where

$C_{p}=$ the annual consumption of pasture in a half-degree cell by livestock $(\mathrm{kg} / \mathrm{yr})$ and

$A_{p}=$ the area of pasture (Fig. 4.22) in the cell $\left(\mathrm{m}^{2}\right)$.

Pasture consumption is calculated according to

$$
\begin{gathered}
C_{p}=R_{f}-0.75 P_{h f}, \text { and } \\
P_{h f}=P_{s}+P_{h},
\end{gathered}
$$




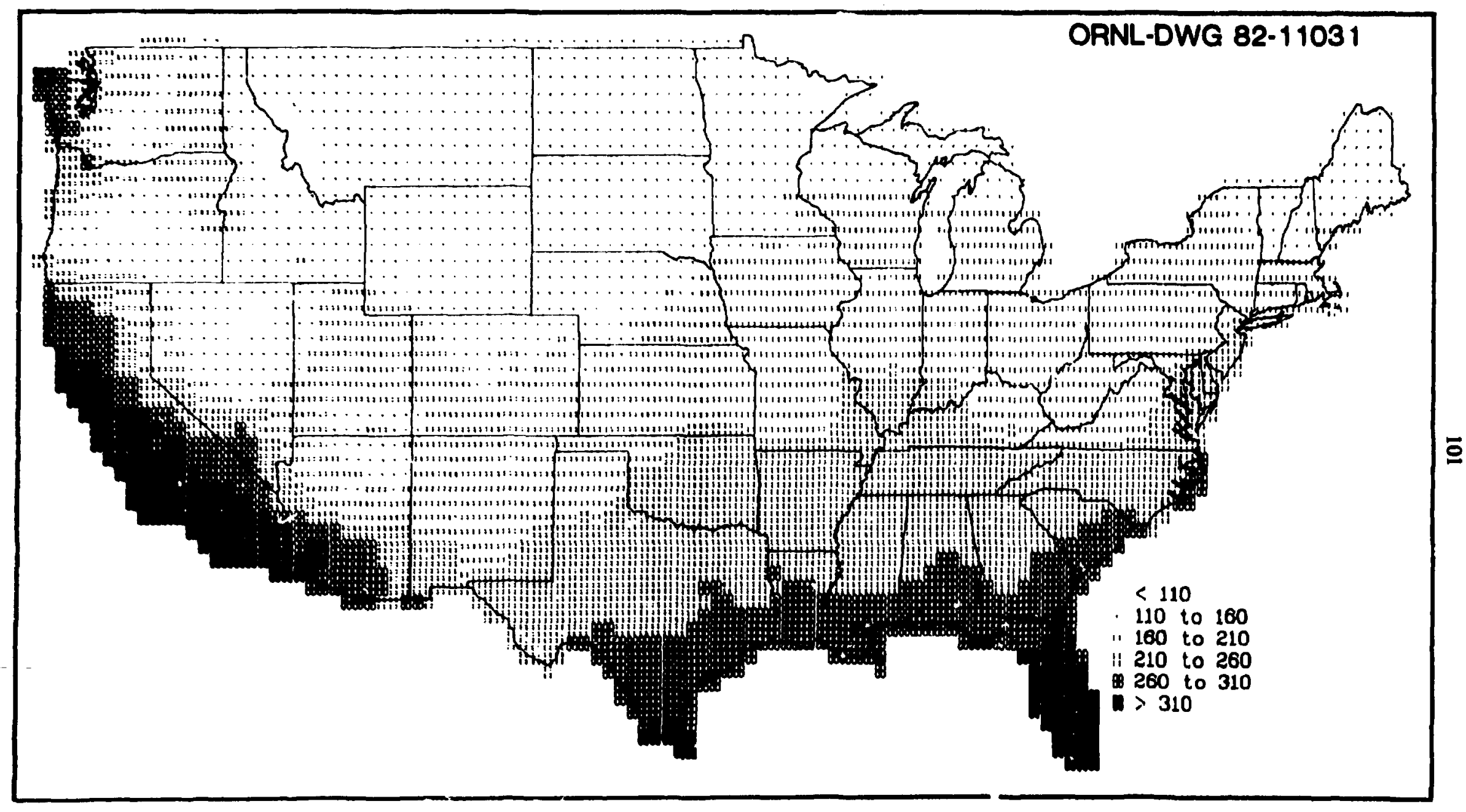

Figure 4.17. Geographic distribution of SITE parameter number of frost-free days, $d_{f f}$. 


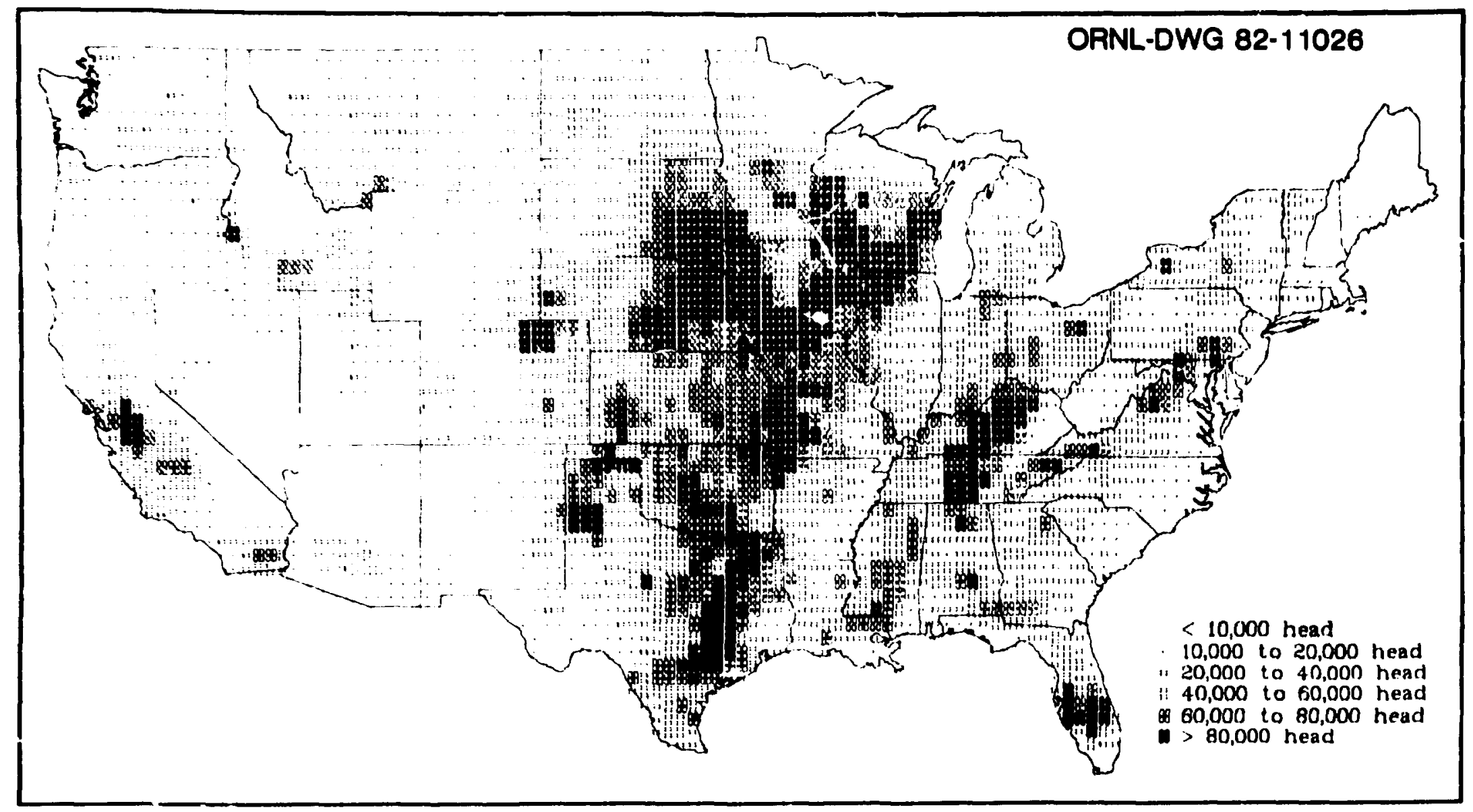

Figure 4.18. Geographic distribution of SITE parameter cattle and calves inventory, $n_{c c}$. 


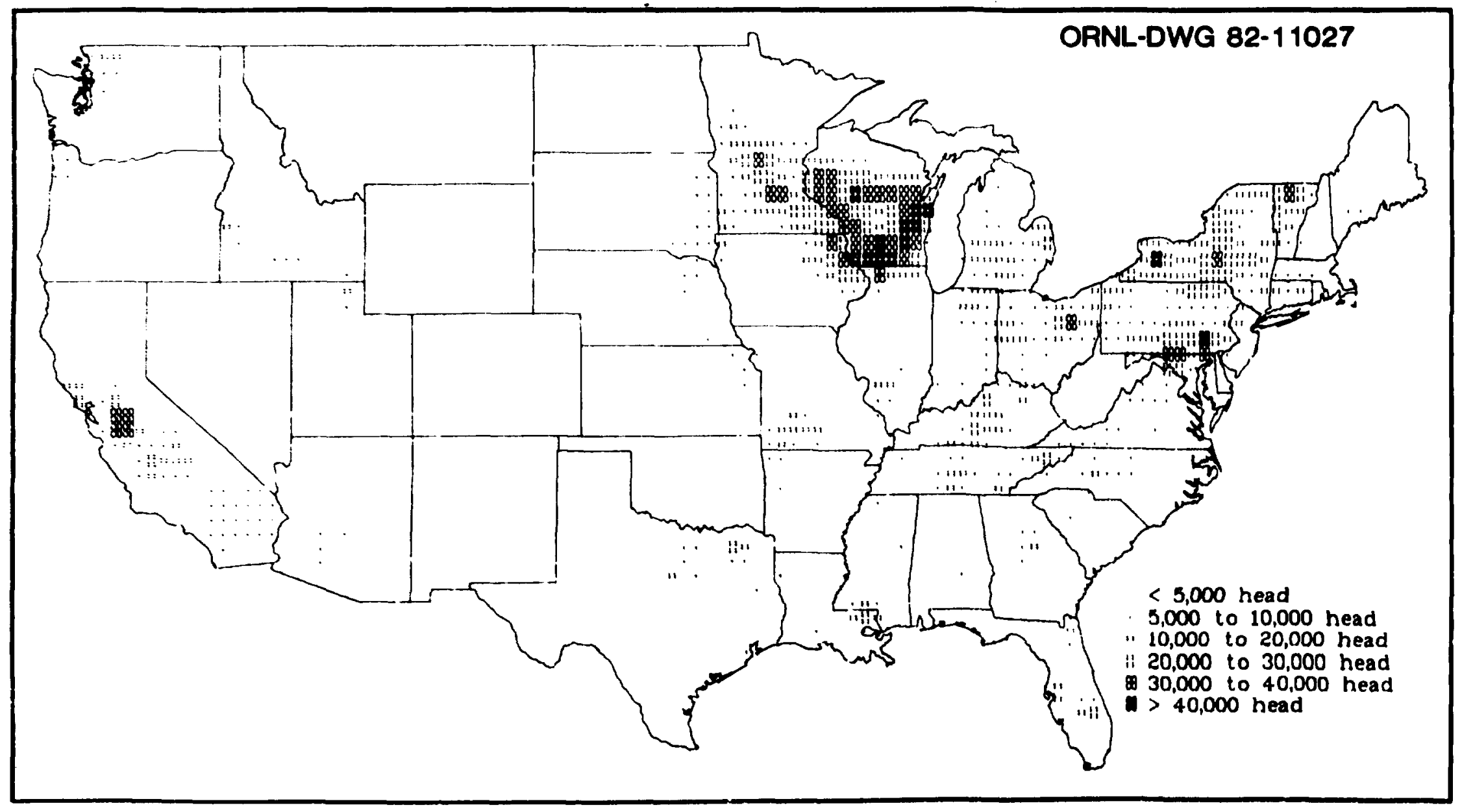

Figure 4.19. Geographic distribution of SITE parameter milk cow inventory, $n_{m}$. 


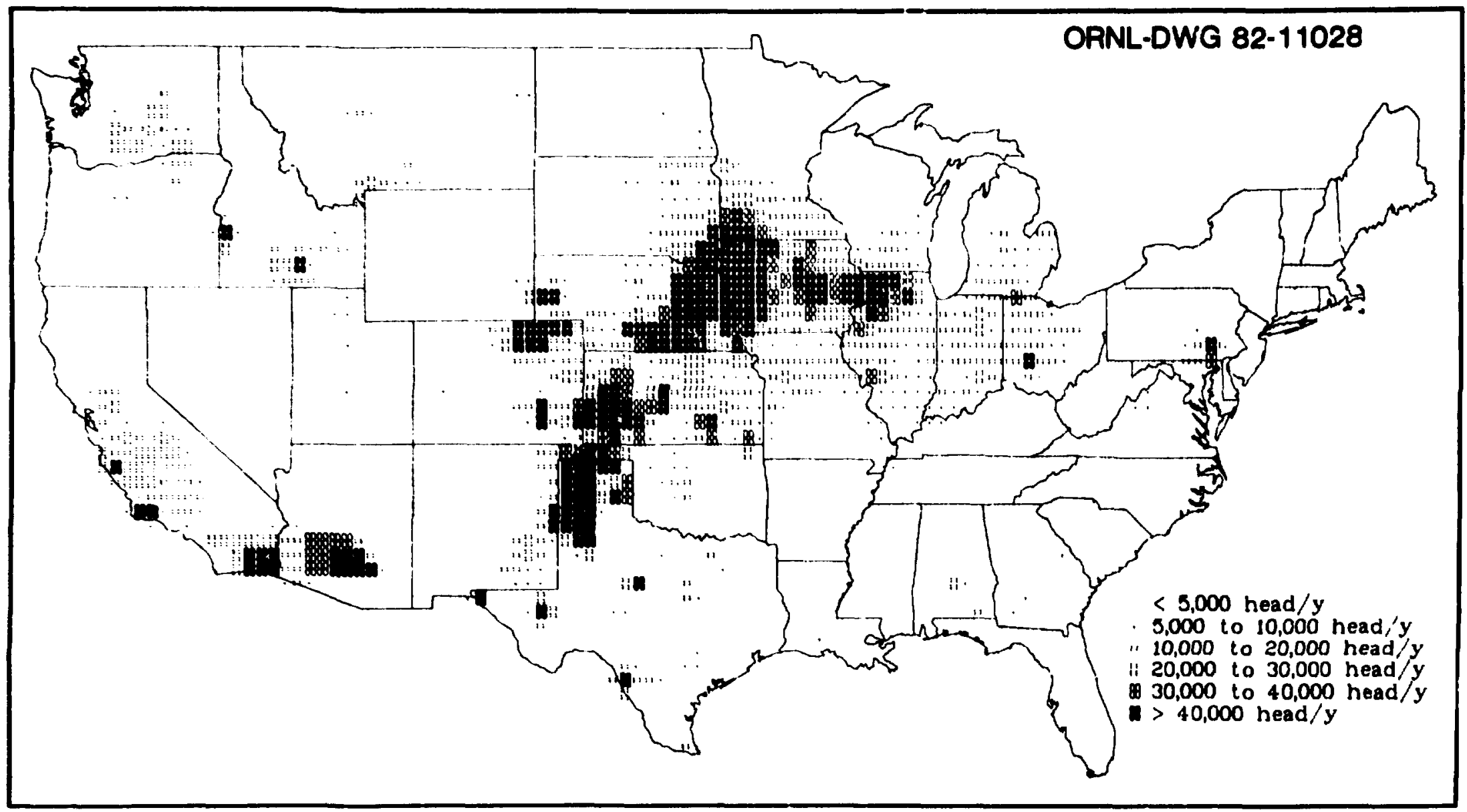

Figure 4.20. Geographic distribution of SITE parameter annual number of cattle on feed sold, $s_{z}$. 


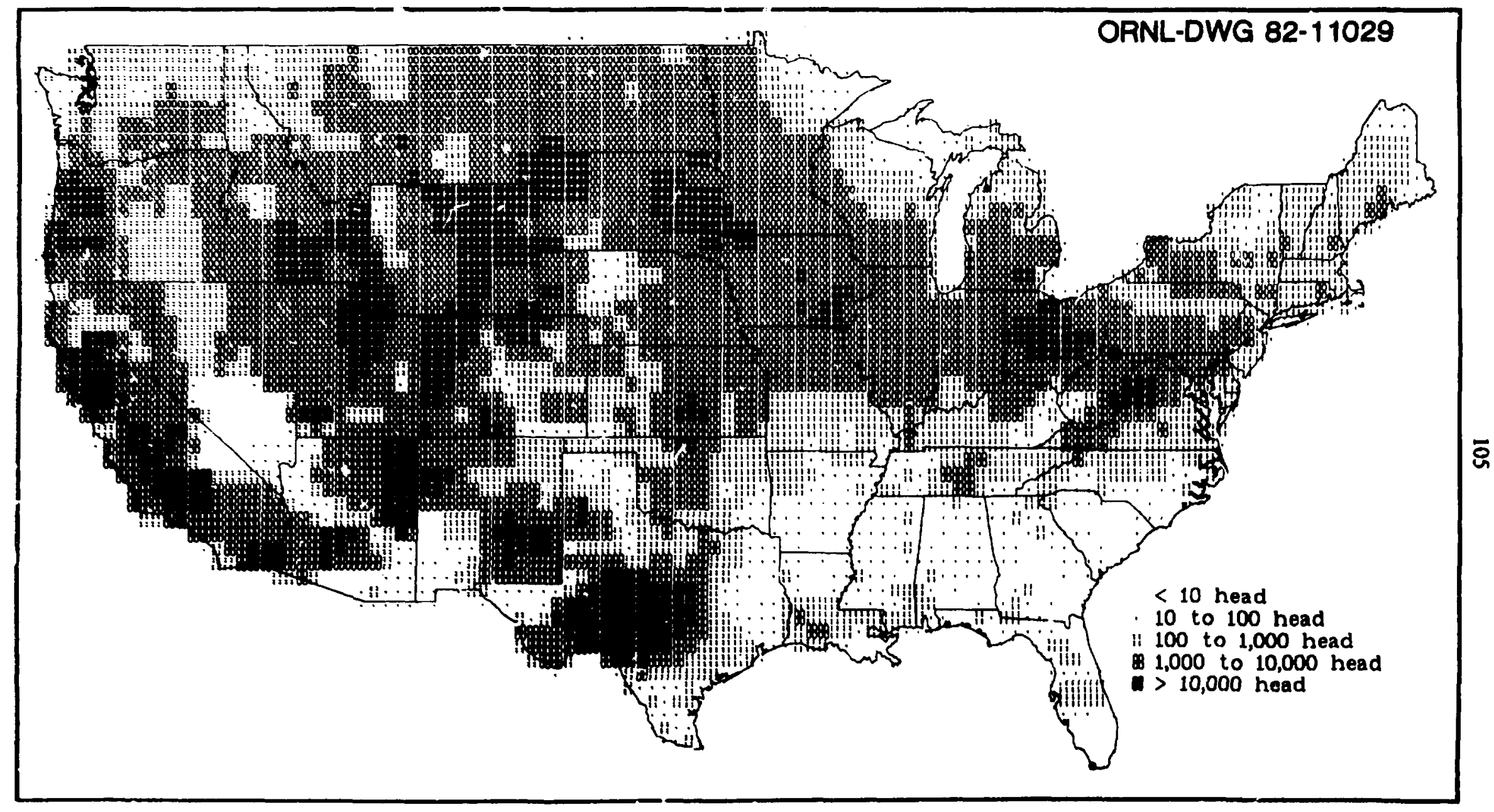

Figure 4.21. Geographic distribution of SITE parameter sheep inventory, $n_{s}$. 


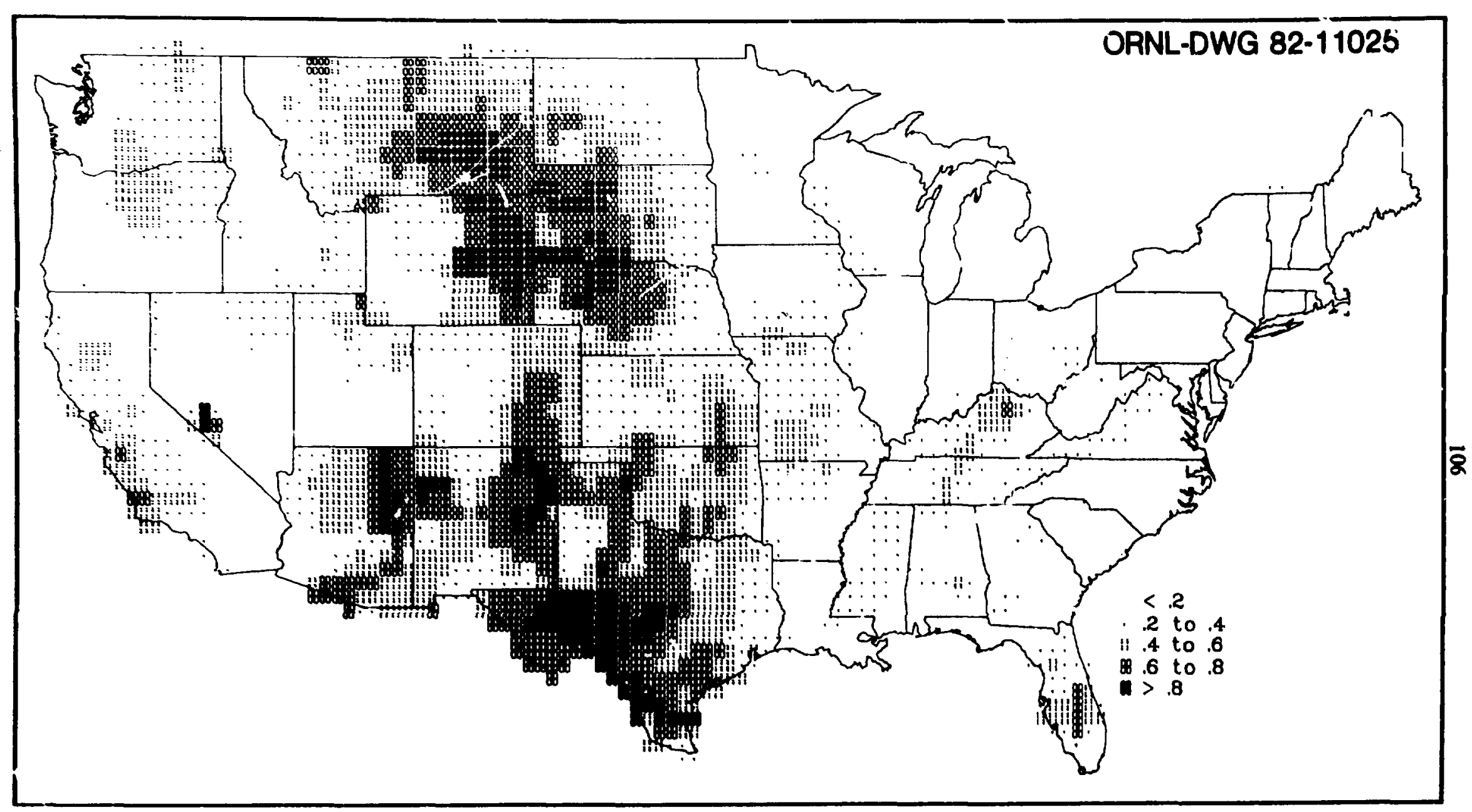

Figure 4.22. Geographic distribution of SITE parameter pasture area, $A_{p}$, shown as a fraction of total cell area. 
where

$R_{f}=$ the collective forage requirement by forage-consuming livestock in the cell (kg/yr),

$P_{h f}=$ annual production of tiarvested forage in the cell (kg/yr),

$P_{s}=$ the annual production of silage in the cell $(\mathrm{kg} / \mathrm{yr})$, and

$P_{h}=$ the annual production of hay in the cell $(\mathrm{kg} / \mathrm{yr})$.

The collective livestock : rrage requirement is given by

$$
R_{f}=4010 n_{m}+970 n_{g}+3030 n_{\varepsilon}+600 n_{s} \text {, }
$$

where

$n_{g}=$ the inventory of cattle on grain (head) in the cell,

$n_{a}=$ the average annual inventory of "all other cattle" (neither milk cows or cattle on

feed) in the cell (head), and

the coefficients are annual forage requirements for each livestock category (kg/head/yr). ${ }^{7}$ Inventory numbers of milk cows, $n_{m}$, and sheep, $n_{s}$, are given in SITE, and $n_{g}$ and $n_{a}$ are calculated by

$$
\begin{gathered}
n_{g}=\frac{s_{g}}{\lambda_{g}}, \text { and } \\
n_{d}=n_{c c}-n_{m}-\frac{3}{2} n_{g},
\end{gathered}
$$

where

$\lambda_{g}=$ the turnover rate of cattle on feed grain $(1 / \mathrm{yr})$.

The number of cattle and calves in the cell, $n_{e c}$ is given in SITE. The turnover rate $\lambda_{z}$ is assumed to be $2.0 / \mathrm{yr}^{?}$

In some states, notably Texas, Oklahoma, Nebraska, and Kansas, large numbers of cattle are imported and placed on feedlots for fattening. In these areas Eq. (43) may produce a negative value due to the high value of $n_{g}$. This possibility is tested for in the TERRA code, and when Eq. (43) is negative the value of $n_{a}$ is set equal to the SITE parameter beef cow inventory, $n_{b}$ (Fig. 4.23).

As shown in Eq. (39), all forage consumed by livestock in a cell is assumed to be produced locally within the cell in TERRA. This type of assumption is not applied to grain. That is, a grain requirement for all livestock in the cell is calculated according to

$$
R_{g}=2600 n_{m}+1820 n_{g}+150 n_{a},
$$

where

$$
\begin{gathered}
R_{g}=\text { the collective grain requirement of all grain-consuming livestock in the cell }(\mathbf{k g} / \mathbf{y r}) \\
\text { and }
\end{gathered}
$$

the coefficients are the annual grain requirements for each livestock category (kg/head/yr). ${ }^{7}$ Sheep are assumed to consume forage only. The grain requirement is compared to the SITE parameter, annual harvest yield or production of grain feed, $P_{\& g}(\mathrm{~kg})$, and the fraction of grain imported from outside of the cell, $f_{g}$, is calculated according to 


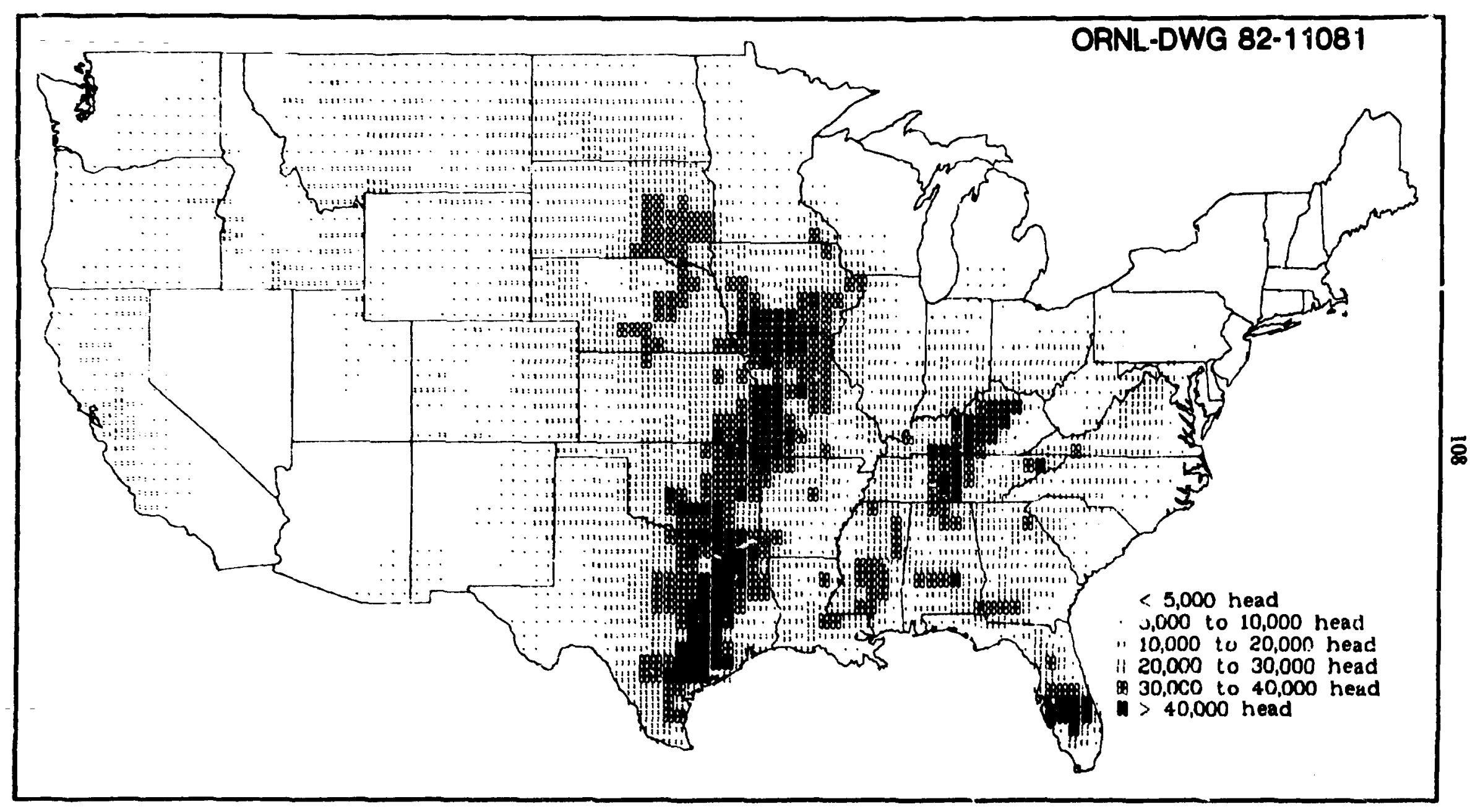

Figure 4.23. Geographic distribution of SITE parameter beef cows inventory, $n_{b}$. 


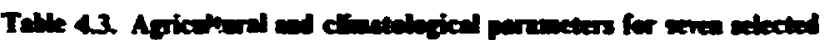

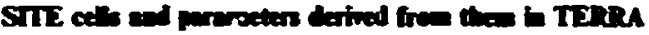

\begin{tabular}{|c|c|c|c|c|c|c|c|}
\hline \multirow[b]{2}{*}{ Parmeter } & \multicolumn{7}{|c|}{ Cell number, $(X, Y)$, state } \\
\hline & $\begin{array}{c}1655 \\
(82,31.5) \\
\text { GA }\end{array}$ & $\begin{array}{c}12069 \\
(115.33) \\
\text { CA }\end{array}$ & $\begin{array}{c}12273 \\
(101.34) \\
T x\end{array}$ & $\begin{array}{c}13051 \\
184.37 .5) \\
\mathrm{KY}\end{array}$ & $\begin{array}{c}13182 \\
(91.5,38) \\
\text { MO }\end{array}$ & $\begin{array}{c}13628 \\
(82.5,40) \\
\text { O11 }\end{array}$ & $\begin{array}{c}45 \$ 1 \\
(75,44) \\
N Y\end{array}$ \\
\hline \multicolumn{8}{|l|}{ STTE Parameter } \\
\hline$Y_{c}\left(\mathrm{~kg} / \mathrm{m}^{2}\right)$ & 0.536 & 2.28 & 0.577 & $\mathbf{0 . 7 2 1}$ & 0.154 & 1.13 & 1.29 \\
\hline$Y_{N}\left(\mathrm{tg}_{\mathrm{g}} / \mathrm{m}^{2}\right)$ & 0.0 & 284 & 0.0 & 0.209 & 0.0 & 206 & 0.17 \\
\hline$r_{s}\left(\mathrm{~kg} / \mathrm{m}^{2}\right)$ & 0.843 & 0.187 & 0.391 & 1.04 & 0.591 & 0.847 & 0.91 ? \\
\hline 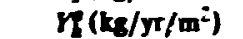 & 0.540 & 1.40 & 0.365 & 0.397 & 0.394 & 0.495 & 0.441 \\
\hline$d_{g f}(\mathrm{day} / \mathrm{yr})$ & 287 & 357 & 209 & 201 & 206 & 191 & 162 \\
\hline$A_{p}\left(\mathrm{~m}^{2}\right)$ & $2.73 \times: 0^{2}$ & $4.00 \times 19^{7}$ & $9.18 \times 10^{8}$ & $1.28 \times 10^{\circ}$ & $1.06 \times 10^{\circ}$ & $3.10 \times 10^{2}$ & $22+\times 10^{2}$ \\
\hline$P_{g}(\mathrm{lg} / \mathrm{yr})$ & $6.42 \times 10^{6}$ & $2.36 \times 10^{5}$ & $4.43 \times 10^{6}$ & $1.75 \times 10^{7}$ & $5.52 \times 10^{6}$ & $1.88 \times 10^{7}$ & $3.38 \times 10^{7}$ \\
\hline$P_{h}(k g / y T)$ & $8.54 \times 10^{6}$ & $1.61 \times 10^{2}$ & $4.01 \times 10^{6}$ & $6.97 \times 10^{7}$ & $5.70 \times 10^{7}$ & $5.97 \times 10^{7}$ & $7.22 \times 10^{7}$ \\
\hline$n_{c \pi}$ & 29.536 & 72,784 & 35.451 & 125,414 & 67,263 & 42,645 & 27,564 \\
\hline$m_{m}$ (bead) & 2,446 & 1,460 & 40 & 3,504 & 2,250 & 8,907 & 15,125 \\
\hline$m_{3}$ (head) & 1 & 34.385 & 1.776 & 3,184 & 44 & 22,226 & 280 \\
\hline$n_{b}$ (head) & 12,543 & 2,334 & 13,265 & 52,694 & 32,797 & 10,748 & 817 \\
\hline$s_{t}($ bead $/ y r)$ & 2,117 & 136,978 & 1.391 & 3,856 & 2,437 & 6,279 & 127 \\
\hline$P_{g}$ (kg) & $8.64 \times 10^{7}$ & $9.32 \times 10^{6}$ & $1.05 \times 10^{3}$ & $2.23 \times 10^{7}$ & $1.47 \times 10^{7}$ & $1.24 \times 10^{2}$ & $1.83 \times 10^{6}$ \\
\hline \multicolumn{8}{|c|}{ Parameters calculated in TERRA } \\
\hline$h_{h}(1 / y)$ & 5 & 6 & 3 & 3 & 3 & 3 & $\xi$ \\
\hline$r_{k}\left(\mathrm{~kg} / \mathrm{m}^{2}\right)$ & 0.108 & 0.233 & 0.122 & 0.132 & 0.131 & 0.165 & 0.147 \\
\hline$n_{f}$ (head) & 1,059 & 68,489 & $6 \%$ & 1,592 & 1,219 & 3,140 & 64 \\
\hline$n_{c}$ (head) & 25.502 & $233^{\circ}$ & 34,367 & 119,522 & 63,184 & 29,028 & 12,343 \\
\hline$R_{f}(\mathrm{~kg} / \mathrm{yr})$ & $8.81 \times 10^{7}$ & $1.00 \times 10^{8}$ & $1.06 \times 10^{2}$ & $3.80 \times 10^{8}$ & $2.02 \times 10^{5}$ & $. .40 \times 10^{8}$ & $9.83 \times 10^{7}$ \\
\hline$C_{p}(\mathrm{ks} / \mathrm{yr})$ & $7.69 \times 10^{7}$ & 0 & $9.97 \times 10^{7}$ & $3.15 \times 10^{8}$ & $1.55 \times 10^{8}$ & $8.11 \times 10^{7}$ & $1.88 \times 10^{7}$ \\
\hline$r_{z}\left(\mathrm{~kg} / \mathrm{yr} / \mathrm{m}^{2}\right)$ & 0.282 & 0 & 0.109 & 0246 & 0.146 & 0.262 & 0.084 \\
\hline $8_{n}(1 / y \gamma)$ & 10 & 0 & 7 & 7 & 7 & 6 & 5 \\
\hline$Y_{n}\left(\mathrm{~kg} / \mathrm{m}^{2}\right)$ & 0.028 & 0 & 0.016 & 0.035 & 0.021 & 0.044 & 0.017 \\
\hline
\end{tabular}

- Set equal to inventory of beef catile in this SITE cell.

$$
f_{8 i}=1-\frac{P_{8 f}}{R_{g}}
$$

unless $P_{g} / R_{g}>1.0$, in which case $f_{g i}$ is set to 1.0 .

Table 4.3 lists 13 of the 14 agricultural parameters in SITE and number of frost-free days, which is used by TERRA for selected SITE cells in the United States. The $14^{\text {th }}$ agricultural parameter, irrigation, is discussed in Sect. 4.2. The other seven parameters-annual yields (production) of leafy vegetables, $\boldsymbol{P}_{l v}$, exposed produce, $\boldsymbol{P}_{e}$, protected produce, $\boldsymbol{P}_{p p}$, grains consumed by man, $P_{z h}$, and productivity estimates for protected produce, $Y_{p p}$, grain feeds, $Y_{e f}$, and grain foods consumed by man, $\boldsymbol{Y}_{s h}$.- are not currently used by TERRA.

\subsection{Climatologieal Parneters}

The SITE data base contains six climatological parameters-precipitation, evapotranspiration, absolute humidity, morning mixing height, afternoon mixing height, and number of frost-free days. All except evapotranspiration have been calculated according to the method described in Sect. 4. for climatological parameters (interpolation among the three nearest weather stations). 
Evapotranspiration was calculated by United States county and cunverted to SITE cell basis according to Method B. Of the six, only precipitation, erapotranspiration, absolute humidity, and frost-free days are used by TERRA. Frost-free days has been discussed in Sect. 4.I. The following discussion will detail the derivation and use of the remaining five climatological parameters and the agricultural parametcr irrigation.

Evapotranspiration (Fig. 4.24), irrigation (Fig- 4.25), and precipitation (Fig. 4.26) are used in the calculation of leaching constants [Eq. (7)] as described in Sect. 24. Leaching constants are calculated for both irrigated and nonirrigated soiis in TERRA. Food crops (except grains) are assumed to be grown on irrigated soils and all livestock feeds are assinmed to be grown on conirigated soils. The numerator of Eq. (7), $(P+I-E)$, is assumed to be a mass balance of water inputs and outpelts for a given agricultural area. Surfiase runoff and storage of water in surface arricultural soils is not considered in TERRA.

Evapotianspiration was calculated according to a model proposed by Morton. ${ }^{216}$ The model requires as unput annual precipitation, sea level pressure (or altitude), monthly dew point, monthly ambient air temperatures, and monthly fraction of maximum possible sunshine. Annual precipitation was taken from Olson, Emerson, and Nungesser ${ }^{217}$ by county in eastern states and by state climatic division in western states. Conversion of precipitation by state climatic division $t \omega$ county basis was achieved using the IUCALC code.215 The altitude of each county centroid in meters was estimated using the TERGHT code. ${ }^{218}$ Each altitude was converted to sea level pressure in millibars using ${ }^{219}$

$$
P_{s l}=\left(\frac{z-44308}{-11876.94}\right)^{5.25679}
$$

where

$$
\begin{aligned}
P_{s l} & =\text { sea level prissure }(\mathrm{mb}) \text { and } \\
z & =\text { altitude }(\mathrm{m}) .
\end{aligned}
$$

Monthl! dew point and ambient air temperatures were taken from references 210,211 , and 212 for various United States weather stations. The monthly fractions of maximum possible sunshine were taken from references 211 and 212 for various weather stations. All parameters derived from weather station data were interpolated to county centroids and finally to the half degree cells using methods previously described.

Annual irrigation in centimeters was taken from information reported in the 1974 Census of Agriculture. For each county the 1974 Census reports total land irrigated in acres and the estimated quantity of irrigation water applied in acre-feet. The latter was divided by the former and the quotient was converted to centimeters.

Irrigation was not included with precipitation in the model input parameters, although it is considered in Eq. (7). This discrepancy will add a small amount of error to the evapotranspiration by county calculation. Because the Morton model is designed for large land areas and does not provide for local discontinuities, it was assumed that irrigation water is an insignificant fraction of total precipitation over the entire county or cell. This assumption is supported by the observation that nationally only 3-4\% of all farmland is irrigated. However, in some counties irrigated land may be a significant fraction of the total land a.ea and c"- calculations inappropriate.

According to Morton, the evapotranspiration mod. has been verified over a wide range of environments and compares satisfactorily with annual precipitation less runoff for 81 river basins in Canada, 36 river basins in the southern United States, three river basins in Ireland, and two river basins in Kenya. Wailace ${ }^{220}$ compared the model with the Thornthwaite-Mather ${ }^{221}$ and Penman ${ }^{222}$ approaches to modeling evapotranspiration and found the Morton model to be superior in modeling arid environments. Morton, however, warns against use of the model near sharp environmental discontinuities. Therefore, estimates of evapotranspiration near coast-lines and nountain rar.zes are suspect. 




Figure 4.24. Geographic distribution of SITE parameter estimated annual average evapotranspiration, $E$. 


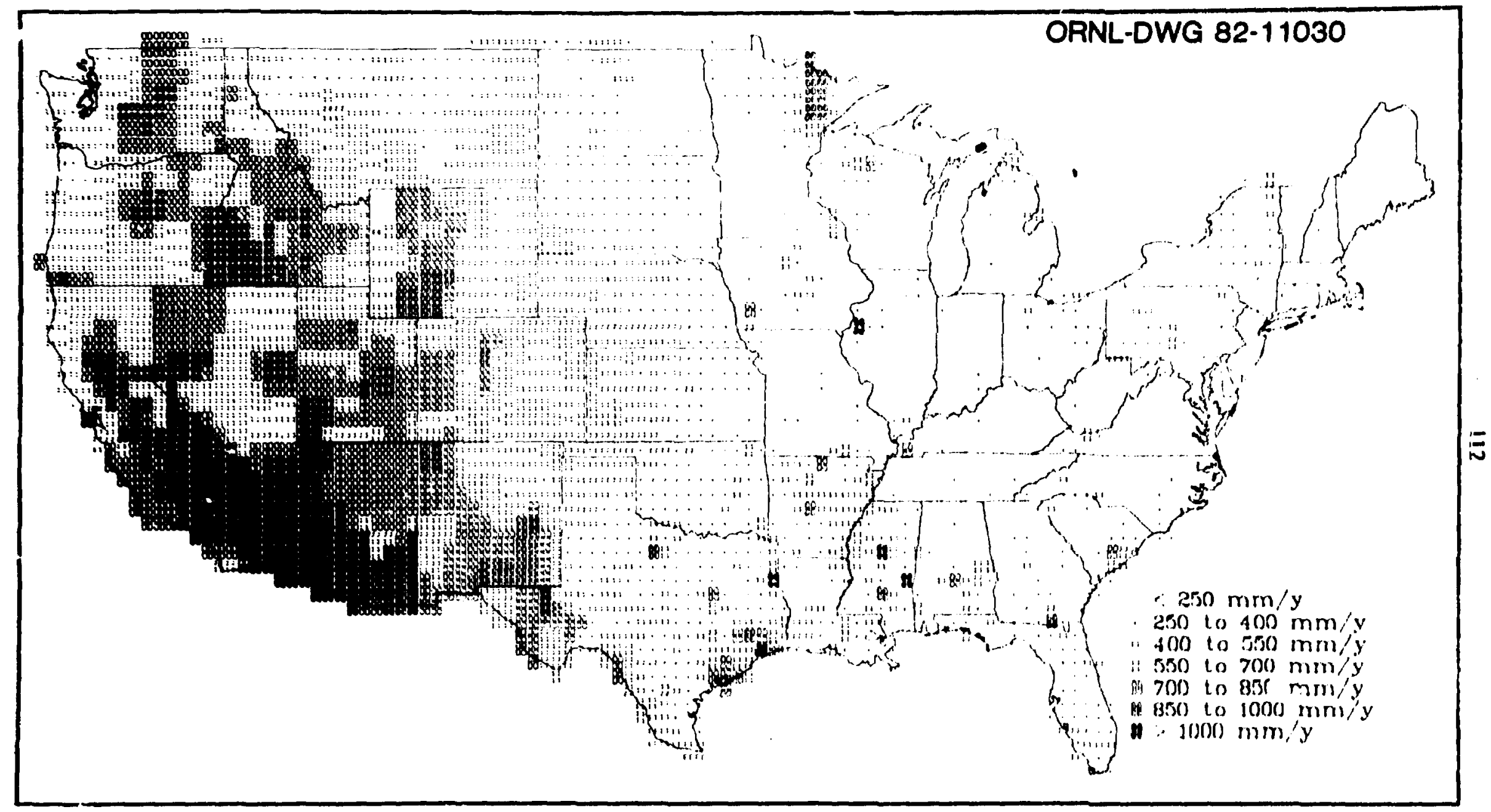

Figure 4.25. Geographic distribution of SITE parameter estimated annual average irrigalion, $I$. 




Figure 4.26. Geographic distribution of SITE parameter estimated annual average precipitation, $P$. 
Morning and afternoon mixing heights in meters (Figs. 4.21 and 4.28, respectively) were taken from the annual average tabulation for 62 United States weather stations reported by Holzwurth23 under both precipitation and nonprecipitation conditions. Cell values are interpolations among the three nearest weather stations. Currently, morning and af iernoon mixing height estimations are not used in TERRA. However, they may be of use to atmospheric dispersion somputer codes and models which calculate dispersion of elevated releases.

The estimates of absolute humidity (Fig 4.29) were takes from the annual averages for 218 United States weather stations cakulated by Eniex ${ }^{22}$ from anneal-average temperature and relative humidity data The cell-averaged valwes were interpolated from the three nearest weather stations as previously described.

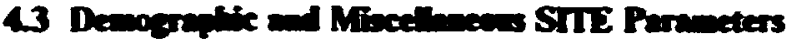

In addition to the 29 parameters previonsly discussed, SITE includes seven parameters describing the population of the cell and cell characteristics. These parameters include the ctimatei :980 population and fractions (based on the 1970 Census) which are classified as urban, rural-farm, and rural-nonfarm, the actual land area of the cell, the dominant land feature in the cell, and the coarse sispended particulate matter due to resuspension.

The 1980 population extimate for half degree cells (Fig. 4.30) was determined from data by enumeration district as descriled in references 213 and 214. The definitions of "urban," "ruralfarm," and "rural-nonfarm" are as follows. The urban population (Fig 4.31) comprives all persons living in (1) places of 2,500 inhabitants or more incorporated as citiex, boroughs, villagex, and towns (except towns in New England, New Yort, and Wisconsin); (2) the densely settled urban fringe, whether incorporated or unincorporated, of urbanized areas; (3) towns in New England and townships in New Jersey and Penusytrania which contain no incorporated municipalities as subdivisions and have either 25,000 inhabitants or more or a population of 2,500 to 25,000 and a density of 580 persons or more per square kilometer (1,500 persons per square mile); (4) counties in states other thas the New England States, New Jersey, and Pennsylvania that have no incorporated municipalitites within their boundaries and have a density of 580 persons or more per square kilometis (1,500 persons per square mile), and (5) unincorporated places of 2,500 inhabitants or more. The rural population is divided into "rural-farm," (Fig. 4.32) comprising all persons living on farms, and "rural-nonfarm," (Fig. 4.33) comprising the remainder. According to the 1970 Census definition, the farm population consists of all persons living in rural tern!'sry on places of less than $0.04 \mathrm{~km}^{2}$ yielding agricultural products which sold for $\mathbf{5 2 5 0}$ or more in the previous year, or on places of $0.04 \mathrm{~km}^{2}$ (10 acres) or more yielding agricultural products which sold for $\$ 50$ or more in the previous year.

The land area of the cell in square meters is less than or equal to the theoretical area of the ceil, depending on the area of surface waters in the cell. The actual area of the cell was determined from the county areas reported in the 1974 Census of Agriculture. "Land areas" includes land temporarily or partially covered by water (marshlands, swamps, etc); canals under $201 \mathrm{~m}$ (one eighth statute mile) wide; and lakes, reservoirs, and ponds under $0.16 \mathrm{~km}^{2}$ (40 acres).

The SITE data base contains a coded number which deacribes the dominant land feature of the vell (Fig. 4.34). The dominant land feature may be useful to atmespheric dispersion calculations requiring location-specific surface rcuginness correctior. factors. The dominant land features considered are

1) Tall row crops,

2) Short row crops,

3) Hay or tall grass.

4) Urban areas,

5) Small lakes,

6) Short grass, and

7) Forest. 


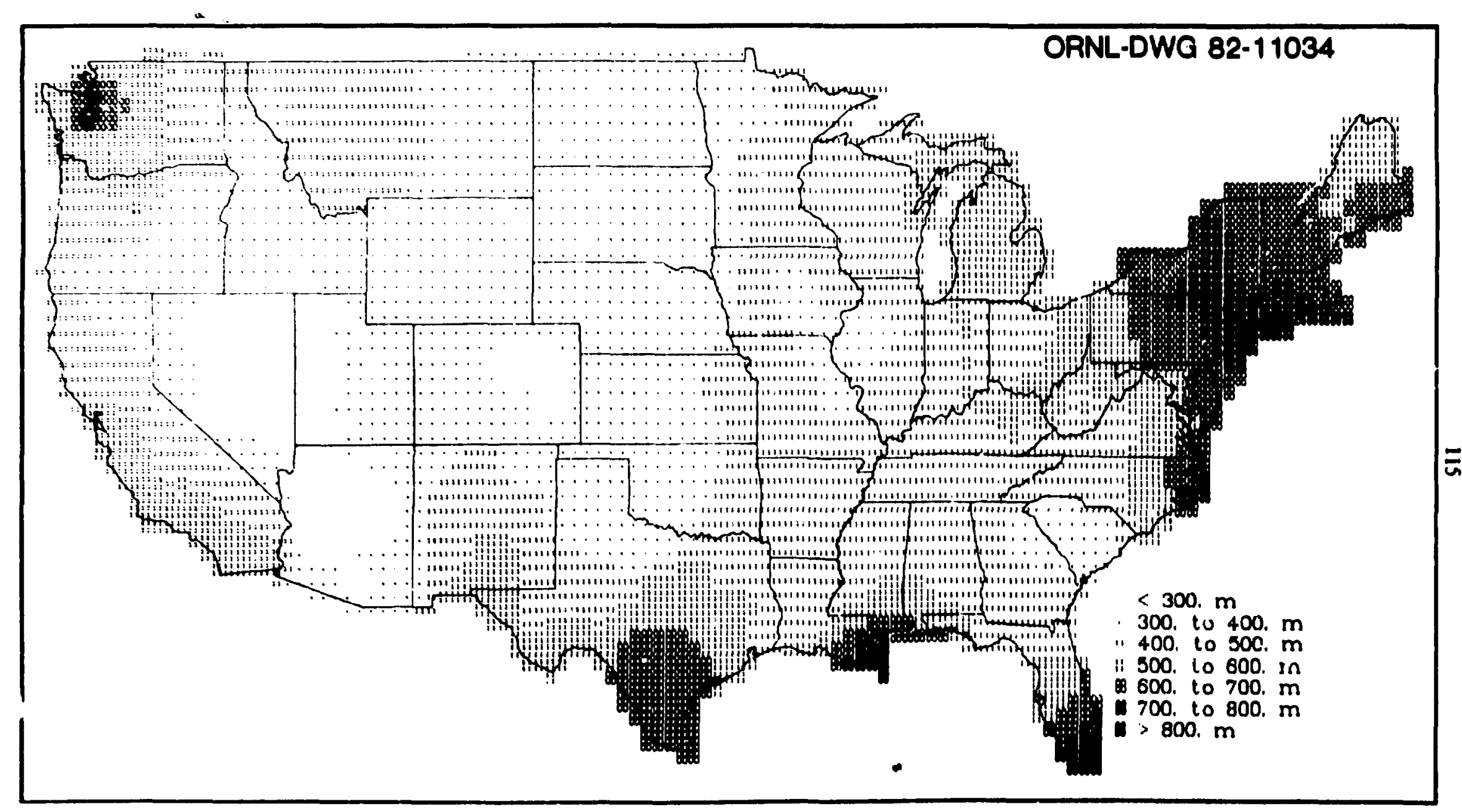

Figure 4.27. Geograplic distribution of SITE parameler estimated annual average morning mixing height, $M_{a m}$ 


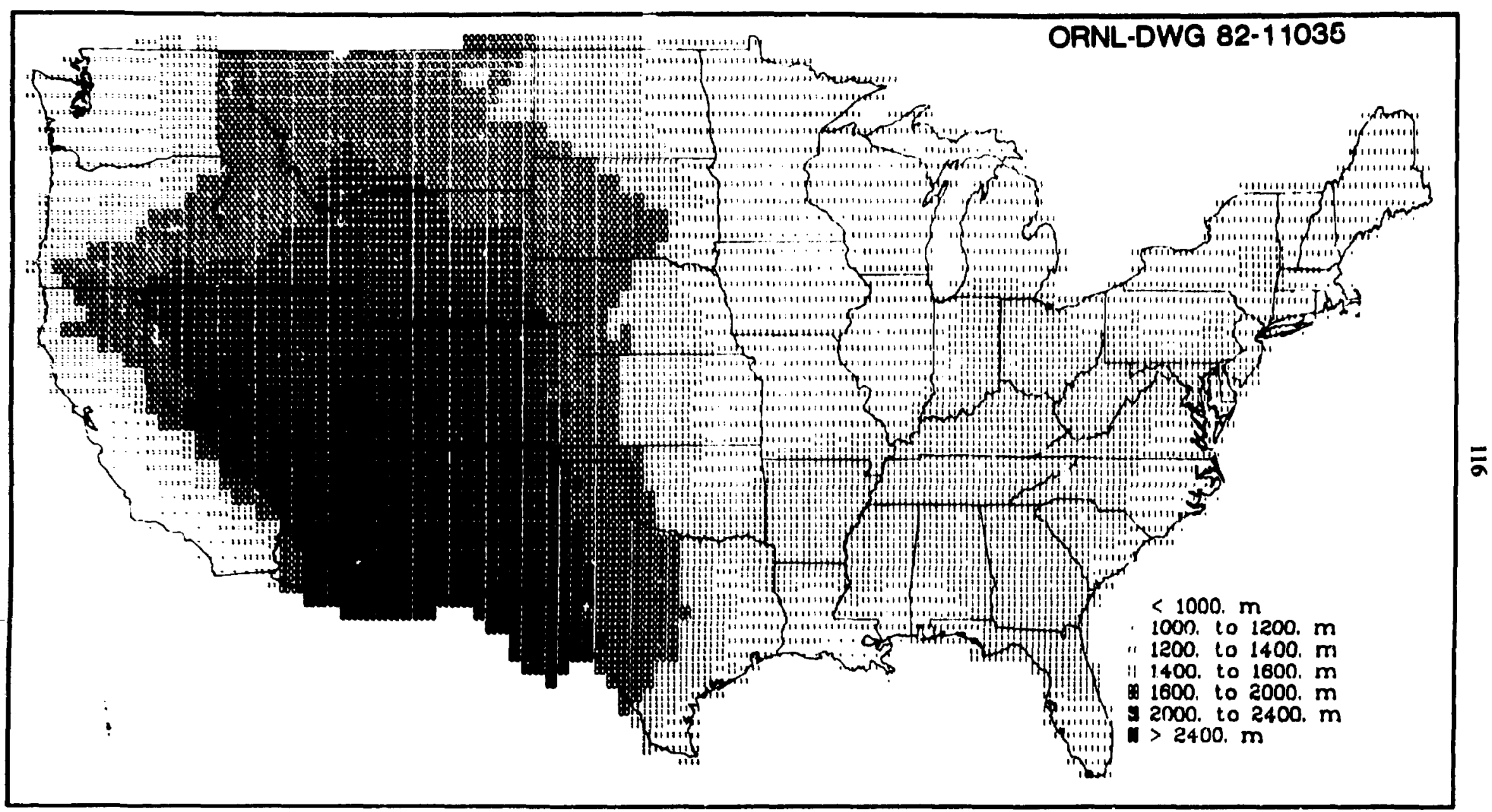

Figure 4.28. Geographic distribution of SITE parameter estimated annual average afternoon (evening) mixing height, $M_{\mathrm{pm}}$. 


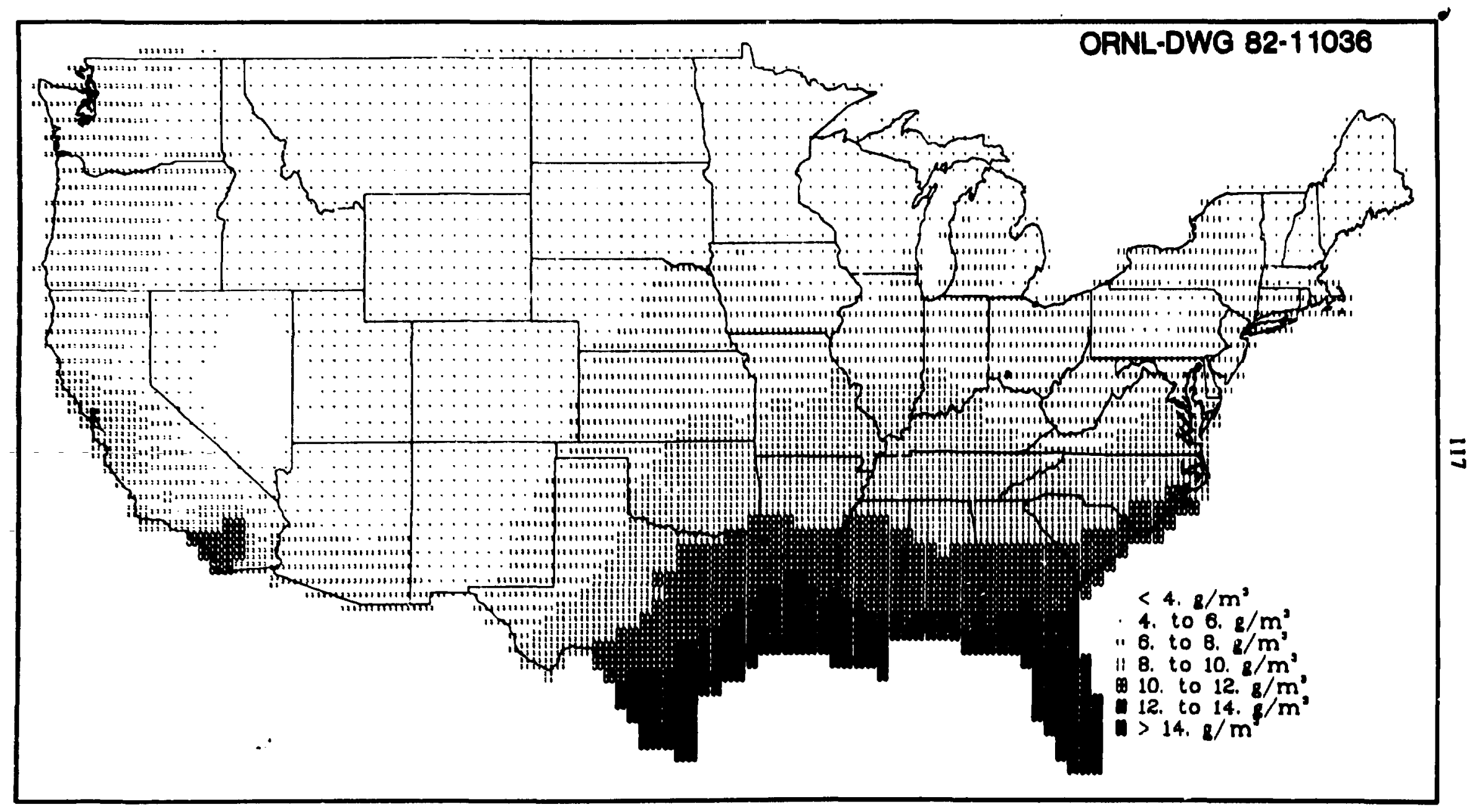

Figure 4.29. Geographic distribution of SITE parameter estimated annual average absolute humidity, $H$. 


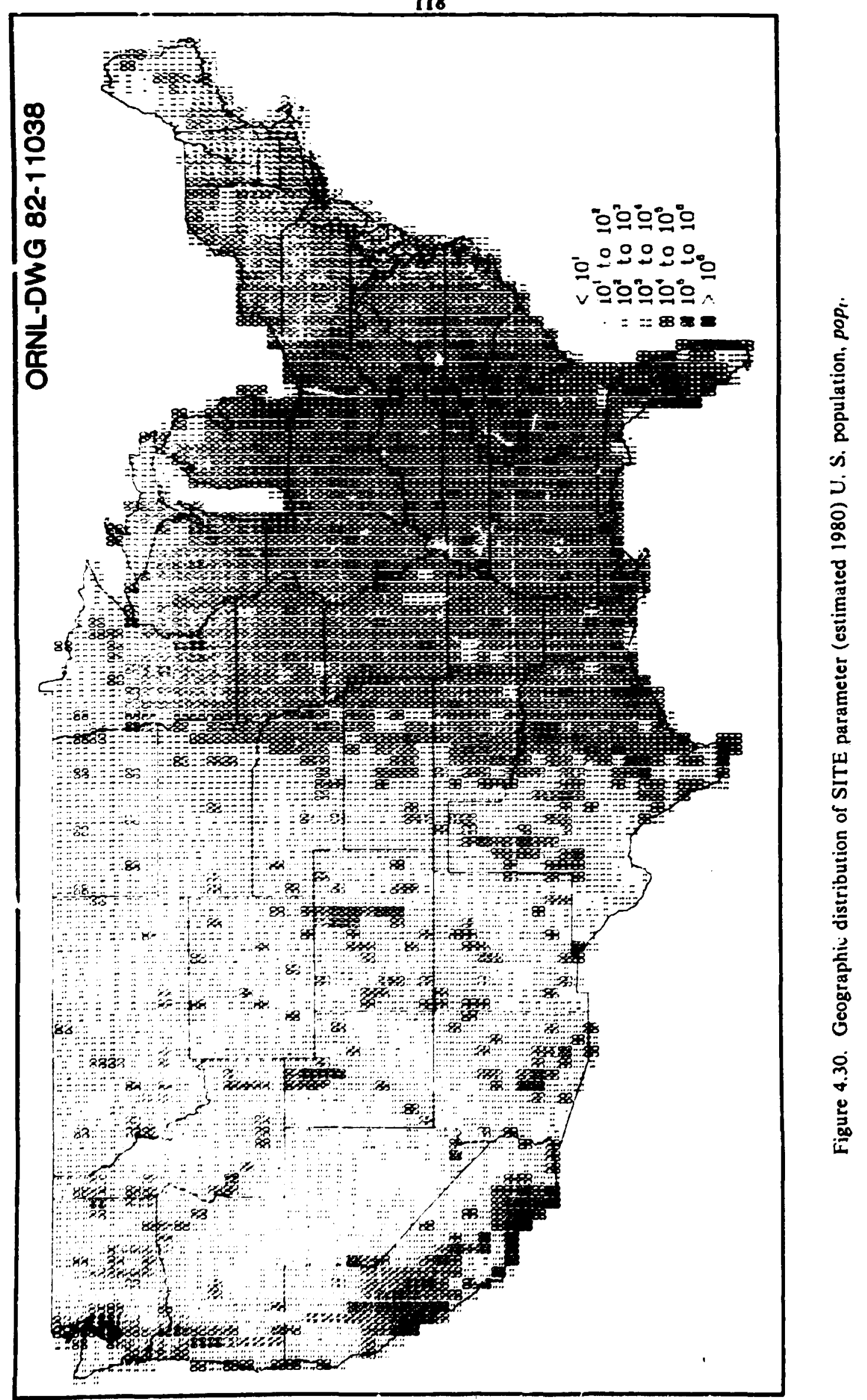




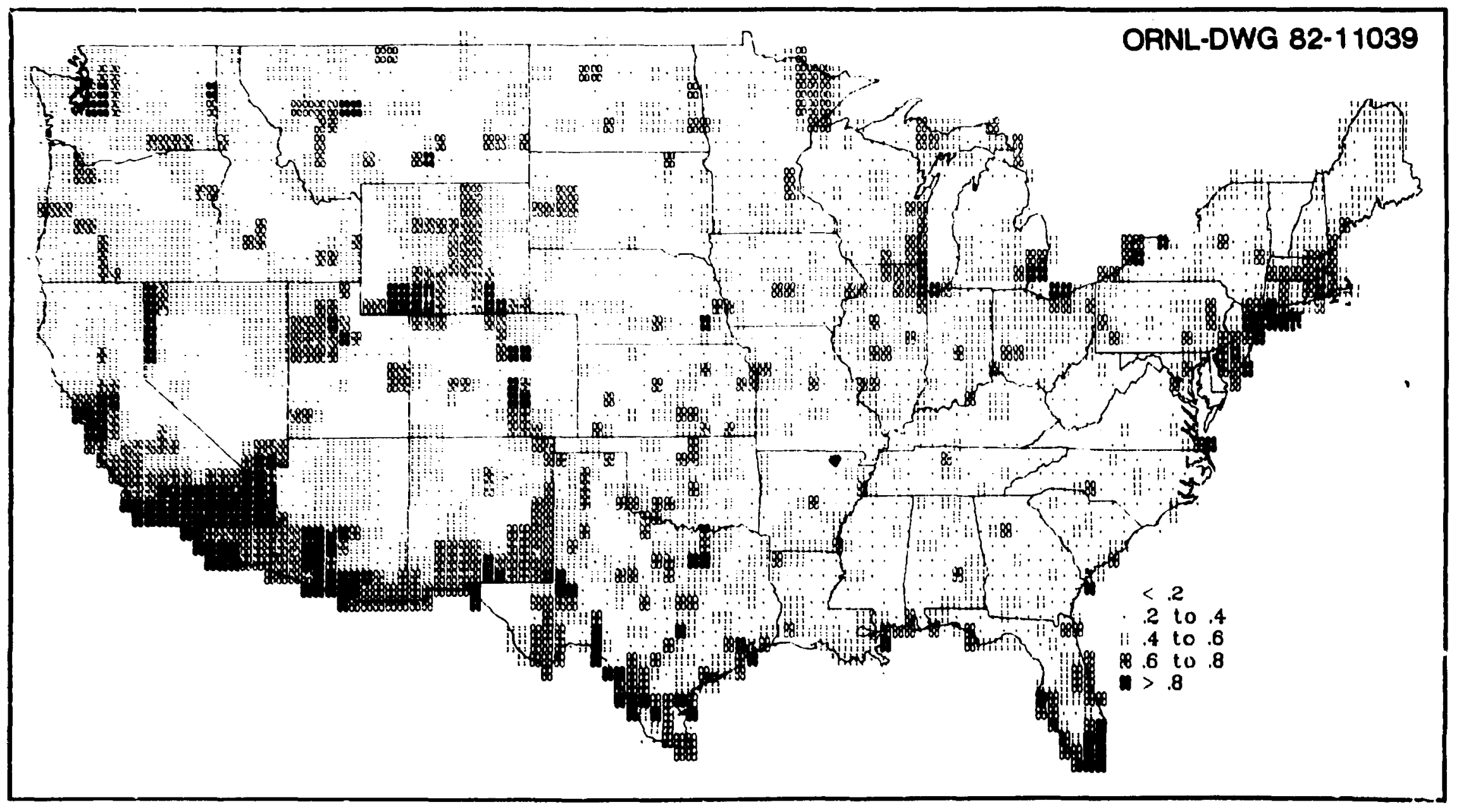

Figure 4.31. Geographic distribution of SITE parameter fraction of (1970) population classified as urban. pop ${ }_{n}$. 


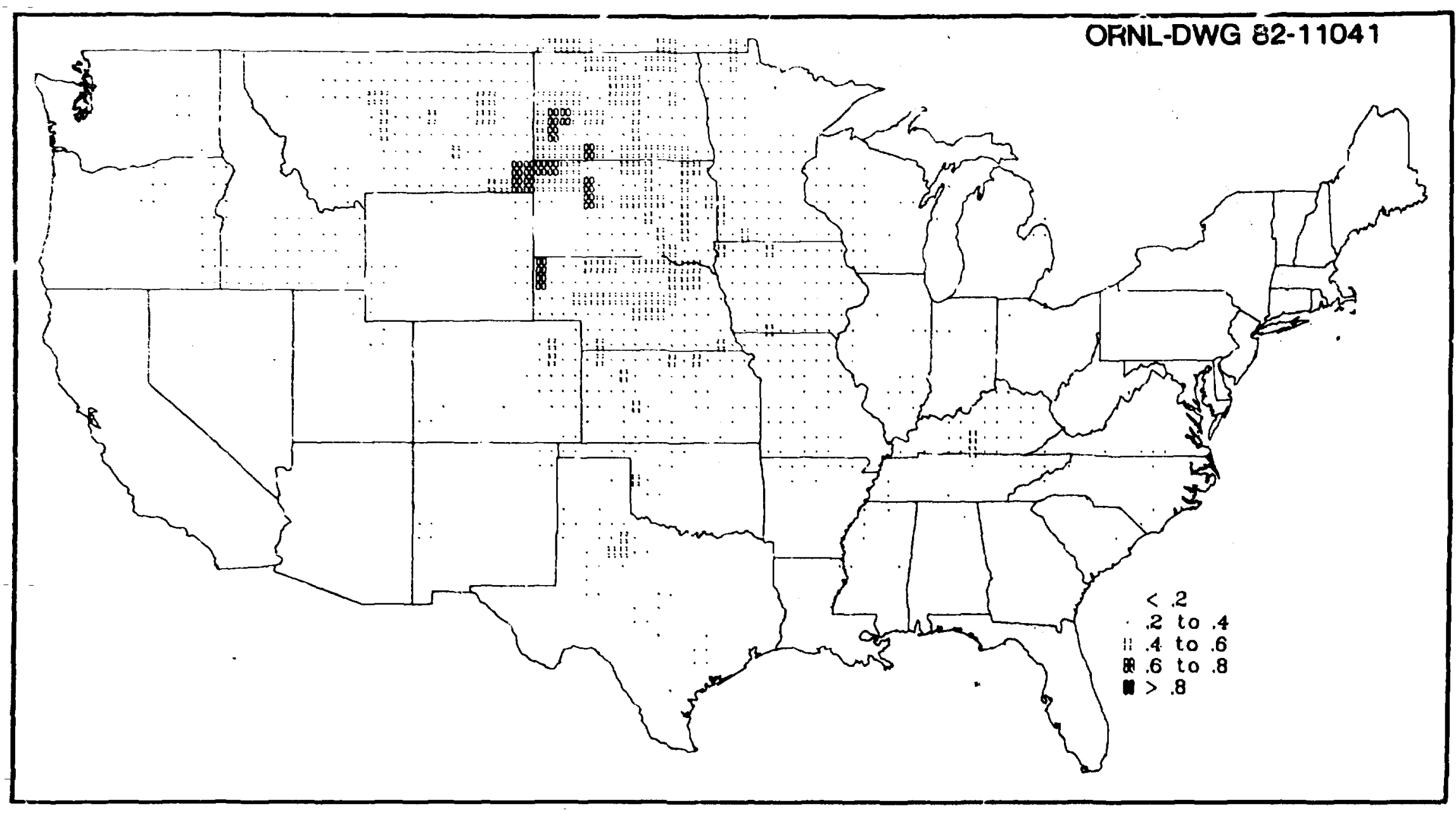

Figure 4.32. Geographic distribution of SITE parameter fraction of (1970) population classified as rural-farm. poprf. 


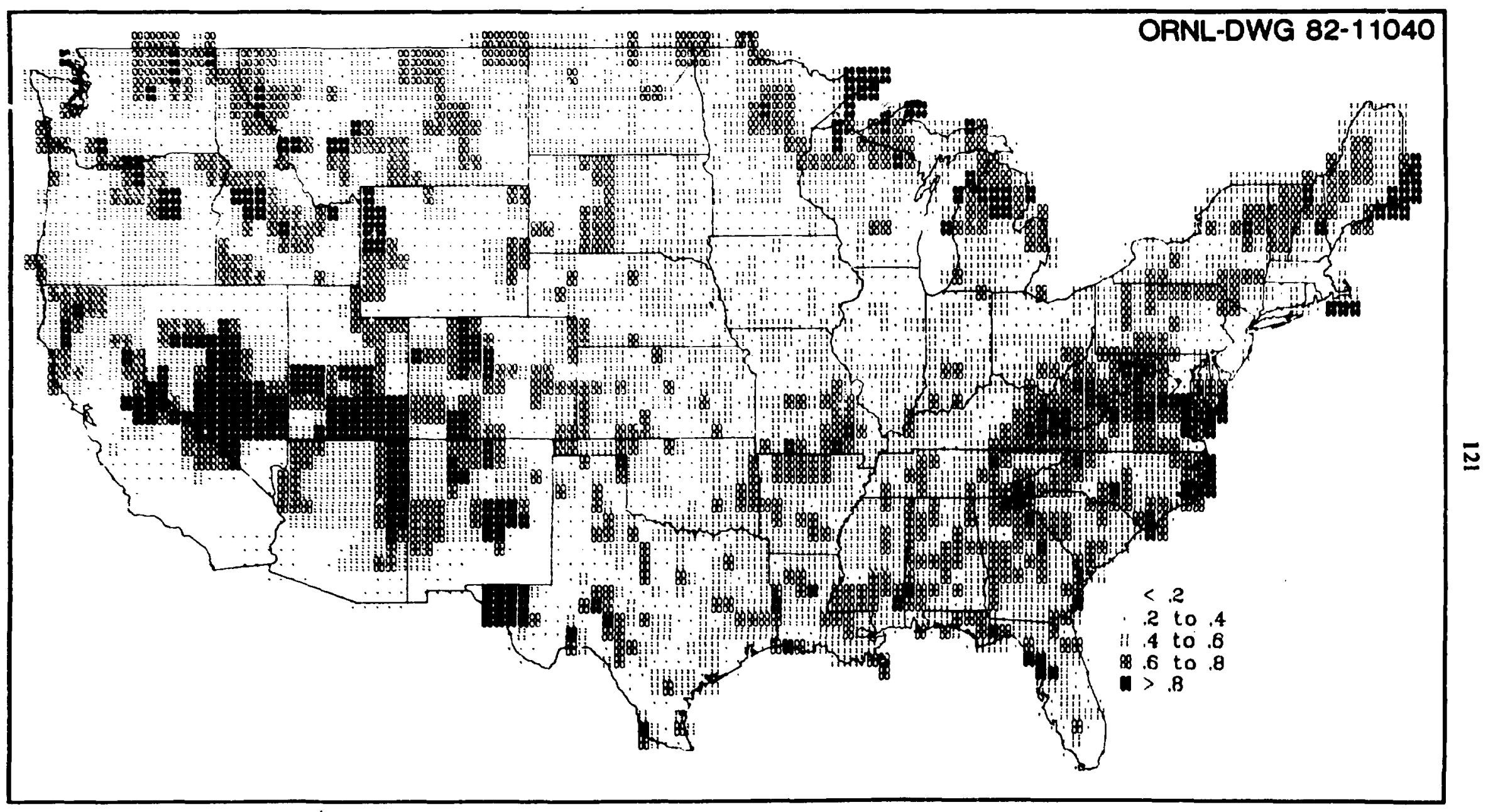

Figure 4.33. Geographic distribution of SITE parameter fraction of (1970) population classified as rural-nonfarm, pop $n$. 


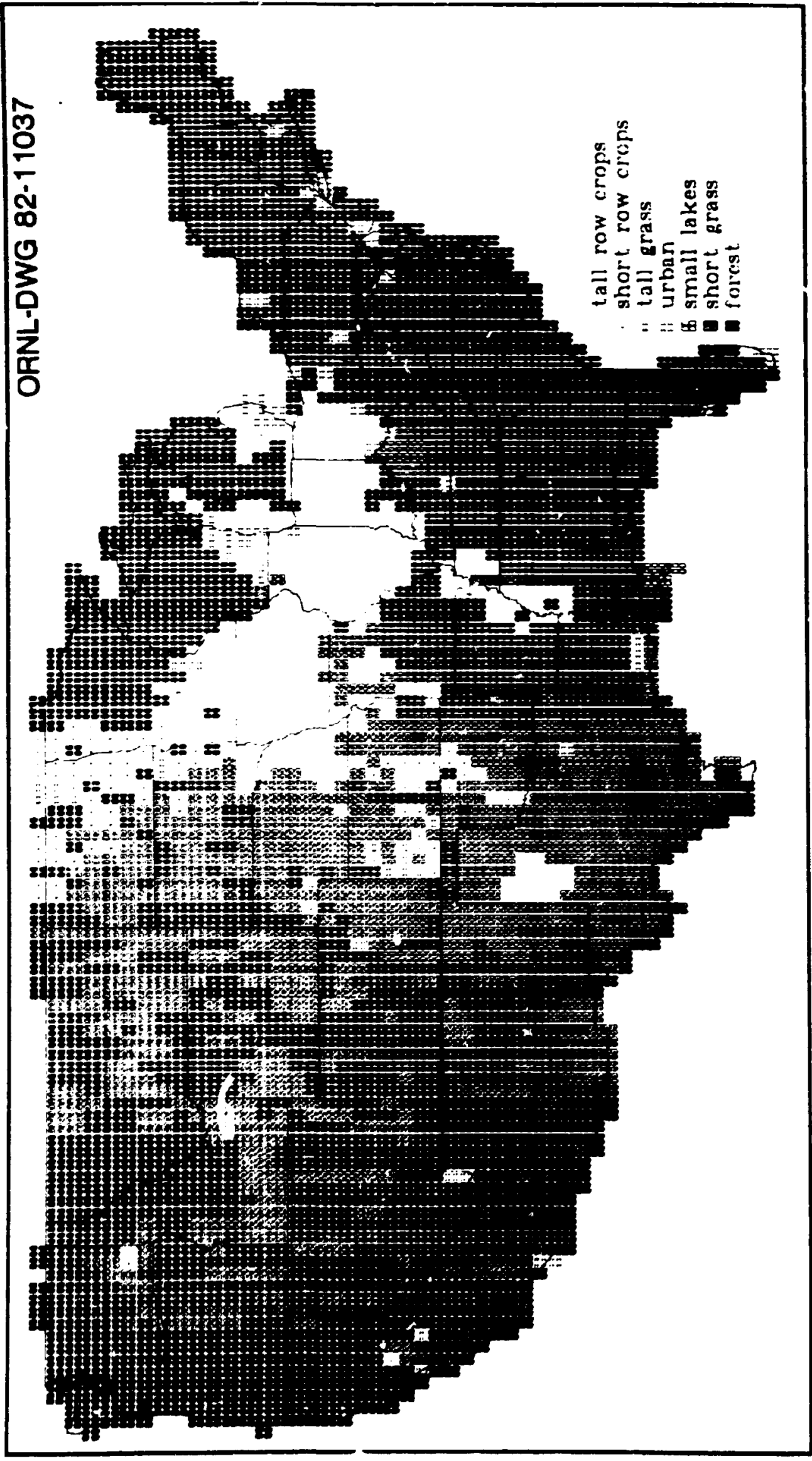

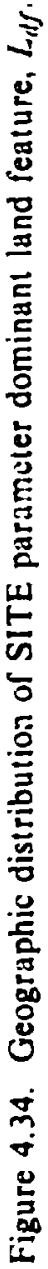


The dominant land features were determined from data gathered by Olson, Emerson, and Nungesser. ${ }^{217}$ They reported areas for each land feature by county. The county areas were converted to cell areas by methods previously described. The land feature with the largest area is considered the dominant land feature.

The dominant land feature is expressed as a code of the form FLPPP. The "F" value is either "0" or "1," for less than or more than $50 \%$ of the total area in the cell classified as Federal land, respectively. Federal land was not subclassified as to land use in data gathered by Olson, Emerson, and Nungesser. ${ }^{217}$ Therefore, an assumption inherent in our estimation of dominant land feature is that Federal and privately owned lands are similar in land feature make up. This assumption may be incorrect, especially when Federal lands are protected forest or wildife areas. The " $L$ " value corresponds to the seven land features previously given. The "PPP" value indicates the percentage of the total area of the cell corresponding to the " $L$ " category. 


\section{MISCELLANEOUS PARAMETERS}

Other default parameters included in the TERRA code are the weathering removal constant, $\lambda_{w}$, the metabolic removal rate constants from milk and beef, $\lambda_{m}$ and $\lambda_{f}$, respectively, and the lifetirie grain and forage requirements of cattle on feed, $Q_{\varepsilon}^{f c}$ and $\mathcal{Q}_{f}$, respectively. The weathering removal constant is extremely important in calculating surface plant concentrations due to direct deposition processes, and the latter four parameters are utilized in calculating beef and milk concentrations.

\subsection{The Weathering Removal Loss Constant, $\lambda$,}

After radionuclides are initially deposited on vegetation surfaces environmental processes (in addition to radiological decay) will begin to remove the deposited material. Miller and Hoffman 225 have reviewed the literature on weathering removal of radionuclides from vegetation. They classify the environmental removal processes as wind removal, water removal, growth dilution, and herbivorous grazing. Wind removal may be very effective in removal of freshly deposited large particles ( $>1 \mu \mathrm{m}$ diameter), but not nearly as effective after the first few days. Submicron particles may be released from plant surfaces during periods of rapid growth and high transpiration rates. Also, surface abrasion from wind action may dislodge salt particles, wax, and other surface fragments. Radioactivity associated with these components would also be removed from the vegetation.

Precipitation, fog, dew, and mist-all may remove surface-deposited radionuclides via direct washoff and leaching. Leaching, in addition, may remove radionuclides incorporated into plants through root uptake. Wash-off, like wind removal, seems to be most effective on freshly deposited material. Precipitation falling as a light, continuous drizzle is more efficient than a large quantity of precipitation falling over a much shorter period. 225

Removal due to growth dilution and grazing by herbivores may vary considerably by plant and location. Produce growth characteristics may be quite varied. Slow-growing varieties may be expected to be less affected by growth dilution than faster growing varieties. Grazing by herbivores may be particularly hard to predict.

Weathering removal tends to occur in an exponential manner with a characteristic half-time, $T_{w}{ }^{225}$ From this half-time a weathering removal constant, $\lambda_{w}$, may be derived according to

$$
\lambda_{w}=\frac{\ln 2}{T_{w}}
$$

In the TERRA code the value of $\lambda_{w}$ adopted by the USNRC 6 of $5.73 \times 10^{-7} \mathrm{~s}^{-1}$ (equal to a $T_{w}$ of $14 \mathrm{~d}$ ) is used for all radionuclides (except for iodine) on all plant surfaces. This value is somewhat arbitrary, but is within the range of reported values in the literature. In their literature review, Miller and Hoffman ${ }^{22 s}$ found measured values of $T_{w}$ to range between 2.8 to 34 days with a geometric mean of all reported values of 10 days. For $l_{2}$ vapor, iodine particulates, and other particulates on herbaceous vegetation the geometric means of reported values of $T_{w}$ are 7.2, 8.8, and 17 days, respectively. The value of $T_{w}$ used in TERRA is $1.0 \times 10^{-6} \mathrm{~s}^{-1}$, which corresponds to a $T_{w}$ of 8 days.

\subsection{The Metabolic Turnover Constant For Millk, $\lambda_{\boldsymbol{w}}$}

In the TERRA code radionuclide transfers to beef and milk are modeled via a single compartment model whereby the radionuclide is transferred from feed directly in milk and beef. This approach differs from the approach taken by the USNRC ${ }^{6}$ in that isot pes of the same 
element with significantly different half-lives may yield different milk and beef concentrations, even though the milk and beef transfer coefficients $\left(F_{m}\right.$ and $F_{f}$, respectively) are the same for the isotopes. Such one-compartment models require quantification of all inputs and outputs from the compartment. For milk and beef the metabolic removal constants must be known.

The model for radionuclide transfer to milk is given by

$$
C_{m}=\frac{C_{f e a d} Q_{f m e} f_{m m}\left(1-\exp -\left(\lambda_{m} t_{m}\right)\right)}{m_{p} \lambda_{m}},
$$

where

$\begin{aligned} C_{m} & =\text { the radionuclide concentration in milk (Bq or } \mathrm{Ci} / \mathrm{kg}), \\ C_{\text {feed }} & =\text { the radionuclide concentration in feed (Bq or } \mathrm{Ci} / \mathrm{kg}), \\ Q_{\text {feed }} & =\text { the ingestion rate of feed }(\mathrm{kg} / \mathrm{s}), \\ f_{c m} & =\text { the fractional transfer from ingested feed to milk (unitless), } \\ \lambda_{m} & =\text { the metabolic turnover constant for milk }\left(\mathrm{s}^{-1}\right), \\ t_{m} & =\text { the time at which milk is sampled }(\mathrm{s}), \text { and } \\ m_{p} & =\text { the quantity of milk collected per milking }(\mathrm{kg}) .\end{aligned}$

At equilibrium Eq. (48) reduces to

$$
C_{m}=\frac{C_{\text {feed }} Q_{\text {feed }} f_{\text {Im }}}{m_{p} \lambda_{m}}
$$

Since by the USNRC ${ }^{6}$ approach,

$$
C_{m}=86,400 C_{\text {feed }} Q_{\text {feed }} F_{m} \text {. }
$$

where $86,400=$ the number of seconds in a day, then

$$
f_{l m}=86,400 F_{m} m_{p} \lambda_{m}
$$

Since $F_{m}$ and $m_{p}$ are already known (from reference $7 m_{p}=13.4 \mathrm{~kg}$ ), then the unly parameter which needs to be defined is $\lambda_{m}$.

$\mathrm{Ng}$ and his associates ${ }^{145}$ have determined values of metabolic halftimes, $T_{m}$, for various elements in milk (Fig. 5.1: note that these values of $T_{m}$ are in terms of days rather than seconds). They consider a value of $T_{m}$ of $0.693 \mathrm{~d}$ (equi! to $\ln 2$ ) to be conservative. Such a value of $T_{m}$ is equivalent to a $\lambda_{m}$ of $1.0 / \mathrm{d}$ or $1.16 \times 10^{-5} / \mathrm{s}$. This latter value is adopted for calculation of milk concentrations in the TERRA code. Using this value in Eqs. (49) and (51) allows for an equilibrium milk concentration to be achieved within approximately seven days.

\subsection{The Metabolic Tumover Constant For Beef, $\lambda_{1}$}

The metabolic turnover constant for beef is determined in a manner similar to that for milk by substituting the fractional transfer to beef, $f_{i f}$, the time to slaughter, $t_{s}$, the muscle mass of teef cattle, $m_{m}$, the metabolic turnover constant for beef, $\lambda_{f}$, and the beef transfer coefficient. $F_{f}$ for the respective parameters $f_{i m}, t_{m}, m_{p}, \lambda_{m}$, and $F_{m}$ in Eqs. (49)-(51). However, estimates of $\lambda_{f}$ in not appear to be available in the literature. In fact, the question of whether equilibrium heef concentration ever occurs for some radionuclides has never been completely resolved. As default in 


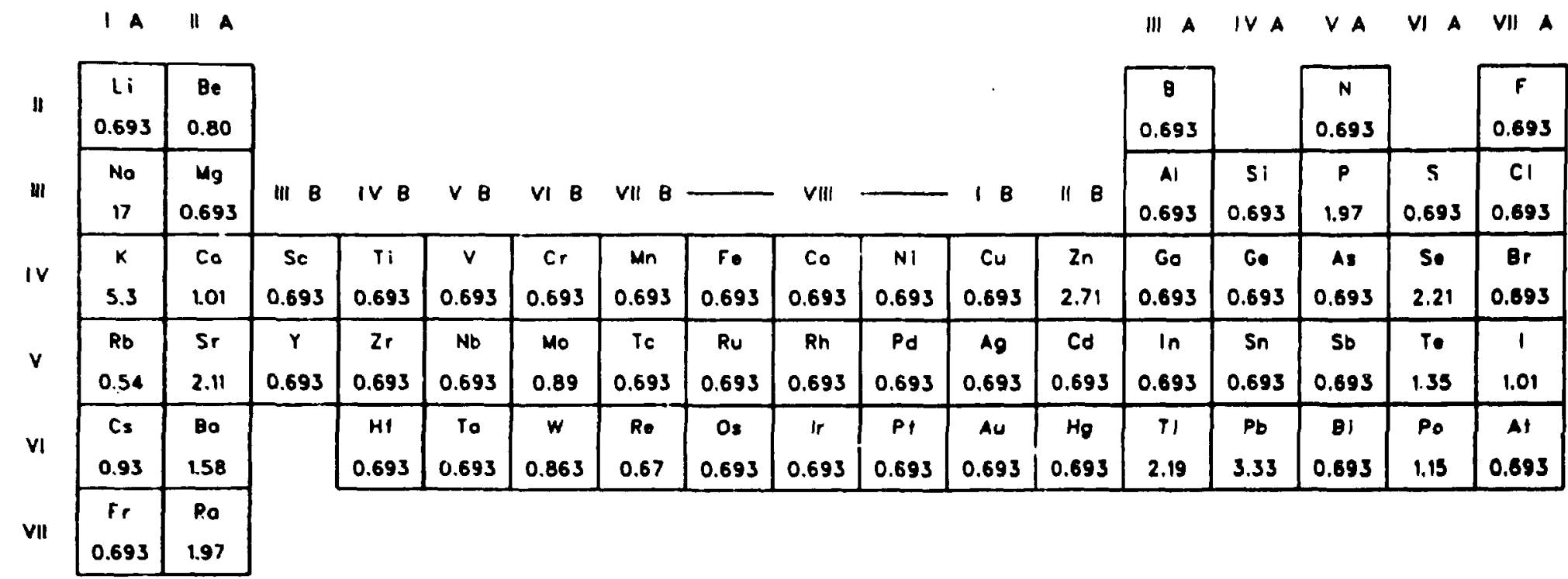

\begin{tabular}{|c|c|c|c|c|c|c|c|c|c|c|c|c|c|c|c|}
\hline Lonthonides & $\begin{array}{c}\text { Lo } \\
0.693\end{array}$ & $\begin{array}{c}c_{1} \\
0.693\end{array}$ & $\begin{array}{c}\text { Pr } \\
0.693\end{array}$ & $\begin{array}{l}\text { Nd } \\
0.693\end{array}$ & $\begin{array}{l}P_{m} \\
0.693\end{array}$ & $\begin{array}{c}\mathrm{Sm} \\
0.693\end{array}$ & $\begin{array}{c}\text { Eu } \\
0.693\end{array}$ & $\begin{array}{c}\text { Gd } \\
0.693\end{array}$ & $\begin{array}{c}\text { To } \\
0.693\end{array}$ & $\begin{array}{c}D_{y} \\
0.693\end{array}$ & $\begin{array}{l}\text { Ho } \\
0.6983\end{array}$ & $\begin{array}{c}\text { Er } \\
0.693\end{array}$ & $T_{0.693}^{T m}$ & $\begin{array}{c}Y_{b} \\
0.693\end{array}$ & $\begin{array}{l}\text { Lu } \\
0.693\end{array}$ \\
\hline Actinides & $\begin{array}{c}A c \\
0.693\end{array}$ & $\begin{array}{c}\text { Th } \\
0.693\end{array}$ & $\begin{array}{c}P_{0} \\
0.693\end{array}$ & $\begin{array}{c}U \\
0.693\end{array}$ & $\begin{array}{c}\text { Np } \\
0.693\end{array}$ & $\begin{array}{c}P_{u} \\
0.693\end{array}$ & ${ }_{0.693}^{A m}$ & $\begin{array}{c}\mathrm{cm} \\
0.693\end{array}$ & & & & & & & \\
\hline
\end{tabular}

Key: $\begin{gathered}L i \\ 0.693\end{gathered}-\begin{aligned} & \text { Symbol } \\ & \text { Transfor Coefficiont. } T_{m}\end{aligned}$

Figure 5.1. Metabolic half-times for the elements in milk (days), based on reference 145. 
TERRA we have assumed that equilibrium does, indeed, occur, and a $\lambda_{f}$ of $5.73 \times 10^{-7} / \mathrm{s}$ (equal to a $T_{f}$ of $14 \mathrm{~d}$ ) is reasonable. Such a turnover rate constant allows for equilibrium to be achieved after approximately 90 days.

\subsection{Lifetine Grain and Forage Repireneats For Cattle O. Feed, $Q_{c}^{k}$ and $Q_{i}^{k}$, Reqpectively}

In calculating radionuclide transport into beef the average annual lifetime feeding schedule of the cattle is combined with the predicted radionuclide concentrations in the feed to predict average annual intake of radionuclides by the cattle. For milk cows and "ail other" cattle the inventory feeding schedules may be used in the calculation because slaughtered individuals from these categories may be assumed to have always resided in their respective category. However, lifetime grain and forage requirements for cattle on feed are different from the inventory grain and forage requirements (discussed in the report by Shor, Baes, and Sharp. ${ }^{7}$ ) which are used in the calculation of pasture production (Sect. 4.1) because they take into account the moversent of the individuals from one inventory category to another. These lifetime average feeding rates are used in the calculation of beef concentrations in the TERRA code.

Since the cattle in feedlots are slaughtered after an average occupancy of six months, and since they enter and leave the feedlot throughout the year, the lifetime feeding rate of grain and forage is a mix of the feeding schedules in the inventory categories "all other cattle" and "cattle on feed." For example, an animal entering the feedlot at the beginning of the year would have been fed on the feedlot schedule only before slaughter, but those entering thereafter until the end of the year would have been fed a combination of the feedlot and "all other cattle" schedules before slaughter. In determining the lifetime feeding schecule of slaughtered cattle from feedlots, we assume that entry and exit from the feedlot is at a constant rate equal to $s_{g} / 365$ or $n_{g} / 182.5$. The ideal animal entering the lot is 9 months old and is fed for 6 months or 182.5 days. In order to find an average feeding rate for this animal, his feed is added over the last 13.5 months of his life (the first 1.5 months is assumed to be on milk) and 12/13.5 of this amount is his annual rate of feeding. From Table 17 of reference 7 the daily grain consumption rate for cattle on grain is $5.0 \mathrm{~kg} / \mathrm{d}$ (equal to 1820/365). The comparable rate for forage is $2.7 \mathrm{~kg} / \mathrm{d}$. The respective rates for the "all other cattle" category are $0.4 \mathrm{~kg} / \mathrm{d}$ for grain and $8.3 \mathrm{~kg} / \mathrm{d}$ for forage. Therefore the totals for grain and forage for the last 13.5 months of life are $910 \mathrm{~kg}$ and $1003 \mathrm{~kg}$, respectively. The annual rates are $891 \mathrm{~kg}$ and $2108 \mathrm{~kg}$ for grain and forage, respectively. These rates are used in the TERRA code in the calculation of radionuclide concentrations in beef from slaughtered feedlot cattle.

\subsection{The Carbou and Water Coatent of Foods}

In the TERRA code concentrations of tritium (H-3) and carbon-14 in foods are calculated according to a model which assumes that the specific activities of tritium and carbon-14 in foods at a given location are the same as the specific activities of $\mathrm{H}-3$ and $\mathrm{C}-14$ in atmospheric $\mathrm{H}_{2} \mathrm{O}$ and $\mathrm{CO}_{2}$, respectively (equilibrium is assumed). Thus, the first step in calculating activity concentrations of tritium and carbon-14 in food is calculating their respective activity concentrations in atmospheric water vapur and carbon dioxide. For tritium, this calculation is made by utilizing the SITE parameter, absolute humidity, $\mathrm{H}$, by the equation

$$
C_{w \nu}^{H 3}=1000 \frac{C_{d}^{H 3}}{H}
$$

$$
\begin{aligned}
& \text { where, } \\
& C_{m}^{*}=\text { the activity concentration of tritium in atmosr seric water vapor ( } \mathrm{Bq} \text { or } \mathrm{Ci} / \mathrm{kg} \text { ), } \\
& C_{a}^{H 3}=\text { the activity concentration of tritium in air based on the atmosp. seric dispersion } \\
& \text { calculation ( } \mathrm{Bq} \text { or } \mathrm{Ci} / \mathrm{m}^{3} \text { ), and } \\
& H=\text { the absolute humidity }\left(\mathrm{g} / \mathrm{m}^{3}\right) \text {. }
\end{aligned}
$$


Oace the specific activity of $\mathrm{H}-3$ in atmospheric water vapor is calculated, then the same activity in the atmospherically derived water of vegetable produce, beef, and mill is assumed. That is

$$
C_{f o n}^{+3}=C_{i}^{+13} \cdot f
$$

where

$$
\begin{aligned}
C_{f o d}^{H 3}= & \text { The tritium activity concentration in food (Bq or } \mathrm{Ci} / \mathrm{kg} \text { ) and } \\
f_{w} & =\text { the fraction of water in food derived from atmospheric sources (unitless). }
\end{aligned}
$$

Traditionally, the tritium concentration in food has been assumed to be $50 \%$ of tritium concentration in air $(F=0.5)$ based on a model by Anspaugh, et al. 23 However, recest empirical evidence suggests that tritium concentration in vegetation under chronic exposure conditions is searly equal to the tritium air concentration $(F=1.0)^{m}$ In the TERRA code the default is the latter assumption.

The water content of the produce categories may be derived from the dry-to-wet weight conversion factors presented in Tabi= 2.3. The value (1.0 - the listeo conversion factor) gives the kilograms of $\mathrm{H}_{2} \mathrm{O}$ per kjlogram fresh produce. For beef and milk, reference 14 yiekds 0.615 and 0.87 kilograms of water :er kilogram oi fresh, uncooked food, respectively. The water content of leafy vegetables is assumed to be 0.934 (Table 5.1).

A specific activity approach, analogous to that for tritium, is used for carbon-14. The specific activity of $\mathrm{C}-14$ in atmospheric $\mathrm{CO}_{2}$ is given by

$$
C_{c i}^{C 14}=1000 \frac{C_{a}^{C 14}}{0.18}
$$

where

$$
\begin{gathered}
C_{c d}^{C i 4}=\text { the activity concentration of carbon-14 in atmospheric } \mathrm{CO}_{2}(\mathrm{~Bq} \text { or } \mathrm{Ci} / \mathrm{kg}) \text {, } \\
C_{d}^{C 14}=\begin{array}{c}
\text { the activity concent-ation of carbon-14 in air based on the atmospheric dispersion } \\
\text { calculation }\left(\mathrm{Bq} \text { or } \mathrm{Ci} / \mathrm{m}^{3}\right) \text {, and }
\end{array} \\
0.18=\begin{array}{c}
\text { the average concentration of } \mathrm{CO}_{2} \text { in the atmosphe: }\left(\mathrm{g} / \mathrm{m}^{3}\right) \text {, corresponding to } 330 \\
\text { ppm by volume. } 228
\end{array}
\end{gathered}
$$

The carbon content of the food categories in TERRA, based on a recent review by Killough ${ }^{229}$ and supplemental information from reference 14, is given in Table 5.2.

\subsection{Coarse (2.5 - $15 \mu \mathrm{m})$ Suspended Particulate Matter}

Resuspension of material deposited on surface soils is calculated in TERRA via a mass loading approach. ${ }^{230}$ In such an approach the specific activity of a radionuclice in resuspended material is assumed to be the same as the specific activity of surface soil. Thus, the calculation of surface soil concentration is used together with the quantity of recuspended material in the air (mass loading) to calculate an air concentration due to resuspension. This air concentration is given by

$$
C_{a}^{*}=\frac{C_{s} P_{s w}}{1 \times 10^{9}},
$$




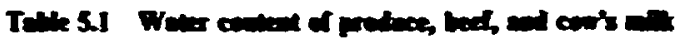

\begin{tabular}{|c|c|c|c|c|}
\hline Food & $\begin{array}{l}\text { Writer } \\
\text { conteate }\end{array}$ & $\begin{array}{l}\text { Wcightin: } \\
\text { Isctort }\end{array}$ & Food & $\begin{array}{l}\text { Winter } \\
\text { content }\end{array}$ \\
\hline Leafy regetables & & & Beed & \\
\hline Brocooli & 0.899 & 3.7 & Chuct & 0.65 \\
\hline Bressed sprouts & 0.849 & 0.6 & Flant & 0.61 \\
\hline Cabbuge & 0.924 & 220 & Hamburger & 0.55 \\
\hline Caulifiomer & 0.917 & 28 & Liver & 0.697 \\
\hline Cetery & 0.937 & 15.5 & Ponterhouse & 0.58 \\
\hline Escarole & 0.866 & 1.1 & Rib roest & 0.59 \\
\hline Green onjous & 0.876 & 26 & Round & 0.69 \\
\hline Lettuce & 0.948 & 46.0 & Rump & 0.55 \\
\hline Spinach greens & 0.927 & 5.7 & Sirboia & 0.62 \\
\hline Weighted average & 0.936 & & Average & 0.615 \\
\hline Exposed producer & 0.874 & & Whole com's milk & 0.870 \\
\hline Protected producer & 0.778 & & & \\
\hline Grain foods & 0.112 & & & \\
\hline
\end{tabular}

'Kilograms of water per kilogram frech, uaprepared produce or edible portions of uncooked food (reference 14).

'Relative importance based on production in kilograms ( $\%$ of total) in tine conteminous United States.

'Based on values given in Table 2.3.

where

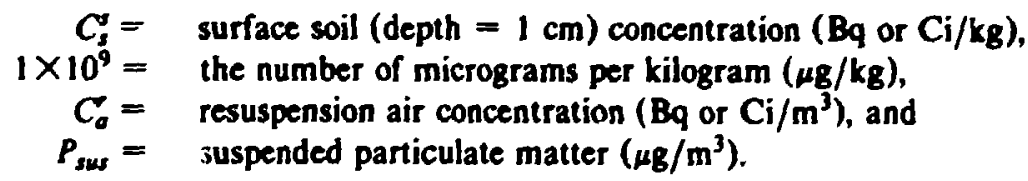

In TERRA the mass loading value $P_{\text {sus }}$ is based on data reported by the EPA. ${ }^{23 I}$ This

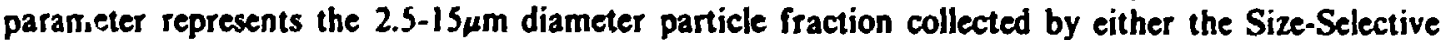
Inlet (SSI) hi vol or the dichotomous samplers operated as part of the Inhalabie Particulate Network (IPN) operated by EPA's Environmental Monitoring and Support Laboratory, Research Triangle Park. Inhalable suspended particulate matter appears to be bimodally distributed into fine and coarse particle sizes. The fine fraction $(<0.1-2.5 \mu \mathrm{m})$ are mostly generated by fossil fuel combustion and atmospheric photochemistry processes. The coarse fraction $(2.5-15 \mu \mathrm{m})$ is primarily a result of windblown dusts, mechanical processes, and polien.

The value of $P_{\text {sus }}$ of $15.5 \mu \mathrm{g} / \mathrm{m}^{3}$ used as default in TERRA is the geometric mean of values taken from the April 1979.June 1980 IPN summary (Fig. 5.2). The data are reported for 46 sampling locations in the conterminous United States, and represent annual arithmetic avcrages for each station. As shown in Fig. 5.2, the parameter $P_{\mathrm{f}, \mathrm{r}}$ is lognormally distributed. The range of measured values is from 3.2 to $52.4 \mu \mathrm{g} / \mathrm{m}^{3}$. 


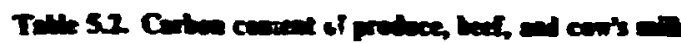

\begin{tabular}{|c|c|c|c|c|c|c|c|}
\hline Food & $\begin{array}{l}\text { Carbon } \\
\text { coateat" }\end{array}$ & $\begin{array}{l}\text { Weighting } \\
\text { fector" }\end{array}$ & Reference & Food & $\begin{array}{l}\text { Carbon } \\
\text { content }\end{array}$ & $\begin{array}{l}\text { Weighting } \\
\text { factor }\end{array}$ & Referesce \\
\hline Leafy regetables & & & & Protected prodece & & & \\
\hline Brocooli & 0.042 & 3.7 & 230 & Bean (dy) & 0.198 & 22 & 230 \\
\hline Brossed sprouts & 0.065 & 0.6 & 230 & Cantaloupe & 0.025 & 1.1 & 230 \\
\hline Cabbage & 0.032 & 22.0 & 230 & Carrot & 0.049 & 24 & 230 \\
\hline Canlifiower & 0.035 & 28 & 230 & Grapefruä & 0.048 & 5.5 & 14 \\
\hline Ceiery & 0.024 & 15.5 & 230 & Lemon & 0.047 & 24 & 14 \\
\hline Escarole & 0.056 & 1.1 & 14 & Onion & 0.054 & 3.6 & 14 \\
\hline Green onioas & 0.053 & 26 & 14 & Orange & 0.055 & 228 & 230 \\
\hline Lettuce & 0.020 & 46.0 & 230 & Peanut & 0.574 & 3.4 & 230 \\
\hline \multirow[t]{2}{*}{ Spinach groecus } & 0.028 & 5.7 & 230 & Peas & 0.114 & 0.4 & 14 \\
\hline & & & & Potato & 0.035 & 33.7 & 230 \\
\hline \multirow[t]{2}{*}{ Weighted average } & 0.026 & & & Segarbeet & 0.051 & 6.5 & 14 \\
\hline & & & & Sugarcane & 0.438 & 5.5 & 230 \\
\hline \multirow[t]{2}{*}{ Exposed produce } & & & & Sweet corn & 0.118 & 6.0 & 230 \\
\hline & & & & Sreet potato & 0.137 & 1.5 & 230 \\
\hline Apple & 0.070 & 15.4 & 230 & Tree auts & 0.659 & 0.4 & 230 \\
\hline Asperagus & 0.030 & 0.6 & 230 & Watermeloa & 0.034 & 2.6 & 14 \\
\hline Bushberries & 0.070 & 1.6 & 230 & & & & \\
\hline Cherry & 0.074 & 0.7 & 14 & Weighted average & 0.116 & & \\
\hline Cucumber & 0.016 & 4.0 & 14 & & & & \\
\hline Eesplant & 0.031 & 0.1 & 14 & Grains & & & \\
\hline Grape & 0.083 & 20.2 & 230 & & & & \\
\hline Peach & 0.056 & 6.9 & 230 & Barley & 0.395 & 10.1 & 230 \\
\hline Pear & 0.076 & 3.5 & 230 & Corn (for meal) & 0.118 & 37.1 & 230 \\
\hline Plums and prunes & 0.062 & 3.1 & 230 & Oats & 0.431 & 2.3 & 230 \\
\hline Sweet peppet & 0.033 & 1.3 & 14 & Rye & 0.396 & 0.5 & 230 \\
\hline Snap bean & 0.047 & 0.7 & 230 & Soybean & 0.465 & 5.3 & 230 \\
\hline Squash & 0.021 & 1.8 & 230 & Wheat & 0.391 & 44.0 & 230 \\
\hline Strawberry & 0.044 & 1.3 & 230 & & & & \\
\hline Tomato & 0.025 & 38.8 & 230 & Weighted average & 0.293 & & \\
\hline Weighted average & 0.050 & & & & & & \\
\hline Beef & 0.228 & & 230 & Whole cow's milk & 0.069 & & 14 \\
\hline
\end{tabular}

-Kilograms of carbon per kilogram fresh, unprepared produce. Based on protein, fat, and carbohydrate content of 50 . 76, and $44 \%$ carbon, respectively.

- Relative importance based on production in kilograms (\% of tolal) in the conterminous United States. 


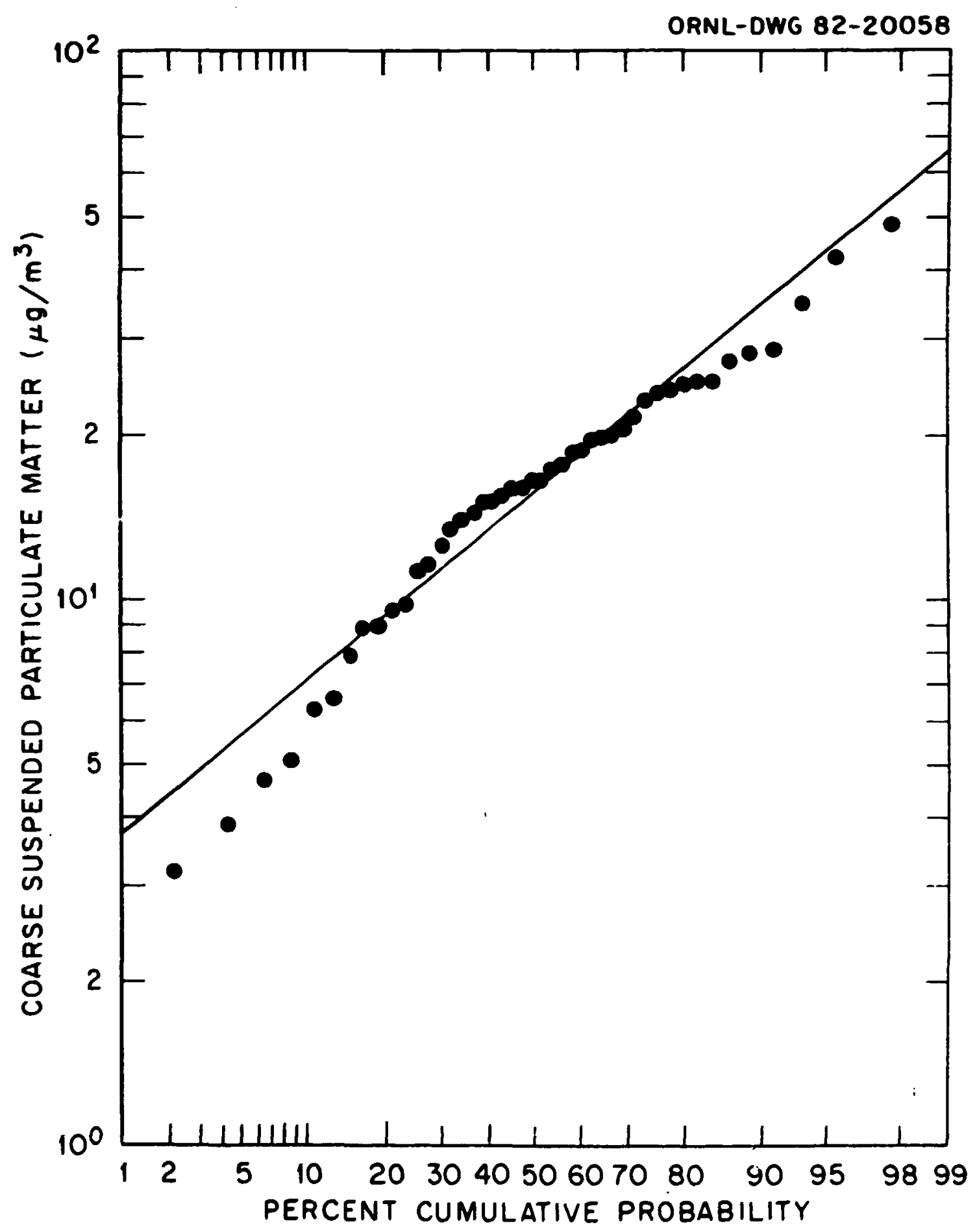

Figure 5.2. Lognormal probability plot of coarse suspended particulate matter $(2.5-15 \mu \mathrm{m})$. 
Resuspended material may contribute to plant surface concentrations before and after termination of the atmospheric source term. In TERRA a deposition rate of the resuspended activity is calculated acco.ding to

$$
D_{r}^{r}=\frac{C_{e} r_{d}}{100},
$$

where

$D_{r}^{\prime}=$ the deposition rate of resuspended material (Bq or $\left.\mathrm{Ci} / \mathrm{m}^{2} / \mathrm{s}\right)$,

$V_{d}=$ deposition velocity of the resuspended material $(\mathrm{cm} / \mathrm{s})$, and

$100=$ the number of centimeters in a meter $(\mathrm{cm} / \mathrm{m})$.

The value of $V_{d}$ used in TERRA is $0.1 \mathrm{~cm} / \mathrm{s}$, which is a reasonable estimate for particle diameters between 2 and $15 \mu \mathrm{m}$, a friction velocity of $30 \mathrm{~cm} / \mathrm{s}$, and particle densities $>1 \mathrm{~g} / \mathrm{cm}^{3}$ as shown by Sehmel ${ }^{32}$ (Figure 5 in reference 232). 


\section{SUMMARY}

In this report we have documented most of the default parameters incorporated into the TERRA computer code. Especially, we have presented a literature review ard systematic anal! sis of element-specific transfer parameters $E_{v}, B_{r,}, F_{m}, F_{f}$, and $K_{d}$. This review and enalysis merely suggests default values which are censistent with the modeling aporoactes taken in TERF $A$ and may he acceptable for most assessment applications of the computer r.ode. However, purticular applications of the code and additional analysis of elemental transport may require al' :rnative values to the default values in TERRA. Also, use of the values reported herein in other computer codes simulating terrestrial transport is not advised without careful interpretation of the litsitations and scope of our analyses.

In addition to the default elemental transport parameters, we have discussed an approach to determination of vegetation-specific interception fractions. The limitations of this approach arc many, and its use indicaies the need for analysis of deposition, interception, and weathering processes. Judgement must be exercised in interpretation of plant surface concentrations generated through use of our approach.

Finally, we have documented the location-specific agricultural, climatological, and population parameters in the default SITE data base. These parameters are intended as alternatives to "average" values currently used in assessment models. Indeed, areas in the United States where intensive crop, milk, or teef production occurs will be reflected in the parameter values as will areas where little agricultural activity occurs. However, the original information sources contained some small error and the interpolation and conversion methods used will add more. Therefore, our values should be regarded as default best estimates, not absolute "correct" values. As with any assessment, site-specific information is recommended over default values.

Parameters used in TERRA not discussed herein are discussed in the companion report to this one-ORNL-5785. ${ }^{3}$ In the companion report the models employed ir, and the coding of TERRA are discussed. These reports together provide documentation of the TERRA code and its use in assessments. 


\section{REFERENCES}

[1] Moore, R. E., C. F. Laes, III, L. M. McDowell-Boyer, A. P. Watson, F. O. Hoffman, J. C. Pleasant, and C. W. Miller. 1979. AIRDOS-EPA: A Computerized Methodology for Estimating Environmental Concentrations and Dose to Man from Airborne Releases of Radionuclides. ORNL-5532. Oak Ridge National Laboratory.

[2] Begovich, C. L., K. F. Eckerman, E. C. Schlatter, S. Y. Ohr, and R. O. Chester. 1981. DARTAB: A Program to Combine Airborne Radionuclide Environmental Exposure Data with Dosimetric and Ilealth Effects Data to Generate Tabulntions of Predicted Impacts. ORNL-5692. Oak Ridge National Laboratory.

[3] Baes, C. F., III, R. D. Sharp, A. L. Sjoreen, and O. W. Hermann. In press. TERRA: A Computer Code for Calculation of the Transport of Environmentally Released Radionuclides Through Agriculture. ORNL-5785. Oak Ridge National Laboratory.

[4] Miller, C. W., C. L. Begovich, O. W. Hermann and A. L. Sjoreen. In press. ANEMOS: A Computer Code to Estimate Air Concentrations and Ground Deposition Rates for Atmospheric Nuclides Emitted from Multiple Operating Sources. ORNL-5913. Oak Ridge National Laboratory.

[5] Begovich, C. L., S. Y. Ohr, R. O. Chester, and A. L. Sjoreen. In press. ANDROS: A Code for Assessment of Nuclide Doses and Risks with Option Selection. ORNL-5889. Oak Ridge National Laboratory.

[6] U.S. Nuclear Regulatory Commission. 1977. Regulatory Guide 1.109, Calculation of Annual noses to Man from Routine Releases of Reactor Effluents for the Purpose of Evaluating Compliance with 10 CFR Part 50 Appendix I (Revision I). Office of Standards Development.

[7] Shar, R. W., Baes, C. F., III, and R. D. Sharp. 1982. Agricult'sral Production in the United States by County: A Compilation of Information from the 1974 Census of Agriculture for Use in Terrestrial Food Chain Transport and Assessment Models. ORNL5768. Oak Ridge National Laboratory.

[8] Gibbons, J. W., D. C. Adriano, J. J. Alberts, and K. W. McLeod. 1978. Critical Paıhways of Radionuclides to Man from Agro-Ecosystems. NUREG/CR-0536.

[9] Hersloff, L. W. and J. C. Corey. 1978. "Uptake of three isotopes of plutonium from soil by sweet corn grown in a growth chamber." In Adriano, D. C. and I. L. Brisbin, Jr., (eds.) Environmental Chemistry and Cycling Process. Proceedings of a symposium held at Aug:sta, Ga. April 28-May 1, 1976. pp. 622-627.

[10] Schreckhise, R. G. and J. Z. Clíne. 1980. "Comparative uptake and distribution of plutonium, amerizium, curium, and neptunium in four plant species." Health Phys. 38: 8i 7-824.

[11] Morgan, A. 1959. "The uptake of ${ }^{90} \mathrm{Sr}$ by rye grass." J. Nucl. Energy Part A: Reactor Sci. 11: 8-13.

[12] Baes, C. F., III and R. D. Sharp. 1981. A Directory of Parameters Used in a Series of Assessment Applications of the AIRDOS-EPA and DARTAB Computer Codes. ORNL5710. Oak Ridge National L,aboratory.

[13] Morrison, F. B. 1956. Feeds and Feeding. A Handbook for the Student and Stockman. 22nd ed. The Morrison Publishing Co., Ithaca, New York.

114] Spector, W S. 1956. Handbook of Biological Data. W. B. Saunders Co., Philadclphia. p. 187. 
[15] Ng, Y. C., C. A. Burton, S. E. Thompson, R. K. Tandy, H. K. Kretner, and M. W. Pratt. 1968. "Prediction of the maximum dosage to man from the fallout of nuclear devices." In Handbook for Estimating the Maximum Internal Dase from Radionuclides Released to the Biosphere. UCRL-50163, Pt. IV. Lawrence Radiation Laboratory.

[16] Baes, C. F., III and J. A. Katz. Unpublished analysis of East Tennessee pumpkins, vines, and soils.

[17] Haghiri, F. 196 \&. "Strontium-90 accumulation by some vegetable crops." Ohio J. Sci. 64(5): $371-374$.

[18] Fredriksson, L. and $\dot{A}$. Eriksson. 1970. "Plant uptake of fission products I. Uptake of ${ }^{90} \mathrm{Sr}$ in pot experiments in relation to uptake under field conditions " Lantbrkögsk. Annlr. 36: 3-18.

[19] Cherry, D. S. and R. K. Guthrie. 1979. "The uptake of chemical elements from coal ash and settling basin effluent by primary producers II. Relation between concentrations in ash deposits and tissues of grasses growing on the ash." Sci. Tot. Environ 13: 27-31.

[20] Sheaffer, C. C., A. M. Decker, R. L. Chaney, and L. W. Douglass. 1979. "Soil temperature and sewage sludge effects on metals in crop tissue and soils." J. Environ. Qual. 8(4): $455-459$.

[21] Andersen, A. J. 1971. "Influence of phosphorus and nitrogen nutrition on uptake and distribution of strontium and calcium in oat plants." Soil Sci. Soc. Am. Proc. 35: 108-11.

[2] Essington, E., H. Nishita, and A. Wallace. 1963. "Effect of chelating agents on the uptake of Y-91, Ru-106, Ce-144, and Pm-147 by beans grown in a calcareous soil.' Soil. Sci. 95: $331-337$.

[23] Gast, R. G., E. R. Landa, L. J. Thorvig, D. F. Grigal, and J. C. Balogh. 1979. The behavior of technetium-99 in soils and plants: Final Report for the period April 1, 1974 to December 31. 1978. COO-2447-6. National Technical Information Service, Springfield, Virginia.

[24] Schroeder, H. A. and J. J. Balassa. 1963. "Cadmium: uptake by vegetables from superphosphate in soil." Science 140: 819-820.

[25] Orr, J. B., F. C. Kelly, and G. L. Stuart. 1978. "The effect of iodine maturing on the iodine content of plants." J. Agri. Sci. 18: 159-161.

[26] Haak, E. and Aं. Friksson. 1973. Studies on Plant Accumulation of Fission Products under Swedish Conditions XIV. Uptake of ${ }^{137}$ Cs by Wheat and Timothy from Six Different Soils as Influenced by Rate of K-Fertilization and by Type and Rate of N-Fertilization in Pot Experiments. FOA 4 Rapport. C4557-A3. October, 1973. 36 pp.

[27] Ter Haar, G. 1970. "Air as a source of lead in edible crops." Environ. Sci. Technol. 4(3): 226-30.

[28] Watters, R. L., J. E. Johnson, and W. R. Hansen. 1969. A Study of Unsupported Polonium-210 for Ion Exchangc in Soil and Uptake in Vegetation. Second Technical Progress Report of the Department of Radiology and Radiation Biology, Colorado State University, Fort Collins, Colorado. 80521. COO-1733-3.

[29] Prister, B. S. 1970. "Behavior of uranium in the biologic chain." In USSR Reports on Natural and Fallout Radioactivity. pp. 194-207. AEC-tr-7128, USAEC/HSL.

[30] Wallace, A., E. M. Romney, H. Nishita, and E. K. Schulz. 1979. Preliminary Analysis of First Crop of Plants Grown in Seven Soils Uniformily Contaminated with Four Transuranic Elements Simultaneously. University of California, L.A. NUREG/CR-0700. 
[31] Romney, E. M., W. L. Ehrler, A. H. Lange, and K. H. Larson. 1960 . "Some environmental factors influencing radiostrontium uptake by plants." Plant and Soil 12(1): 41-48.

[32] Duckworth, R. B. and J. Hawthorn. 1960. "Uptake and distribution of strontium in vegetables and cerals." J. Sci. Food Agric. 11: 218-225.

[33] Evans, E. J. and A. J. Dekker. 1962. "Comparative Sr-90 content of agricultural crops grown in a contaminated soil." Can. J. Plant Sci 42: 252-258.

[34] Evans, E. J. and A. J. Dekker. 1968. "Comparative Cs-137 content of agricultural crops grown in a contaminated soil." Can. J. Plant Sci. 48: 183-188.

[35] Singh, B. R. and K. Steenberg. 1974. -Plant response to micronutrients I. Uptake, distribution and translocation of zinc in maize and barley plants." Plant and Soil 40: 637-646.

[36] Singh, B. R. and K. Steenberg. 1974. "Plant response to micronutrients II. Uptake, distribution and translocation of mangaulese in maize and barley plants." Plant and Soil 40: 647-654.

[37] Singh, B. R. and K. Steenberg. 1974. "Plant response to micronutrients III. Interaction between manganese and zinc in maize and barley plants." Plant and Soil 40: 655-667.

[38] National Siaderny of Sciences. 1971. Nutrient Requirements of Dairy Cattle (fourth ed.). ISBN 0-309-01916-8.

[39] Ng, Y. C., C. S. Colsher, and S. E. Thompson. 1979. "Transfer coefficients for terrestrial food chains - their derivation and limitations." In Kellermann, H. J. (ed.) Radioaktivitat and Umwelt. Proceedings of the 12th Annual Conference of the Fachverband fur Strahlenchutz, Norderney, West Germany, 2-6 October 1978. Band I. pp: 45,-481.

[40] Ng, Y. C., C. S. Colsher, and S. E. Thompson. 1979 "Transfer factors for assessing the dose from radionuclides in agricultural products." In Biological Implications of Radionuclides Released from Nuclear Industries, Vol. II. Proceedings of an International Symposium on Biological Implications of Radionuclides Released from Nuclear Industries, Vienna, 26-30 March 1979. pp. 295-318 (IAEA-SM-237/54).

[41] Hansen, W. R. and R. L. Watters. 1970. "Plant uptake of ${ }^{210}$ Po f: om soil." Rat. Bot. 10(4): $371-375$.

[42] Vavilov, P. P., I. N. Verkhovskaya, O. N. Popova, and R. P. Kodaneva. 1972. "Conditions of radium accumulation by plants from the soil." Radioekologicheskie Issledovaniya $v$ Prirodnykh Biogeotsenozakh (Verkhovskaya, I. N., ed.) pp. 95-103. Moscow: Izdatel'stvo Nauka.

[43] Routson, R. C. and D. A. Cataldo. 1978. "A growth chamber study of the effect of soil concentration and plant age on the uptake of $\mathrm{Sr}$ and $\mathrm{Cs}$ by tumbleweed." Comm. Soil Sci. PI. Anal. $9(3)$ : 215-30.

[44] Il'ina, G. V. and S. G. Rydkii. 1965. "Uptake of radioactive fission products by field crops. Report 1: Accumulation of radioactive fission products by grain and oil-bearing crops." Fed. Am. Soc. Exp. Bio. Proc. 25: T123-T127.

[45] Andersen, A. J. 1971. "The uptake and distribution of strontium in oat as influenced by the time of supply." Soil Sci. 111(6): 379-81.

[46] Baranova, Z. A. and A. S. Frid. 1975. "Absorption of strontium-90, potassium and calcium by oat plants from soil during ontogenesis." Soviet Ph. Phys. (tr.) 22(6): 1173-1176. 
[47] Myttenaere, C. 1965. "The influence of the strontium/calcium ratio of the nutrient solution on the translocation and chemical forms of strontium and calcium in Pisum sativum." Rad. Bot. 5: 1143-151.

[48] Ringoet, A. and D. de Zeeuw. 1968. "Discrimination between calcium and strontium in oat plants. I. Influence of the growth stage of the plants and of the osmotic potential of the root medium." Z. Pflan. Bd. 5Y(3): 238-248.

[49] Ringoet, A. and D. de Zeeuw. 1968. "Discrimination between calcium and strontium in oat plants. II. Relation to the differential chemical binding of both ions." Z. Phlan. Bd. 59(3): 249-257.

[50] Soileau, J. M. 1973. "Activity of barley seedling roots as measured by strontium uptake." Agron. J. 65(4): 625-628.

[51] Kodaira, K., A. Tsumura, and H. Kobayashi. 1973. "Uptake of r-dioactive strontium and cesium in rice plants. (1) Accumulation of $\mathrm{Sr}$ and $\mathrm{Cs}$ in rice grains through roots." $J$. Radiat. Res. 14: 31-39.

[52] Vinogradov, A. P. 1959. The Geochemistry of Rare and Dispersed Elements in Soils, 2nd ed. Consultants Bureau, Inc., New York.

[53] Shacklette, H. T., J. A. Erdman, T. F. Harms, and C. S. E. Papp. 1978. "Trace elements in plant foodstuffs." In Dehme, F. W. (ed.). Toxicity of Heavy Metals in the Environment Part 1. Marcel Dekker, Inc., New York. pp. 25-68.

[54] Oakes, 1. W., K. E. Shank, C. E. Easteriy, and L. R. Quintana. 1977. "Concentrations of of radionuclides and selected stable elements in fruits and vegetables." In Environmental Health. Ilth Annual Conference on Trace Substances.

[55] Barber, D. A. 1964. "Influence of soil organic matter on the entry of cesium-1 37 into plants." Nature 294: 1326-1327. Schulz, R. K. 1965. "Soil chemistry of radionuclides." Health Prys. I1: 1317-1324.

[56] Fredriksson, L., A. Eriksson, and H. Lönsjö. 1966. Studies on Plant Accumulation of Fission Products under Swedish Conditions. VIII. Uptake of ${ }^{137}$ Cs in Agricultural Crops as Influenced by Soil Characteristics, and Rate of Potassium Fertilization in a Three Year Micro Plot Experiment. Research Institute of National Defense, Stockholm, Sweden. FOA 4 Rapport A 4486-4623.

[57] Fredriksson, L., H. Lönsjö and $\dot{A}$. Eriksson. 1969. Studies on Plant Accumulation of Fission Products under Swedish Conditions. X. Absorption of ${ }^{90} \mathrm{Sr}$ and ${ }^{137} \mathrm{Cs}$ from Soil by Vegetable Crops. Research Institute of National Defense, Stockholm, Sweden. FOA 4 Rapport C 4387-28.

[58] Fredriksson, L., H. Lönsjö, and $\dot{A}$. Eriksson. 1969. Studies on Plant Accumulation of Fission Products under Swedish Conditions. XII. Uptake of ${ }^{137} \mathrm{Cs}$ by Barley and Peas from 12 Different Top Soils Combined with 2 Sub-soils in a Long Term Micro Plot Experiment. Research Institute of National Defense, Stockholm, Sweden. FOA 4 Rapport C 4405-4428.

[59] Rediske, J. H., J. F. Cline, and A. A. Selders. 1955. The Absorption of Fission Products by Plants. HW-36734.

[60] Romney, E. M., J. W. Neel, H. Nishita, J. H. Olafson, and K. H. Larson. 1957. "Plant uptake of ${ }^{90} \mathrm{Sr},{ }^{91} \mathrm{Y},{ }^{106} \mathrm{Ru},{ }^{137} \mathrm{Cs}$, and ${ }^{144} \mathrm{Ce}$ from soils." Soil Sci. 83; 369-376.

[61] Fredriksson, L., H. Lönsjö, and Ȧ. Eriksson. 1969. Studies on Plant Accumulation of Fission Products Under Swedish Conditions. X. Absorption of ${ }^{90} \mathrm{Sr}$ and ${ }^{137} \mathrm{Cs}$ from Soil by Vegetable Crops. Research Institute of National Defense, Stockholm, Sweden. FOA 4 Rapport C 4387-28. 
[62] Andersen, A. J. 1967. Investigations on the Plant Uptake of Fission Products from Contaminated Soils. I. Influence of Plant Species and Soil Types on the Uptake of Radioactive Strontium and Caesium. Danish Atomic Energy Commission, Research Establishment Risö. Risö Report No. 170. November, 1967.

[63] Neel, J. W., J. H. Olafson, A. J. Steen, B. E. Gillooly, H. Nishita, and K. H. Larson. 1953. Soil-Plant Interrelationships with Respect to the Uptake of Fission Products: I. The Uptake of $\mathrm{Sr}_{,}{ }^{90} \mathrm{Cs}_{,}{ }^{137} \mathrm{Ru}_{1}{ }^{106} \mathrm{Ce}^{144}$ and $\mathrm{Y}^{-91}$ The University of California. UCLA-247.

[64] Reutson, R. C. 1975. The Effect of Soil Concentration on the Tumbleweed Uptake of ${ }^{90} \mathrm{Sr}$ and ${ }^{137}$ Cs from a Burbank Sand. Bi:telle-Pacific Northwest Laboratories. BNWL-1905.

[65] Furr, A. K., T. F. Parkinson, C. L. Heffron, J. T. Reid, W. M. Haschek, W. H. Gutenmann, C. A. Bache, L. E. St. John, Jr., and D. J. Lisk. 1978. "Elemental content of tissues and excreta of lambs, goats, and kids fed white sweet clover growing on fly ash." J. Agric. Food Chem. 26(4): 847-851.

[66] Cataldo, D. A. 1979. Comparative Availability of Cesium and Strontium for Plant Absorption from Amended Rupert Surface Soil and Associated Subsoil: Influence of Growth Conditions. Pacific Northwest Laboratory PNL-2741.

[67] Essington, E., H. Nishita, and A. Wallace. 1962. "Influence of chelates on availability of fission products to plants grown in a contaiminated soil." Soil Sci. 94: 96-105.

[68] Nishita, H., A. J. Steen, and K. H. Larson. 1958. "Release of Sr90 and Cs137 from Vina loam upon prolonged cropping." Soil Sci. 86: 195-201.

[69] Nishita, H., R. M. Haug, and M. Hamilton. 1968. "Influence of minerals on Sr90 and Cs137 uptake by bean plants." Soil Sci. 105: 237-243.

[70] Nishita, H. and R. M. Haug. 1972. "Influence of clinoptilolite on Sr90 and Cs137 uptakes by plants." Soil Sci. 114(2): 149-157.

[71] Fredriksson, L., B. Eriksson, B. Rasmuson, B. Gahne, K. Edvarson, and K. Löw. 1958. "Plant uptake of $\mathrm{Sr}^{90}$ and $\mathrm{Cs}^{137}$ from soils." In Proceedings of the Second United Nations International Conference on the Peaceful Uses of Atomic Energy Vol. 18, held in Geneva 1-13, September, 1958. pp. 449.470.

[72] Vose, P. B. and Koontz, H. V. 1959. U-Uptake of strontium by pasture plants and its possible significance in relation to the fall-out of strontium." Nature 183: 1447-1448.

[73] Milbourn. G. M., F. B. Ellis, and R. S. Russell. ;959. "The absorption of radioactive strontium by plants under field conditions in the United Kingdom." J. Nucl. Energy Part A: Reactor Sci. 10: 116-132.

[74] Ralls, J. W., S. Primbsch, T. R. Guckeen, H. J. Maagdenberg, J. Rinehart, F. C. Lamb, and W. A. Mercer. 196\%. "Distribution of strontium and calcium in major vegetable and fruit crops and criteria for use of fallout-contaminated foods." Radiol. Health Data Rep. 8(7): 355-358.

[75] Andersen, A. J. 1965. "Uptake by plants of radionuclides from contaminated soils." Nature 208(5006): 195-196.

[76] Furr, A. K., T. F. Parkinson, R. A. Hinrichs, D. R. Van Campen, C. A. Bache, W. H. Gutenmann, L. E. St. John, Jr., I. S. Pakkala, and D. J. Lisk. 1977. "National survey of elements and radioactivity in fly ashes and absorption of elements by cabbage grown in fly ash-soil mixtures." Environ. Sci. Technol. 11(3): 1194-120!.

[77] Arkhipov, N. P., Y. A. Fedorov, E. F. Bondar, R. M. Aleksakhin, G. N. Romanov, and L. T. Feuraleva. 1974. "Predicting ${ }^{90} \mathrm{Sr}$ accumulation in the crop harvest as a result of its uptake from the soil." Soviet Soil Sci. 6(4): 412-419. 
[78] Fredriksson, L., A.. Eriksson, and E. Haak. 1961. Studies on Plant Accumulation of Fission Products Under Swedish Conditions. II. Influence of Lime and Phosphate Fertilizer on the Aicumulation of Sr-89 in Red Clover Grown in 29 Different Swedish Soils. Research Institute of National Defense. Stockholm, Sweden. FOA 5 Rapport A4188-4626.

[79] Fredriksson, L., E. Haak, and Ȧ. Eriksson. 1969. Studies on Plant Accumulation of Fission Products Under Swedish Conditions. XI. Uptake of ${ }^{90} \mathrm{Sr}$ by Different Crops as Influenced by Liming and Soil Tillage Operations. Research Institute of National Defense. Stockholm, Sweden. FOA Rapport C 4j95-28.

[80] Haak, E. and H. Lönsjö. 1975. Studies on Plant Accumulation of Fission Products Under Swedish Conditions. XVI. Uptake of ${ }^{90} \mathrm{Sr}$ by Barley and Peas from 12 Different Topsoils Combined with 2 Subsoils in a Long Term Microplot Experiment. Department of Radiobiology, Agricultural College of Sweden. S-750 07 UPPSALA 7.

[81] Romney, E. M., G. V. Alexander, G. M. LeRoy, and K. H. Larson. 1959. "Influence of stable Sr on plant uptake of Sr90 from soils." Soil Sci. 87: 42-45.

[82] Lee, C. C. 1961. "Effects of plant nutrients on uptake of radiostrontium by thatcher wheat." Science 133: 1921-1922.

[83] Andersen, A. J., G. Gissel-Nielsen, and G. Nielsen. 1967. "Effects of fertilization on the strontium-calcium and cesium-potassium relationships in plants. I. The uptake and distribution of radioactive strontium and calcium in oats." Kgl. Vet.-og. Landbohojskoles Arsskrift 1967: 154-167.

[84] Shirshova, R. A. 1962. "Effect of potassium fertilizers on the uptake of radioactive strontium by plants." Pochvovedenie 1962(3): 36-43.

[85] Mel'nikova, M. K. and Z. A. Baranova. 1969. "The mechanism of radiostrontium intake in pot: ' tubers." In USSR Reports on Natural and Fallout Radioactivity. U.S. Atomic Energy Commission, Health and Safety Laboratory. UNSCLEAR Number A/AC.82/G/L.-1288. pp. 127-142.

[86] Wallace, A., R. K. Schulz, E. M. Romney, and H. Nishita. 1979. Biological Transport of Radionuclides at Low Level Waste Storage Sites. Laboratory of Nuclear Medicine and Radiation Biology, University of California. NUREG/CR-0701.

[87] Kirchmann, R., R. Roulenger, and A. LaFontaine. 1968. "Absorption of ${ }^{226} \mathrm{Ra}$ in cultivated plants." pp. 1015-1051. In W. S. Synder et al., eds.). Proceedings of the IRPA Congress on Radiation Protection. Vol. II. Rome, 1966. Pergamon Press.

[88] DeBortoli, M. and P. Gaglione. 1972. "Radium-226 in environmental materials and foods." Health Phys. 22(1): 43-48.

[89] Grzybowska, D. 1974. "Uptake of ${ }^{226}$ Ra by plants from contaminated soils." Nukleonika 19: 71-78.

[90] Mordberg, E. L., V. M. Aliksandruk, G. F. Kovygin, I. I. Shevckenko, V. M. Blyumshtein, and G. F. Yush'ievich. 1976. "Translocation of isotopes of the uranium-radium series into the grain of some agricultural crops." Gig. Sanit. 2: 58-61.

[91] Moffett, D. and $M$. Tellier. 1977. "Uptake of radioisotopes by vegetation growing on uranium tailings." Can. J. Soil. Sci. 56: 417.424.

[92] Khademi, B., A. Alemi, and A. Nasseri. 1980. "Transfer of radium from soil to plants in the area of high natural radioactivity in Iran (Ramsar)." In Gesell, T. F., W. M. Lowder, and J. E. McLaughlin. (eds.) The Natural Radiation Environment II!, Vol. I. CONF. 78422. 
[93] Marpte. M. L 1980. Radium-226 in Vegetation and Substrates at Inactive Uranium Mill Sites. Ph.D. Thesis. University of New Mexico, Albuquerque, New Mexico. LA-8183-T.

[94] Nelson, V. A. 1979. Radiological Survey of Plants, Animals, and Soil at Five Atolls in the Marshall Islands September - October 1976. University of Wastington, College of Fisheries, Laboratory of Radiation Ecology, Seattle, Washington. NVO-269-36.

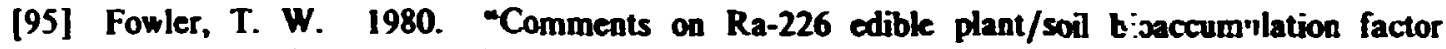
recommended by ORNL in the AIRDOS-EPA manual." Letter to Christopher B. Nelson, May 21, 1980.

[96] McDowell-Boyer, L. M., A. P. Watson, and C. C. Travis. 1979. Review and Recommendations of Dose Conversion Factors and Environmental Transpon Parameters for ${ }^{210} \mathrm{~Pb}$ and ${ }^{226} \mathrm{Ra}$. Final Report Oak Ridge National Laboratory. NUREG/CR-0574. ORNL/NUREG-56.

[97] Mulla, D. J., A. L. Page, and T. J. Ganje. 1980. Cadmium accurnulations and bioavailability in soils from long-term phosphorus fertilization." j. Environ Qual. $\boldsymbol{Y}(3)$ : 408-412.

[98] Isaac, R. A., S. R. Wilkinson, and J. A. Stuedemann. 1978. "Analysis and fate of arsenic in broiler litter applied to coastal Bermuda grass and Kentucky-31 tall fescue." In Adriano, D. C. and I. L. Brisbin, Jr. (eds.), Environmental Chemistry and Cycling Processes. Proceedings of a symposium held at Augusta, Georgia April 28-May 1, 1976. pp. 207-220.

[99] Dedolph, R., Ter Haar, G., Holtzman, R., and Lucas, H., Jr. 1970. "Sources of Pb in perennial ryegrass and radishes." Environ. Sci. Technol. 4(3): 217-225.

[100] Rabinowitz, M. 1972. "Plant uptake of soil and atmospheric lead in southern California." Chemosphere 1(4): 175-180.

[101] Wilson, D. O. and J. F. Cline. 1966. "Removal of plutonium-239, tungsten-185, and lead210 from soils." Naturc 209: 941-942.

[102] Keefer, R. F., R. M. Singh, D. J. Horvath, and A. R. Khawaja. 1979. -Heavy metal availability to plants from sludge application." Compost. Sci. 20(3): 31-34.

[103] Karamanos, R. E., J. R. Betlany, and J. W. B. Stewart. 1976. -The uptake of native and applied lead by alfa!fa and bromegrass from soil." Can. J. Soil Sci. 56: 485-494.

[104] Okamoto, K., Y. Yamamoto, and K. Fuwa. 1978. "Accumulation of manganese, zinc, cobalt, nickel, and cadmium by Clethra barbinervis." Agric. Biol. Chem. 42(3): 663-664.

[105] Preer, J. R., H. S. Sekhon, B. R. Stephens, and M. S. Collins. 1980 . "Factors affecting heavy metal content of garden vegetables." Environ. Pollut. B 1: 95-104.

[106] Menzel, R. G. 1965. "Soil-plant relationships of radioactive elements." Health Phys. 11: 1325-1332.

[107] Cataldo, D. A. 1979. Behavior of Technetium and lodine in a Hanford Sand and Associated Subsoil: Influence of Soil Aging on Uptake by Chealgrars and Tumbleweed. Pacific Northwest Laboratory. PNL-2740. Marsh 1979.

[108] Davis, R. D. 1980. -Uptake of flotride by ryegrass grown in soil treated with sewage sludge." Environ. Pollul. B 1: 277-284.

[109] Nishita, H., A. Wallace, and E. M. Romney. 1978. Radionuclide Uproke by Plants. Laboratory of Nuclear Medicine and Radiation Biology, University of California, Los Angeles. NUREG/CR-0336. UCLA 12-1158.

[110] Baes, C. F., Jr. and R. E. Mesmer. 1976. The Hydrolysis of Cations. John Wiley \& Sons, New York. 489 pp. 
[111] Gibson, J. A., J. F. Miller, P. S. Kennedy, and G. W. P. Rengstorff. 1959. The Properties of the Rare Earth Metals and Compounds. Prepared for the Rare Earth Research Group. Battelle Memorial Institute.

[112] Salcedo, I. H., B. G. Ellis, and R. E. Lucas. 1979. 'Studies in soil manganese: II. Extractable manganese and plant uptake." Soil Sci. Soc. Am. J. 43: 138-141.

[113] Shuman, L. M. and O. E. Anderson. 1974. "Evaluation of six extractants for their ability to predict manganese concentrations in wheat and soybeans." Soil. Sci. Amer. Proc. 38: 788-790.

[114] Sommers, L. E. 1980. "Toxic metals in agricultural crops." In Britton, G., B. L. Damron, G. T. Edds, and J. M. Davidson (eds) Sludge - Health Risks of Land Application. Ann Arbor, Michigan. pp. $105-140$.

[115] Safaya, N. M. 1976. "Phosphorus-zinc interaction in relation to absorption rates of phosphorus, zinc, copper, maaganese, and iron in corn." Soil Sci. Soc. Am. J. 40: 1976.

[116] Giordano, P. M., D. A. Mays, and A. D. Behel, Jr. 1979. "Soil temperature effects on uptake of cadmium and zinc by vegetables grown on sludge-amended ssii." $J$. Environ. Qual. 8(2): 233-236.

[117] Shukla, U. C. and H. Raj. 1974. "Influence of genetic variability on zinc response in wheat." Soil Sci. Soc Amer. Proc. 38: 477-479.

[:18] MaClean, A. J. 1974. "Effects of soil properties and ammendments on the availability of zinc in soils." Can. J. Soil. Sci. 54: 369-378.

[119] Coffman, C. B. and J. R. Miller. 1973. "Risponse of corn in the gresnhouse to soil applied zinc and a comparison of three chemical extractions for determining available zinc." Soil. Sci. Soc. Amer. Proc. 37: 721-724.

[120] Gammon, N., Jr., G. M. Volk, E. N. McCubbin, and A. H. Eddins. 1954. "Soil factors affecting molybdenum uptake by cauliflower." Soil Sci. Soc. Amer. Proc. 18: 302-305.

[121] Singh, M. and V. Kumar. 1979. "Sulfur, phosphorus, and molybdenum interactions on the concentration and uptake of molybdenum in soybean plants (Glycine max)." Soil Sci. 127(5): $307-312$.

[122] Wildung, R. E., T. R. Garland, and D. A. Calaldo. 1977. *Accumulation of technetium by plants." Health Phys. 32: 315-317.

[123] Hoffman, F. O., J. W. Huckabee, D. M. Lucas, C. T. Garten, Jr., T. G. Scott, R. L. Walker, P. S. Gouge, and C. V. Holmes. 1980. Sampling of Technetium-99 in Vegetation and Soils in the Vicinity of Operating Gaseous Diffusion Facilities. ORNL/TM-7386. Oak Ridge National Laboratory. October, 1980.

[124] Mahler, R. J., F. T. Bingham, G. Sposito, and A. L. Page. 1980. "Cadmium-enriched sewage sludge application to acid and calcareous soils: relation we!ween treatment, cadmium in saturation extra:ts, and cadmium uptake." J. Environ. Qual. 9 (ji: 359-364.

[125] Peel, J. W., R. J. Vetter, J. E. Christian, W. V. Kesslez, and W. W. McFee. 1978. "The uptake and distribution of cadmium in corn." In Adriano, D. C. and I. L. Brisbin, Jr., (eds.) Environmerial Chemistry and Cycling Processes. Proceedings of a symfosium held at Augusta, Georgia April 28-May 1, 197c. pp. 628-636.

[126] Harhiri, F. 1973. "Cadmium uptake by plants." J. Environ. Qual. 2(1):93-95.

[127] Gast, R. G., E. R. Landa, and I. J. Thorvig. 1976. The Behavior of Technetium-99 in Soils and Plants: Progress Report for the Period April I, 1974-March 31, 1977. COO2447-5. 
[128] Landa, E. R., L. H. Thorvig, and R. G. Gast. 1977. "Effect of selective dissolution, electrolytes, aeration, and sterilization on technetium-99 sorption by soils." J. Environ. Qual. 6: 181-187.

[129] Romney, E. M., A. Wallace, and J. E Kinnear. 1978. Plant Uptake of Pu and Am Through Roots in Nevada Test Site Soils, Vol. I. Laboratory of Nuctear Medicine and Radiation Biology, University of California, Los Angeles. NVO-192. June 1978.

[130] Crawford, T. V. 1977. Savannah River Laboratory Environmental Transport and Effects Research, Annual Report-1977. Savannah River Laboratory, Aiken, South Carolina. DP1489. pp. 25-28.

[131] Price, K. R. 1972. Uptake of ${ }^{237} N p,{ }^{239} \mathrm{Pu},{ }^{241} \mathrm{Am}$, and ${ }^{241} \mathrm{Cm}$ from Soil by Tumbleweed and Cheatgrass. Battelle Pacific Northwest Laboratories, Richland, Washington. BNWL1688.

[132] Romney, E. M., H. M. Mork, and K. H. Larson. 1970. "Persistence of plutonium in scil, plants, and small mammals." Health Phys. 19: 487-49I.

[133] Schulz, P. K., G. A. Tomplins, and K. J. Babock. 1976. "Uptake of plutonium and americium by plants from soil: uptake by wheat from various soils and effect of oxidation of plutonium added to soil." In Proc. Int. Symp. Transuranium Nuclides in the Environment. San Francisco, 17-21 November 1975, Vienna. IAEA.

[134] Gnevsheva, G. I. 1971. "Uptake of plutonium-239 into agriculture plants from soil." Biol. Nouki. 14: 60 (Chemical Abstracts) 76: $1446 f$.

[135] Lipton, W. V. and A. S. Goldin. 1976. "Some factors influencing the uptake of plutonium239 by pea plants." Health Phys. 31: 425-430.

[136] Au, F. H. F., V. D. Leavitt, W. F. Beckert, and J. C. McFarlane. 1977. "Incorporation of transuranics into vegetable and field crops grown at the Nevada Test Site." pp. 1-16. In White, M. G. and P. B. Dunaway (eds.) Transuranics in Desert Ecosystems. Nevada Applied Ecology Group. NVO-181. November, 1977.

[137] Cline, J. F. 1968. "Uptake of ${ }^{241} \mathrm{Am}$ and ${ }^{239} \mathrm{Pu}$ by plants." pp. 8.24-8.25. In Thompson, R. C., P. Teal, and E. G. Swezea (eds.) Pacific Northwest Laboratory Annual Report for 1967 to the USAEC Division of Biology and Medicine, Vol. I. Biological Sciences. BNWL-714. May 1968.

[138] Dahlman, R. C., E. A. Bondietti, and L. D. Eyman. 1976. “Biological pathways and chemical behavior of plutonium and other actinides in the environment." pp. 47-8C. In Friedman, A. M. (ed.) Actinides in the Environment. ACS Symposium Series, No. 35.

[139] Wallace, A., R. T. Mueller, and E. M. Romney. 1978. "Variable ${ }^{241}$ Am concentration in soil uptake and C. R. in barley plants." pp. 629-635. In White M. G. and P. B. Dunaway (eds.) Selected Environmental Plutonium Research Reports of the NAEG. Nevada Applied Ecolugy Group. NVO-192.

[140] Wallace, A. 1972. "Effect of soil pH and chelating agent (DTPA) on uptake by and distributions of ${ }^{241} \mathrm{Am}$ in plant parts of bush beans." Rad. Bot. 12: 433-435.

[141] Wallace, A. 1972. "Increased uptake of ${ }^{241}$ Am by plants caused by the chelating agent DTPA." Health Phys. 22: 559-562.

[142] Wallace, A., R. K. Schulz, E. M. Romney, and H. Nistita. 1979. Biological Transport of Radionuclides at Low Level Waste Storage Sites, Annual Report, October I, 1977-September 30, 1978. Laboratory of Nuclear Medicine and Radiation Biology, University of Callifornia. NUREG ICR-070!. 
[143] Fedorov, Ye. A. and G. N. Romanov. 1969. "Quantitative characteristics of the relation between the environmental contamination icvels and radioisotope concentrations in selected types of farm produce." pp. 112-126. In USSR Reports on Natural and Fallout Radioacti:ity. U.S. Atomic Energy Commission, Health and Safety Laboratory.

[144] Montford, M. A., K. E. Shank, C. Hendricks, and T. W. Oakes. 1980. "Concentration of stable elements in food products." In Proceedings of the Ith Annual Conference on Trace Substances in Emironmental Health. University of Missouri, June 3-6, 1980.

[145] Ng, Y. C. , C. S. Colsher, D. J. Quinn, and S. E. Thompson. 1977. Transfer Coefficients for the Predictions of Dose to Man Via the Forage-Cow-Milk Pathway from Radionuclides Released to the Biosphere. Lawrence Livermore Laboratory. UCRL-51939.

[146] Weast, R. C. and M. J. Astle (eds.). 1979. CRC Handbook of Chemistry and Physics 60't Ed. CRC Press, Inc., Boca Raton, Florida. p. F-3.

[147] Francis, C. W., M. Reeves III, R. S. Fisher, and B. A. Smith. 1977. "Soil chromatograph k values." In Waste Isolation Safety .4ssessment Program, Task 4, Contractor Information Meeting Proceedings. September 23-23, 1977. Battelle Memorial Institute. Human Affairs Research Centers, Seattle, Washington. PNL-SA-6957. pp. 403-431.

[148] Sheppard, J. C., J. A. Kittrick, M. J. Campbell, and T. L. Hardt. 1977. Determination of Distribution Ratios and Diffusion Coefficents of isiptunium, Americium and Curium in Soil-Aquatic Environments. Washington State University, Pullman, Washington. RLO2221-T-12-3.

[149] Inoue, $Y$. and S. Morisawa. 1976. "Distribution coefficient $k_{d}$ of radionuclide between sample soil and water." Nippon Genshiryoku Gakkai Shi 18(8): 525-534.

[150] Griffin, R. A. and N. F. Shimp. 1976. "Effect of pH on exchange-adsorption or precipitation of lead from landfill leachates by clay minerals." Environ Sci. Technol. 10(13): 1256-1261.

[151] Relyea, J. F. and D. A. Brown. 1978. "Adsorption and diffusion of plutonium in soil." In Adriano, D. C. and I. L. Brisbin, Jr. (eds.) Environmental Chemistry and Cycling Processes. Proceedings sí a symposium held at Augusta, Georgia, April 28-May 1, 1976. Technical Information Center, U.S. Department of Energy. pp. 479-495.

[152] Rhodes, D. W. 1957. "Adsorption of plutonium by soil." Soil Sci. 84: 465-471.

[153] Nishita, H. 1978. "Extractability of plutonium-238 and curium-242 from a contaminated soil as a function of $\mathrm{pH}$ and certain soil components. $\mathrm{CH}_{3} \mathrm{COOH}-\mathrm{NH}_{4} \mathrm{OH}^{n}$ In Adriano, $\mathrm{D}$. C. and I. L. Brisbin, Jr. (eds.) Environmental Chemistry and Cycling Processes. Proceedings of a symposium held at Augusta, Georgia, April 28-May 1, 1976. Technical Information Center, U.S. Department of Energy. sp. 403-416.

[154] Rhodes, D. W. 1957. "The effect of $\mathrm{pH}$ on the uptake of radioactive isotopes frum solution by a soil." Soil Sci. Soc. Am. Pror. 21: 389-392.

[155] Bishop, R. F. and D. Chisholm. 1962. "Arsenic accumwai.. Annapolis Valley orchard soils." Can. J. Soil Sci. 42: 77-80.

[156] Frost, R. R. and R. A. Griffin. 1977. "Efiect of pH on adsorption of arsenic and selenium from landfill leachate by clay minerals." Soil Sci. Soc. Am. J. 41: 53-57.

[157] Frost, R. R. and R. A. Griffin. 1977. "Effect of pH on adsorption of copper, zinc, and cadmium from landfill leachate by clay minerals." J. Environ. Sci. Health. A12(\$\&5): 139.156.

[158] Graham, E. R. 1973. "Selective distribution and labile pools of micro-nutrient elements as factors affecting plant uptake." Soil Sci. Soc. Am. Proc, 37: 70-74. 
[159] Reddy, M. R. and H. F. Perkins. 1974. "Fixation of zinc by clay minerals." Soil Sci. Soc. Amer. Proc. 38: 229-231.

[160] Wildung, M. W. and D. W. Rhodes. 1963. Removal of Radioisotopes from Solution by Earth Materials from Eastern Idaho. Phillips Petroleum Company, Atomic Energy Division. National Reactor Testing Station. U.S. Atomic Energy Commission. IDO-14624, November 1963.

[161] Cole, M. A. 1979. "Solubilization of heavy metal sulfides by heterotrophic soil bacteria." Soil Sci. 127(5): 313-317.

[162] Wildung, R. E. and J. R. Garland. 1977. The Relationship of Microbial Processes to the Fate and Behavior of Transuranic Elements in Soils, Plants, and Animals. Battelle Pacific Northwest Laboratories. PNL-2416, October 1977. 45 pp.

[163] Holtan, H. N., C. B. England, G. P. Lawless, and G. A. Schumaker. 1968. Moisture-Tension Data for Selected Soils on Experimental Watersheds. U.S. Department of Agriculture, Agricultural Research Service. ARS 41-144.

[164] Free, G. R., G. M. Browning, and G. W. Musgrave. 1940. "Relative infiltration and related physical characteristics of certain soils." U.S. Department of Agriculture Technical Bullesin 729. U.S. Department of Agriculture. 52 pp.

[165] Graham, E. R. and C. G. Silva. 1979. "Labile pools and distribution coefficients for soil calcium, magnesium, and potassium determined with exchange equilibria and radioisotopes." Soil Sci. 128(1): 17-22.

[166] Mokwunye, A. U. and S. W. Melsted. 1973. "Magnesium fixation and release in soils of temperate and tropical origins." Soil Sci. 116(5): 349-362.

[167] Inoue, Y. and S. Morisawa. 1976. "Migration of radionuclides in a model saturated zone, (1)." Nippon Genshiryoku Gakkai Shi 18(5): 42-50.

[i68] Sims, J. L., P. Duangpatra, J. H. Ellis, and R. E. Phillips. 1979. "Distribution of available manganese in Kentucky soils." Soil Sci. 127(5): 270-274.

[169] Rancon, D. 1972. Utilisation Pratique du Coefficient de Distribution pour la Mesure de la Contamination Radioactive des Mineraux, des Roches, du sol et des Eaux Souterraines. Department de Surete Nucleaire, Centre d'Etudes Nucleaires de Cadarache, Saclay, France. Rapport CEA-R-4274. 35 pp.

[170] Graham, E. R. and D. D. Killion. 1962. "Soil colloids as a factor in the uptake of cobait, cesium, and strontium by plants." Soil Sci. Soc. Am. Proc. 26: 545-547.

[171] Schmalz, B. L. 1972. Radionuclide Distribution in Soil Mantle of the Lithosphere as a Consequence of Waste Disposal at the Nationai Reactor Testing Station Idaho Operations Office. U.S. Atomic Energy Commission. IDO-10049. 62 pp.

[172] Inoue, Y., S. Morisawa, and Y. Mahara. 1975. "Radionuclide migration in aerated zones, (1). Migrition characteristics of nuclides contained in percolating water." Nippon Genshiryoku Gakkai Shi 17(7): 376-384.

[173] Klechkovski,, V. M. 1957. On the Behavior of Radioactive Fission Products in Soil, their Absorptio' by Plants and their Accumulation in Crops (Translated from Russian). U.S. Atomic Energy Commission, Washington, DC.

[174] Gailledreau, C. 1963. "Reactions physico-chemiques lors du mouvement souterrain des radioisotopes." In The International Symposium on the Retention and Migration of Radioactive Ions in Soils. Saclay, 16, 17, and 18 Oclober, 1962. Center for Nuclear Studies, Saclay, The University Press of France. pp. 270-275. 
[175] Jacobs, D. G. 1963. "Ion exchange in the deep-well disposal of radioactive wastes." In International Symposium on the Retention and Migration of Radioactive Ions in Soils. Saclay, 16, 17, and 18 October, 1962. Center for Nuclear Studies, Saclay, The University Press of France. pp. 43-54.

[176] McHenry, J. R. 1958. "Ion-exchange properties of strontium in a calcareous soil." Soil Sci. Soc. Amer. Proc. 22: 514-518.

[177] Tamura, T. 1972. "Sorption phenomena significant in radioactive-waste-disposal." In Cook, T. D. (ed.) Underground Waste Management and Environmental Implications. Proceedings of a Symposium 6-9 December, 1971. Houston, Texas. American Association of Petroleum Geologists and United States Geological Survey. pp. 318-330.

[178] Nishita, H., B. W. Kowalewsky, A. J. Steen, and K. H. Larson. 1956. "Fixation and extractability of fission products contaminating various soils and clays: I. Sr90, Y91, Ru 106, Cs137, and Ce144." Soil Sci. 81: 317-326.

[179] Juo, A. S. R. and S. A. Barber. 1970. "The retention of strontium by soils as influenced by $\mathrm{pH}$, organic matter and saturation cations." Soil Sci. $109(3)$ : 143-148.

[180] Dames and Moore. 1977. Assessment of the Levels, Potential Origins and Transport Routes of the Radioactivity Measured in the Vicinity of the Maxey Flat Low-Level Radioactive Waste Disposal Site. March 1977 report.

[181] Rogowski, A. S. and T. Tamura. 1965. "Movement of ${ }^{137} \mathrm{Cs}$ by runoff, erosion and infiltration on the alluvial captina silt loam." Health Phys. 11: 1333-1340.

[182] Prout, N. E. 1958. “Adsorption of radioactive wastes by Savannah River Plant soil." Soil Sci. 85(1): 13-17.

[183] Tamura, T. 1966. "Development and applications of minerals in radioactive waste disposal." In Proceedings of the Insernational Clay Conference. Jerusalem, Israel. Vol. 1. pp. 425-439.

[184] Tso, T. C. 1970. "Limiten removal of $\mathrm{Po}^{210}$ and $\mathrm{Pb}^{210}$ from soil and fertilizer by leaching." Agron. J. 62: 663-664.

[185] Rancon, D. 1973. "Comportement dans les milieux souterrains de l'uranium et du thorium rejetes par l'industrie nucleaire." pp. 333-346. In Environmental Behavior of Radionuclides Released in the Nuclear Industry. Proceedings of a Symposium. Aix-enProvence. 14-18 May 1973. IAEA-SM-172/55.

[186] Dahiman, R. C., E. A. Bondietti, and L. D. E.yman. 1976. "Biological pathways and chemical behavior of plutonium and other actinides in the environment." In $A$. M. Friedman (ed.) Environmental Behavior of the Actinide Elements. American Chemical Society Symposium Series 35. pp. 47-80.

[187] Bondietti, E. A., S. A. Reynolds, and M. H. Shanks. 1976. "Interaction of plutonium with complexing substances in soils and natural waters" (IAEA-SM-199/51). In Transuranium Nuclides in the Environment. Proceedings of the Symposium Held in San Francisco, 17-21 November 1975. International Atomic Energy Agency, Vienna, 1976. pp. 273-287.

[188] Routson, R. C., G. Jansen, and A. V. Robinson. 1975. Sorption of ${ }^{99} \mathrm{TC}$. ${ }^{237} \mathrm{~Np}$ and ${ }^{241} \mathrm{Am}$ on Two Subsoils from Differing Weathering Intensity Areas. Battelle Pacific Northwest Laboratories. Richland, Washington. BNWL-1889. 13 pp.

[189] Nishita, H., A. Wallace, E. M. Romney, and R. K. Schulz. 1979. Effect of Soil Type on the Extractability of ${ }^{237} \mathrm{Pu},{ }^{241} \mathrm{Am}$ and ${ }^{244} \mathrm{Cm}$ as a Function of $\mathrm{pH}$. Laboratory of Nuclear Mcdicine and Radiation Biology, University of California at Los Angeles. UCLA 12-1192. $32 \mathrm{pp}$. 
[190] Nishita, H. and M. Hamilton. 1977. "Factors influencing the chemical extractability of ${ }^{241}$ Am from a contaminated soil." In White, M. G. and P. B. Dunaway (eds.) Transuranics in Natural Environments. A Symposium at Gatlinburg, Tennessee, October 1976. Nevada Applied Ecology Group, U.S. Energy Research and Development Administration, Las Vegas, Nevada. NVO-178. pp. 77-96.

[191] Van Dorp, F., R. Eleveld, and M. J. Frissel. 1979. "A new approach for soil-plant transfer calculations." In International Symposium on Biological Implications of Radionuclides Released from Nuclear Industries. Vienna, 26-30 March 1979. IAEA-SM-237/34.

[192] Chamberlain, A. C. 1967. "Transport of Lycopodium spores and other small particles to rough surface: Proc. R. Soc. London A296: 45-70.

[193] Chamberlain, A. C. 1970. "Interception and retention of radioactive aerosols by vegetation." Almos. Environ. 4: 57-78.

[194] Chamberlain, A. C. and R. C. Chadwick. 1966. "Transport of iodine from atmosphere to ground." Tellus XVIII(2): 226-237.

[195] Chadwick, R. C. and A. C. Chamberlain. 1970. "Field loss of radionuclides from grass." Atmos. Environ 4: 51-56.

[196] Mibourn, G. M. and R. Taylor. 1965. "The contamination of grassland with radioactive strontium. I. Initial retention and loss." Radiat. Bot. 5: 337-47.

[197] Peters, L. N. and J. P. Witherspoon. 1972. "Retention of 44-88 $\mu$ simulated fallout particles by grasses." Health Phys. 22: 261-266.

[198] Withe spoon, J. P. and F. G. Taylor, Jr. 1970. "Interception and retention of a simulated fallout by agricultural plants." Health Phys. 19: 493-499.

[199] Hoffman, F, O. and C. F. Baes, III (eds.). 1979. A Statistical Analysis of Selected Parameters for Predicting Food Chain Transport and Internal Dose of Radionuclides. Final Repart. ORNL/NUREG/TM-282. Oak Ridge National Laboratory

[200] Knoti, J. E. 1957. Handbook for Vegetable Growers. J. Wiley and Sons, Inc., New York.

[201] Brenchley, W. E. and V. G. Jackson. 1921. "Koot development in barley and wheat under different conditions of growth." Ann. Bot. XXXV: 533-556.

[202] Watson, D. J., G. N. Thorne, and S. A. W. French. 1958. "Physiological causes of differences in grain yield between varieties of barley." Anm. Bot. 22: 321-352.

[203] Thorne, G. N. 1961. "Effects of age and environment on net assimilation rate of barley." Ann. Bot. 25: 29-38.

[204] Crow, J. F. and M. Kimura. 1970. An Introduction to Population Genetics Theory. Harper and Row, publishers, New York.

[205] Ryan. J. W., P. A. Garza, and S. L. Brown. 1974. A Damage Assessment Model for Agriculsural Crops. Stanford Research Institute. AD/A-002.

[206] Hanaway, J. J. 1963. "Growth stages of corn (Zea mays, l.)." Agron. J. 55: 487-492.

[207] Norman, A. G. 1956. Advonces in Agronomy. Academic Press Inc., New York.

[208] Rutledge, A. D. 1979. "Vegrtable garden guide." Publication 447(Revised) University of Tennessee Agricultural Extension Service, The University of Tennessee.

- [209] U.S. Department of Commerce, Bureau of the Census. 1977. The 1974 Census of Agriculture, United States Summary and State Data. Vol. 1, Part 51. U.S. Government Printing Office, Washington, D.C. 
[210] U.S. Department of Commerce. 1968. Climatic Atlas of the United States. Environmental Science Services Administration, Environmental Data Service. Reprinted by the National Oceanic and Atmospheric Administration. 1977.

[211] U.S. Department of Commerce. 1979. Comparative Climatic Data for the United States ihrough 1978. Environmental Data and Information Service, National Climatic Center, Asheville, N.C.

[212] Ruffner, J. A. 1978. Climates of the States. Vols. 122. Gale Research Company. Book Tower, Detroit, Michigan.

[213] Haaland, C. M. and M. T. Heath. 1973. Mapping of Population Density. ORNL-TM4246. Oak Ridge National Laboratory.

[214] Haaland, C. M. and M. T. Heath. 1974. "Mapping of population density." Demography 11(2): 321-336.

[215] Edwards, R. G. and P. R. Coleman. 1976. IUCALC-A FORTRAN Subroutine for Calculating Polygon-Line Intersections, and Polygon-Polygon Intersections, Unions, and Re.ative Differences. ORNL/CSD/TM-12. Oak Ridge National Laboratory.

[2i6] Morton, F. I. 1978. "Estimating evapotranspiration from potential evaporation: practicality of an iconoclastic approach." $J$. Hydro. 38: 1-32.

[217] Olson, R. J., C. J. Emerson, and M. K. Nungesser. 1980. GEOECOLOGY: A County-Level Environmental Data Base for the Conternninous United States. ORNL/TM-7351. Environmental Sciences Division Publication No. 1537. Oak Ridge National Laboratory.

[218] Taylor, A. B. TERHGT program. Air Sources Laboratory, NOAA, Rockville, Md. 20952.

[219] Haltiner, G. J. and F. L. Martin. 1957. Dynamical and Physical Meteorology. McGrawHill Book Co., Inc. New York.

[220] Wallace, R. W. 1978. A Comparison of Evapotranspiration Estimates Using DOE Hanford Climatological Data. Pacific Northwest Laboratory. Richland, Washington. PNL-2698. $20 \mathrm{pp}$.

[221] Thornthwaite, C. W. and J. R. Mather. 1955. "The water balance." Climatol. 8(1); Laboratory of Climatology, Drexel Institute. 104 pp.

[222] Penman, H. L. 1948. "Natural evaporation from open water, bare soil and gras." Proc. Royal Soc. London, Series A 193: 120-145.

[223] Holzworth, G. C. 1972. Mixing Heights, Wind Speeds, and Potential for Urban Air Pollultion Throughout the Contiguous United States. PB-207 103. Environmental Protection Agency, Research Triangle Park, North Carolina. U.S. Department of Commerce. National Technical Information Service. January 1972.

[224] Etnier E. L. 1980. "Regional and site-specific absolute humidity data for use in tritium dose calculations." Health Phys. 39: 318-320.

[225] Miller, C. W. and F. O. Hoffman. (Submitted to Health Phys.) "An examination of the environmental half-time for radionuclides deposited on vegetation."

[226] Anspaugh, L. R., J. J. K.oranda, W. L. Robison, and J. R. Martin. 1972. Dose to Man vio the Food-Chrin Tran:fer Resulting from Exposure 10 Tritiated Water Vapor. USAEC Report UCRL-73195. Rev. 1.

[227] Murphy, C. E., 1. and M. M. Pendergast. 1979. "Environmental transport and cycling of tritium in the vicinity of atmospheric releases." pp. 361-371. In Freeman, S. (ed.) Symposium on the Behavior of Tritium in the Environment. IAEA. Vienna. 
[228] Baes, C. F., Jr., H. E. Goeller, J. S. Olson, and R. M. Rctty. 1976. The Global Carbon Dioxide Problem. ORNL-5194. Oak Ridge National Laboratory.

[229] Killough, G. G., J. L: Till, E. L. Etnier, and B. D. Murphy. In press. "Dose equivalent due to atui $x$ pheric releases of carbon-14." In Miller, C. W. (ed.). Models and Parameters for Environmental Radiological Assessments. DOE/TIC-1!468. Department of Energy Technical Information Center, Oak Ridge, Tennessee.

[230] Linsley, G. S. 1978. Resuspension of the Transuranium Elements - A Review of Existing Dala. NRPB-R75. National Radiological Protection Board. Harwell, Didcot, Oxon 0XII ORQ.

[231] Suggs, J. C., C. E. Rodes, E. G. Evans, and R. E. Bumgardner. 1981. Inhalable Particulate Network Annual Report: Operation and Data Summary (Mass Concentrations Only) April i979-June 1980. EPA-600/4-81-037. United States Environmental Protectio.n Agency. May 1981.

[232] Sehmel, G. A. 1980. "Particle and gas dry deposition: a review." .itmos. Environ. 14: 983-1011

[233] Francis, C. W. 1978. Rediostrontium Meviement in Soils and Uptake in Plants. DOE Critical Review Series. Technical Information C.nter. U. S. Department of Energy.

[234] Klepper, B., D. G. Watson, and J. F. Cline. 1976. "Iodine-129 conceniration factors for food pioduc's." in Pacific Northwest Laboratory Annual Report for $1975^{\circ}$ to the USERDA Division of Biomedical a.td Environmental Research Part 2 Ecslogical Sciences. BNWL2000 PT2.

[235] Johnson, J. M. and G. 'v. Butleı 1957. "Iodine content of pasture plants I. Method of determination and pre'sminary ir'estigation of species and strain differences." Physiol. Plant. î́: $100-111$. 


\section{INTERNAL DISTRIBUTION}

$\begin{aligned} \text { 1. } & \text { S. I. Auerbach } \\ \text { 2-6. } & \text { C. F. Baes III } \\ \text { 7. } & \text { L. W. Barnthouse } \\ \text { 8. } & \text { E. A. Bondietti } \\ \text { 9. } & \text { R. O. Chester } \\ \text { 10. } & \text { W. D. Cottrell } \\ \text { 11. } & \text { C. C. Coutant } \\ \text { 12. } & \text { K. E. Cowser } \\ \text { 13. } & \text { A. G. Croff } \\ 14 . & \text { B. S. Ellis } \\ \text { 15. } & \text { W. R. Emanuel } \\ \text { 16. } & \text { J. T. Ensminger } \\ \text { 17. } & \text { W. Fulkerson } \\ \text { 18. } & \text { R. H. Gardner } \\ \text { 19. } & \text { W. R. Garrett } \\ \text { 20. } & \text { C. T. Garten, Jr. } \\ 21 . & \text { H. B. Gerstner } \\ 22 . & \text { S. G. Hildebrand } \\ 23 . & \text { F. O. Hoffman, Jr. } \\ 24 . & \text { S. V. Kaye } \\ 25 . & \text { C. W. Miller } \\ 26 . & \text { T. W. Oakes }\end{aligned}$

27. D. C. Parzyck

28. H. A. Pfuderer

29. R. M. Reed

30. D. E. Reichle

31. C. R. Richmond

32. P. S. Rohwer

33. T. H. Row

34. R. D. Sharp

35. R. W. Shor

36. A. L. Sjoreen

37. S. H. Stow

38. G. W. Suter

39. C. C. Travis

40. R. I. Van Hook, Jr.

41. W. Van Winkle

42. P. J. Walsh

43. A. P. Watson

44. Central Research Library

45. Y-12 Technical Library

46-47. Laboratory Records

48. ORNL Patent Otfice

\section{EXTERNAL DISTRIBUTION}

49. L. K. Anspaugh, Lawrence Livermore Laboratory, P.O. Box 808, Livermore, California 94550

50. J. A. Auxier, Applied Science Laboratory, Inc., P. O. Box 549, Oaik Ridge, Tennessee 37830

51 D. A. Baker, Battelle-Pacific Northwest Laboratories, P.O. Box 999, Richland, Washingtor. 99352

52. P. Cho, HHAD/OHER/ER, U.S. Department of Energy, Washington, D.C. 20545

53. Hugh W. Church, Sandia Laboratory, Division 5333, A!huquerque, New Mexico 87115

54. Bernard L. Cohen, Dapartment of Physics and Astronomy, University of Pittsburg, Pittsburg, Pernsylvania 15260

55. Frank J. Congel, U.S. Nuclear Regulatory Commission, Washington, D.C. 20555

56. T. V. Crawford, Savannah River Laboratory, Aiken, South Carolina 29801

57. R. G. Cuddihy, Irinalation Toxicology Research Institute, 5200 Gibson Blvd., S.E., Albuquerque, New Mexico 87108 
58. F. L. Culler, Electric Power Research Institute, P.O. Box 10412, Palo Alto, California 94303

59. Ray Dickson, National Oceanic and Atmospheric Administration, 550 Second Street, Idaho Falls, Idaho 93401

60. G. G. Eichholz, School of Nuclear Engineering, Georgia Institute of Technology, Atlanta, Georgia 30332

61. J. Falco, ORD, U.S. Environmental Protection Agency, 401 M Street, SW, Washington, D.C. 20460

62. Mike Smith, EERF, U.S. Environmental Protection Agency, P.O. Box 3009, Montgomery, Alabama 36193

63. Carl V. Gogolak, U. S. Department of Energy, Environmental Measurement Laboratory, 376 Hudson Street, New York, New York 10014

64. J. W. Healy, Health Physics Division, Los Alamos Scientific Laboratory, P.O. Box 1663, Los Alamos, New Mexico 97544

65. Bruce Hicks, Director, Air Resources Atmospheric Turbulence and Diffusion Laboratory, National Oceanic and Atmospheric Administration, Oak Ridge, Tennessee 37830

66. Wayne Lowder, U.S. Department of Energy, Washington, D.C. 20545

67. W. A. Mills, U.S. Nuclear Regulatory Commission, Washington, D.C. 20555

68. Dade Mocller, School of Public Health, Harvard University, 677 Huntington Ave., Boston, Massachusetts 02115

69. A. A. Moghissi, ORD, U.S. Environmental Protection Agency, 401 M Street, SW, Washington, D.C. 20460

70. Sam Morris, Brookhaven National Laboratory, Building 475 , Upton, New York 11973

71. Paul Moskowitz, Brookhaven National Laboratorv, Building 475, Upton, New rork 11973

72-76. Christopher B. Nelson, Office of Radiation Programs, U.S. Environmental Protection Agency, Washingion, D.C. 20460

77. Yook C. Ng. Biomedical and Environmental Research Division, Lawrence Livermore Laboratory, P.O. Box 808, Livermore, California 94550

78. J. K. Soldat, Pacific Northwest Laboratories, Battelle Memorial Institute, Richland, Washington 99352

79. W. L. Templeton, Ecosystems Department, Battelle-Pacific Norihwest Laboratories, Richland, Washington 99352

80. E. C. Watson, Battelle-Pacific Northwest Laboratories, P.O. Box 999, Richland, Washington 99352

81. F. W. Whicker, Department of Radiology and Radiation Biology, Colorado State University, Fort Collins, Colorado 80521

82. W. H. Wilkie, Tennessee Valley Authority, River Oaks Building, Muscle Shoals, Alabama 35660

83. Office of Assistant Manager, Energy Research and Development, Department of Energy, Oak Ridge Operations Office, Oak Ridge, Tennessee 37830

84-96. Technical Information Center, P. O. Box 62, Oak Ridge, Tennessee 37831 


\section{ACKNOWIEDGEMENT}

We wish to express our deepest gratitude to C. B. Nelson, C. W. Miller, S. Y. Ohr, B. D. Murphy, O. W. Hermann, and C. L. Begovich for their cooperation, suggestions, help, and encouragement in producing the TERRA computer code. We also wish to acknowiedge G. G. Killough for his assistance in the Monte Carlo simulations which were essential to some of our analyses and P. E. Johnson and R. C. Durfee for their assistance in creating the SITE data base. Finally, we wish to recognize Y. C. Ng. C. A. Little, D. E. Fields, A. P. Watson, and R. J. Raridon ir their time and effort in reviewing this manuscript.

\section{HIGHLIGHTS}

Assessment models of radionuclide transport through terrestrial agricultural systems rely on input parameters to describe transport behavior and define interrelationships among the agricultural ecosystem compartments. Often a single set of default parameters, such as those given in the USNRC Reg. Guide 1.109, is recommended for use in generic assessments in lieu of site specific information. These parameters are often based on an incomplete knowledge of transport prucesses, on readily available literature references, and on generalized or idealized conceptualizations of common agricultural practice. Usually, in lieu of solid experimental, observational, or theoretical support, parameters are chosen to provide conservative results. Further, inconsistencies may occur between experimental determination of the parameter and its use in the assessment model.

The above-mentioned limitations in model input parameters are usually unavoidable and seem to be inherent in the assessment modeling process, but are usually acceptable (in many applications) within the context of overall uncertaintity in assessment methodology. However, in some assessment applications, including comparisons among various facilities and source terms in a variety of geographical locations, many of these limitations are not acceptable. This report describes an evaluation of terrestrial transport parameters designed to address many of ti: abovementioned limitations and provides documentation of default parameters incorporated into the food-chain-transport assessment code TERRA.

The parameters discussed in this report are divided into five categories: agricultural, climatological, demographic, element-specific, and miscellaneous. The climatological, demographic, and many of the agricultural parameters have been determined on a location-specific basis for the conterminous United States with a resolution of $1 / 2 \times 1 / 2$ degree longitude-latitude. These parameters include various land use and geographic information, population and its distribution in rural and urban settings, agriculeural production and productivity, precipitation, and estimates of evapotranspiration, morning and afternoon mixing heights, absolute humidity, and number of frostfree days. These location-specific parameters have been stored in computer readable format and are collectively referred to as the Specific-Information on the Terrestrial Environment (SITE) data base. This report describes the SITE data base and the protocols used in its generation.

The element-specific parameters include soil-to-plant concentration factors, $\boldsymbol{B}_{v}$ and $\boldsymbol{B}_{r}$, ingestion-to-milk and ingestion-to-beef transfer parameters, $F_{m}$ and $F_{f}$, respectively, and the soilwater distribution coefficient, $K_{d}$. The report describes the available literature references, the protocols and assumptions made, and correlations between parameters used to determine these default parameters and compares concentrations predicted using them with experimentally measured concentrations. 